\title{
EMPIRICAL ASSESSMENT OF MULTI-WAVELENGTH SYNTHETIC APERTURE RADAR FOR LAND COVER AND CANOPY HEIGHT ESTIMATION
}

\section{By}

\author{
Mary Lorraine Tighe
}

A thesis submitted to the Faculty of Graduate and Postdoctoral Affairs

in partial fulfillment of the requirements for the degree of

Doctor of Philosophy

in

Department of Earth Sciences

Ottawa - Carleton Geoscience Centre

Ottawa, Ontario

(C) 2012

Mary Lorraine Tighe 
Library and Archives

Canada

Published Heritage

Branch

395 Wellington Street

Ottawa ON K1A ON4

Canada
Bibliothèque et

Archives Canada

Direction du

Patrimoine de l'édition

395 , rue Wellington

Ottawa ON K1A ON4

Canada
Your file Votre référence

ISBN: 978-0-494-93699-3

Our file Notre référence

ISBN: $978-0-494-93699-3$
NOTICE:

The author has granted a nonexclusive license allowing Library and Archives Canada to reproduce, publish, archive, preserve, conserve, communicate to the public by telecommunication or on the Internet, loan, distrbute and sell theses worldwide, for commercial or noncommercial purposes, in microform, paper, electronic and/or any other formats.

The author retains copyright ownership and moral rights in this thesis. Neither the thesis nor substantial extracts from it may be printed or otherwise reproduced without the author's permission.
AVIS:

L'auteur a accordé une licence non exclusive permettant à la Bibliothèque et Archives Canada de reproduire, publier, archiver, sauvegarder, conserver, transmettre au public par télécommunication ou par l'Internet, prêter, distribuer et vendre des thèses partout dans le monde, à des fins commerciales ou autres, sur support microforme, papier, électronique et/ou autres formats.

L'auteur conserve la propriété du droit d'auteur et des droits moraux qui protege cette thèse. $\mathrm{Ni}$ la thèse ni des extraits substantiels de celle-ci ne doivent être imprimés ou autrement reproduits sans son autorisation.
In compliance with the Canadian Privacy Act some supporting forms may have been removed from this thesis.

While these forms may be included in the document page count, their removal does not represent any loss of content from the thesis.
Conformément à la loi canadienne sur la protection de la vie privée, quelques formulaires secondaires ont été enlevés de cette thèse.

Bien que ces formulaires aient inclus dans la pagination, il n'y aura aucun contenu manquant. 
ABSTRACT

Synthetic aperture radar interferometry (InSAR) and polarimetric InSAR (PolInSAR) techniques have gained traction in the last decade as a viable technology for vegetation parameter estimation at local and regional scales, but large spatial extent methods and physical models are not yet available. This research presents an empirical methodology for use with airborne X-band InSAR and L-band PolInSAR to classify vegetation type and estimate canopy height over diverse environments and large geographic extents common in North America. The methodology includes: 1) derivation of the scattering phase height centre $\left(\mathrm{h}_{\mathrm{spc}}\right)$ as an initial canopy height estimate by subtracting an InSAR derived digital terrain model from an InSAR digital surface model, 2) classification of vegetation type using InSAR data, 3) correction of $h_{\text {spc }}$ using empirically derived factors per vegetation type, and 4) refinement of height estimates at forest edges and gaps. The method yields a root mean square error (RMSE) of $1.00-$ $1.93 \mathrm{~m}$ over five vegetation types evaluated, which is a substantial improvement over the 5.4 - 6.96 m RMSE for raw X- and L-band $h_{\text {spc. }}$. Relative height estimate error decreased with increasing canopy height and density; it was generally higher in shrub/wetlands vegetation and lower in dense conifer. Height estimate error also increased with increasing terrain slope, but effects of incidence angle were mixed. This research confirms that the proposed X-band InSAR and L-band PolInSAR empirical methodology is well-suited to derive land cover and canopy height over large geographic areas and varied vegetation types, providing an alternative to costlier spaceborne InSAR and LiDAR. 


\section{DECLARATION}

I certify that the work contained in this thesis, including text, figures, and tables, is my own, except where specifically stated. The thesis has been composed by myself and has not been previously accepted for a degree or professional qualification. Co-authors on conference and journal papers from this research provided research advice and editorial contributions that were incorporated into this thesis, but the thesis as a whole was written solely by the author. The fieldwork conducted was organized, planned, and managed by myself with the fieldwork carried out by myself and a number of Intermap field assistants. The InSAR and LiDAR data processing to create the DSM (digital surface model), DTM (digital terrain model), and ORI (orthorectified radar image), where applicable were performed by Intermap. The NEXTMap data used in this research were interferometrically processed and edited by Intermap staff, who I trained in these procedures. The conversion of the InSAR DSM ellipsoidal heights to orthometric heights, the collection of tree height and bare ground measurements directly extracted from the InSAR and LiDAR data, and the creation of the slope and DSM-DTM difference data were conducted by the author. The land cover classification using the InSAR data was performed by me. The methodology to classify the NGS (National Geodetic Survey) reference points was organized, planned, and managed by myself with the classification of the NGS points carried out by Intermap's production facility; however, the quality assessment of the NGS points was carried out by me. Analysis of all data was organized, planned, managed, and analyzed by me. 


\section{ACKNOWLEDGEMENTS}

Thank you to Dr. Douglas King of Carleton University (Canada), for supervising this research, and for all your guidance, tough constructive criticism, availability to offer advice, willingness to learn about InSAR, and for being confident in my ability to conduct research at a $\mathrm{PhD}$ level while working fulltime, coping with the difficulties at my place of employment, and undergoing open heart surgery. To Dr. Abderrazak Bannari of Ottawa University (Canada), for providing constructive, no-nonsense direct feedback, willingness to keep me on track, and for conducting the summer of 2009 field course. To Professor Heiko Balzter, of the University of Leicester University (UK), for providing insight to InSAR data for canopy height measurements and guidance in my research on single look complex radar InSAR data. To Dr. Heather McNairn of Agriculture Canada, for your advice, SAR expertise, and critical analysis of materials presented over the course of my PhD. To colleagues who have been involved with this and other work along the way, thank you: Dr. Shane Cloude, and Dr. Dave Maune. To those at Intermap Technologies for their assistance with field data acquisition, data processing and queries, including Ivan Maddox, Matt Malone, Drew Chamberlain, Garth Lawrence, Stephen Townsend, and Marcus Schwäbisch. Lastly, I would like to thank my family, friends, especially my husband Len, Soya, Tobas, and my mom for your support, patience, and encouragement over the years. I can finally say I am finished! 


\section{TABLE OF CONTENTS}

ABSTRACT

DECLARATION

ACKNOWLEDGEMENTS iii

TABLE OF CONTENTS iv

LIST OF TABLES $\quad$ xi

LIST OF FIGURES $\quad$ xvi

LIST OF EQUATIONS $\quad$ xxii

LIST OF ACRONYMS AND ABBREVIATIONS xxiii

\section{CHAPTER ONE: INTRODUCTION}

$1.1 \quad$ Problem Definition 1

$1.2 \quad$ Forest Biophysical Parameter Measurement Techniques 3

1.3 InSAR and PolInSAR Techniques as Potential Tools for Canopy Height Estimation $\quad 6$

$\begin{array}{lll}1.4 & \text { Research Objectives } & 7\end{array}$

1.5 Contributions and Uniqueness of This Research 9

$\begin{array}{lll}1.6 & \text { Thesis Structure } & 10\end{array}$

$\begin{array}{lll}1.7 & \text { Research Approach } & 12\end{array}$

$\begin{array}{lll}1.8 & \text { Summary } & 14\end{array}$

CHAPTER TWO: SAR, INSAR, AND POLINSAR REMOTE SENSING THEORY FOR THE APPLICATION OF LAND COVER AND CANOPY HEIGHT MAPPING

2.1 Synthetic Aperture Radar (SAR) Background $\quad 16$

$2.2 \quad$ Interferometric SAR (InSAR) For Topographic Mapping 20

2.2.1 Interferometric Coherence Image Generation and Interferogram $\begin{array}{ll}\text { Filtering } & 28\end{array}$

2.2.2 Interferogram Phase Unwrapping 31 
2.2.3 Magnitude Image Creation and Orthorectification 32

2.2.4 Elevation Model Geocoding 32

$\begin{array}{lll}2.3 & \text { InSAR Systems } & 33\end{array}$

$2.4 \quad$ Polarimetric InSAR (PolInSAR) Background 35

2.5 Literature Review: InSAR and PolInSAR Techniques for Biophysical Parameter Estimation $\quad 40$

2.5.1 InSAR for Vegetation Cover Mapping 40

2.5.2 InSAR and PolInSAR for Canopy Height Estimation 42

2.6 Suitability of the InSAR and PollnSAR Remote Sensing

Technique for Forest Biophysical Parameter Extraction 46

2.6.1 Canopy Height and SAR Wavelength 46

2.6.2 Canopy Height and SAR Viewing Geometry 48

2.6.3 Canopy Height and SAR Incidence Angle 49

2.6.4 Canopy Height and InSAR System Configuration 50

2.6.5 Canopy Height and Feature Cover Structure 50

2.6.6 Canopy Height and Terrain Slope and Aspect 52

2.6.7 Canopy Height and Vegetation Discontinuity Effects 53

$\begin{array}{lll}2.7 & \text { Summary } & 54\end{array}$

CHAPTER THREE: RESEARCH SITES AND DATA DESCRIPTIONS

$3.1 \quad$ Site Selection 55

3.1.1 International Falls, Minnesota Site 56

3.1.2 Ely, Minnesota Site $\quad 58$

3.1.3 Morrison, Colorado Site $\quad 59$

$\begin{array}{lll}3.1 .4 & \text { Southern Arizona Site } & 60\end{array}$

3.1.5 Burnstick Lake, Alberta Site $\quad 62$

3.1.6 Edson, Alberta Site 63

3.2 InSAR and PollnSAR Data and Data Processing 65 
3.2.1 X-HH InSAR - NEXTMap 65

$\begin{array}{lll}3.2 .2 & \text { C-HH InSAR - SRTM } & 69\end{array}$

$\begin{array}{lll}\text { 3.2.3 L-Quad PolInSAR - TOPOSAR } & 72\end{array}$

$\begin{array}{lll}3.3 & \text { Ancillary Data } & 73\end{array}$

3.3.1 National Land Cover Database (NLCD) 74

3.3.2 LANDFIRE Canopy Height 75

3.3.3 National Geodetic Survey (NGS) 76

3.3.4 US National Elevation Dataset (NED) 77

$\begin{array}{lll}\text { 3.3.5 LiDAR Data } & 78\end{array}$

$\begin{array}{lll}\text { 3.3.6 Optical Aerial Photography } & 79\end{array}$

$\begin{array}{lll}\text { 3.3.7 National Agriculture Image Program (NAIP) Imagery } & 79\end{array}$

$\begin{array}{lll}3.4 & \text { Summary } & 80\end{array}$

\section{CHAPTER FOUR: METHODS}

$\begin{array}{lll}4.1 & \text { Reference Data Collection } & 81\end{array}$

$\begin{array}{lll}\text { 4.1.1 Field Plot Installations - U.S. Sites } & 81\end{array}$

$\begin{array}{lll}\text { 4.1.2 NGS Reference Points } & 87\end{array}$

4.1.3 LiDAR Reference Measurements 88

4.2 Research Objective 1: X-HH InSAR and L-Quad PollnSAR

Derived DTM Vertical Accuracy Assessments 89

4.2.1 Vertical Accuracy Assessment of DEMs: All Reference Data Combined - Six Research Sites $\quad 92$

4.2.2 Vertical Accuracy Assessment of DEMs: All Reference Data Combined - Conterminous U.S. $\quad 92$

4.2.3 Vertical Accuracy Assessment of DEMs: Stratified by Barren and Five Vegetation Cover Classes: Six Research Sites and Conterminous U.S. Site

4.2.4 Vertical Accuracy Assessment of DEMs: Stratified by Slope U. S. Research Sites and Conterminous U.S. Site 
4.2.5 Vertical Accuracy Assessment of DEMs: All Data Combined Canadian Research Sites

4.2.6 Vertical Accuracy Assessment of DEMs: Stratified by Barren Land and Five Vegetation Cover Classes - Canadian Research Sites

4.3 Research Objective 2: Derivation of Scattering Phase Centre Height $\left(\mathrm{h}_{\mathrm{spc}}\right)$ and Evaluation of its Vertical Accuracy as an Estimate of Canopy Height

Research Objective 3: Refinement of Canopy Height Estimation Based on Adjustments to $h_{s p c}$ for Vegetation Type and Proximity to Vegetation Discontinuities

$\begin{array}{lll}\text { 4.4.1 Land Cover Classification } & 97\end{array}$

4.4.2 Refinement of hspc Canopy Height Estimates within the Canopy, at Vegetation Boundaries, and Gaps Using Vegetation Dependent Correction Factors Applied Using Buffers

4.4.2.1 Creation of Vegetation Dependent Correction Factors

4.4.2.2 Application of Vegetation Dependent Correction Factors

4.4.3 Canopy Height Estimation Vertical Accuracy Assessment

4.5 Performance of the Canopy Height Estimation in Sloped

Terrain and Effects of Variation in Incidence Angle

4.5.1 Performance of the Canopy Height Estimation over a Range of Terrain Slopes

4.5.2 Performance of the Canopy Height Estimation over a Range of Incidence Angles

4.6 Summary

CHAPTER FIVE: RESULTS

5.1 Research Objective 1: DEM Vertical Accuracy Assessment

5.1.1 DEMs Vertical Accuracy Assessments - All Reference Data Combined 
5.1.1.1 Six Research Sites

5.1.1.2 Across the Conterminous U.S.

5.1.2 DEMs Vertical Accuracy Assessment - Stratified by Barren and Five Vegetation Classes

5.1.2.1 Six Research Sites

5.1.2.2 Across the Conterminous U.S.

5.1.3 DEM Vertical Accuracy Assessment - Stratified by Slope

5.1.3.1 Six Research Sites

5.1.3.2 Across the Conterminous U.S.

5.2 Research Objective 2: X-HH InSAR, L-Band PolInSAR and SRTM C-HH InSAR $h_{\mathrm{spc}}$ Assessment as an Estimate of Canopy Height

5.2.1 Visual Comparison of InSAR and PolInSAR $h_{s p c}$ Surfaces

5.2.2 X-HH InSAR, L-Quad PolInSAR, and C-HH SRTM InSAR hspc as an Estimate of Canopy Height - Stratified by Vegetation Type

5.2.3 X-HH InSAR, L-Quad PollnSAR and C-HH InSAR Assessment of hspc as an Estimate of Canopy Height - Stratified by Research Site

5.2.4 Performance of the $h_{\text {spc }}$ over a Range of Incidence Angles

5.2.4.1 Incidence Angle Analysis of Single- and Multi-Takes X-HH InSAR hspc as an Estimate of Canopy Height

5.2.4.2 Incidence Angle Effects on the $h_{s p c}$ as an Estimate of Canopy Height - All Data Combined and Stratified by Research Site

5.3 Research Objective 3: Assessment of Refined InSAR and PolInSAR Canopy Height Estimates

5.3.1 Land Cover Classification Assessment

5.3.1.1 Visual Assessment of Land Cover Classification Maps 
5.3.1.2 Quantitative Assessment of Land Cover Classification Stratified by Research Site

5.3.1.2.1 U. S. Research Sites

5.3.1.2.2 Canadian Research Sites

5.3.2 Accuracy Assessment of the Refined X-HH InSAR and L-Quad PolInSAR Canopy Height Estimates (CHE)

5.3.2.1 CHE - All Data Combined, Stratified by Vegetation Type

5.3.2.2 CHE - All Data Combined, Stratified by Research Site

5.3.3 Performance of the Proposed $h_{\text {spc }}$ and the Refined Canopy Height Method over a Range of Terrain Slopes

5.4 Summary

\section{CHAPTER SIX: DISCUSSION}

6.1 Vertical Accuracy of the DTMs and DSMs Evaluated in this Research

6.1.1 X-HH InSAR DTM - Airborne

6.1.2 L-Quad PolInSAR DTM - Airborne 187

6.1.3 C-HH InSAR DSM - Spaceborne 189

6.1.4 U.S. National Elevation Data (NED) 190

6.2 Canopy Height Estimated by InSAR/PolInSAR Scattering Phase Centre Height

6.2.1 X-HH InSAR $h_{\text {spc }}$ as an Estimate of Canopy Height 192

6.2.2 L-PolInSAR $h_{\text {spc }}$ as an Estimate of Canopy Height 195

6.2.3 C-HH InSAR $\mathrm{h}_{\mathrm{spc}}$ as an Estimate of Canopy Height 196

6.3 Refinement of hspc as an Estimate of Canopy Height Using Vegetation Dependent Correction Factors and Corrections at Canopy Gaps and Edges

6.3.1 Vegetation Dependent Correction Factors 
6.3.2 CHE Refinement within in Canopy, in Gaps, and at Canopy Edges Using Buffers

6.4 Impact of Incidence Angle on $\mathrm{h}_{\mathrm{spc}}$ and $\mathrm{CHE}$ as an Estimate of Canopy Height

6.5. Impact of Terrain Slope on $\mathrm{h}_{\mathrm{spc}}$ and CHE as an Estimates of Canopy Height

Proposed Canopy Height Methodology Benefits and Limitations

$\begin{array}{lll}\text { 6.6.1 Benefits } & 206\end{array}$

$\begin{array}{lll}\text { 6.6.2 } & \text { Limitations } & 207\end{array}$

6.7 Proposed Canopy Height Methodology Compared to Other

Canopy Height Methods that Use InSAR and PolInSAR Data

$6.8 \quad$ Summary

CHAPTER SEVEN: CONCLUSIONS

7.1

X-HH InSAR Derived Canopy Height Estimates - Airborne

7.2 L-Quad PolInSAR Derived Canopy Height Estimates Airborne

7.4 Broader Implications of this Research

7.5 Improvements to the Proposed Empirical Method to Estimate Canopy Height

7.6 Comparison to Other InSAR/PolInSAR Canopy Height Estimate Methods 


\section{LIST OF TABLES}

Table 1 A summary of the key parameters of select SAR systems suitable for deriving elevation data via interferometric methods, where polarization $=\mathrm{POL}$, Image horizontal accuracy $=\mathrm{IA}$; elevation vertical accuracy $=$ EA; InSAR Pass $=I P ;$ Single $=S ;$ Repeat $=R$.

Table 2 Research site land cover class descriptions (modified after Homer et al., 2004) and the National Land Cover Data (NLCD) class \#. Water, grass, crops, and urban land cover were not included in this research; however they were classified, grouped together and masked leaving only the vegetation classes of interest.

Table 3 InSAR and PolInSAR datasets per research site. Accuracies shown are vendor stated values. 'Posting' refers to the distance in the $\mathrm{x}$ or $y$ direction between data values.

Table 4 Ancillary data available for given research sites.

Table 5 Number of in situ, NGS, and LiDAR reference bare ground measurements per vegetation type and research site.

Table 6 Number of tree height observations per vegetation class for the six research sites.

Table 7 41,322 NGS reference points per land cover class and slope class.

Table 8 Sequential rule set used in land cover classification. Digital number is denoted as DN.

Table 9 Number of land cover reference observations from the in situ observations and from interpretation of high resolution optical imagery shown per vegetation type and research site.

Table 10 Buffers and attenuation bias correction factors for vegetation types.

Table 11 Number of $h_{s p c}$ and CHE data samples per slope, incidence angle, and land cover classes.

Table 12 Number of data samples per near- (NR), mid- (MR), and far-range (FR) per research site, in flat terrain with slopes less than $10^{\circ}$.

Table 13 Number of data samples per near- (NR), mid- (MR), and far-range (FR) per research site, in flat terrain with slopes less than $10^{\circ}$.

Table 14 Number of across-swath transects per site.

Table 15 DEMs vertical accuracy assessment against combined in situ, NGS, and LiDAR reference data for the six research sites. 
Table 16 DEMs vertical accuracy assessment against 41,322 NGS reference elevations for the conterminous United States over terrain slopes less than $30^{\circ}$.

Table 17 DEMs vertical accuracy assessment against reference measurements stratified by land cover at the six sites for all terrain slopes.

Table 18 DEMs vertical accuracy assessment against 41,322 NGS reference elevations for the conterminous United States stratified by land cover type.

Table 19 DEMs accuracy stratified by terrain slope at the four U.S. research sites, all data combined.

Table 20 DEMs accuracy stratified by terrain slope over the conterminous United States.

Table 21 X-HH InSAR, L-Band PolInSAR and SRTM C-HH InSAR derived $\mathrm{h}_{\mathrm{spc}}$ vertical error assessment against in situ and LiDAR canopy height for all research sites (where applicable), stratified by vegetation type. Mean tree height for all sites are given in column 3 for comparison with X-, and C-band errors given in columns 4 and 5. Mean tree height for the two Alberta sites is given in column 6 for comparison with L-Band height estimate errors shown in column 7.

Table 22 X-HH InSAR, L-Band PolInSAR and SRTM C-HH InSAR derived $\mathrm{h}_{\mathrm{spc}}$ relative error and canopy height estimate stratified by vegetation type for all data combined.

Table 23 X-HH InSAR and SRTM C-HH InSAR derived $\mathrm{h}_{\text {spc }}$ error assessment against in situ canopy height for International Falls, stratified by vegetation type.

Table $24 \quad \mathrm{X}-\mathrm{HH}$ InSAR and SRTM C-HH InSAR derived $\mathbf{h}_{\text {spc }}$ error assessment against in situ canopy height for Ely, stratified by vegetation type.

Table $25 \mathrm{X}$-HH InSAR and SRTM C-HH InSAR derived $\mathrm{h}_{\text {spc }}$ error assessment against in situ canopy height for Arizona, stratified by vegetation type.

Table $26 \quad \mathrm{X}-\mathrm{HH}$ InSAR and SRTM C-HH InSAR derived $\mathrm{h}_{\mathrm{spc}}$ error assessment against in situ canopy height for Colorado, stratified by vegetation type. 
Table 27 X-HH InSAR, SRTM C-HH InSAR and L-Band PolInSAR derived $\mathrm{h}_{\mathrm{spc}}$ error assessment against LiDAR CHE for Edson, stratified by vegetation type.

Table 28 X-HH InSAR, SRTM C-HH InSAR and L-Band PollnSAR derived $\mathrm{h}_{\mathrm{spc}}$ error assessment against LiDAR CHE for Burnstick Lake, stratified by vegetation type.

Table 29 Single- and multi- (NEXTMap) data takes InSAR-derived $h_{\text {spc }}$ error assessment against in situ canopy height for the Ely site, stratified by vegetation type and incidence angle range for $\leq 10^{\circ}$ terrain slope. * Multi-takes InSAR incidence angle is not known due to the combining of multiple flight lines (or takes) to generate the final output.

Table 30 Single- and multi- (NEXTMap) data takes InSAR-derived $h_{\text {spc }}$ error assessment against in situ canopy height for the International Falls site, stratified by vegetation type and incidence angle range for $\leq 10^{\circ}$ terrain slope. * Multi-takes InSAR incidence angle is not known due to the combining of multiple flight lines (or takes) to generate the final output.

Table 31 Single- and multi- (NEXTMap) data takes InSAR-derived $h_{\text {spc }}$ error assessment against in situ canopy height for the Arizona site, stratified by vegetation type and incidence angle range for $\leq 10^{\circ}$ terrain slope. * Multi-takes InSAR incidence angle is not known due to the combining of multiple flight lines (or takes) to generate the final output.

Table 32 Single- and multi- (NEXTMap) data takes InSAR-derived $\mathrm{h}_{\mathrm{spc}}$ error assessment against LiDAR canopy height for the Edson site, stratified by vegetation type and incidence angle range for $\leq 10^{\circ}$ terrain slope. ${ }^{*}$ Multi-takes InSAR incidence angle is not known due to the combining of multiple flight lines (or takes) to generate the final output.

Table 33 Single- and multi- (NEXTMap) data takes InSAR-derived $h_{\text {spc }}$ error assessment against LiDAR canopy height for the Burnstick Lake site, stratified by vegetation type and incidence angle range for $\leq 10^{\circ}$ terrain slope. * Multi-takes InSAR incidence angle is not known due to the combining of multiple flight lines (or takes) to generate the final output.

Table $34 \mathrm{~h}_{\mathrm{spc}}$ comparison for 19,561 sample points located along transect lines of slopes less than $10^{\circ}$ in the $\operatorname{NR}\left(\theta=35^{\circ}\right), \operatorname{MR}\left(\theta=45^{\circ}\right)$, and FR $\left(\theta=55^{\circ}\right) . h_{\text {spc }}$ was generated from single-data take X-HH InSAR and compared to multi-data takes X-HH InSAR (NEXTMap) for all site data combined in weighted averages based on samples per site 
Table 35 Comparison of $\mathrm{h}_{\mathrm{spc}}$ for sample points located along transect lines of slopes less than $10^{\circ}$ in the NR $\left(\theta=\left(35^{\circ}\right), \operatorname{MR}\left(\theta=45^{\circ}\right)\right.$, and FR $(\theta$ $=55^{\circ}$ ) generated from SLC X-HH InSAR (single-data takes) and NEXTMap X-HH InSAR (multi-data takes).

Table 36 Comparison of $h_{\text {spc }}$ for combined sample points located along transect lines running across swath from NR - MR - FR of slopes less than $10^{\circ}$ generated from X-HH InSAR (single-data take) and NEXTMap X-HH InSAR (multi-data takes).

Table 37 X-HH InSAR land cover classification accuracy assessment, U.S. sites. The reference data are in the rows; classified data are in the columns.

Table 38 NLCD land cover classification accuracy assessment, U.S. sites.

The reference data are in the rows; classified data are in the columns.

Table 39 X-HH InSAR and NLCD land cover classification accuracy assessment for all data combined, U.S. sites. The reference data are in the rows; classified data are in the columns.

Table 40 X-HH InSAR land cover classification accuracy for the Canadian sites. The reference data are in the rows; classified data are in the columns.

Table 41 X-HH InSAR derived canopy height estimates error at vegetation canopy gaps and vegetation non-vegetation canopy boundaries with and without gap/edge corrections applied: error assessment is against in situ canopy height measurements.

Table 42 X-HH InSAR and L-Band PolInSAR derived canopy height error assessment for all research sites stratified by vegetation type. Reference data were: in situ (U.S. sites) and LiDAR (Canadian sites) canopy height measurements.

Table 43 Percentage of canopy height retrieved by the X-HH InSAR and LBand PolInSAR CHEs for all research sites combined, stratified by vegetation type.

Table 44 X-HH InSAR derived CHE error assessment against in situ canopy height for International Falls, stratified by vegetation type.

Table 45 X-HH InSAR derived CHE error assessment against in situ canopy height for Ely, stratified by vegetation type.

Table 46 X-HH InSAR derived CHE error assessment against in situ canopy height for Arizona, stratified by vegetation type. 
Table 47 X-HH InSAR derived CHE error assessment against in situ canopy height for Colorado, stratified by vegetation type.

Table 48 X-HH InSAR and L-Band PolInSAR derived CHE error assessment against LiDAR CHE for Edson, stratified by vegetation type.

Table 49 X-HH InSAR and L-Band PollnSAR derived CHE error assessment against LiDAR canopy height for Burnstick Lake, stratified by vegetation type.

Table $50 \quad \mathrm{X}$-HH InSAR derived $\mathrm{h}_{\mathrm{spc}}$ and proposed CHE error stratified by vegetation type and terrain slope for data located in the near range $\left(30^{\circ}-39^{\circ}\right.$ Incidence angle).

Table $51 \quad \mathrm{X}-\mathrm{HH}$ InSAR derived $\mathrm{h}_{\mathrm{spc}}$ and proposed $\mathrm{CHE}$ error stratified by vegetation type and terrain slope for data located in the mid range (40 $-49^{\circ}$ Incidence angle).

Table $52 \quad \mathrm{X}$-HH InSAR derived $\mathrm{h}_{\mathrm{spc}}$ and proposed CHE error stratified by vegetation type and terrain slope for data located in the far range (50 - $59^{\circ}$ Incidence angle).

Table 53 X-HH InSAR derived $h_{\text {spc }}$ and proposed CHE error stratified by terrain slope and incidence angle for all vegetation classes combined.

Table 54 Key X-InSAR DTM vertical accuracy studies over varied land cover.

Table 55 Key X-InSAR derived $h_{\text {spc }}$ canopy height studies. 


\section{LIST OF FIGURES}

Figure 1 Summary of the steps applied in this research to achieve the stated goal of development of an InSAR methodology for vegetation type and canopy height estimation over large geographic extents, diverse vegetation types, varied eco-regions, and terrain conditions as well as to compare capabilities for DEM extraction and canopy height estimation amongst three different InSAR technologies.

Figure 2 Scanning configuration for a right-hand looking rectangular SAR antenna, modified after Olmsted (1993). $L$ is the antenna length, D is the antenna width, $\mathrm{T}$ is the pulse duration, and $\mathrm{H}$ is the Nadir Range. The recorded signal data (amplitude and phase) can produce a two-dimensional radar image. The distances measured between the antenna and the target is known as slant range.

Figure 3 InSAR collection mode for repeat-pass interferometry, modified after Richards (2007) and Bamler and Hart (1998). Parameters in this figure are defined following discussion of Equation 1.

Figure 4 InSAR collection mode for single-pass interferometry, modified after Richards (2007) and Bamler and Hart (1998). Parameters in this figure are defined following discussion of Equation 1

Figure 5 InSAR interferogram (modified after Gens, 2001). One set of colours (red, pink, yellow, green and blue) represents one $0-2 \pi$ interferometric fringe.

Figure 6 InSAR coherence image where the image tones range from dark to bright, indicating increasing coherence or increasing agreement between SAR observations. (Modified after Gens, 2001).

Figure 7 An interferogram (bottom) has been processed to unwrap the phase data to derive a DSM represented by the wire mesh (top) (modified after Gens, 2001).

Figure 8 InSAR derived elevation model (modified after Gens, 2001).

Figure 9 PollnSAR ground topography (blue dot) and canopy height (pink cross) extraction in a complex plane, for one image pixel (ellipsoid $=$ high coherence). 
Figure 10 Figure 10. Relative position of X-Band InSAR $h_{s p c}$ and true canopy height for dense forest (red and white line, respectively) as well as $h_{\text {spc }}$ and true canopy height for bare ground, which are coincident (blue line). The data presented in this illustration represents the DSM LiDAR data over a section of the Edson research site (See Section 3.1.6.). A1 and A2, represent antenna 1 and antenna 2 on a single-pass InSAR configuration.

Figure 11 InSAR signal penetration over dense vegetation and barren ground at different wavelengths for a profile line in grey, superimposed on a LiDAR DSM.

Figure 12 Incidence angle effect on $\mathrm{h}_{\mathrm{spc}}$ retrieval for a forest canopy for single pass InSAR.

Figure 13 Surface roughness effects on radar backscatter for four land cover types. L-R: a body of water (specular reflection), grass (diffuse scattering), forest (volume scattering), and buildings (dihedral reflection: Intermap, 2011).

Figure 14 Slope and aspect effect on signal attenuation (penetration) into a forest canopy. For the same incidence angle $(\theta), h_{s p c}$ (yellow line) varies depending on the direction the slope faces with respect to the sensor (aspect) and on the amount of terrain slope (in degrees).

Figure $15 \mathrm{~h}_{\mathrm{spc}}$ underestimation of canopy height at a forest edge (see B to C points).

Figure 16 International Falls, Minnesota study site with 22 field plot installation locations represented as red diamonds superimposed on National Agriculture Imagery Program (NAIP) imagery.

Figure 17 Ely, Minnesota study site with 54 field plot installation locations represented as red diamonds superimposed on NAIP imagery.

Figure 18 Morrison, CO study site with 179 field plot installation locations represented as red diamonds superimposed on NAIP imagery

Figure 19 Arizona study site with 234 field plot installation locations represented as red diamonds superimposed on NAIP imagery.

Figure 20 Burnstick Lake, Alberta study site with six transect lines (red dashed lines) superimposed on optical imagery. Transect line data were derived from LiDAR data, in lieu of plot installations.

Figure 21 Edson, Alberta study site with six transect lines (red dashed lines) superimposed on optical imagery. Transect line data were derived from LiDAR data, in lieu of plot installations. Transect lines are numbered $1-8$, left to right. 
Figure 22 Intermap InSAR specifications for the data used in this research. Typical swath is $10 \mathrm{~km}$ wide and $1200 \mathrm{~km}$ long, allowing for the collection of two flight lines per sortie (approximately 5 hours in the air).

Figure 23 NEXTMap X-HH InSAR DSM data collection of primary (green and orange single data take data strips) and tie (blue single data take strips) flight line strips that are merged to derived the final DSM given in the right mosaic.

Figure 24 SRTM single-pass C-HH InSAR platform specifications. This system mapped approximately $80 \%$ of the Earth's landmass in eleven days.

Figure 25 Single-pass L-Quad PolInSAR TOPOSAR platform specifications. Typical swath size is $5 \mathrm{~km}$ wide and $200 \mathrm{~km}$ long.

Figure 26 Distribution of the 41,322 US National Geodetic Survey points (NGS, 2003).

Figure 27 Photographs of the field plot conditions for the five vegetation types investigated in this research.

Figure 28 Sample field plot directional photographs for the North, South, East, and West facing locations.

Figure 29 Scattering phase centre height was calculated by subtracting the InSAR DTM height (red line) from the InSAR DSM Height (red line).

Figure 30 Flowchart illustrating the data and processes used to derive and validate the canopy height estimates.

Figure 31 Land cover object-based classification process flow.

Figure 32 Vegetation buffers illustrated.

Figure 33 Transect (dashed lines) positions in near-, mid-, and far-range for one strip of single-data take data. Example from the International Falls, $\mathrm{MN}$ site

Figure 34 Transect line (dashed line) running across one single-data take data swath in the range direction. Example from the International Falls, MN site 
Figure 35 Cumulative distribution of the absolute value of individual point vertical errors for the X-HH InSAR DTM, NED DTM and SRTM C-HH InSAR DSM for the six sites compared to the reference data.

Figure 36 Comparison of DEM data for the International Falls, MN site. Top left: ca. 2007 X-HH InSAR DTM; top right: ca. 2000 SRTM DSM; bottom left: elevation profiles for each data set over the A-B transect; bottom right: ca. 2007 NAIP image.

Figure 37 Comparison of DTM data for the International Falls, MN site. Top left: ca. 2007 X-HH InSAR DTM; top right: ca. 1986 NED DTM; bottom left: elevation profiles for each data set over the A-B profile; bottom right: ca. 2007 NAIP data.

Figure 38 Cumulative distribution of the vertical error for the X-HH InSAR DTM, NED DTM and SRTM C-HH InSAR DSM for the conterminous U.S. Error was calculated through comparison with NGS data.

Figure 39 Data collection conditions for the Arizona research site (red box) where shrub plot installations over vegetation samples were observed. Top right photo is an example of leaf-off shrub; lower right photo is an example of leaf-on shrub vegetation.

Figure 40 3-D perspective view of $h_{\text {spc }}$ for a section of evergreen and mixed forests within the Ely, AB study site. LiDAR CHE (Top Left), XHH InSAR $h_{\text {spc }}$ (Top Right), C-HH InSAR $h_{\text {spc }}$ (Bottom Left), and the L-Band PolInSAR $h_{\text {spc }}$ (Bottom Right).

Figure 41 Ely research site X-HH InSAR derived $h_{\text {spc }}$.

Figure 42 International Falls research site X-HH InSAR derived $h_{\text {spc }}$.

Figure 43 Colorado research site X-HH InSAR derived $h_{\text {spc }}$.

Figure 44 Arizona research site X-HH InSAR derived $h_{\text {spc }}$.

Figure 45 Edson research site X-HH InSAR (left image) and L-Quad PolInSAR (right image) derived $h_{\text {spc }}$.

Figure 46 Burnstick Lake research site X-HH InSAR (left image) and LQuad PolInSAR (right image) derived $h_{\text {spc }}$. 
Figure 47 Profile comparisons of X-HH InSAR DSM (red line), C-HH InSAR DSM (green line), and the X-HH InSAR DTM (blue line) over barren and vegetated land cover at the International Falls research site. Arrows indicate regions where the C-band DSM is higher than the shorter wavelength X-band DSM, providing a better estimate of tree height.

Figure 48 Structure and density examples for mixed, evergreen, wetlands, and deciduous vegetation type. Wetlands and deciduous vegetation types have better canopy height estimates than the evergreen forests, possibly due to the vegetation structure.

Figure 49 Comparison of LiDAR canopy height (dark blue) to X-HH InSAR $h_{\text {spc }}$ (pink), SRTM C-HH InSAR $h_{\text {spc }}$ (yellow), and L-Quad PolInSAR $h_{\text {spc }}$ (turquoise) for three transects (\#1, \#4, and \#6, 1.3 $\mathrm{km}$ in length, Figure 21) at the Edson research site.

Figure 50 Three examples of X-HH airborne flight line twisting.

Figure 51 Three profiles located across one swath (NR-MR-FR) over singledata take $h_{\text {spc }}$ data) compared to multi-data takes X-HH InSAR derived $h_{\text {spc }}$ data for the Ely site.

Figure 52 Two profiles located across one swath (MR-FR) over single-data take $h_{\text {spc }}$ data) compared to multi-data takes X-HH InSAR $h_{\text {spc }}$ data for the International Falls site.

Figure 53 Three profiles located across one swath (NR-MR-FR) over singledata take $h_{\text {spc }}$ data) compared to multi-data takes X-HH InSAR derived $h_{\text {spc }}$ data for the Arizona site.

Figure 54 International Falls X-HH InSAR derived land cover map (top left); NLCD (top right); NAIP imagery (bottom right).

Figure 55 Ely X-HH InSAR derived land cover map (top left); NLCD (top right); NAIP imagery (bottom right).

Figure 56 Arizona X-HH InSAR derived land cover map (top left); NLCD (top right); NAIP imagery (bottom right).

Figure 57 Colorado X-HH InSAR derived land cover map (top left); NLCD (top right); NAIP imagery (bottom right) 
Figure 58 Burnstick Lake $2007 \mathrm{X}-\mathrm{HH}$ InSAR derived land cover map (top left) differs in time from the 2008 Google Earth (top right) optical image, showing a deforested patch of land that was a forest at the time of the InSAR data collection. The L-HH InSAR imagery (bottom left) and the $2007 \mathrm{X}-\mathrm{HH}$ InSAR scattering phase centre height.(bottom right image) correlate well with the land cover classification. The Google imagery does not correlate well with $\mathrm{X}$ HH derived InSAR land cover classification, due to the temporal differences.

Figure 59 Edson X-HH InSAR derived land cover map (left); aerial photography supplied by Valtus (right).

Figure 60 International Falls research site X-HH InSAR DTM derived slope map.

Figure 61 Ely research site X-HH InSAR DTM derived slope map.

Figure 62 Colorado research site X-HH InSAR DTM derived slope map. 175

Figure 63 Arizona research site X-HH InSAR DTM derived slope map. 


\section{LIST OF EQUATIONS}

$z(y)=H-\rho \cos (\theta)$

(1) Page 26

$(\rho+\delta \rho)^{2}=\rho^{2}+\beta^{2}-2 \rho \beta \cos (90-\theta+\alpha)$

(2) Page 26

$z(y)=H-\left\{\frac{\delta \rho 2-\beta^{2}}{2 \beta \sin (\alpha-\theta)-2 \delta \rho}\right\} \cos (\theta)$

(3) Page 27

$\delta \rho=\frac{\lambda \Phi}{2 \pi}$

(4) Page 27

$\gamma=\frac{\left\langle I_{1} I_{2}^{*}\right\rangle}{\sqrt{\left\langle I_{1} I^{*}{ }_{2}\right\rangle}\left\langle I_{1} I_{2}{ }^{*}\right\rangle}$

(5) Page 30

$M\left(s_{m}, \rho_{k}\right)=\sqrt{\sqrt{P_{1}\left(s_{m}, \rho_{k}\right)} \sqrt{P_{2}\left(s_{m}, \rho_{k}\right)}}$

(6) Page 32

$\gamma(w)=\exp ^{i \Phi}\left[\frac{\widetilde{\gamma}_{\nu}+m(w)}{1+m(w)}\right]$

(7) Page36

$\gamma(w)=\exp ^{i \oplus}\left[\tilde{\gamma}_{v}+\frac{m(w)}{1+m(w)}\left(1-\widetilde{\gamma}_{v}\right)\right]$

(8) Page 37

$\phi=K_{z} h_{v}$

(9) Page 38

$K_{z}=\frac{4 \pi \Delta \theta}{\lambda \sin \theta}$

(10) Page 39

$x=\left\lfloor z D E M-z_{\text {reference }}\right\rfloor$

(11) Page 90

$x_{R M S}=\sqrt{\frac{x_{1}^{2}+x_{2}^{2}+\ldots \ldots x_{n}^{2}}{n}}$

(12) Page 91

$\bar{x}=\frac{\sum x}{N}$ 


\section{LIST OF ACRONYMNS AND ABBREVIATIONS}

$2 \mathrm{D}$

3D

ALOS

CCRS

$\mathrm{CSH}$

DARPA

DBH

DSM

DTM

DEM

CHE Canopy Height Estimator

$\mathrm{CSH}$

Cross-Scan- Height coordinates

ERIM Environmental Research Institute of Michigan

ERS European Remote Sensing

FR

GPS

$\mathrm{HH}$

HV

$h_{\text {spc }}$

ICESat

IMU

InSAR

Two Dimensional

Three Dimensional

Advanced Land Observation Satellite

Canada Centre for Remote Sensing

Cross-scan Height

Defense Advanced Research Projects Agency

Diameter at Breast Height

Digital Surface Model

Digital Terrain Model

Digital Elevation Model

Far Range

Global Positioning System

Horizontal Transmission, Horizontal Received

Horizontal Transmission, Vertical Received

Scattering Phase Centre Height

Ice, Cloud, and land Elevation Satellite

Inertia Measurement Unit

Interferometric Synthetic Aperture Radar

xxiii 
JPL Jet Propulsion Laboratory

LiDAR Light Detection And Ranging

NGS National Geodetic Survey

NOOA - National Oceanic and Atmospheric Administration

NR Near Range

MR Mid-Range

MLE Maximum Likelihood Estimate

NASA National Aeronautics and Space Administration

NAD83 North American Datum 1983

NED National Elevation Data

ORI Orthorectified Radar Image

PALSAR Phased Array L-band SAR

PolInSAR Polarimetric Interferometric Synthetic Aperture Radar

PRIS Polarimetric Radar Interferometry Simulator

RADAR Radio Detection and Ranging

RCS Radar Cross Section

RMSE Root Mean Square Error

SAR Synthetic Aperture Radar

SIR Shuttle Imaging Radar

SRTM Shuttle Radar Topographic Mission

SLC Single-Look Complex

Tandem-X TerraSAR-X Add-on DEM X

UTM Universal Transverse Mercator 
VH Vertical Transmission, Horizontal Receiver

VV Vertical Transmission, Vertical Receiver 


\section{CHAPTER ONE: INTRODUCTION}

\subsection{Problem Definition}

The Earth's landmass is covered by $70 \%$ vegetation comprised of herbaceous (grassland, agriculture, tundra), shrub, forest (temperate, arid, semi-arid, tropical, and Boreal) and wetlands (NOAA, 2011). Vegetation cover represents key dynamic components in the global carbon cycle. The world's vegetation influences climate through physical, chemical, and biological processes that affect the hydrologic cycle and atmospheric composition locally, regionally, and globally. The photosynthetic composition of vegetation is essential for accurate simulations of biosphere-atmosphere exchanges of carbon, water, and energy. Vegetation helps to cycle nutrients, maintain and support biodiversity, regulate climate and greenhouse gases, and stabilize soil. It provides habitat for wildlife, goods such as food, medicine, wood, and timber, and the opportunity for recreation (Bonan, 2008; Feddema, et al., 2005; Kleidon, 2012).

Human and natural forces play a significant role in removal of vegetation, and include wildfires, volcanic eruptions, floods, human habitation and urban expansion, agriculture, forest product extraction, open pit mining, dam building, and energy infrastructure. Landscape cover and structure are changing rapidly due to these forces, with implications for the Earth's biodiversity, including loss of habitat, deforestation, increasing extinction, invasive species, and alteration of the ecosystem (Sala et al., 2000).

As vegetation is depleted, more carbon is added to the atmosphere, climatic conditions are further altered, and more topsoil is lost to erosion (Bonan, 2008; Le Toan et al., 2004; 2011). To understand change in vegetation cover and its impact on the 
environment, climate, atmosphere, habitat and ecosystem, fine spatial resolution globalscale maps of vegetation cover and vegetation canopy height are needed.

Vegetation cover and vegetation canopy height maps are of great value in many types of regional- to global-scale modeling and are an essential precursor to many techniques for extracting physical, topographic, and cultural data for a plethora of applications such as flood plain modeling, geological hazard assessment, land slide analysis, urban planning, topographic and geologic mapping, biomass studies, and landfire initiatives, amongst others.

In timber resource management, tree height is an important parameter used to calculate the amount of wood in trees (West, 2009), where vegetation canopy height is combined using allometric relationships with, for example, diameter at breast height (DBH), crown width, basal area and stem taper to produce estimates of timber volume (Franklin, 2001). These estimates can then be scaled up to stand and forest areas to produce predictions of timber yield. Regular estimations are required to accurately predict and manage the forest crop to maximize yield over time.

Vegetation canopy height is also useful in obtaining more accurate estimates of aboveground woody biomass and is a key indicator of succession status (Balzter et al., 2007a; Wofsy et al., 2008). Mapped estimates of vegetation canopy height are relevant to the understanding of carbon storage and cycling, susceptibility to wildfire, changes in structure from disturbance (insect outbreaks, wildfire, storms, forest management practices such as thinning and logging), and assessment of biodiversity and wildlife habitat. Furthermore, knowledge of vegetation canopy structure is required for modeling 
processes such as photosynthesis, energy transfer, and evapo-transpiration at local to global scales (Gamon et al., 1995; Drewry et al., 2010).

The level of sophistication and complexity of many remote sensing modeling activities that estimate fundamental land cover characteristics are well developed and forest structure can be estimated with high precision for local to regional areas at resolutions of $10 \mathrm{~cm}$ to $5 \mathrm{~m}$. Detailed mapping of vegetation cover and canopy height (resolutions between $50 \mathrm{~cm}-2 \mathrm{~m}$ ) for varied vegetation cover types over large spatial extents is lacking. This information must be available in a spatially comprehensive form. The ability to derive finer-resolution forest biophysical parameters remotely and for large geographic regions would be of great benefit to monitor the Earth's vegetation landscape at regional, national, and global scales.

\subsection{Forest Biophysical Parameter Measurement Techniques}

Measurement of forest biophysical parameters such as vegetation cover and canopy height using traditional field techniques is time-consuming, costly, and impossible to implement over large geographic extents (Andersen et al., 2006). For example, forests of the United States and other mid- to high-latitude nations are covered by extensive inventory plot networks; however, these data are largely inadequate for the provision of high-resolution estimates of aboveground biomass and carbon stocks at a national scale. Moreover, estimates for large areas with limited ground-based sampling are potentially uncertain or biased (Fisher et al., 2008). The limitation of under-sampling has been a concern in field-oriented environmental studies because there is a need for a vast amount of information to characterize the spatial and temporal patterns of vegetation dynamics, which cannot be obtained by field survey. Furthermore, to-date and for the 
foreseeable future, there is no consistent global coverage of vegetation cover and vegetation canopy height available based on ground measurements.

Data from airborne and satellite remotely sensed systems can provide economical and efficient means to estimate vegetation cover type and canopy height over large geographic regions at reduced cost and time, and at accuracies approaching that of ground based measurements, for example, within $10 \%$ of measured tree height (Naesset, 2002; Drake et al., 2002; Andersen et al., 2006). Remote sensing is not limited by undersampling as are field methods because it provides a synoptic view over large geographic extents. Moreover, advances in spatial information and decision-support systems, coupled with advances in remote sensing system technologies, offer great potential to achieve gains in measuring, mapping, and monitoring 3D vegetation structure at regional, national, and global scales.

Foremost among remote sensing technologies for 3D vegetation structure measurements are traditional aerial photography which has been used for several decades in the field of forestry (Mikhail et al., 2001: Jensen, 2005; Lillesand et al., 2008), laser altimetry and scanning, the latter generally known as LiDAR (Light Detection and Ranging; e.g., Means et al., 2000; Lefsky et al., 2002; Andersen et al., 2005a), synthetic aperture radar (SAR), interferometric SAR (InSAR or IFSAR; Madsen et al., 1993; Hensley et al., 2000; 2001; Rabus et al., 2003), and polarimetric InSAR (PolInSAR; Cloude and Papathanassiou, 1997; 1998; 2003; Mercer et al., 2007). These technologies are capable of generating high resolution elevation models, land cover maps, and detailed measurements of 3D vegetation canopy structure such as cover type, canopy height, and vegetation density (Balzter et al., 2001; Andersen et al., 2007; Williams et al., 2010). 
Airborne LiDAR, for example, has been shown to be an accurate tool for measuring ground topography (Hyyppä et al., 2000; Reutebuch et al., 2003) and basic canopy structure (Harding and Carabajal, 2005; Lefsky et al., 2007; Pang et al., 2011). Spaceborne LiDAR, like the ICESat satellite mission, is proving invaluable for consistency and global coverage of vegetation structure, however, contiguous coverage is limited (Carabajal and Harding, 2005). While the costs to acquire high-density LiDAR data (approximately USD \$2-3/ha; Anderson et al., 2005b; McInerney et al., 2010) continue to decrease, they are still prohibitive in regional and national applications. Furthermore, clear weather requirements, altitude restrictions for effective laser operation, and associated data coverage limitations (e.g. small footprint) also make the technology limited to regional to local scales. Nonetheless, the availability of LiDAR data will increase with the launch of future spaceborne LiDAR missions and the broader use of airborne sensors for topographic and vegetation canopy height mapping. As LiDAR data availability grows, a variety of regional-scale applications will become feasible.

Microwave systems such as SAR, InSAR, and PolInSAR, on the other hand, can acquire data in most weather conditions, from a platform flying at a higher altitudes and greater speeds than LiDAR systems, leading to greater data collection rates at lower costs over larger geographic extents (USD \$0.10- 0.80/ha for X-band data; Anderson et al., 2005b; McInerney et al., 2010). For example, InSAR makes use of interferometric phase

- difference information (e.g. interference patterns of two electromagnetic waves) for a location imaged by two radar beams to obtain high resolution $x, y$, and $z$ coordinates of the terrain being imaged (Graham, 1974; Zebker and Goldstein, 1986; Evans et al., 1992). 
The $\mathrm{x}, \mathrm{y}, \mathrm{z}$ information is then used to create surface and terrain digital elevation models and orthorectified radar images, from which vegetation cover type and canopy height can been extracted (Hensley et al., 2001; Rosen et al., 2001a; Kellndorfer et al., 2004). This thesis focuses on the use of InSAR/PolInSAR techniques to estimate and map vegetation cover and canopy height over a variety of landscapes.

\subsection{InSAR and PollnSAR Techniques as Potential Tools for Canopy Height Estimation}

Methods to estimate vegetation canopy height from InSAR/PollnSAR techniques vary (Kellndorfer et al., 2004; Balzter et al., 2007b; Garestier et al., 2011). One approach, applied in this study, is to subtract an independent elevation measurement of the ground surface from interferometric surface height, to derive what is called scattering phase centre height $\left(\mathrm{h}_{\mathrm{spc}}\right.$; Kellndorfer et al., 2004; Simard et al., 2006) to yield an estimate of vegetation canopy height. Another, also applied in this study, utilizes polarimetric interferometry (referred to as PollnSAR) where interferometric height, phase, and phase correlation between two SAR antennae, along with multiple baselines and/or polarizations are used to estimate canopy height directly (Cloude and Papathanassiou, 1998; Papathanassiou et al., 2005; Williams et al., 2010). Detailed descriptions of these methods are provided in chapters two (Theory) and five (Methods).

While a significant amount of research has been published on the application of InSAR/PolInSAR for 3D vegetation parameter extraction, in particular for canopy height, - most studies have focused on a limited set of vegetation types within a given region, rather than multiple vegetation types across diverse landscapes and varied eco-regions. Additional research is needed to gain further understanding of how SAR signals interact 
with diverse vegetation types and ecosystems and how this interaction can be exploited to derive vegetation cover type and canopy height over large geographic extents (Izzawati et al., 2006; Balzter et al., 2007a). Furthermore, comprehensive assessment of the operational potential and limitations of PollnSAR for 3D forest parameter extraction has been limited, thus, additional investigation into PolInSAR techniques and their application to 3D forest biophysical parameter retrieval are warranted.

This thesis research builds on developments to-date by analyzing and comparing $\mathrm{X}-\mathrm{HH}$ (horizontal transmission, horizontal received) airborne InSAR, spaceborne C-HH InSAR, and airborne L-Quad PolInSAR data over a variety of vegetation classes (shrub, deciduous, conifers, mixed, and wetlands), terrain types (various slopes and geologic settings), and continental environments (arid, semi-arid, temperate, and Boreal). The multi-frequency (X-, C-, and L-Band) InSAR and PolInSAR data are used to develop a new vegetation canopy height methodology that incorporates vegetation cover maps, also derived from InSAR data, and new processing steps to improve canopy height estimation near forest edges, in forest gaps, and within the forest canopies.

\subsection{Research Objectives}

This research was motivated by advances in, and the current availability of InSAR and planned PollnSAR technologies to remotely image and quantify vegetation cover, canopy height, and biomass measurements. The aim of this research is to evaluate the capability of airborne X-HH InSAR and L-Quad PolInSAR, as well as satellite based CHH InSAR, for estimating vegetation cover type and canopy height. The three SAR data types were selected for three reasons. First, the airborne X-, and L-band sensors represent systems currently in use or testing at Intermap Inc. where the author is an employee. 
Second, the SAR systems are capable of acquiring data from high speed airborne platforms and are currently used operationally to derive large area digital surface and terrain elevation models and SAR imagery. Third, there are many X-and L-band InSAR spaceborne systems available commercially, with the capacity to collect data at global scales.

This research focuses on the capability of the airborne systems to derive accurate vegetation cover and canopy height estimates which will contribute to both developments of Intermap's mapping capabilities and to the science of airborne and spaceborne InSAR/PollnSAR for 3D vegetation parameter extraction and mapping. The $\mathrm{C}-\mathrm{HH}$ data were selected for comparison because they are freely available globally. Additional details for this research are provided in Chapters Two (Theory) and Three (Sites and Data). The research objectives were:

1) To investigate the absolute vertical accuracy of bare ground elevation estimates derived using these three InSAR data types over a variety of land cover types, ecoregions, and terrain slopes in comparison to bare ground measurements given by in situ, National Geodetic Survey (NGS) reference points, and LiDAR digital terrain model (DTM) data, as well as against existing national DTM data (e.g. United States Geological Survey National Elevation Data - NED).

2) To determine the reliability of $h_{s p c}$ as an estimate of vegetation canopy height derived from the three InSAR/PolInSAR data types over a variety of vegetation types, terrain slopes, and eco-regions by comparing the results against in situ and LiDAR tree height measurements, as well as available national canopy height data. 
3) To develop a methodology for estimation of vegetation cover and for the correction of signal penetration within the canopy and at canopy edges and gaps that can be used to refine canopy height estimates derived from the two airborne InSAR data types for a variety of vegetation types, terrain conditions, and eco-environments. A secondary objective of this was to assess the performance of the proposed refined vegetation canopy height estimation methodology over a range of SAR incidence angles and terrain slopes.

The major eco-regions and vegetation groups of this research were selected because they represent several of the major eco-regions of North America, because such comparisons amongst eco-regions and vegetation types haven't been done before, and because Intermap had intensive field and mapping campaigns in these regions, which provided the opportunity to acquire excellent reference data for development of the methodology and validation of the results. Additional justification for the selection of the eco-regions and vegetation groups are provided in Chapter Three (Sites and Data). The analyses of the results with respect to incidence angle and terrain slope were conducted because these are two major factors known to affect InSAR/PolInSAR signals and resulting height estimates. More details on these methods are provided in Chapter Four (Methods).

\subsection{Contributions and Uniqueness of This Research}

This research was designed to provide new knowledge on SAR technologies regarding: 1) the vertical accuracy of DEMs derived from airborne X-HH InSAR, LQuad PolInSAR, and satellite based C-HH InSAR over a range of land covers, and 2) microwave attenuation of these three InSAR techniques over a variety of vegetation 
covers, varied terrain conditions, and diverse eco-regions. Furthermore, the biogeophysical characteristics of the six research sites presented in this research provided a unique opportunity to evaluate the three InSAR datasets as a source for high-resolution vegetation cover and canopy height estimates across a range of vegetation densities and structural classes as well as under a variety of topographic conditions and environments (arid, semi-arid, temperate and boreal). Evaluation and comparison of these data types over such diverse climatic and vegetation conditions as well as over such large geographic extents has not been conducted before.

The rich data sets, diverse vegetation cover types, and varied terrain conditions also provided a unique opportunity to conduct multiple comparative analyses between research sites, vegetation cover types, and data types, which has been lacking in the literature. This provided capability to develop a methodology to derive vegetation cover and canopy height that combines elements of methods presented in previous studies with new elements related to use of derived height in vegetation classification (Section 4.4.1), and use of refinement steps to improve the accuracy of $h_{s p c}$ as an estimate of canopy height (Section 4.4). Moreover, this research provides information that may be useful to future satellite based sensor development and use for vegetation cover and vegetation canopy height retrieval over large geographic extents.

\subsection{Thesis Structure}

Chapter one provides a brief background on the general issues addressed by the thesis, including the need for accurate large area estimates of vegetation cover and vegetation canopy height, and why these parameters are important. It presents InSAR and PolInSAR as suitable remote sensing technologies to extract such vegetation 
biophysical parameters, leading to the research motivation, objectives, and new scientific contributions. Chapter two provides a literature review of the relevant theory for SAR, InSAR, and PolInSAR and their previous use in land cover classification and vegetation canopy height extraction. A discussion is provided on SAR system and target characteristics that can affect the extraction of vegetation biophysical parameters. In Chapter three, the location of the six research sites and their various physical characteristics such as vegetation structure, geological, and terrain conditions that might affect the SAR return signals and the derived InSAR and PollnSAR elevation responses are presented. This is followed by an overview of the data processing and preparation steps. Chapter four describes the in situ methods that were used to measure vegetation cover type, vegetation canopy height, and bare ground terrain elevations measurements as reference data to validate the results given in Chapter five. In addition, the methodology to analyze the bare ground InSAR/PolInSAR elevation models, produce the scattering phase centre height, vegetation cover maps, and canopy height estimates are described. The chapter closes with a discussion on the methods conducted to assess the impact of the SAR system and target parameters on vegetation canopy height retrieval methodology presented in this research. Chapter five presents the results of these data analyses. Chapter six discusses the general meaning and implications of the research findings, their relationship to previous work, and implications of the results for regional to global scale vegetation cover and canopy height estimation and mapping. The chapter ends with a discussion of the limitations of the research. Chapter seven concludes with a summary of the research findings and recommendations for further work in the field of InSAR/PolInSAR for vegetation biophysical parameter estimation. 


\subsection{Research Approach}

The empirical methodology proposed in this research is represented as a conceptual process flowchart (Figure 1) comprised of multiple data types and a sequential set of procedures to estimate vegetation cover type and vegetation canopy height from multi-wavelength InSAR and PolInSAR data. It is presented here to provide an overview of the complete research process and the material presented in subsequent chapters.

The methodology starts with a literature review of the field of vegetation canopy height estimation from remote sensing techniques, in particular, InSAR and PolInSAR configurations, followed by the rationale for the selection of the research sites (Section 3.1.) and the acquisition of the reference, InSAR/PolInSAR, and ancillary data (Sections 3.2. and 3.3.). Multi-wavelength InSAR and PolInSAR data preparation includes the derivation of scattering phase centre height $\left(\mathrm{h}_{\mathrm{spc}}\right)$ as an initial canopy height estimate by subtracting an InSAR derived digital terrain model from the InSAR digital surface model (Section 4.2.), along with the classification of vegetation cover type using the InSAR data (Section 4.4.1.). The $h_{\text {spc }}$ is then refined using empirically derived correction factors for each vegetation type to correct for signal penetration into vegetation canopies (Section 4.4.3.). Additional refinements of vegetation canopy height estimates at forest edges and gaps are applied (Section 4.4.2.) to derive the proposed vegetation canopy height estimates. Multiple comparative analyses against in situ, National Geodetic Survey, and LiDAR reference data are performed on the multi-wavelength data sets (Sections 4.2.1. through to 4.2.6. and Sections 4.4.4. through to 4.4.7.). The findings are discussed and the conclusions of this research are presented in chapters six and seven, respectively. 


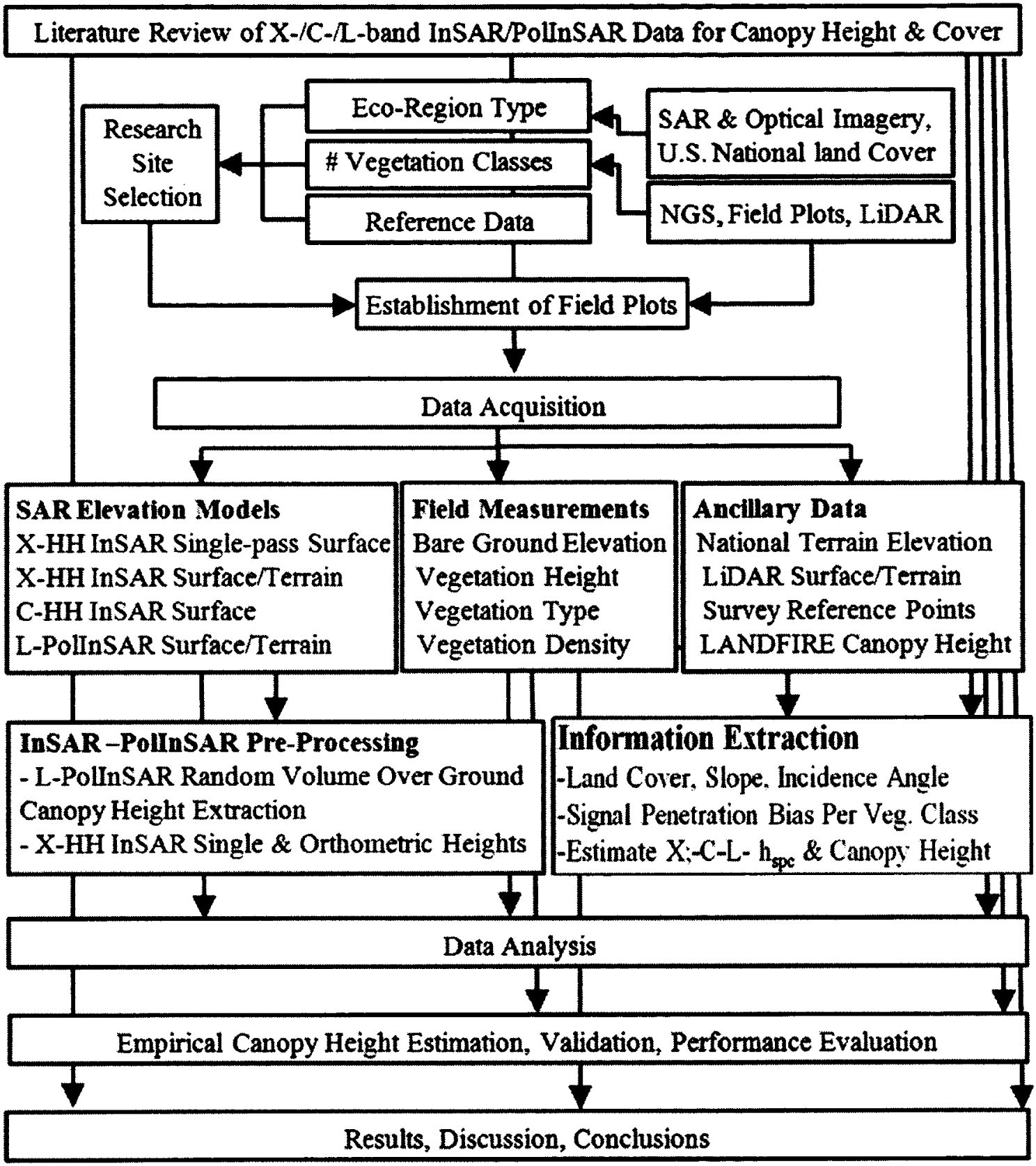

Figure 1. Summary of the steps applied in this research to achieve the stated goal of development of an InSAR methodology for vegetation type and canopy height estimation over large geographic extents, diverse vegetation types, varied eco-regions, and terrain conditions as well as to compare capabilities for DEM extraction and vegetation height estimation amongst three different InSAR technologies. 


\subsection{Summary}

This chapter has defined the need for research to develop methodology for vegetation cover and canopy height mapping capabilities over large areas, diverse vegetation types, varied eco-regions, and terrain conditions. A review of current forest biophysical estimation remote sensing techniques was provided, with emphasis on the use of multi-frequency InSAR and PolInSAR data to derive vegetation cover and canopy height estimates. Details about the research objectives were presented, along with a discussion on the uniqueness and contributions of this research. The chapter concludes with a summary of the thesis structure and the overall methodology implemented in the research. 


\section{CHAPTER TWO: SAR, INSAR, AND POLINSAR REMOTE SENSING THEORY}

FOR THE APPLICATION OF LAND COVER AND CANOPY HEIGHT

\section{MAPPING}

Various approaches have been used for canopy height estimation. They have included: 1) traditional field methods using height poles (Schreuder et al., 1993) and indirectly estimating tree canopy height using triangular geometry between an observer and the tree base and top (Wing et al., 2004), 2) the use of air photos and stereo photogrammetric methods (e.g., Fensham et al., 2002; Paine and Kiser, 2012), 3) optical satellite image reflectance associations with canopy height, or photogrammetric methods (e.g., Miller et al., 2000; Franklin et al., 2003; Riccehetti, 2005), 4) LiDAR (light detection and ranging), which provides perhaps the most accurate and detailed remotely sensed canopy height estimates (e.g., Means et al., 2000; Lefsky et al., 2002; Andersen et al., 2005a), and 5) synthetic aperture radar (SAR) images based on radargrammetric methods (Bresnahan, 2009; Toutin et al. 2009; Capaldo, et al., 2011), interferometric SAR (InSAR) methods (e.g., Balzter et al., 2007a; Izzawati et al., 2006; Sexton et al., 2009) and polarimetric interferometric (PolInSAR) methods (e.g., Cloude and Papathanassiou, 1998; Woodhouse et al., 2003; Papathanassiou et al., 2005).

Remotely sensed methods are the most efficient over large geographic areas. In the case of optical sensors, while success has been documented, in regions of persistent cloud cover, they are not able to obtain full coverage data. Research using InSAR and PollnSAR has intensified in recent years because of their increased availability, their capability to penetrate clouds, their ability to collect large areas of data quickly, and their ability to achieve accuracies in the range of $80 \%-90 \%$ of canopy height for large areas. 
The research presented in this thesis focuses on the use of InSAR and PolinSAR techniques for vegetation type identification and canopy height estimation. The SAR aspects pertinent to this research are described in this chapter. An in-depth review of the fundamentals of SAR, InSAR, and PolInSAR can be found in Hendersen and Lewis (1998), Richards (2007), and Cloude and Corr (2003), and a review of SAR systems for use in InSAR and PollnSAR configurations can be found in Lee and Pottier (2009). Here, the basic concepts of SAR imaging and its features are explained before presenting a summary of InSAR and PolInSAR technologies. These are followed by a literature review of the application of InSAR and PolInSAR for vegetation type mapping and canopy height estimation and a discussion on SAR system and terrain parameters that affect the derivation of vegetation type and canopy height estimates.

\subsection{Synthetic Aperture Radar (SAR) Background}

RADAR, which stands for "radio detection and ranging," subsequently referred to as radar, is an active remote sensing instrument that operates in the microwave portion of the electromagnetic spectrum. It provides its own source of illumination in the form of microwave pulses that are transmitted to the terrain being imaged. Therefore, radar sensors operate independently of the sun, often collecting data during night.

To obtain high resolution data from radar sensors, a synthetic aperture radar (SAR) configuration is implemented. SAR is a form of radar where the radar antennae, onboard a platform (air or space), transmit radio waves in the form of a wide beam of high-power pulses ('echoes") of microwave energy to the area being imaged (Elachi 1988; Curlander and McDonough 1991). Radar pulses are transmitted toward the terrain of interest in a vertically oblique direction that intersects the terrain with an oval footprint 
elongated in the range direction (e.g. across track; Figure 2). Consequently, two different scanning mechanisms are employed: one in the range direction, the second in the azimuth direction (direction of flight). In the range direction each transmitted pulse sweeps across the swath at the velocity of light. In the azimuth direction, the swath is scanned in the along-track direction at the speed of the antenna footprint (or forward movement of the platform). These two mechanisms differ in timescales from each other by several orders of magnitude, which allows us to treat them as mutually independent (Bamler and Hartl, 1998).

SAR sensors record the interference (Doppler) pattern from echo signals over several hundred to several thousand metres along the flight path. The received echoes form the raw data matrix or complex image containing amplitude and phase. The coordinates of the $2 \mathrm{D}$ raw signal image are range for the distance of the scatterer from the SAR (or equivalently echo delay time) and azimuth for the position of the scatterer along the sensor path (Figure 2). The target of interest is imaged (illuminated) several hundred times from different locations along the flight path generating numerous echoes that are recorded coherently (i.e., amplitude and phase as a function of time).

The accepted parameter for discussion of a radar system's "resolution" performance is impulse response. The microwave pulses are combined to synthesize a linear array with angular resolution equivalent to an antenna several hundred metres in length, resulting in what is called the azimuth resolution, in the direction parallel to the sensor flight path and the range resolution, perpendicular to the flight path direction. Azimuth impulse response is a function of antenna beam-width and the number of azimuth looks processed, whereas range resolution is a function of the range bandwidth. 
Azimuth resolution is equal to approximately one-half the actual (real) antenna length (L/2) and does not depend on platform altitude (distance). Range resolution, on the other hand, is determined by the transmitted pulse width ( $\mathrm{T}$ in Figure 2; e.g. narrow pulses yield fine range resolution (Elachi, 1988)). Range is determined by precisely measuring the time from transmission of a pulse to receiving the echo from a target.

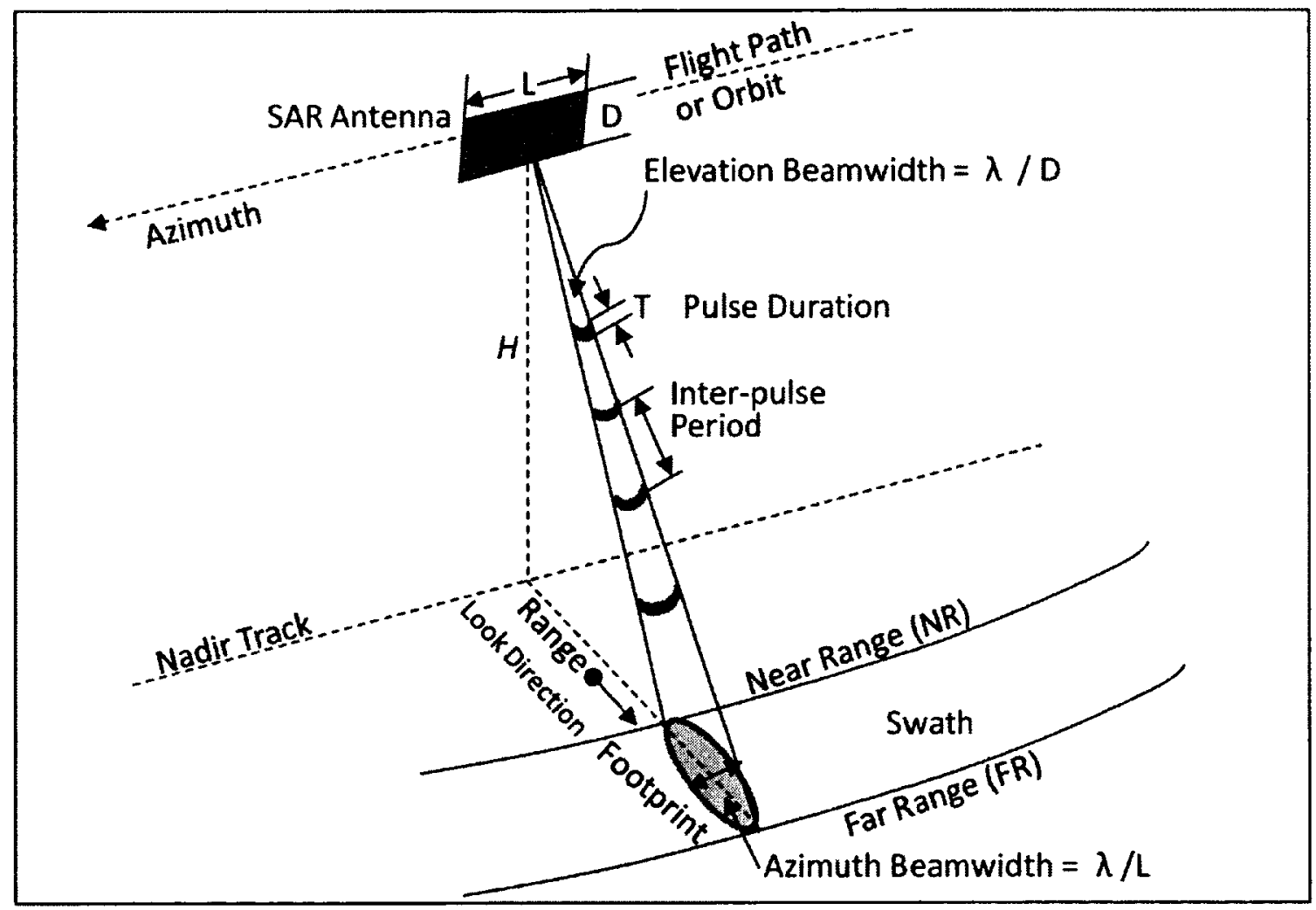

Figure 2. Scanning configuration for a right-hand looking rectangular SAR antenna, modified after Olmsted (1993). $\mathrm{L}$ is the antenna length, $\mathrm{D}$ is the antenna width, $\mathrm{T}$ is the pulse duration, and $\mathrm{H}$ is the Nadir Range. The recorded signal data (amplitude and phase) can produce a two-dimensional radar image. The distance measured between the antenna and the target is known as slant range. 
Microwaves are transversal waves, for example, in the direction of propagation the electric and magnetic fields are mutually orthogonal. By convention, polarized electromagnetic radiation is described by specifying the orientation of the wave's electric field at a point in space over one period of oscillation. Most earth observation SARs systems use Linear (or planar) polarizations where the vibration of the electric field vector is in a parallel direction to the propagating wave. The radar signals can be set up to vibrate in either a horizontal $(\mathrm{H})$ or vertical $(\mathrm{V})$ plane or in a circular fashion. Antennae can transmit in one plane and receive in another. Possible variations are $\mathrm{HH}, \mathrm{VV}, \mathrm{HV}$, and VH for: horizontal transmit, horizontal receive; vertical transmit, vertical receive; and so on. All four polarizations are typically denoted as "Quad" polarization.

Targets on the Earth's surface scatter microwave radiation differently depending on the polarization of the wave transmitted. Volume scattering (illustrated in Figure 13) is the main interaction in vegetated canopies. It causes the incoming signal to be depolarized, for example, the signal is scattered in other directions, at different relative vibrational planes. A H-polarized wave might hit a tree, bounce back and forth among leaves/twigs, and be backscattered to the SAR sensor in a V-polarized state. Using an HV setup, the antenna could receive these V-polarized returns. Though the overall radar backscatter received would be less than, say, a VV setup, the resulting image would have increased variation between regions of volume scattering (higher potential to return Vpolarized backscatter - usually vegetation) and regions of surface scattering.

SAR systems are not impeded by darkness, atmospheric conditions such as haze, clouds, light rain, or smoke (Bamler and Hartl, 1998). The resulting microwave energy can produce two-dimensional cloud free radar images. These have significant advantages 
over optical systems providing a suitable sensor technology for nearly all weather and day or night data acquisitions, across the globe. SAR systems require a complex integrated array of onboard navigational and control systems with location accuracy provided by both Doppler and inertial navigation equipment. The outputs produced are typically two-dimensional (2D) SAR imagery.

\subsection{Interferometric SAR (InSAR) for Topographic Mapping}

By combining two SAR measurements from two antennae displaced in space and/or time, the phase difference between the two returns SAR signals can be measured (Graham, 1974; Zebker and Goldstein, 1986; Evans et al., 1992). This method is called interferometric SAR (denoted as InSAR in this text; also denoted as IFSAR in other publications) which generates a digital elevation model in addition to the 2D SAR image. The first reported experiments to determine digital elevations of the Earth's topography using InSAR techniques were by Graham (1974). It took ten more years before InSAR was being researched for non-military applications by various groups, including the Canada Centre for Remote Sensing (CCRS), the U.S. Jet Propulsion Laboratory (JPL), the Environmental Research Institute of Michigan (ERIM), European Space Agency (ESA), German Aerospace Centre (DLR), and others. These investigations utilized airborne platforms including the CCRS CV-580, the JPL DC-8, and space platforms, such as SEASAT, European Remote Sensing-1/2 (ERS), and the space shuttle Shuttle Imaging Radar-A to -C (SIR-A-C) radars. In 1996, Intermap Inc. applied the world's first commercial implementation of a high-performance airborne interferometer, called STAR-3i. Today, there are a plethora of SAR systems available for earth observations, which are discussed in Section 2.3 and listed in Table 1. 
The theory of InSAR has been well described (e.g., Rodriguez and Martin, 1992; Madsen et al., 1993; Balmer and Hartl, 1998). A brief introduction to the fundamentals of InSAR for topographic mapping, the terminology, basic definitions, and InSAR- and PolInSAR-based techniques for vegetation type and canopy height are presented below.

A SAR system illuminates the area of interest with a beam of coherent microwave energy, retaining both amplitude and phase information in the radar echo during data acquisition. InSAR techniques make use of the phase difference of SAR backscatter received by two SAR observations separated in space and time to construct an interferogram (Figure 5; details on interferogram generation are provided below). The interferogram can be used to derive topographic height measurements (Graham, 1974; Zebker and Goldstein, 1986; and $\mathrm{Li}$ and Goldstein, 1990). The phase difference represented in the interferogram is the quantity from which the height of the pixel (with respect to a reference) is retrieved. This is because the phase difference is directly related to the difference in path lengths traversed by the radar signal between the point on the Earth surface and the two antennae.

InSAR systems rely on reception of the radar return signal using antennae at two different locations in an across-track arrangement (range direction), to derive the interferogram. InSAR configurations differ from traditional stereo models which require parallax to derive height, where parallax is dependent on the separation between images relative to the viewing distance (Lillesand et al., 2008). In InSAR, the patterns of electromagnetic radiation backscattering from the same point on the ground strike each antenna independently, due to their slightly different locations (ranges) from the target. Consequently, the microwaves do not always overlap each other exactly. For any point 
on the ground, if the point is an integer number of wavelengths away from each antenna, the waves will be exactly in phase. If the point is slightly closer or further away from the sensor platform, then the waves will be out of phase. On flat terrain, these phase changes - will occur at a consistent rate. When phase changes occur more quickly than normal, this indicates an increase in terrain elevation. Conversely, when the phase changes occur more slowly, this indicates a decrease in elevation from the previously measured point. This phase difference results from the triangular geometry formed by the two antennae and any ground point. It allows determination of the three dimensional coordinates $(x, y$, z) of a ground point by solving for unknown components of the triangle (e.g. Figure 3).

An InSAR interferogram is formed by using two successive images taken by two SAR antennae with nearly the same viewing geometry (Gray and Farris-Manning, 1993). The time lapse between the two image acquisitions is called the temporal baseline and it typically ranges from less than a day (e.g. ERS tandem mission phases) to many days representing the orbit length of the satellite (e.g., 24 days for RADARSAT). There are two standard approaches to obtain the two radar images necessary for InSAR configuration suitable for topographic elevation mapping: 1) repeat-pass and 2) singlepass interferometry. The configurations for repeat-pass and single-pass interferometry are illustrated in Figures 3 and 4, and are described in subsequent paragraphs.

Repeat-pass InSAR is the common technique utilized with satellite based data because these sensors are typically equipped with only one antenna requiring interferometric baselines of tens to hundreds of meters in length (Toutin and Gray, 2000). Although there is no time limit on the temporal baseline, it is commonly restricted to a few weeks due to the possibility of changes in surface conditions that make SAR signals 
incoherent with each other. Incoherent or loss of coherence (called decorrelation in InSAR phase) precludes interferogram construction, and therefore, digital elevation model (DEM) generation. Decorrelation in phase can result from changes in soil moisture, surface roughness, vegetation quantity, and structure, or vegetation orientation (e.g., due to wind differences) and landscape changes which may have occurred between the two data takes. This is a significant limitation of repeat-pass interferometry.

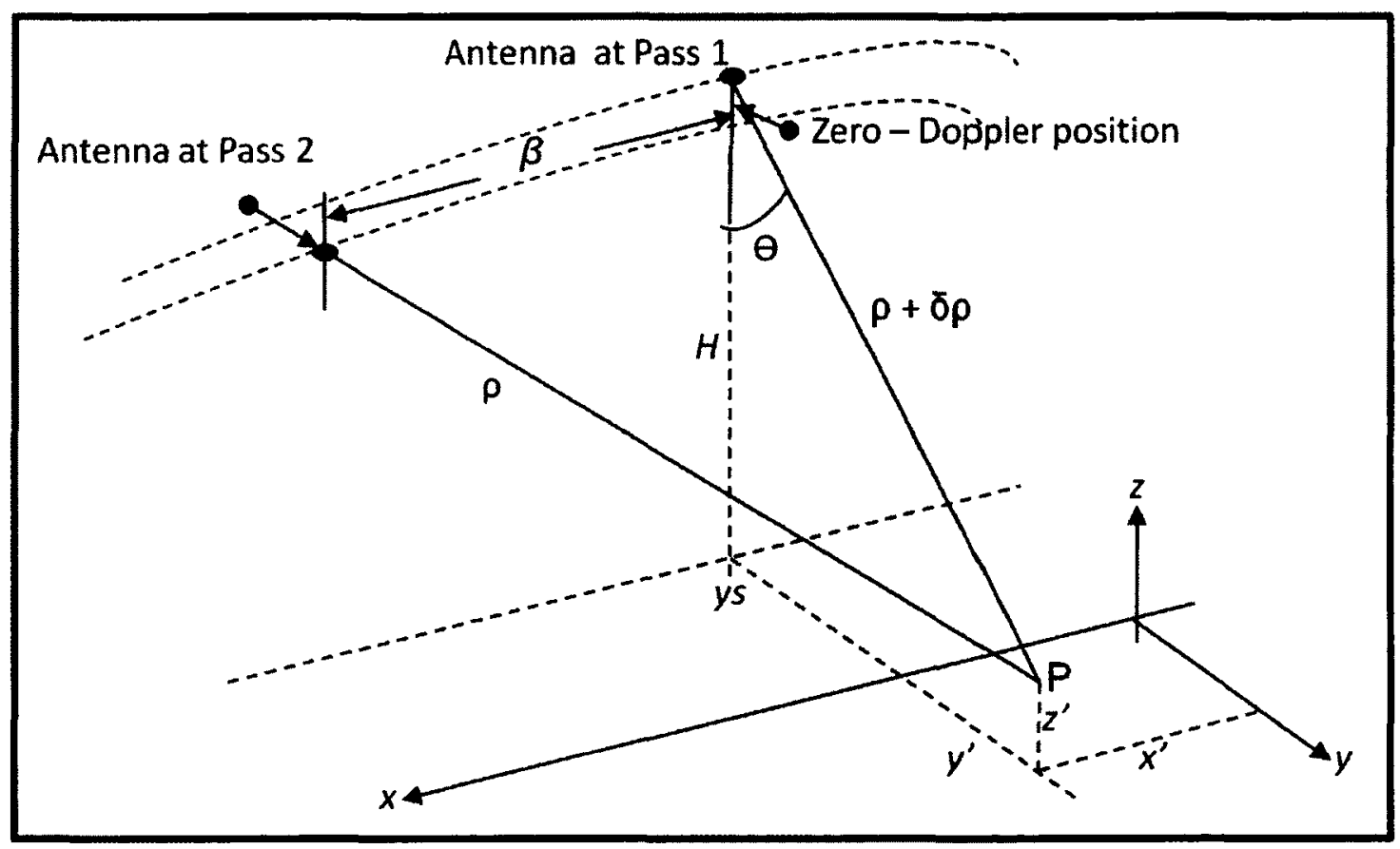

Figure 3. InSAR collection mode for repeat-pass interferometry, modified after Richards (2007) and Bamler and Hartl (1998). Parameters in this figure are defined following discussion of Equation 1.

Single-pass InSAR systems are equipped with two identical SAR antennae mounted on the same platform and separated by a fixed baseline, called an interferometric baseline ( $\beta$ - Figure 4). Each antenna collects amplitude and phase data 
independently of the other, and the signal data each antenna receives are almost identical, except for the very small difference in the range to the target.

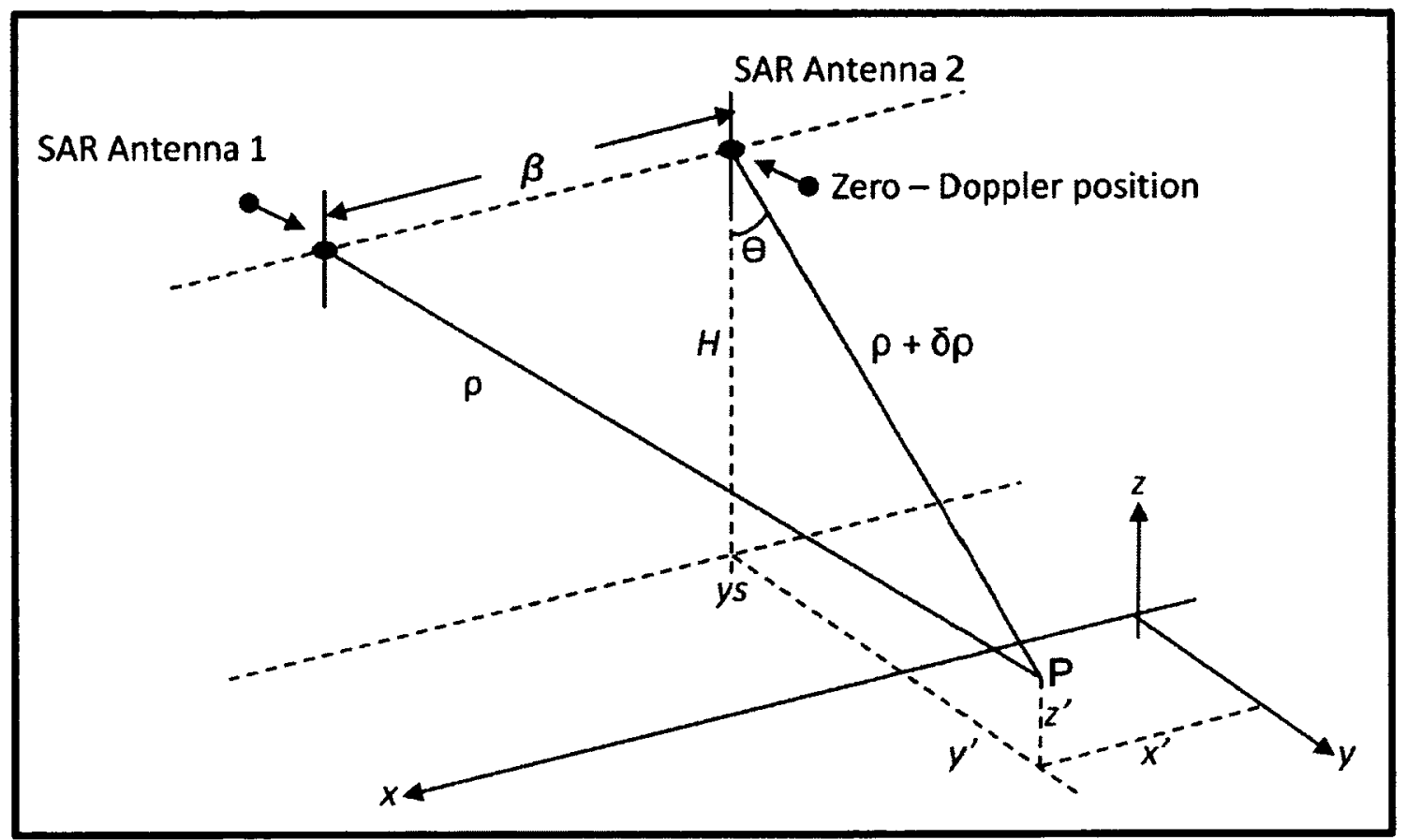

Figure 4. InSAR collection mode for single-pass interferometry, modified after Richards (2007) and Bamler and Hartl (1998). Parameters in this figure are defined following discussion of Equation 1.

The multi-frequency InSAR/PolInSAR data presented in this thesis are from single-pass interferometry provided by the Intermap airborne STAR X-band and TopoSAR PolInSAR L-band configurations, as well as the spaceborne SRTM (Shuttle Radar Topographic Mission) InSAR system. The InSAR STAR system configuration will be used to explain the mathematical fundamentals of single-pass InSAR; however, these 
fundamentals are characteristic of both single- and repeat-pass airborne and spaceborne InSAR system configurations.

The Intermap X-HH InSAR system was developed by the Environmental Research Institute of Michigan (ERIM) under contract to the U.S. Defense Advanced Research Projects Agency (DARPA). Intermap acquired this system in 1996, upgraded it over the past decade and a half, and built other similar platforms. This InSAR sensor is mounted onboard a Learjet 36A aircraft capable of high-speed data collection, imaging up to $600 \mathrm{~km}^{2}$ per minute. This system is a single-pass interferometer with dual X-HH antennae that are separated by a one-meter interferometric baseline in the across-track plane (Figure 4). One antenna transmits a microwave pulse towards a target on the earth and both antennae receive the return signal, such that all data are collected in one flight pass (Figure 4), mitigating temporal decorrelation in phase. Accurate positioning of the two SAR antennae with respect to the ground being imaged is achieved through postprocessing of onboard global positioning system (GPS) data, precise inertia measurement unit (IMU; measures aircraft speed and orientation) data, and careful calibration of the interferometric baseline. This is accomplished with a GPS ground station that is established within $200 \mathrm{~km}$ of the site being mapped so that minimal in-scene ground control is required.

The development of the mathematics behind this single-pass InSAR process is best explained with the aid of a diagram as shown in Figure 4 and a series of equations (equations 1 through to 4) based on the theory presented in Kobayshi et al. (2000). In this example, assume that Antenna \#1 transmits and receives while Antenna $\# 2$ receives at the same time as Antenna \#1. From Figure 4 it can be shown that the surface height above 
the geoid $\mathrm{z}$ (or elevation of the target above the geoid) is given by Equation (1), as described below:

$$
z(y)=H-\rho \cos (\theta)
$$

Where:

$z(y) \quad$ is the target surface height above the geoid in metres

$\mathrm{H}$ is the altitude of the radar antenna above the geoid (determined by differential global positioning system (DGPS) in metres

$\rho \quad$ is the distance or slant range to the target recorded as time in seconds

$\theta \quad$ incidence angle at the target location in degrees

From Figure 4, we can see that, Antenna $\# 1$ and Antenna $\# 2$ at an altitude $H$ are separated by a baseline $\beta$ oriented at an angle $\alpha$ with respect to local horizontal. The ranges $\rho$ and $\rho$ $+\delta \rho$ to a scatterer $P$ at height $z=h$ and ground range $y_{1}$ are measured independently at the two receiving antennae. From the law of cosines, we can state that:

$$
(\rho+\delta \rho)^{2}=\rho^{2}+\beta^{2}-2 \rho \beta \cos (90-\theta+\alpha)
$$

Where:

$\delta \rho \quad$ is the difference in the slant ranges in metres

$\beta \quad$ is the interferometric baseline in metres

$\alpha \quad$ is the angle of the baseline with respect to the horizontal in degrees

$\delta \quad$ is the orientation of the interferometric baseline with respect to the horizon in degrees

Solving Equation 2 for $\rho$ and substituting into Equation 1 gives: 


$$
z(y)=H-\left\{\frac{\delta \rho 2-\beta^{2}}{2 \beta \sin (\alpha-\theta)-2 \delta \rho}\right\} \cos (\theta)
$$

The SAR signal data are transmitted to the side of the STAR aircraft creating an incidence angle range of $35^{\circ}-55^{\circ}$, centred on $45^{\circ}$. Thus, it is not possible to determine $(\theta)$ in Equation 1. Equation (3) reveals an obstacle. For example, the incidence angle $(\theta)$ cannot be directly measured when trying to determine $\delta \rho$, which is given by:

$$
\delta \rho=\frac{\lambda \Phi}{2 \pi}
$$

Where:

$\lambda$ is the radar wavelength of the SAR sensor in metres

$\Phi \quad$ is the absolute phase difference between the two return signals in degrees.

The phase difference can be measured by multiplying the phase of one SAR image by the complex conjugate of the other SAR image (i.e. the corresponding amplitudes have to be averaged and the corresponding phases have to be differenced at each point in the image) to form what is called an interferogram whose phase is proportional to the range difference for the point being measured on the ground (Bamler and Hartl, 1998). The interferogram is a pattern of fringes containing all the information on the relative geometry of the time of data acquisition for each point being measured on the ground. The fringes trace the topography like contour lines, as shown in Figure 5. 


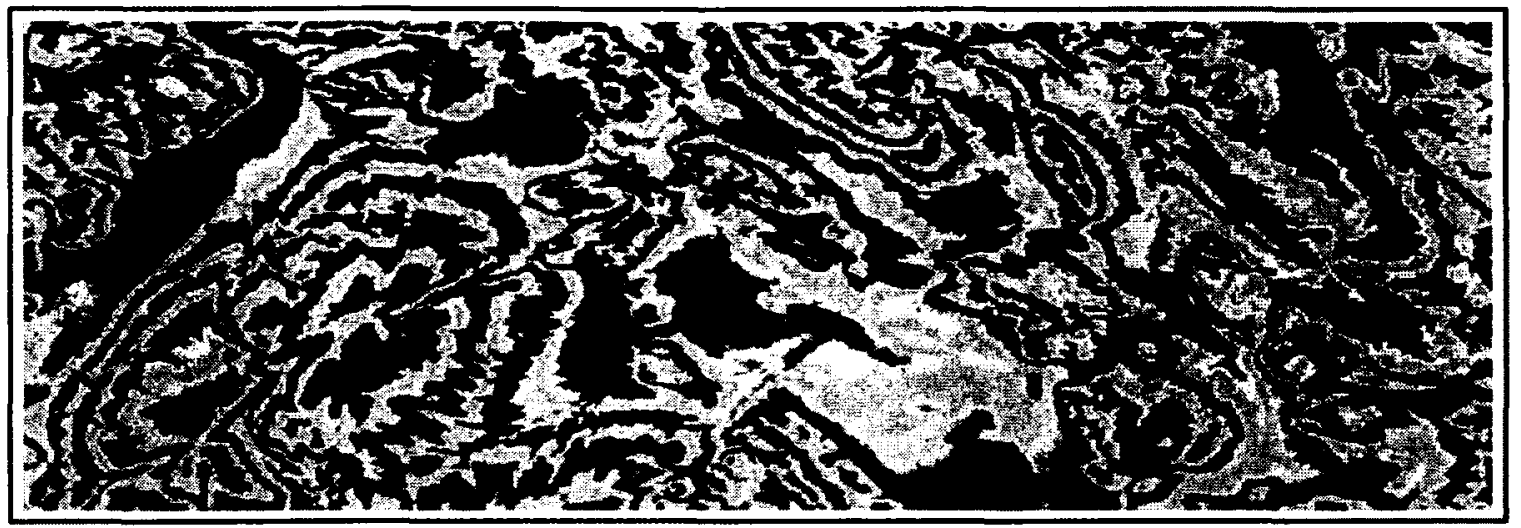

Figure 5. InSAR interferogram (modified after Gens, 2002). One set of colours (red, pink, yellow, green, and blue) represents one $0-2 \pi$ interferometric fringe.

The interferogram requires additional processing to derive digital elevation data and orthorectified radar imagery. This processing typically includes the following steps, which are explained in detail in the sections below:

1) interferometric coherence image generation and interferogram filtering, (2.2.1)

2) interferogram - phase unwrapping (2.2.2),

3) magnitude image creation and orthorectification (2.2.3),

4) elevation model generation (digital surface model - DSM (2.2.4).

\subsubsection{Interferometric Coherence Image Generation and Interferogram Filtering}

InSAR SAR systems are designed to be phase coherent, where the same acquisition conditions provide the same target response. However, in interferometry there are always small perturbations in acquisition parameters such as orbits/flight trajectories, water vapor, or spatial changes in the scattering characteristics of the target (e.g. wind effects). Phase noise from the interferometric SAR pair can be assessed by means of the local InSAR coherence $\gamma$. InSAR coherence is a statistical measure of the similarity of the 
microwave signal received at the two antennae that can be estimated directly from the SAR image data of the two interferometric antennae (Zebker and Villasenor, 1992) illustrated in Figure 6.

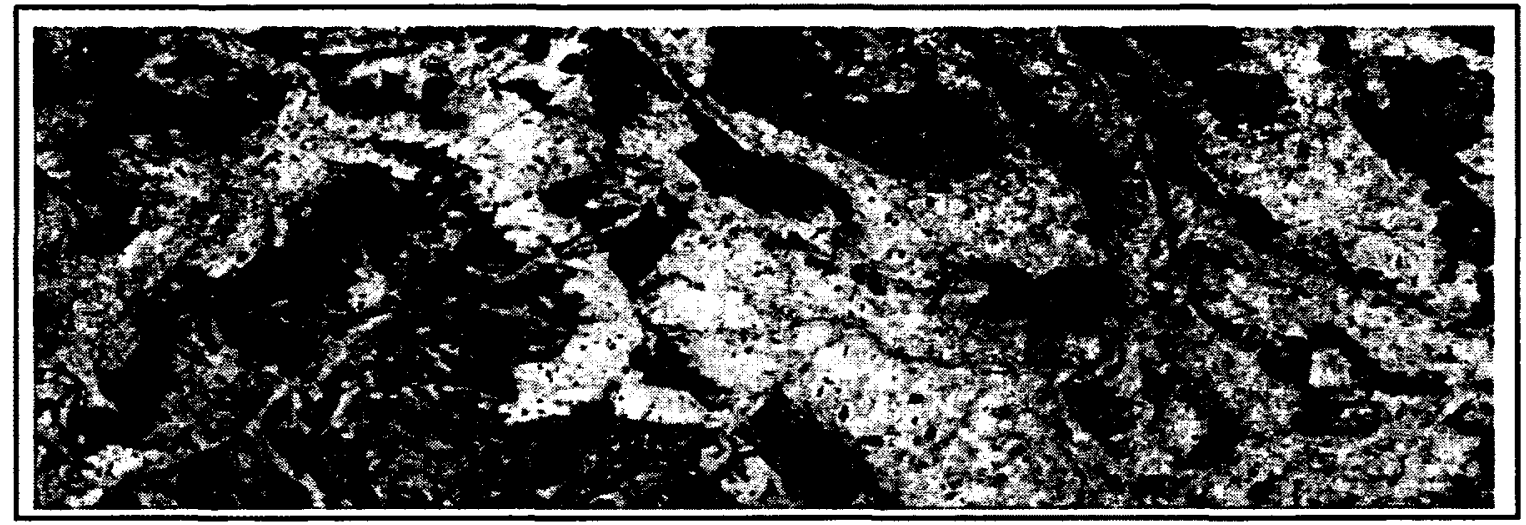

Figure 6. InSAR coherence image, where the image tones range from dark to bright indicating increasing coherence or increasing agreement between the two SAR observations (Modified after Gens, 2002).

InSAR coherence is a measure of the complex correlation of both amplitude and phase information from two interferometric signals. It characterizes the uncertainty with which height can be measured (Sarabandi, 1997) or the quality of the InSAR derived elevation model and it represents the stability of the backscattered SAR signal over an area of interest (Parcharidis et al. 2005). It also provides valuable information about the scatterer; for example in repeat-pass interferometry temporal decorrelation is often exploited for object classification (Wegmuller and Werner, 1995; 1997); in single-pass configurations it can give rough estimates of the thickness of the scattering layer (penetration depth; Bamler and Hartl, 1998). Any dissimilarity of the scattering 
mechanism between the two SAR images within an InSAR configuration results in a loss in coherence. A certain loss of coherence results from the different look angles of the two antennae and from receiver noise. Coherence loss can also result from changes in the surface between acquisitions (e.g. repeat-pass interferometry). Coherence values $(\gamma)$ range between zero and one, where zero indicates no relation (the interferometric phase is just noise) and one designates perfect correlation or coherence between the two signals received at each antenna (complete absence of noise). Low coherence values (e.g., $\gamma \leq$ 0.5 ), common in vegetated terrain, typically generate lower quality elevation data. The elevation data can be improved by setting a coherence threshold. A threshold of 0.85 is used for the STAR InSAR processing, such that all elevation values with a coherence of less than 0.85 are not used to compute the DEM and are coded as void data. This allows for the generation of high quality elevation data and is typically for single-pass InSAR. Repeat pass InSAR thresholds are typically set to 0.5 due to repeat-pass configuration and poorer signal-to-noise ratio (SNR) leading to lower quality digital elevation data. Void data are later populated by either secondary InSAR flight line strips of elevation data or via interpolation. Coherence can be computed for the InSAR image pairs using the following (modified from Schneider et al., 2006):

$$
\gamma=\frac{\left\langle I_{1} I_{2}^{*}\right\rangle}{\sqrt{\left\langle I_{1} I^{*}\right\rangle}\left\langle\left\langle I_{1} I_{2}^{*}\right\rangle\right.}
$$

Where:

$$
\begin{array}{ll}
\gamma & \text { InSAR coherence } \\
I_{l}, I_{2} & \text { power Images from antenna } 1 \text { and antenna } 2 \\
* & \text { denotes the complex conjugate }
\end{array}
$$


〈) estimated ensemble average

\subsubsection{Interferogram Phase Unwrapping}

The phase delay of the carrier signal at a certain point in the interferogram (Figure 6) is a function of the terrain height at that point. The $2 \mathrm{D}$ interferogram (Figure 5) provides an ambiguous measurement of the relative terrain height due to the $2 \pi$ cyclic nature of the interferometric phase. In other words, the phase of the carrier signal can only be measured within one cycle, or 360 degrees $(0-2 \pi)$. The phase variation between two points on the flattened interferogram provides a measurement of the actual elevation range of the topography, after resolving for the integer number of $2 \pi$ phase cycles. The process of adding the correct integer multiple of $2 \pi$ to the interferometric fringes is called phase unwrapping. Phase unwrapping of the interferogram is therefore required to create a continuous height surface (Figure 7 , wire mesh). This requires the conversion of the measured phase to absolute phase, by adding the appropriate number of cycles, or multiple of 360 degrees, to the measured phase.

Phase unwrapping is a non-trivial process for which a number of algorithms have been developed. Complications arise due to phase unwrapping errors in regions of shadow, layover (due to the side-looking nature of SAR sensors, layover occurs when the radar beam reaches the top of a tall feature before it reaches the base), low signal return, and for specific land cover types (e.g., calm water). An adaptive power-spectrum filter is applied to amplify the phase signal and to better detect fringe boundaries (Schneider et al., 2006). A continuous elevation surface or elevation model is the outcome of the phase unwrapping process (Figure 7 - wire mesh; also Figure 8). 


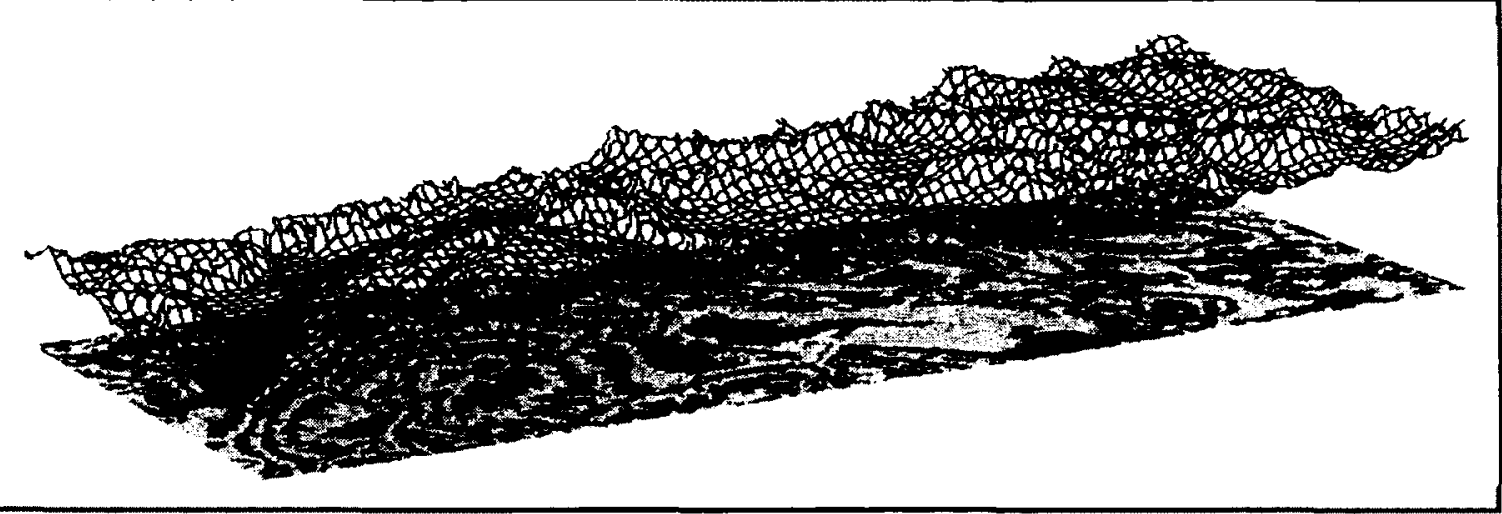

Figure 7. An interferogram (bottom) has been processed to unwrap the phase data to derive a DSM represented by the wire mesh (modified after Gens, 2002).

\subsubsection{Magnitude Image Creation and Orthorectification}

The SAR signal amplitude and phase information are used to generate the radar imagery that is orthorectified using the InSAR derived digital surface elevation model by computing the geometric mean of the SAR signals received at the two antennae. This is accomplished using the following equation:

$$
M\left(s_{m}, \rho_{k}\right)=\sqrt{\sqrt{I_{1}\left(s_{m}, \rho_{k}\right)} \sqrt{I_{2}\left(s_{m}, \rho_{k}\right)}}
$$

Where:

$$
\begin{array}{ll}
M\left(s_{m}, \rho k\right) & \text { raw SAR Signal Data in plane coordinates } \\
I_{1}\left(s_{m}, \rho_{k}\right) & \text { power image from antenna } 1 \\
I_{2}\left(s_{m}, \rho_{k}\right) & \text { power image from antenna } 2 \\
\rho & \text { range (Figure 2) }
\end{array}
$$

\subsubsection{Elevation Model Geocoding}

Geocoding the radar imagery and the InSAR elevation data (Figure 8) are the last steps in the InSAR process chain. The goal of this step is to localize every pixel in the 
radar imagery and every post in the elevation data with respect to a Cartesian reference system: from radar coordinates (called $\mathrm{CSH}$ - Cross-scan- height coordinates; slant range geometry) to a standard description of the local topography (map geometry). This is accomplished by the re-projection and re-sampling of the unwrapped phase data from the acquisition geometry projection (format), into a geographic projection suitable for geospatial applications. The end result is an orthorectified radar image (ORI) and a corresponding digital elevation model (Figure 8) in cartographic coordinates.

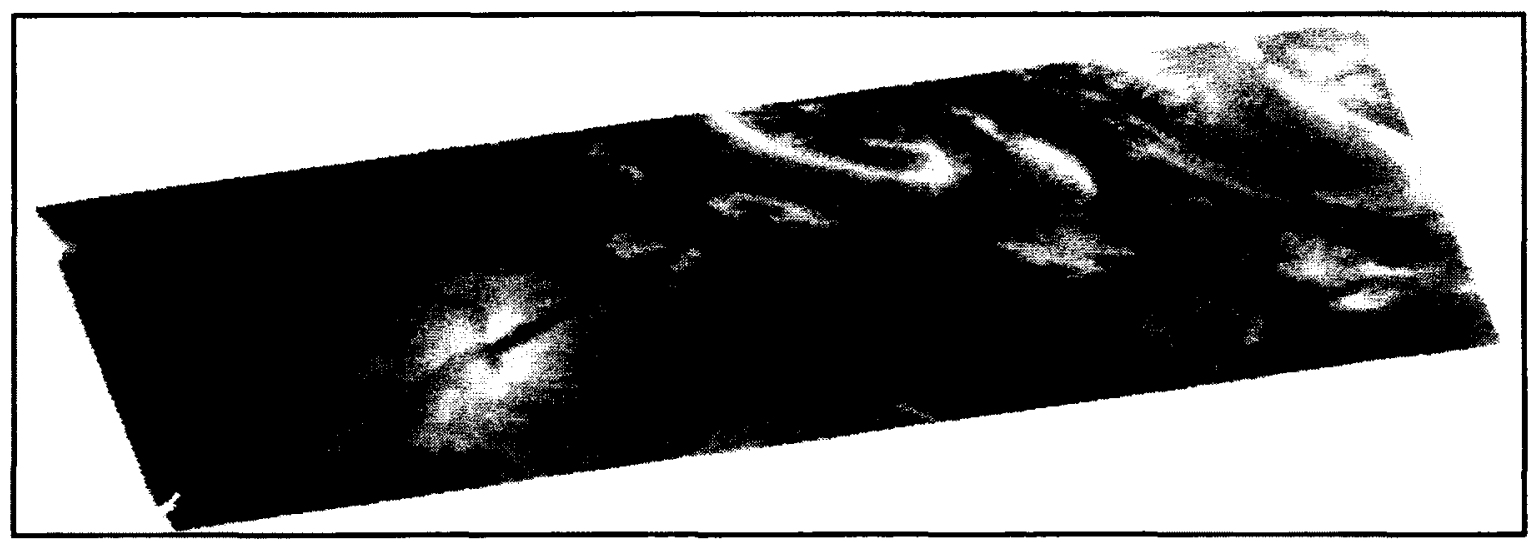

Figure 8. InSAR derived elevation model (modified after Gens, 2002).

\subsection{InSAR Systems}

There are a number of airborne and spaceborne SAR/InSAR/PolInSAR platforms currently in operation that can generate digital elevation data using InSAR and PolInSAR techniques to provide the opportunity to make global observations of the earth (Table 1). For example, the Canadian airborne NEXTMap STAR system (X-band; Dowman et al., 2003; Mercer, 2004) presented in this research, the spaceborne RADARSAT 1/2 (Cband; Joughin et al., 1999), the European ENVISAT/ASAR (C-band; Kumar et al., 
2006), the Japanese ALOS/PALSAR (L-Band; Yu and Linlin, 2010), the German TerraSAR-X and Tandem-X (both X-bands; Krieger et al., 2007), and the Italian Cosmo/SkyMed (X-Band; Agenzia Spaziale Italiana, 2007). Others are planned for launch within 5-10 years including for example, the European BIOMASS (P-band), and the German/Brazilian MAPSAR (L-Band).

Table 1. Summary of the key parameters of select SAR systems suitable for deriving elevation data via InSAR methods, where polarization is POL, Image horizontal accuracy is IA; elevation vertical accuracy = EA; InSAR Pass is IP; Single is S; Repeat is R.

\begin{tabular}{|l|l|l|l|r|r|r|r|r|l|}
\hline Sensor & Country & $\lambda$ & POL & $\begin{array}{l}\text { Pixel } \\
(\mathrm{m})\end{array}$ & $\begin{array}{l}\text { IA } \\
\text { RMSE }\end{array}$ & $\begin{array}{l}\text { DEM } \\
\text { Type }\end{array}$ & $\begin{array}{l}\text { DEM } \\
\text { Post (m) }\end{array}$ & $\begin{array}{l}\text { EA } \\
\text { RMSE }\end{array}$ & IP \\
\hline NEXTMap & Canada & $\mathrm{X}$ & $\mathrm{HH}$ & $\begin{array}{r}0.63- \\
1.25\end{array}$ & $2 \mathrm{~m}$ & $\begin{array}{l}\text { DSM/ } \\
\text { DTM }\end{array}$ & $5 \mathrm{~m}$ & $\begin{array}{r}0.5-6 \\
\mathrm{~m}\end{array}$ & $\mathrm{~S}$ \\
\hline GeoSAR & USA & $\mathrm{X}$ & $\mathrm{VV}$ & $\begin{array}{r}1.25 \\
23\end{array}$ & $?$ & DSM & $3-5 \mathrm{~m}$ & $2-5 \mathrm{~m}$ & $\mathrm{~S}$ \\
\hline Tandem-X & Germany & $\mathrm{X}$ & Quad & 10 & $2 \mathrm{~m}$ & DSM & $12 \mathrm{~m}$ & $10 \mathrm{~m}$ & $\mathrm{R}$ \\
\hline $\begin{array}{l}\text { COSMO- } \\
\text { SkyMed }\end{array}$ & Italy & $\mathrm{X}$ & Quad & $10 \mathrm{~m}$ & $5 \mathrm{~m}$ & DSM & $5-30 \mathrm{~m}$ & $10 \mathrm{~m}$ & $\mathrm{R}$ \\
\hline SRTM & USA & $\mathrm{C}$ & VV & $\begin{array}{r}30- \\
90 \mathrm{~m}\end{array}$ & $?$ & DSM & $30-90 \mathrm{~m}$ & $8 \mathrm{~m}$ & $\mathrm{~S}$ \\
\hline RADARSAT & Canada & $\mathrm{C}$ & Quad & $10 \mathrm{~m}$ & $10 \mathrm{~m}$ & DSM & $10-30 \mathrm{~m}$ & $10 \mathrm{~m}$ & $\mathrm{R}$ \\
\hline NEXTMap & Canada & $\mathrm{L}$ & Quad & $2 \mathrm{~m}$ & $2 \mathrm{~m}$ & $\begin{array}{l}\text { DSM/ } \\
\text { DTM }\end{array}$ & $5 \mathrm{~m}$ & $5 \mathrm{~m}$ & $\mathrm{~S}$ \\
\hline Sentinel-1 & Europe & $\mathrm{C}$ & Dual & $\begin{array}{r}5- \\
20 \mathrm{~m}\end{array}$ & $?$ & DSM & $\sim 15 \mathrm{~m}$ & $?$ & $\mathrm{R}$ \\
\hline $\begin{array}{l}\text { ALOS } \\
\text { PolSAR }\end{array}$ & Japan & $\mathrm{L}$ & Quad & $\begin{array}{r}9-30 \\
\mathrm{~m}\end{array}$ & $5 \mathrm{~m}$ & DSM & $20 \mathrm{~m}$ & $20 \mathrm{~m}$ & $\mathrm{R}$ \\
\hline SEÁSAT & USA & L & HH & $25 \mathrm{~m}$ & $?$ & DSM & $30 \mathrm{~m}$ & $30 \mathrm{~m}$ & $\mathrm{R}$ \\
\hline GeoSAR & USA & P & $\begin{array}{r}\text { HH/V } \\
\text { V }\end{array}$ & $3 \mathrm{~m}$ & $3 \mathrm{~m}$ & DSM & $5 \mathrm{~m}$ & $2-9 \mathrm{~m}$ & $\mathrm{~S}$ \\
\hline
\end{tabular}




\subsection{Polarimetric InSAR (PolInSAR) Background}

A recent technique to derive bare ground elevations and canopy height measurements combines polarimetry and interferometry, referred to as PolInSAR, was first introduced by Cloude and Papathanassiou (1997; 1998). PollnSAR techniques are based on the coherent combination of the prevalent scattering mechanisms (SAR polarimetry) and the vertical location of scatterers (SAR interferometry) which together are substantially more sensitive to forest structural parameters than conventional interferometry or polarimetry alone (Papathanassiou and Cloude, 1998; Rowland et al., 2003; Zhang et al., 2008). Combining polarimetric and interferometric data results in information about the penetration depth into the canopy at different polarizations (Papathanassiou and Cloude, 2001; Rowland et al., 2003; Hajnesk et al., 2005). A theoretical introduction to PollnSAR can be found, for example, in Boerner (2008) and in Lee and Pottier (2009); aspects of PolInSAR relevant to this research are briefly described here.

The full polarimetric scattering matrix is collected over both apertures (SAR antennae) of an InSAR pair in the PolInSAR technique. The application of PolInSAR for bare ground and forest canopy height estimates is not straightforward because of the complex structure of forests; it requires the consideration of a scattering model. Current methods of PolInSAR interpretation rely on a generalization of the complex interferometric coherence to polarimetric measurements $(\gamma(w))$. For any polarization vector (e.g. coherent combination of polarizations), coherence function can be computed from the PolInSAR covariance as a ratio of quadratic forms, mathematically described in equations 7 through to 10 . These equations represent the Random Volume over Ground 
(RVoG) model, which has been frequently utilized with success in other studies (Papathanassiou and Cloude, 2001; Cloude and Corr, 2003; Zhang et al., 2008). This model permits separation of the ground and vegetation canopy scattering components of the interferometric phase. RVoG assumes vegetation to be a conglomerate of randomly oriented scatterers situated above a surface layer, for example, bare ground (Cloude and Papathanassiou, 2003). Through model inversion, the interferometric phase related to ground topography and canopy height can be extracted by a simple mathematical extrapolation process. Thus, the PollnSAR data define a polarization-dependent coherence function for each multi-look pixel; the set of possible coherences is called the coherence region. The volumetric scattering models of Cloude-Papathanassiou (2003) and Treuhaft-Siqueira (2000) predict that, in the absence of noise, decorrelation, and sampling error, the coherence region is a straight line segment whose location and orientation depend on the canopy height, attenuation and bare-earth height. Based on these models, terrain characterization becomes a problem of fitting a line segment to the coherence region and inverting the model function to extract the parameters. The complex interferometric coherence $\gamma(w)$, thus can be given in Equation 7 (Treuhaft and Siqueira (2000); Papathanassiou and Cloude (2001); Zhang et al., 2008):

$$
\gamma(w)=\exp ^{i \phi}\left[\frac{\tilde{\gamma}_{\nu}+m(w)}{1+m(w)}\right]
$$

\section{Where:}

$$
\begin{array}{ll}
\phi & \text { ground topography phase } \\
m \quad \text { ground-to-volume amplitude ratio (attenuation through volume included) }
\end{array}
$$




$$
\begin{aligned}
& w \quad \text { optimized polarization state vector } \\
& \tilde{\gamma}_{\nu} \quad \text { complex coherence for the volume (excludes ground component) }
\end{aligned}
$$

Equation (7) illustrates that the complex interferometric coherence $\gamma(w)$, contains both the interferometric phase and interferometric correlation coefficient, where $\phi$ is the phase related to the ground topography. Note that $m$ is polarization dependent while $\tilde{\gamma}_{v}$ is not. The parameters in Equation (7) can be rewritten to represent a line equation on the unit circle (Figure 9) given by Equation ((8) Zhang et al., 2008):

$$
\gamma(w)=\exp ^{i \phi}\left[\tilde{\gamma}_{v}+\frac{m(w)}{1+m(w)}\left(1-\tilde{\gamma}_{v}\right)\right]
$$

The PolInSAR technique requires a good spread of values in the complex plane; otherwise the line elevations will be error prone. In the ideal case, the variation of $m$ as a function of polarization $w$ will trace out a straight line when projected onto the unit circle (Figure 9). In the limit of $m=0$, the observed coherence is just $\tilde{\gamma}_{v}$ rotated by the ctopographic phase. Canopy height can be obtained from $\tilde{\gamma}_{v}$ by an inversion process. Best results in canopy height estimates are obtained when the coherence region is close to an ellipse shape with high eccentricity. A coherence optimization process is then used to identify optimum coherence values that will lie upon a straight line (red crosses in Figure 9) as a function of $m$ within the unit circle (yellow ellipsoid, Figure 9) on the complex plane by manipulating Equation 4. 


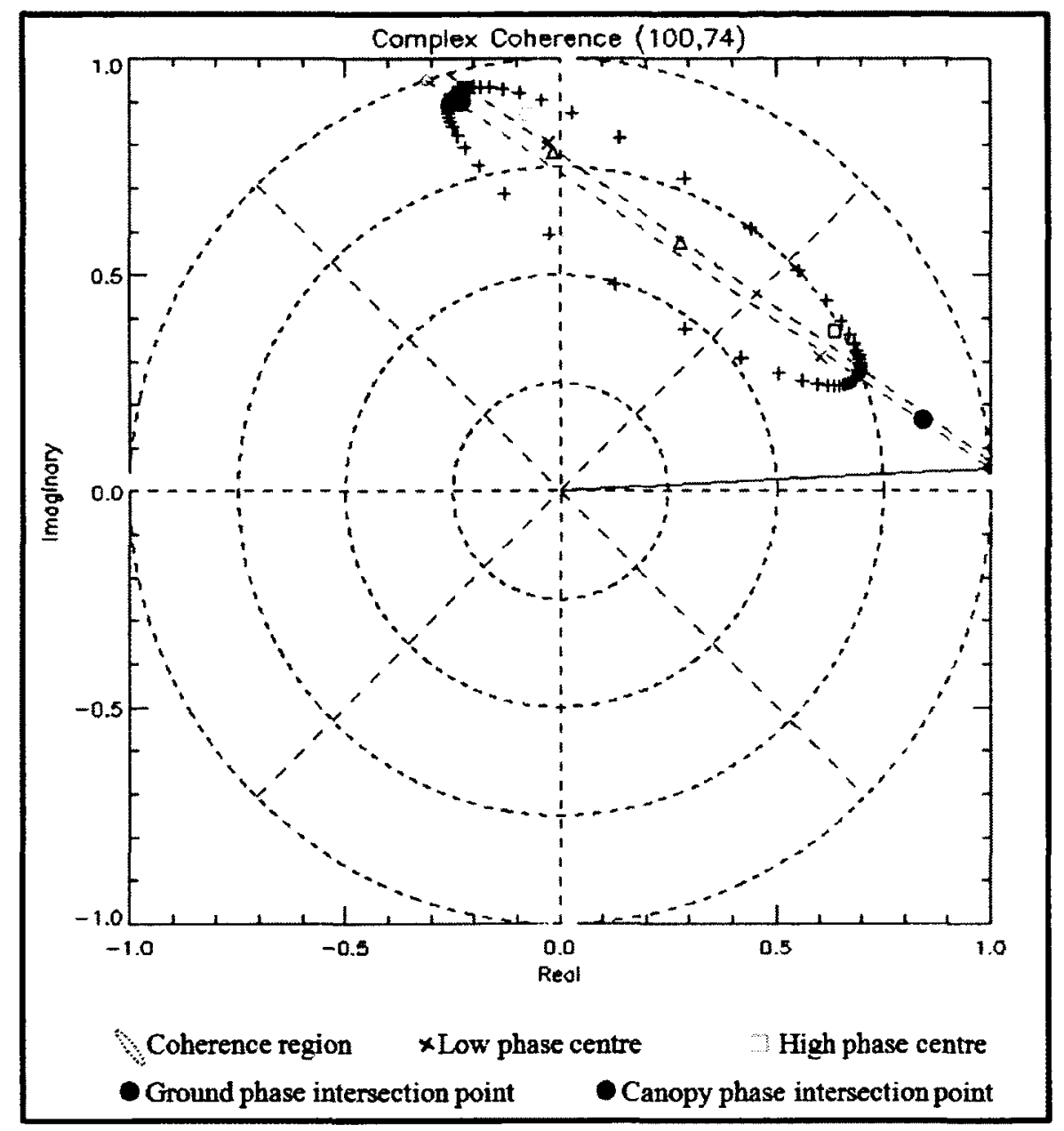

Figure 9. PolInSAR ground topography (blue dot) and canopy height (pink cross) extraction in a complex plane, for one image pixel (ellipsoid $=$ high coherence).

The intersection of this line with the unit circle provides the topographic phase (navy circle, Figure 9) for large $m$ and the associated phase at this point relates directly to the ground elevation. The phase to height conversion is then a simple scaling by vertical wave-number given by Equation ((9) Zhang et al., 2008):

$$
\phi=K_{z} h_{v}
$$


Where:

$$
\begin{array}{ll}
\phi & \text { phase height } \\
K_{z} & \text { vertical wave-number } \\
h_{v} & \text { canopy height in metres }
\end{array}
$$

Where $K_{z}$ is the vertical wave number calculated from the incidence angle $(\theta)$. The difference in the two incidence angles $(\Delta \theta)$ and the wavelength $(\lambda)$ of the radar system is given by Equation (10) Zhang et al., 2008):

$$
K_{z}=\frac{4 \pi \Delta \theta}{\lambda \sin \theta} \quad \text { Radians } / \text { metre }
$$

In repeat pass interferometry temporal de-correlation, thermal noise, and baseline variation may widen this region to be more circular shaped. These effects are less pronounced in single-pass InSAR, like that presented in this research. In the DEM differencing method, the forest height $h_{v}$ is estimated directly from the phase difference between ground phase and the volume-dominated polarization phase (Cloude and Papathanassiou, 1998). This method is a simple implementation of RVoG and computationally light, however, it tends to underestimate canopy height because the interferometric phase centre is seldom near the top of the canopy.

A more robust method given by the two dimensional RVoG, called the RVoG $2 \mathrm{D}$ search method, was implemented in this research. In the 2D search method, a look-up table (LUT) containing values of random volume interferometric coherences as calculated in Equation (8) was established using a set of extinction coefficient values and 
canopy height values displayed in the complex plane (Cloude and Papathanassiou, 1998; Zhang et al., 2008). Estimation of the complex interferometric coherence according to Equation (8) assumes no ground return $(\mathrm{m}=0)$ with $\sigma=0,0.1, \ldots, 1.0 \mathrm{db} / \mathrm{m}$ from centre to outer and $h_{v}=0-40 \mathrm{~m}$ with $0.5 \mathrm{~m}$ as the step interval. In searching to find the closest element in the LUT to the observed complex coherence, we can estimate the extinction coefficient and canopy height at the same time (Zhang et al., 2008). The high phase end is used in the height inversion. While the 2D search with a fine LUT (small step size for $h_{\mathrm{v}}$ and $\sigma$ ) will achieve increased canopy height accuracy, it does so at the cost of increased computation time.

\subsection{Literature Review: InSAR and PollnSAR Techniques for Biophysical Parameter Estimation}

Realization of the role of forests in global change has prompted the need for qualitative and quantitative analysis of forest structural biophysical parameters (Hall et al., 1992). Biophysical forest parameters such as vegetation type and canopy height estimates are critical in these analyses, yet high resolution contiguous regional, national, or global forest structure information is lacking. This literature review is focused on the use of InSAR and PolInSAR for the extraction of vegetation type and canopy height.

\subsubsection{InSAR for Vegetation Cover Mapping}

Reliable vegetation cover mapping benefits forest monitoring, forest management, and climate modelling, to name a few applications. Jointly with canopy height measuremients, vegetation cover improves biomass estimation and forest mapping. Wegmuller and Werner (1995) used the ERS tandem InSAR signatures created from InSAR coherence and SAR imagery of various land-use categories to classify a number 
of vegetation types. Likewise, Engdahl and Hyyppa (2003) utilized InSAR coherence and SAR imagery created from a time-series of 14 ERS-1/2 SAR tandem pairs in a hybrid classifier to classify open land, sparse forest, dense forest, mixed urban, dense urban, and water with overall accuracy of approximately $80 \%$. Santoro (2007) used ERS-ENVISAT spaceborne SARs in repeat-pass InSAR configuration to create coherence data for use in a simple threshold classification scheme to identify bare soil, forest, urban, and water land cover with an overall accuracy on the order of $80 \%$. These authors used the InSAR coherence in addition to the SAR image pairs since the coherence carried more landcover related information than the radar intensity images alone. Unlike SAR images, the InSAR coherence images do not contain speckle, making it possible to classify at a pixel level. They did not, however, make use of the height information found in InSAR data.

There is considerable information published in the literature on land cover classification methods using SAR data. Two common methods reported are: 1) Pixel classifiers (Blaschke and Strobl, 2001; Benz et al., 2004), and 2) object-based classifiers (Benz and Pottier, 2001; Corr et al., 2003; Benz et al., 2004). Pixel classification techniques do not make use of spatial concepts (Blaschke and Strobl, 2001; Benz et al., 2004), whereas object-based classification aggregate pixels of similar data values into objects using a process called image segmentation. Object-based classification is then performed on the segments, rather than the pixels. Moreover, object-based classification methods make use of contextual information, such as feature shape and spatial relations between image regions, thereby generating a more robust classification procedure (Benz and Pottier, 2001; Corr et al., 2003; Benz et al., 2004). 
Successful implementation of object based segmentation and classification techniques using spaceborne and airborne InSAR data has been reported in the literature (Luckman et al., 2000; Stilla et al., 2003; Matikainen et al., 2006). For example, Matikainen (2006) used object based classification of InSAR coherence, SAR imagery intensity, and additional contextual information derived from multi-temporal ERS-1/2 Tandem data to classify open areas, urban, and forest with an overall accuracy of $97 \%$.

Few object-based classification studies have focused on the use of InSAR and PolInSAR height data in land cover applications. In the case of InSAR, this may be attributable to the lack of high-resolution DTMs for use in the generation of $h_{s p c}$ to estimate canopy height and the lack of an effective methodology to extract information from InSAR data. PolInSAR, on the other hand, is a newer technique with no commercial single-pass PolInSAR systems available for land cover classification.

\subsubsection{InSAR and PolInSAR for Canopy Height Estimation}

InSAR digital surface models (DSMs) exhibit frequency-dependent sensitivity to the height of vegetation canopy elements (e.g. leaves, twigs, branches, and tree trunks), and a number of investigators have had success in retrieving estimates of canopy height from interferometric measurements (Treuhaft and Siqueira, 2000; Kellndorfer et al., 2004; Walker et al., 2007). The research undertaken in this thesis focuses on the application of single-pass X-HH InSAR and single-pass L-Quad PolInSAR to derive a DSM and DTM data for use in a method to derive vegetation cover and canopy height. Single-pass spaceborne C-HH InSAR data were available for all research sites and thus evaluated as well. 
The InSAR and PolInSAR DSM data minus the DTM determines the scattering phase centre height $\left(\mathrm{h}_{\mathrm{spc}}\right)$, which is an average of all vertically distributed scattering elements within a resolution cell above ground (red dashed line, Figure 10). Note: at Xband, there is some penetration into the vegetation canopy (Figure 10). The $h_{\text {spc }}$ is at or very near bare ground in barren areas (Mercer, 2001; blue dashed line, Figure 10), whereas in forest canopies, the location of $h_{s p c}$ depends on the penetration depth of microwaves into the canopy, which depends on SAR wavelength, the size and density distribution of the scattering elements, the geometric arrangement of the scatterers, canopy moisture condition, surface roughness, and moisture content of the ground layer (Andersen et al., 2006; Izzawati et al., 2006).

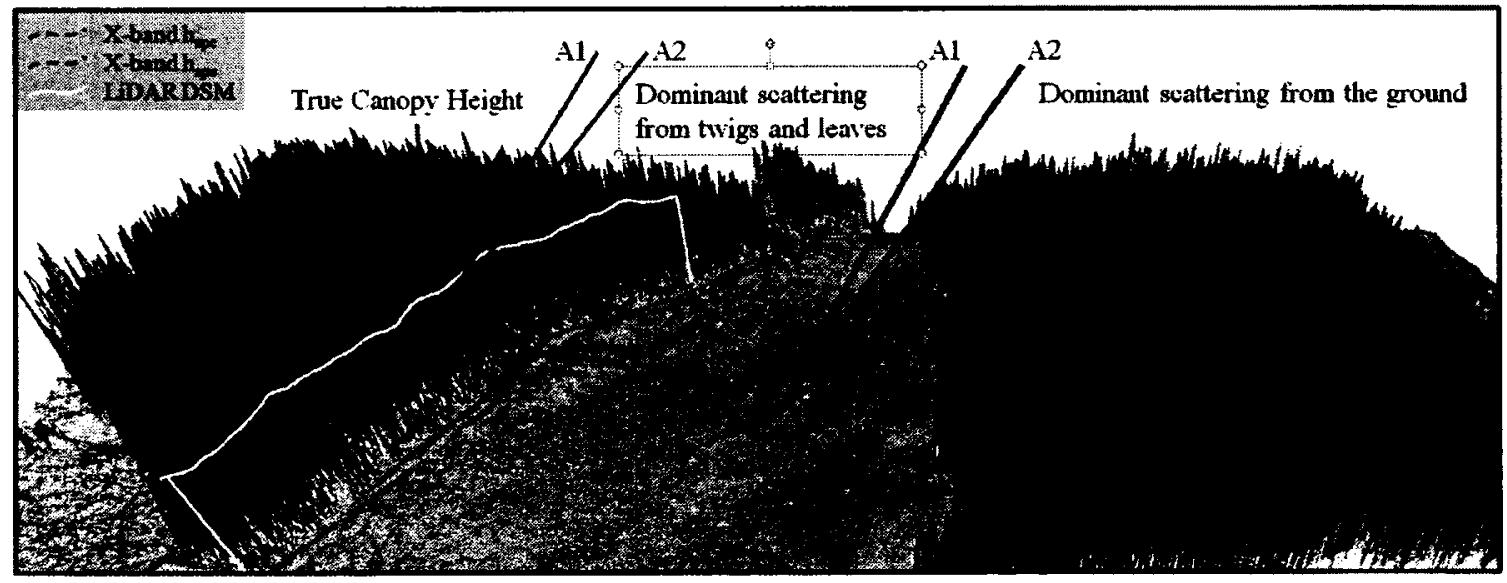

Figure 10. Relative position of X-Band $\ln S A R h_{\text {spc }}$ and true canopy height for dense forest (red and white line, respectively) as well as $h_{\text {spc }}$ and true canopy height for bare ground, which are coincident (blue line). The data presented in this illustration represents the DSM LiDAR data over a section of the Edson research site (See Section 3.1.6.). A1 and $A 2$ represent antenna 1 and antenna 2 on a single-pass InSAR configuration. 
Four methods to estimate canopy height from InSAR and PolInSAR techniques common in the literature are described below.

1) InSAR DSM-DTM Method: This method subtracts a DTM (e.g. bare ground elevation model) from a short wavelength InSAR (e.g. X- or C-band) digital surface model (DSM) to derive $h_{\text {spc, }}$, which can then be related to reference measurements of canopy height. Successful canopy height measurements using this method have been reported in the literature (Kellndorfer et al., 2004; Wallington, 2005; Balzter et al., 2007a; Walker et al., 2007; Andersen et al., 2008). However, this method requires the availability of an accurate bare-ground digital terrain model (DTM). This method was applied in this research.

2) Dual InSAR Frequency Method: The Dual InSAR Frequency method is similar to the InSAR DSM - DTM method but instead, the longer wavelength (L- or P-Band) InSAR DSM (e.g. majority of the radar backscatter comes from the ground surface) is subtracted from canopy estimates provided by a shorter wavelength (X- or C-Band) InSAR DSM (Andersen et al., 2004; Balzter et al., 2001; 2007b; Neeft et al., 2005). Balzter et al. (2007b) utilized X- and L-Band InSAR data to derive canopy height estimates of a mature pine plantation (approximately $20 \mathrm{~m}$ in height) to achieve RMS errors $2.9 \mathrm{~m}$ and $3.1 \mathrm{~m}$, respectively. Andersen et al. (2004) also reported that the mean stand canopy height could be successfully estimated $\left(R^{2}=0.88\right.$ compared to field data) from the dual wavelength (X-and P-band) InSAR Intermap AES-1 system.

3) Height Discontinuity Method: The Height Discontinuity method relies on the height discontinuity between a canopy and an adjacent cleared or open area to derive the canopy height (Hagberg et al., 1995; Woodhouse et al., 2006; Williams et al., 2010). 
Hagberg et al. (1995) used ERS-1 (C-VV) InSAR height data as an estimate of canopy height in dense boreal forest by comparing a sparse forest canopy relative to an open field. The overall canopy height error increased over sparse vegetation canopy, as $h_{s p c}$ was $4.9 \mathrm{~m}$ compared to $9.9 \mathrm{~m}$ in situ measured canopy height. This indicates that $\mathrm{h}_{\mathrm{spc}}$ is close to the top of the canopy for dense forest but much lower in sparse canopy, due to greater penetration in gaps. Woodhouse et al. (2006) performed a similar analysis to that of Hagberg et al. (1995) by investigating the impact of discrete changes in height at the edges of homogenous plantations, these being the most significant discontinuities within plantation forest. They concluded that the use of InSAR products must take into account any edge effects, and methods must seek to minimize their influence, including the effects of incidence angle, tree height, and underlying slope. These issues are addressed in this thesis.

4) PolInSAR Method: The PollnSAR method utilizes polarimetry to separate volume scattering from ground scattering to derive a DSM and DTM (Treuhaft and Siqueira, 2000; Papathanassiou and Cloude, 2004). The DSM and DTM are subsequently subtracted to derive the $h_{\text {spc }}$ in the same way as the other methods. L-Quad PolinSAR is well suited to vegetation mapping because it is sufficiently sensitive to vegetation structure, including canopy, sub-canopy, and ground parameters (Treuhaft and Siqueira, 2000; Woodhouse et al., 2003; Papathanassiou et al., 2005). The first such demonstration of this technique was in a tropical area within the European Space Agency sponsored 2004 INDREX-II program (Hajnsek et al., 2005). This program included several test sites in the forests of Kalimantan, Indonesia. Furthermore, L-band PolInSAR has also shown promise to map structure in higher density regions of the tropics (Hajnsek et al., 2009). 
This program included several test sited in the forests of Kalimantan, Indonesia. However, assessments of both canopy and bare ground height estimates derived from single-pass PolInSAR configurations are limited in the literature.

\subsection{Suitability of the InSAR and PolInSAR Remote Sensing Techniques} for Forest Biophysical Parameter Extraction

While success in extracting canopy height and bare ground measurements have been demonstrated in the literature, SAR system and terrain parameters that affect the accuracy of the derived heights need additional attention (Andersen et al., 2008; Izzawati et al., 2006). There are several system and target parameters that affect the microwave energy recorded by a SAR sensor, and thus, the derived SAR/InSAR/PolInSAR products. These parameters are separated into two categories: 1) SAR system parameters and 2) target parameters. SAR system parameters influence the interaction between the radio pulses and the targets being illuminated. They include wavelength, polarization, viewing geometry, incidence angle, and SAR system configuration. Each are described briefly below. Target parameters, such as moisture content and the physical structure of objects being imaged influence the interaction between the radio pulses transmitted and targets being illuminated. The target parameters that impact the SAR/InSAR/PolInSAR products used in vegetation type and canopy height mapping include: feature cover structure, feature cover discontinuities, soil moisture, and terrain slope. For additional details on these topics also refer to Richards (2007).

\subsubsection{Canopy Height and SAR Wavelength}

The most common wavelengths $(\lambda)$ for SAR remote sensors are labeled K, X, C, $\mathrm{L}, \mathrm{S}$, and $\mathrm{P}$, listed in order of increasing wavelength. Generally, the main scattering 
elements tend to be of comparable size to the wavelength of the radiation. Consequently, where vegetation is present, leaves, twigs, and branches act as strong scatterers of $X-(\lambda=$ 2.4 to $3.75 \mathrm{~cm})$ and $C$-band $(\lambda=3.75-7.5 \mathrm{~cm})$ energy, whilst tree trunks and the ground surface will act as strong scatterers at L-band $(\lambda=15-30 \mathrm{~cm})$ and P-band $(\lambda=60 \mathrm{~cm}$ to $120 \mathrm{~cm}$ ), all else being equal (e.g., density, cover type, incidence angle, polarization, etc.). Moreover, the penetration depth of the microwave signal into a porous medium increases from K-band $(\lambda=1.15 \mathrm{~cm}$ to $1.67 \mathrm{~cm})$ through P-band or with increasing wavelength (Figure 11).

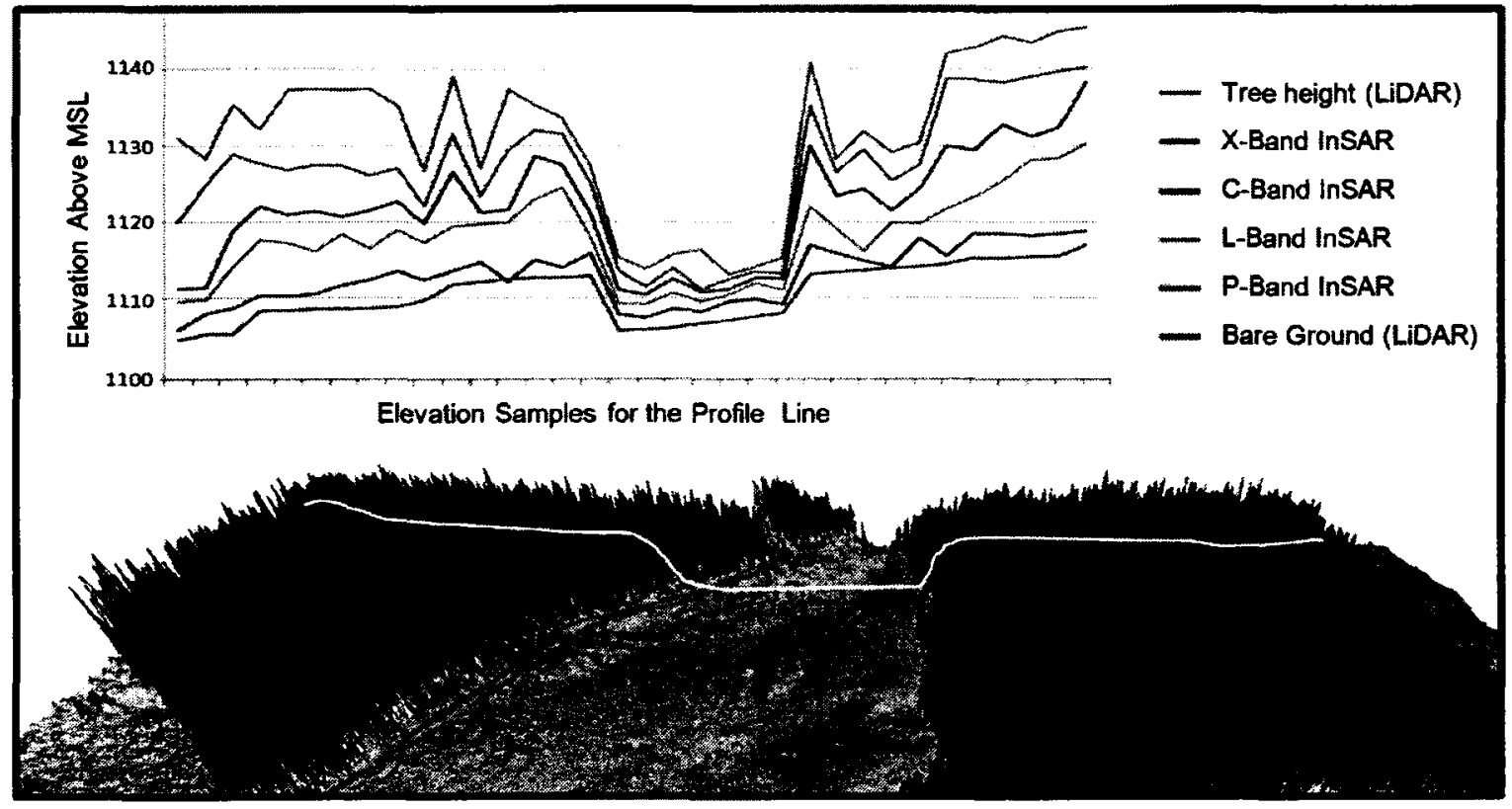

Figure 11. InSAR signal penetration over dense vegetation and barren ground at different wavelengths for a profile line in grey, superimposed on a LiDAR DSM.

For example, the DSM InSAR height for X-/C-band short wavelength InSAR may be in the upper part of a forest canopy and can be used directly as a rough estimate of 
canopy height (Andersen et al., 2008; Kellndorfer et al., 2004; Walker et al., 2007). Conversely, longer wavelengths (such as L- and P-band) penetrate deeper, interacting with the ground, tree trunks, and other lower canopy elements, depending on the characteristics of the canopy, and can provide rough estimates of bare ground surface elevation. Research has shown that SAR signal penetration depth within vegetation varies with wavelength as follows: $1-3 \mathrm{~m}$ at X-band, 3-6 $\mathrm{m}$ at C-band, 9-12 $\mathrm{m}$ at $\mathrm{L}$-band, and 14-24 $\mathrm{m}$ at P-band (Hendersen and Lewis, 1998). In sparse vegetation canopies, all wavelengths will produce signal returns from the ground and lower canopy elements, resulting in a lower overall scattering phase centre height or estimate of vegetation canopy height.

\subsubsection{Canopy Height and SAR Viewing Geometry}

SAR configurations use oblique side looking geometry (Figure 2), which can lead to distortions in the InSAR data. The NEXTMap X-HH InSAR DSM (and likewise the C-HH InSAR SRTM DSM) is the result of processing and averaging of several data acquisitions in an effort to minimize the effect of SAR viewing geometry. This type of processing provides a stable data set for which, for example, canopy and bare ground heights can be estimated (Kellndorfer et al., 2004; Andersen et al., 2008; Chen et al., 2010). However, the single-flight lines of X-HH InSAR (e.g. NEXTMap) and L-band PolInSAR data used in this research, as well as current and planned spaceborne SARs from which InSAR elevation models and canopy height may be derived, will typically be of one data take and may have distortions related to this oblique viewing geometry (Andersen et al., 2006; Izzawati et al., 2006, Woodhouse et al., 2006). This hypothesis 
was tested in this research as part of Research Objective \#3, by investigating the effect of viewing geometry on single and multi-data take InSAR data.

\subsubsection{Canopy Height and SAR Incidence Angle}

The side looking SAR sensor configuration defines an incidence angle range $(\theta-$ Figure 2) with respect to nadir. Incidence angle range is arbitrarily denoted as near-range (NR; closest to Nadir)), mid-range (MR), and far-range (FR; furthest from Nadir) across a flight line strip of data (Figure 2). Incidence angle variations across the swath result in variations in relative signal contributions from ground and surface features. At steep incidence angles (e.g. NR $-\theta=35^{\circ}$ ) more exposure of the lower portion of a vegetation canopy and ground occurs because of greater signal penetration into the canopy, resulting in a lower scattering phase centre height (Izzawati et al., 2006; Figure 12). The opposite effect occurs in the FR (Figure 12).

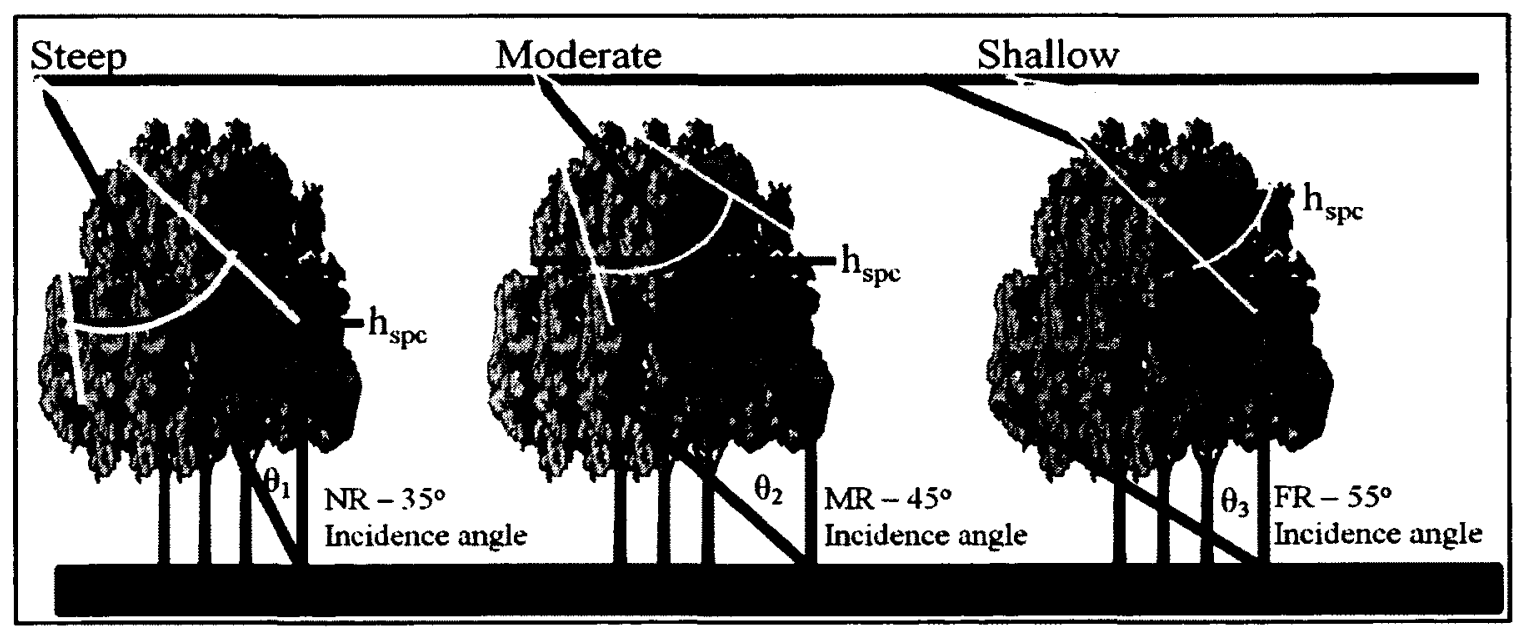

Figure 12. Incidence angle effect on $h_{\mathrm{spc}}$ retrieval for a forest canopy for single-pass InSAR. 
It is anticipated that incidence angle range of a single InSAR/PollnSAR data take (e.g. one flight line strip of data) will result in a larger range of height errors across swath from NR to FR, but this effect will be less pronounced if multiple takes (e.g. SRTM, NEXTMap) are averaged. This hypothesis was tested in this research as part of Research Objective \#3.

\subsubsection{Canopy Height and InSAR System Configuration}

Recall that single- (section 2.2) and repeat-pass (section 2.4) system configurations will play a role in the retrieved elevation data accuracy, where single-pass InSAR will generally produce higher accuracy. The multi-frequency InSAR and PolInSAR techniques used in this research have single-pass system configurations.

\subsubsection{Canopy Height and Feature Cover Structure}

Surface scattering of incoming radar, determined by surface roughness, is often the main factor influencing the radar return. Surface variations on the order magnitude of the radar wavelength will scatter radar as specified by the Rayleigh criterion. The Rayleigh criterion defines a surface as smooth if (Balmer and Hartl, 1998):

$$
h=\frac{\lambda}{8 \sin \theta}
$$

Where:

h surface roughness, defined as the root-mean-square (RMS) height relative to a perfectly smooth surface,

$\lambda \quad$ wavelength of the SAR pulse in centimetres

$\theta \quad$ incidence angle in degrees

The roughness criterion can be used to differentiate between, for example, surface topography in non-vegetated areas or extent of vegetation in others. For a "smooth" 
surface, $\mathrm{h}$ must be less than $1 / 8$ th the radar wavelength (Balmer, 1999). Horizontal smooth surfaces such as calm water reflect nearly all incident energy away from the radar antenna (called specular reflection) at the same angle as the incidence angle according to Snell's law (Figure 13 - specular reflection) returning little to no signal back to the SAR receiver and resulting in a dark image tone or decorrelation in phase. In contrast, microwaves incident upon a rough surface are scattered in many directions (called diffuse scattering/reflectance).

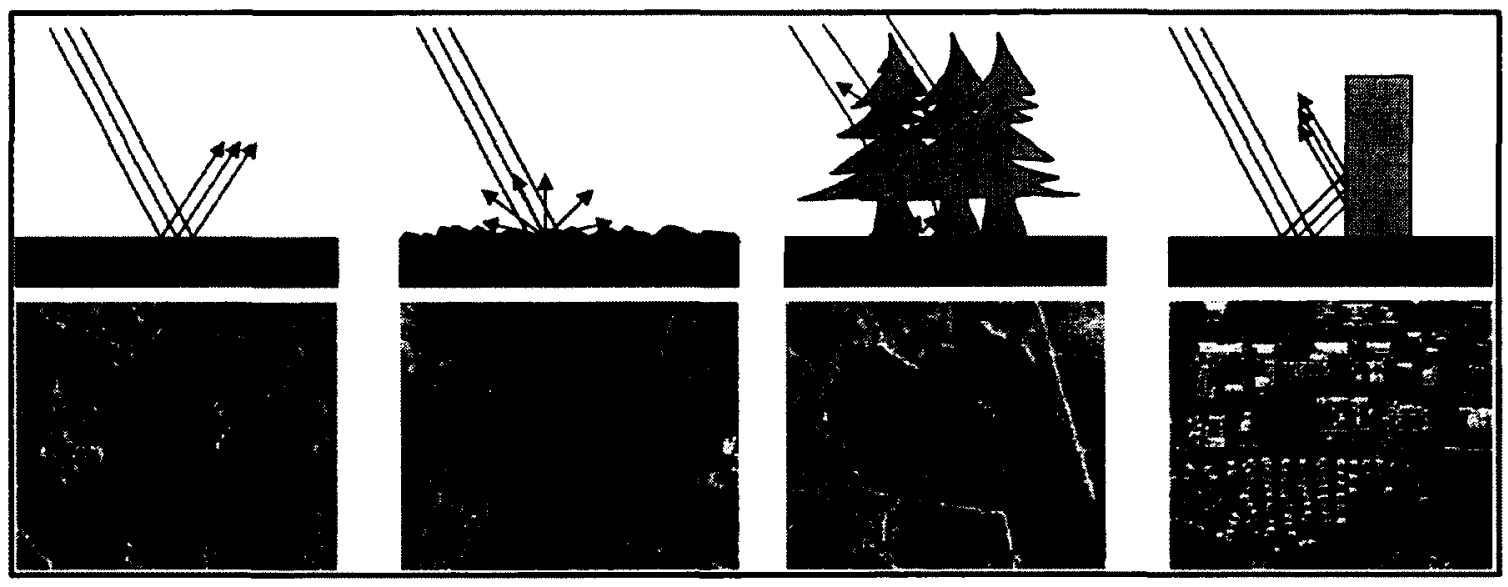

Figure 13. Surface roughness effects on radar backscatter for four land cover types. L-R:

a body of calm water (specular reflection), grass (diffuse scattering), forest (volume scattering), and buildings (dihedral reflection; Intermap, 2011).

Reflections can bounce again off other objects and be redirected back toward the SAR receiver, resulting in a stronger return signal (Figure 13 - volume scattering and dihedral reflection). In the case of volume scattering, which occurs in vegetation where (high water content) leaves reflect radar signals onto other leaves and branches, multiple scattering occurs until the signal exits the vegetation. A percentage of the incoming radar 
is therefore volumetrically scattered back to the SAR sensor, giving the vegetation a brighter signature than a smooth lake.

\subsubsection{Canopy Height and Terrain Slope and Aspect}

Topographic slope changes (Figure 14) the relative SAR sensor-target viewing geometry and thus, the visibility of parts of, for example, vegetation canopy elements, which affects the relative contribution of crown and near-edge ground surfaces (Izzawati et al., 2006; Balzter et al., 2007a, Andersen et al., 2008). This effect is somewhat similar to the incidence angle effect but not exactly because trees stand vertically regardless of the terrain slope.

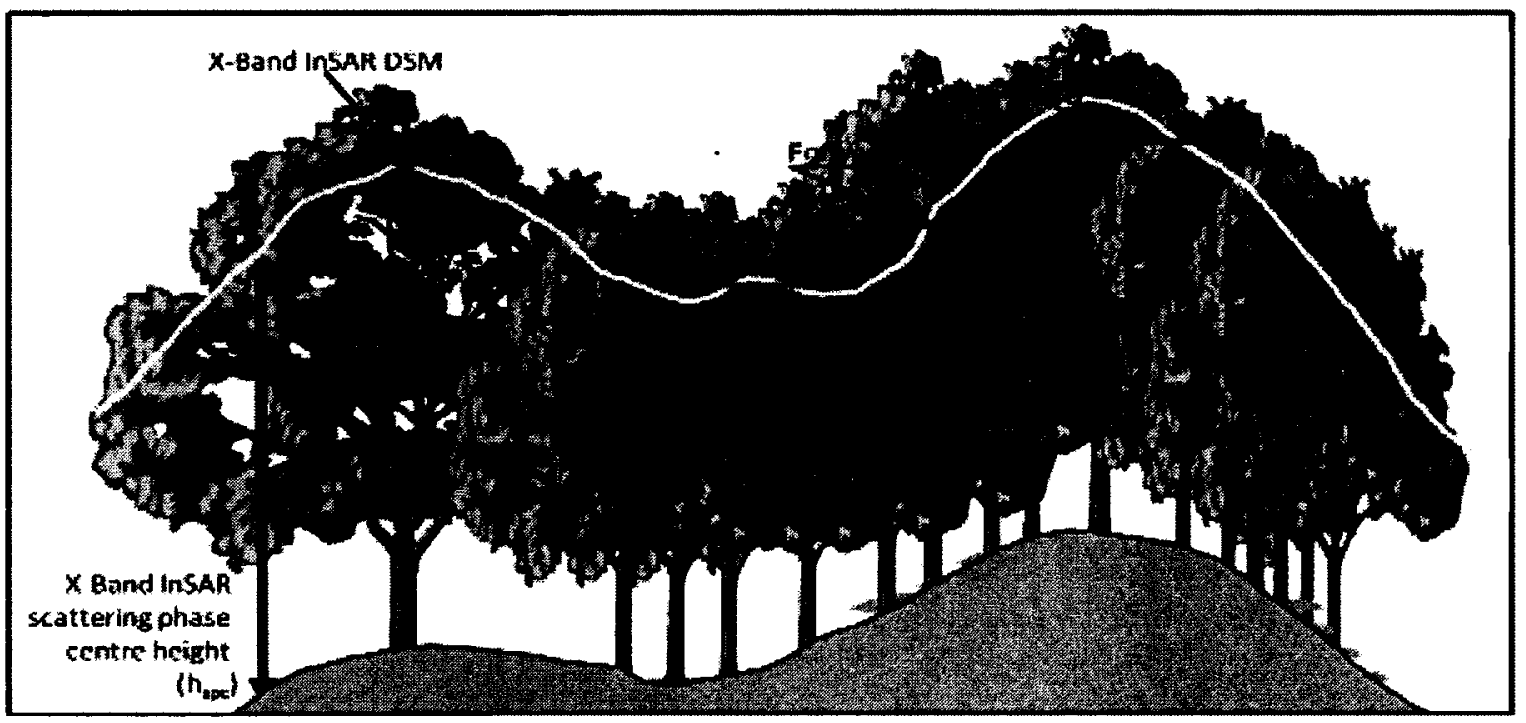

Figure 14. Slope and aspect effect on signal attenuation (penetration) into a forest canopy. For the same incidence angle $(\theta), h_{\text {spc }}$ (yellow line) varies depending on the direction the slope faces with respect to the sensor (aspect) and on the amount of terrain slope (in degrees). 
It is anticipated that in regions of forward slopes (sloped terrain facing the radar illumination beam), SAR signals will interact with the lower portion of vegetation crowns and tree trunks, leading to greater signal contributions from within the canopy and greater canopy height estimate errors (Figure 14). Slopes facing away from the sensor (called back slopes) would have greater contributions from canopy, less from the ground, leading to less canopy height estimate errors compared to forward slope scenarios. This hypothesis is tested in this research as part of Research Objective \#3.

\subsubsection{Canopy Height and Vegetation Discontinuity Effects}

Canopy height retrieval at discontinuities (e.g. gaps within the forest canopy or at the edge of a vegetation canopy) is prone to height errors due to the oblique InSAR viewing geometry. As the contribution of the exposed ground surfaces increases at forest stand edges or gaps (Woodhouse et al., 2006), $\mathrm{h}_{\mathrm{spc}}$ will be lower, resulting in a lower estimate of canopy height. For example, the retrieved height across a coniferous forest of $\sim 22 \mathrm{~m}$ average height is given in the top profile $(\mathrm{A}-\mathrm{C}$ ) of Figure 15. The corresponding profile for $h_{\text {spc }}$ is approximately $7.5 \mathrm{~m}$ at the edge of the forest stand (Figure $15 \mathrm{~B}$, red profile line), significantly underestimating actual tree height at the edge. This is addressed in Section 4.4. as part of research objective \#3.

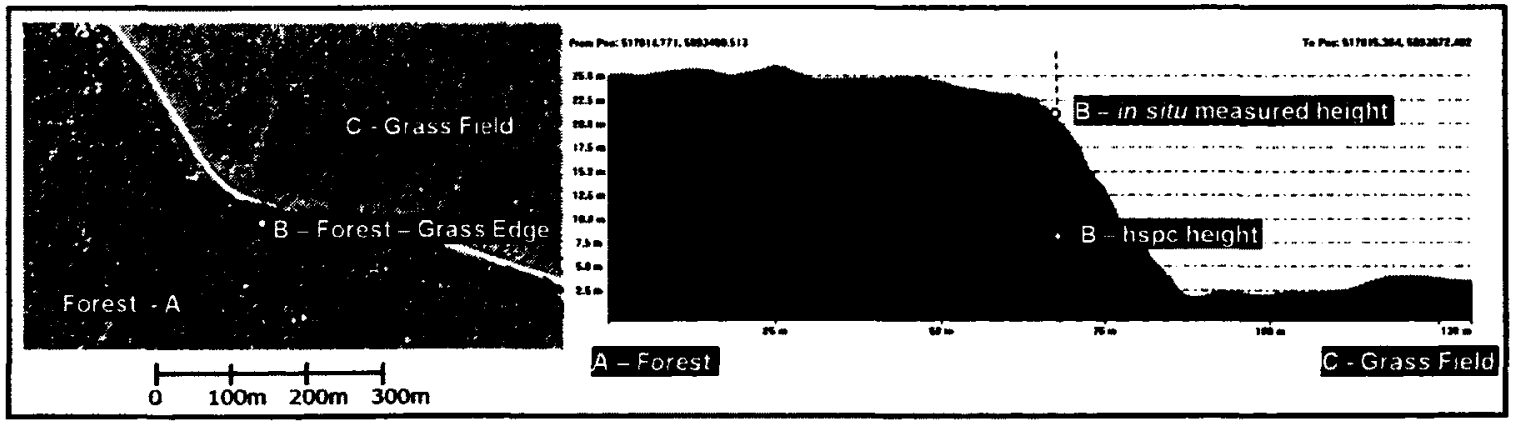

Figure $15 . \mathrm{h}_{\mathrm{spc}}$ underestimation of canopy height at a forest edge (see $\mathrm{B}$ to $\mathrm{C}$ points). 


\subsection{Summary}

This chapter presents a theoretical context and past studies on the use of InSAR and PolInSAR techniques for land cover classification and canopy height estimation. InSAR and PolInSAR techniques provide highly accurate $\mathrm{x}, \mathrm{y}$, and $\mathrm{z}$ coordinates of a location imaged by a radar beam. These SAR systems have the ability to acquire data in the absence of the sun (day or night operation), in the majority of weather and atmospheric conditions, through clouds, and at high collection rates. These characteristics make these systems a viable alternative to conventional aerial photography (Curlander and McDonough, 1991; Goetz et al., 2000; Haack et al., 2000; Hodgson et al., 2003) and LiDAR technologies (Riegier et al., 1999; Means et al., 2000; Zhu et al., 2004) for large area topographic and land cover mapping. This literature review has shown that canopy height estimates derived from InSAR and PolInSAR techniques are achieving accuracies that are approaching those obtained from traditional field surveys, which are expected to be around $90 \%$ (Barron, 2001). Based on this literature analysis, this research was designed to gain a further understanding of how SAR signals interact with vegetation canopies and how this interaction can be exploited to extract vegetation cover and height estimates for use in forestry and large area vegetation mapping applications. This research examines multi-frequency SAR data over a variety of vegetation classes, terrain types, and environments to gain a better understanding of the use of InSAR and PolInSAR derived vegetation type and canopy height over global conditions. Furthermore, given the plethora of current and planned InSAR capable sensors, this research was designed to provide a precursor, and supplement, to future satellite based sensors (e.g. Tandem X and COSMO SkyMed) for canopy height retrieval. 


\section{CHAPTER THREE: RESEARCH SITES AND DATA DESCRIPTIONS}

\subsection{Site Selection}

Six research sites, four located in the United States (Arizona, Colorado, and Minnesota (two sites)) and two in Canada (Alberta), were selected to address the research objectives (Chapter 1, Section 1.5). They vary in extent due to funding and the time allotted per site for the field data collection. Subsequent sections provide descriptions of the sites and the InSAR and ancillary data utilized in this research.

There are several reasons for selecting six research sites.

1) There was an opportunity to collaborate with Intermap Technologies on several research projects underway in these six research sites, where field crews were available to assist in the collection of the in situ measurements.

2) The bio-geophysical characteristics of the different research sites provided an opportunity to evaluate $\mathrm{X}-\mathrm{HH} \operatorname{InSAR}$ data as a source for high-resolution vegetation type and canopy height estimates across a range of vegetation densities and structural classes (listed in Table 2) as well as in a variety of environments (arid, semi-arid, temperate and boreal) and topographic/geologic conditions.

3) The adoption of six research sites facilitated examination of the regional applicability of the proposed canopy height estimation methodology.

4) The data collection configurations differ somewhat between the United States and the Canadian research sites, providing a unique opportunity to compare system factors (X-InSAR and L-PolInSAR) in evaluating canopy height estimation performance. 
Table 2. Research site land cover class descriptions (modified after Homer et al., 2004) and the National Land Cover Data (NLCD) class \#. Water, grass, crops, and urban land cover were not included in this research; however they were classified, grouped together and masked leaving only the vegetation classes of interest.

\begin{tabular}{|l|l|}
\hline \multicolumn{1}{|c|}{$\begin{array}{c}\text { Vegetation Type } \\
\text { (NLCD Class \#) }\end{array}$} & \multicolumn{1}{c|}{ Class Description } \\
\hline Water (11) & $\begin{array}{l}\text { All areas of open water, generally with }<25 \% \text { cover of } \\
\text { vegetation or soil. }\end{array}$ \\
\hline Barren $(21,31)$ & Areas of earth material with $<15 \%$ vegetation cover. \\
\hline Shrub (52)/762 & $\begin{array}{l}\text { Areas dominated by shrubs; }<5 \mathrm{~m} \text { tall with shrub } \\
\text { canopy typically }>20 \% \text { of total vegetation. This class } \\
\text { includes true shrubs, young trees in an early } \\
\text { succession stage, or trees stunted from environmental } \\
\text { conditions. }\end{array}$ \\
\hline Deciduous (41)/258 & $\begin{array}{l}\text { Areas dominated by trees generally }>5 \text { m tall, and } \\
>20 \% \text { of total vegetation cover consisting of greater } \\
\text { than } 75 \% \text { deciduous species. }\end{array}$ \\
\hline Coniferous (42)/803 & $\begin{array}{l}\text { Areas dominated by trees generally }>5 \mathrm{~m} \text { tall, and }> \\
20 \% \text { of total vegetation cover consisting of greater } \\
\text { than } 75 \% \text { conifer species. }\end{array}$ \\
\hline Mixed (43)/581 & $\begin{array}{l}\text { Areas dominated by trees generally }>5 \text { m tall, and } \\
>20 \% \text { of total vegetation cover. Neither deciduous nor } \\
\text { evergreen species are }>75 \% \text { of total tree cover. }\end{array}$ \\
\hline Wetlands (90,95) / 180 & $\begin{array}{l}\text { Areas where forest or shrub vegetation accounts for } \\
>20 \% \text { of vegetative cover and the soil or substrate is } \\
\text { periodically saturated or covered with water, or areas } \\
\text { where perennial herbaceous vegetation accounts for } \\
>80 \% \text { of vegetative cover and the soil or substrate is } \\
\text { periodically saturated or covered with water. }\end{array}$ \\
\hline
\end{tabular}

\subsubsection{International Falls, Minnesota Site}

The International Falls, Minnesota research site is located between $48^{\circ} 37^{\prime} 30^{\prime \prime} \mathrm{N}$ and $48^{\circ} 30^{\prime} 00^{\prime \prime} \mathrm{N}$ and $93^{\circ} 30^{\prime} 00^{\prime \prime} \mathrm{W}$ and $93^{\circ} 15^{\prime} 00^{\prime \prime} \mathrm{W}$ (Figure 16). This site was chosen 
because of the availability of dense vegetation cover located within the Laurentian Mixed Forest (LMF), a transitional forest between the northern boreal forest and temperate broadleaf forests to the south (Ecological Provinces, 1999). The site is $16.35 \mathrm{~km}^{2}$ situated on a lake plain with less than $30 \mathrm{~m}$ topographic relief $(335 \mathrm{~m}-365 \mathrm{~m}$ above mean sea level) and terrain slopes less than $15^{\circ}$. The forests are dominated by evergreen species such as white pine (Pinus strobus), white spruce (Picea glauca), and balsam fir (Abies balsamea) with a small mixture of red pine (Pinus resinosa), and jack pine (Pinus banksiana). This site is part of the northern Superior Upland Section (NSU) which largely coincides with the extent of the Canadian Shield in Minnesota. It is located within the Northern Minnesota and Ontario Peat lands sections. Metasedimentary rocks greywacke, slate, along with fine grained felsic volcanogenic and volcaniclastic rocks and migmatites dominate this research site (Morey, 1967). The soils are clayey to loamy, formed from lake-laid sediments and glacial till.

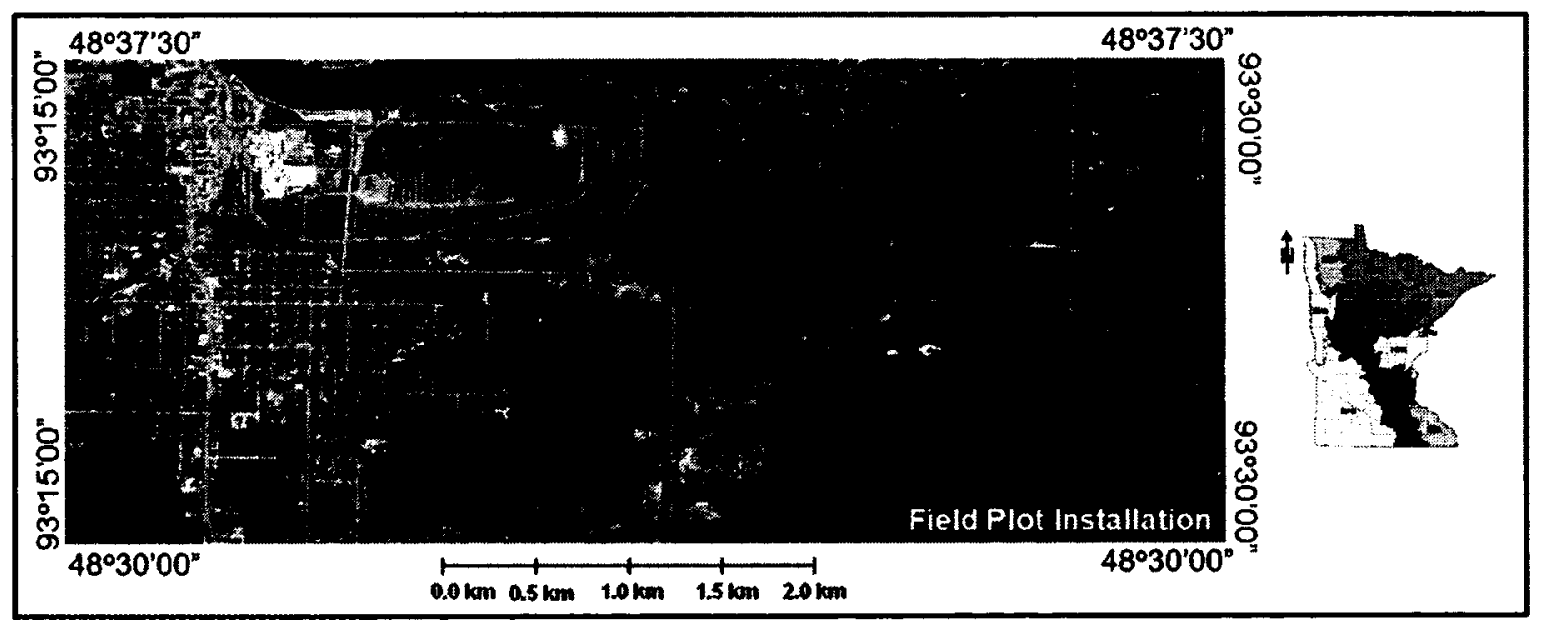

Figure 16. The International Falls, Minnesota research site with 22 field plot installation centre coordinate locations represented as red diamonds superimposed on National Agriculture Imagery Program (NAIP) imagery. 


\subsubsection{Ely, Minnesota Site}

This Ely, Minnesota site is situated in the temperate transition between $47^{\circ} 52^{\prime} 30^{\prime \prime}$ $\mathrm{N}$ and $47^{\circ} 37^{\prime} 30^{\prime \prime} \mathrm{N}$ and $91^{\circ} 52^{\prime} 30^{\prime \prime} \mathrm{W}$ and $91^{\circ} 37^{\prime} 30^{\prime \prime} \mathrm{W}$ near the city of Ely, Minnesota (Figure 17). The site is comprised of dense homogenous evergreen, deciduous, and mixed forests with little understory. The site covers $169.8 \mathrm{~km}^{2}$ and is situated on rolling topography with irregular slopes $\left(0^{\circ}-18.7^{\circ}\right)$ and an elevation range of $422-506 \mathrm{~m}$. The forests predominantly consist of red pine, white pine, black spruce (Picea mariana), and red maple (Acer rubrum).

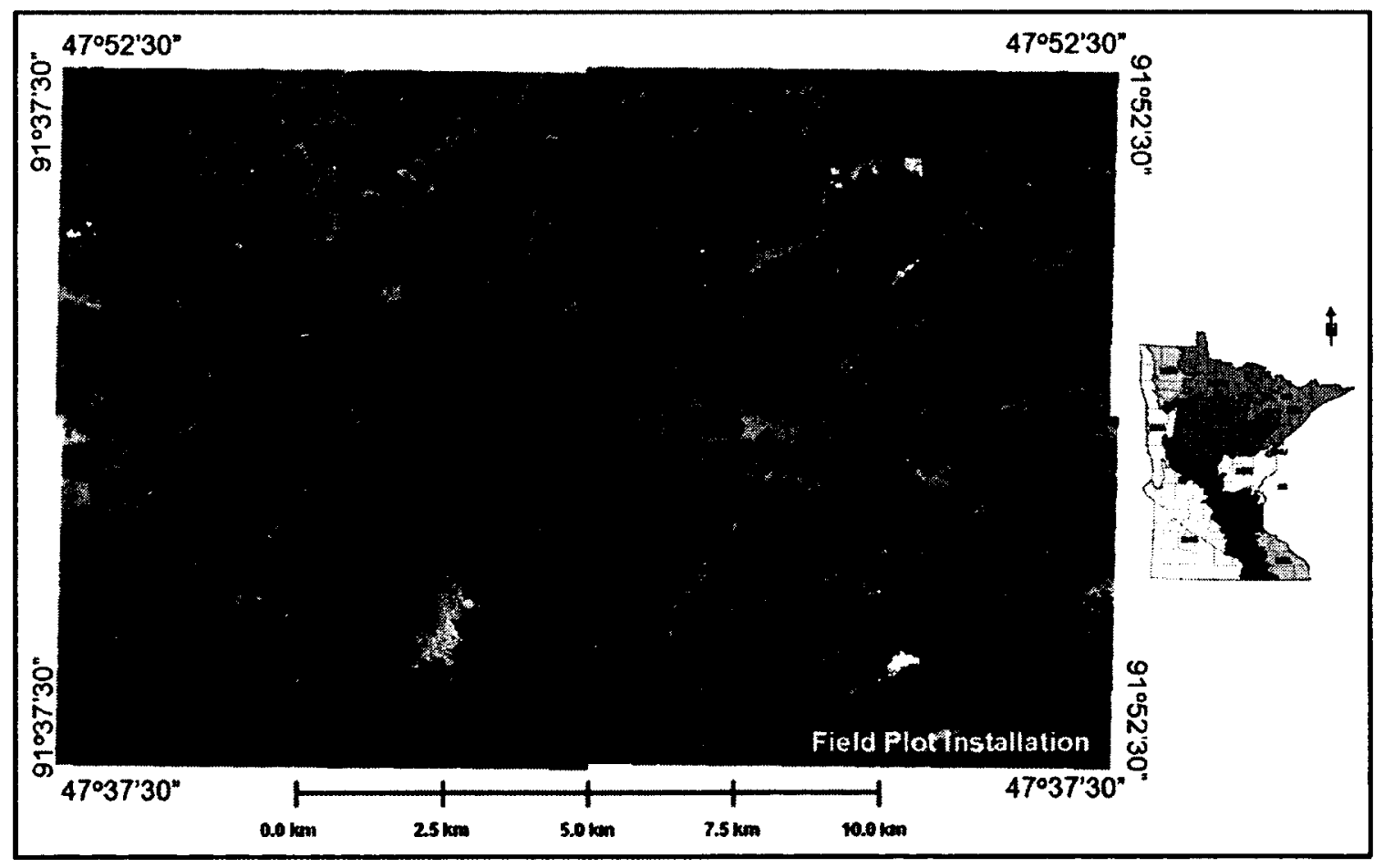

Figure 17. Ely, Minnesota research site with 54 field plot installation centre coordinate locations represented as red diamonds superimposed on NAIP imagery.

This site is also part of the LMF Province that traverses northern Minnesota, Wisconsin, Michigan, southern Ontario, and the less mountainous portions of New 
England (Ecological Provinces, 1999). This research site is located within the Northern Superior Upland (NSU) geologic section which is characterized by glacially scoured bedrock terrain with thin and discontinuous deposits of coarse loamy till and numerous lakes. Glacial ice moved from west to east across the subsection, deepening stream valleys in the bedrock, as evident in (Figure 17).

The bedrock is largely comprised of metasedimentery (greywacke, slate, fine grained felsic volcanogenic and volcaniclastic rocks, local units of conglomerate, graphitic slate, and lean oxide iron-formation rocks) and migmatites (Morey et al., 1967). Also included are the Knife Lake Group and the Lake Vermilion Formation of northeastern Minnesota (Morey, 1967). Long east-west oriented lakes now occupy these enlarged valleys. The site has many craggy outcrops of bedrock.

\subsubsection{Morrison, Colorado Site}

The Morrison, Colorado site (Figure 18) is located near the town of Morrison Colorado, USA between $39^{\circ} 45^{\prime} 09^{\prime \prime} \mathrm{N}$ and $39^{\circ} 37^{\prime} 20^{\prime \prime} \mathrm{N}$ and $105^{\circ} 06^{\prime} 36^{\prime \prime} \mathrm{W}$ and $105^{\circ} 15^{\prime} 55^{\prime \prime} \mathrm{W}$. The site is about $180 \mathrm{~km}^{2}$ with rolling topography over an elevation range from $1660 \mathrm{~m}$ in the foothills to $2435 \mathrm{~m}$ in the mountains and irregular slopes $\left(0^{\circ}\right.$. $46.5^{\circ}$ ). This site represents a semi-arid environment with forests dominated by evergreen stands of spruce and fir (Picea Abies) and including ponderosa pine (Pinus ponderosa), Lodgepole pine (Pinus contorta), Douglas fir (Pseudotsuga menziesii), bristlecone pine (Pinus aristata), limber pine (Pinus flexilis), and Colorado blue spruce (Picea pungens), with smaller amounts of deciduous species, including aspen (Populus tremuloides) and cottonwood (Populus angustifolia) along the major river corridors. The Rocky Mountain foothills run north-south through the centre of the area, with the Great Plains to the east 
and the Colorado Plateau to the west (Boyer and Elliott, 1982). The site is located in a complex zone of multiple folding and uplifting where rocks of the ancient North American craton are exposed, cradling Cenozoic lake beds full of fossils (Boyer and Elliott, 1982).

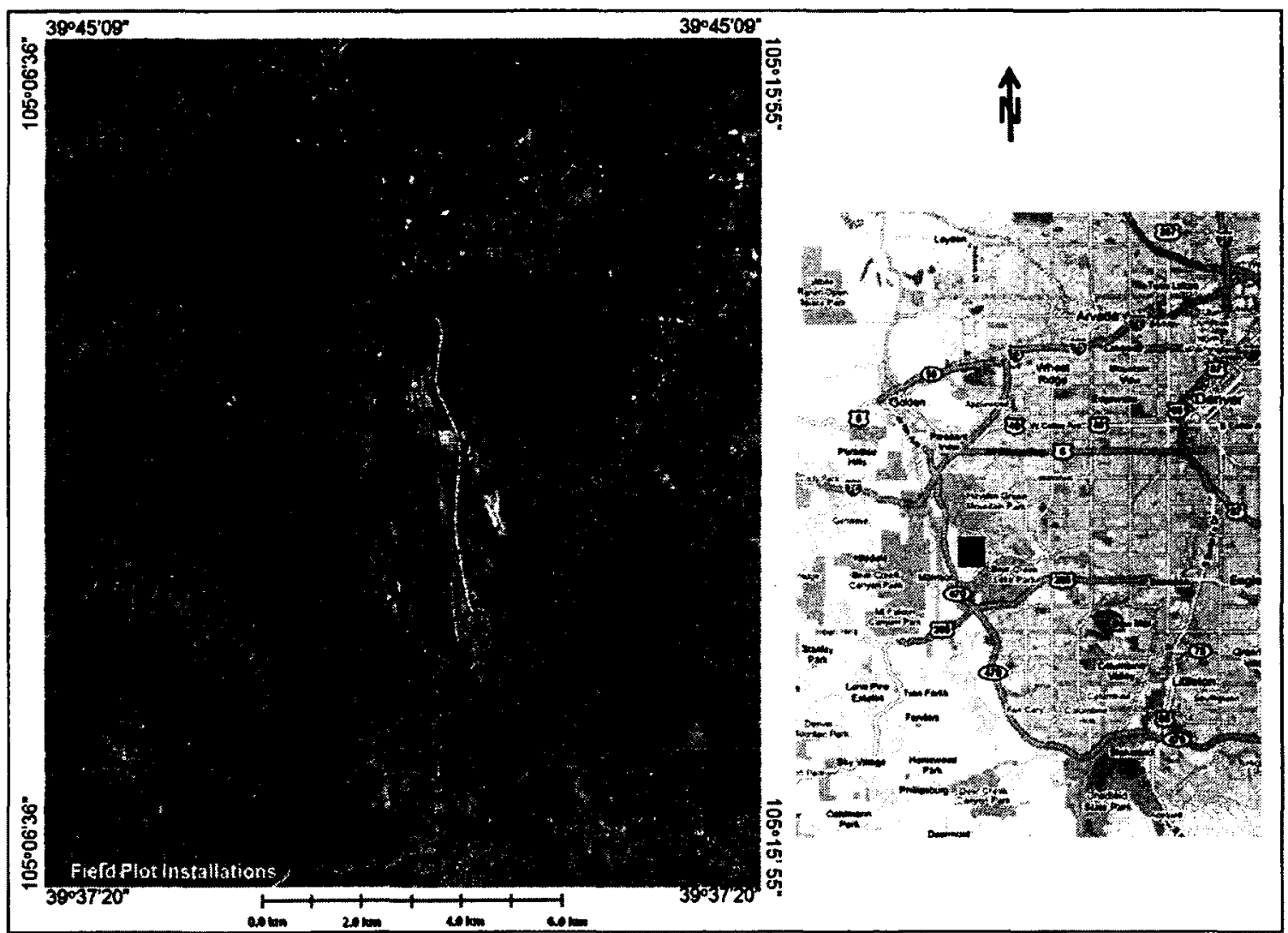

Figure 18. Morrison, CO research site with 179 field plot installation centre coordinate locations represented as red diamonds superimposed on NAIP imagery.

\subsubsection{Southern Arizona Site}

The Arizona site is located near the Mexican border (Figure 19) between $31^{\circ} 45^{\prime} 09^{\prime \prime} \mathrm{N}$ and $31^{\circ} 22^{\prime} 50^{\prime \prime} \mathrm{N}$ and $111^{\circ} 37^{\prime} 42^{\prime \prime} \mathrm{W}$ and $111^{\circ} 14^{\prime} 53^{\prime \prime} \mathrm{W}$. The site is approximately $1484 \mathrm{~km}^{2}$ situated between elevations of $931 \mathrm{~m}$ in the plains to $1762 \mathrm{~m}$ 
with irregular slopes $\left(0^{\circ}-28^{\circ}\right)$. It is in an arid environment that is predominately shrub (e.g., thornscrub (Canotia holacantha)), and evergreen forests, with minor occurrence of wetlands, bare earth, and urban development. Deciduous species include: oak (Quercus spp.), juniper (Juniperu spp.), desert riparian cottonwood (Populus fremontii), Goodding willow (Salix gooddingi), Arizona ash (Fraxinus velutina), and Arizona walnut (Juglans major), Arizona sycamore (Platanus wrightii), Mexican elder (Sambucus mexicana), and velvet mesquite (Prosopis velutina).

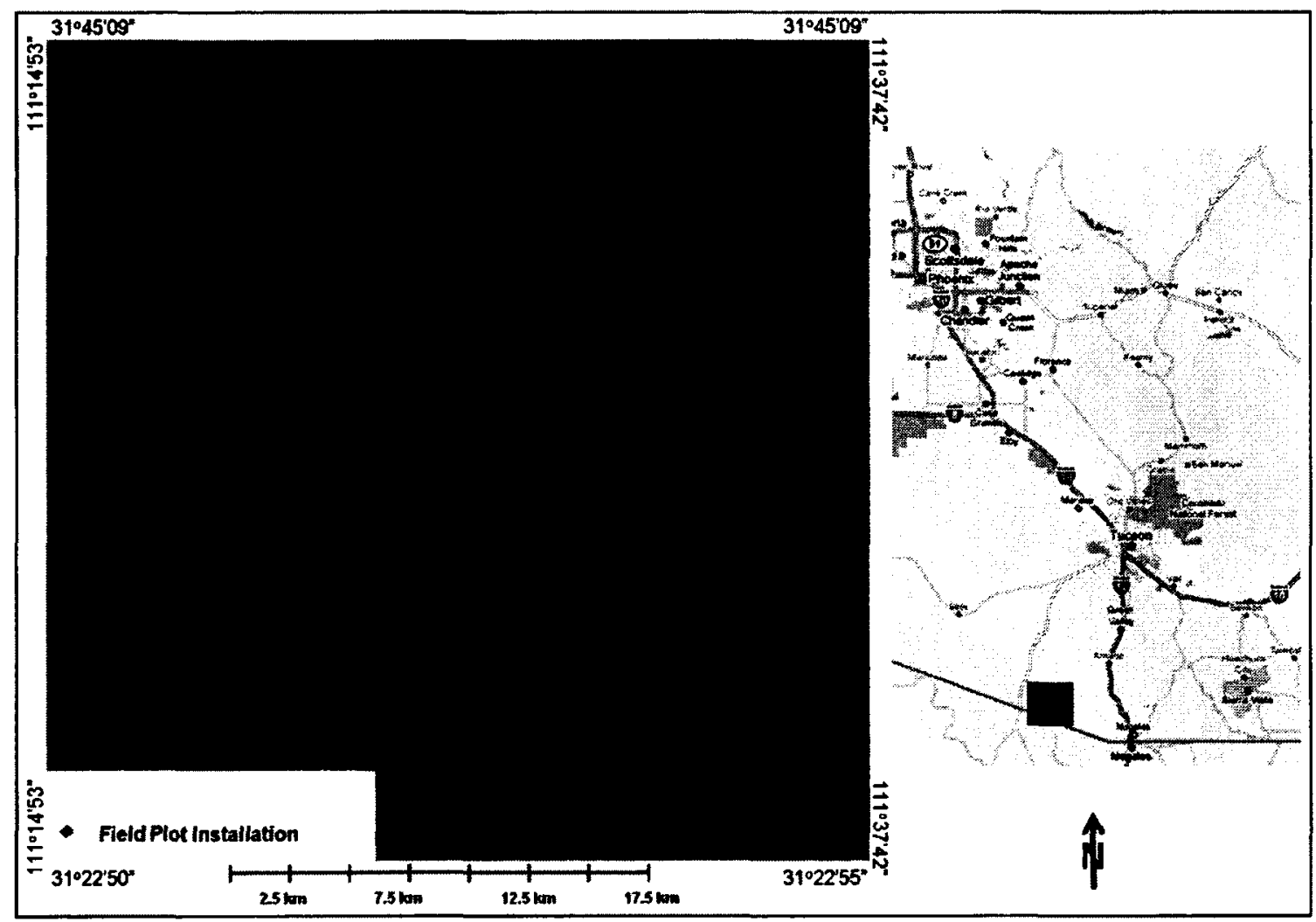

Figure 19. Arizona research site with 234 field plot installation centre coordinate locations represented as red diamonds superimposed on NAIP imagery.

This site is within the Basin and Range Geologic Province (Brod, 2005). These ranges trend northwest-southeast and parallel one another. Whitish deposits composed of 
calcium carbonate and high- and low-grade copper ore deposits are present. The mountainous regions are dominated by the Coronado National Forest and are notably different from the desert conditions of the plains. The Coronado National Forest is comprised of woodland that has its origins in the Sierra Madre mountain range of Mexico and reaches its northern extent in the ranges of south-eastern Arizona. The floodplain has been built up by wide and slow moving floods, and the soil is mostly fine alluvial clay (Brod, 2005). Outside of the mountains, the terrain is generally flat with some undulating hills and plateaus.

\subsubsection{Burnstick Lake, Alberta Site}

The Burnstick Lake site covers approximately $0.5 \mathrm{~km}^{2}$ located between latitudes $53^{\circ} 11^{\prime} 58^{\prime \prime} \mathrm{N}$ and $53^{\circ} 11^{\prime} 17^{\prime \prime} \mathrm{N}$ and longitudes $116^{\circ} 44^{\prime} 14^{\prime \prime} \mathrm{W}$ and $116^{\circ} 43^{\prime} 38^{\prime \prime} \mathrm{W}$ (Figure 20). This site was selected because it represents a boreal transition "ecozone". The elevation range across the site is $36 \mathrm{~m}$ (1200 $\mathrm{m}$ to $1236 \mathrm{~m}$ above mean sea level) over slopes less than $10^{\circ}$ which represents a relatively flat landscape. The site is comprised of dense homogenous evergreen forests, with little amounts of deciduous, and mixed forests with little understory. The coniferous forests are dominated by Lodgepole pine (Pinus contorta). A small mix of deciduous trees, such as white birch (Betula papyrifera) and trembling aspen (Populus tremuloides) are also present.

Burnstick Lake is located in the Interior Plains where the landscape is characterized by broad flats dominated by Lodgepole pine, which has been cut (thinned) in some locations. The bedrock geology consists of shales and sandstones of the Alberta geologic group. Hummocky ablation terrain is the prominent landform covered with surface materials of glacial till, which forms the basis of the grey-wooded soils known as 
Lobley loam (Bentz et al., 1994). These soils are stony, sandy clay with limited organic content (Bentz et al., 1994).

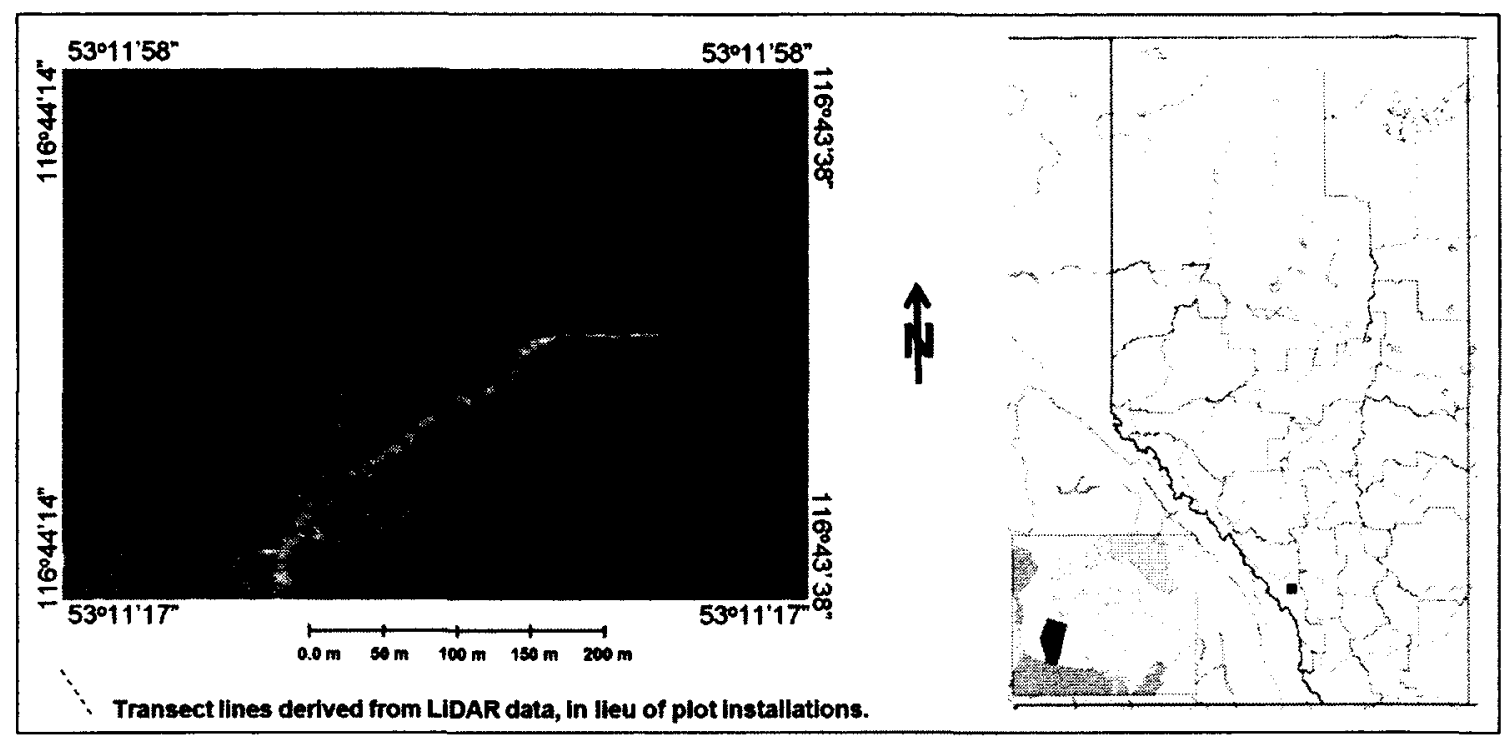

Figure 20. Burnstick Lake, Alberta research site with six transect lines (red dashed lines) superimposed on optical imagery. Transect line data were derived from LiDAR data, in lieu of plot installations.

\subsubsection{Edson, Alberta Site}

The Edson site represents a boreal "ecozone" in the Interior Plains where the landscape is characterized by broad flats. It is located approximately $192 \mathrm{~km}$ west of Edmonton (Figure 21) and covers approximately $1 \mathrm{~km}^{2}$ centred on latitude $53^{\circ} 11^{\prime} 37^{\prime \prime} \mathrm{N}$ and longitude $116^{\circ} 43^{\prime} 56^{\prime \prime} \mathrm{W}$. The terrain elevation range across the site is $31 \mathrm{~m}$ (1090 m to $1121 \mathrm{~m}$ above mean sea level) over topographic slopes of less than $10^{\circ}$ therefore, representing a relatively flat landscape. The site is dominated by dense homogenous Lodgepole pine forests, with small amounts of white birch and trembling aspen, and thus very similar vegetation strata to that found at the Burnstick Lake site. Its geology is comprised of Lower Cretaceous Bluesky sandstone that trend southwest-northeast, 
parallel to the barrier and low stand shoreline sand-bodies of the Glauconite Member (Terzuoli, and Walker, 1997). These sand-bodies have erosive channelized bases that cut down into brackish water shales and sandstones and into the Gething Formation (Terzuoli, and Walker, 1997). The sand-bodies consist mostly of mudstones with a limited number of small trace fossils. The mudstones are interpreted as central estuary deposits. The bedrock geology consists of Alberta geologic group shales and sandstones.

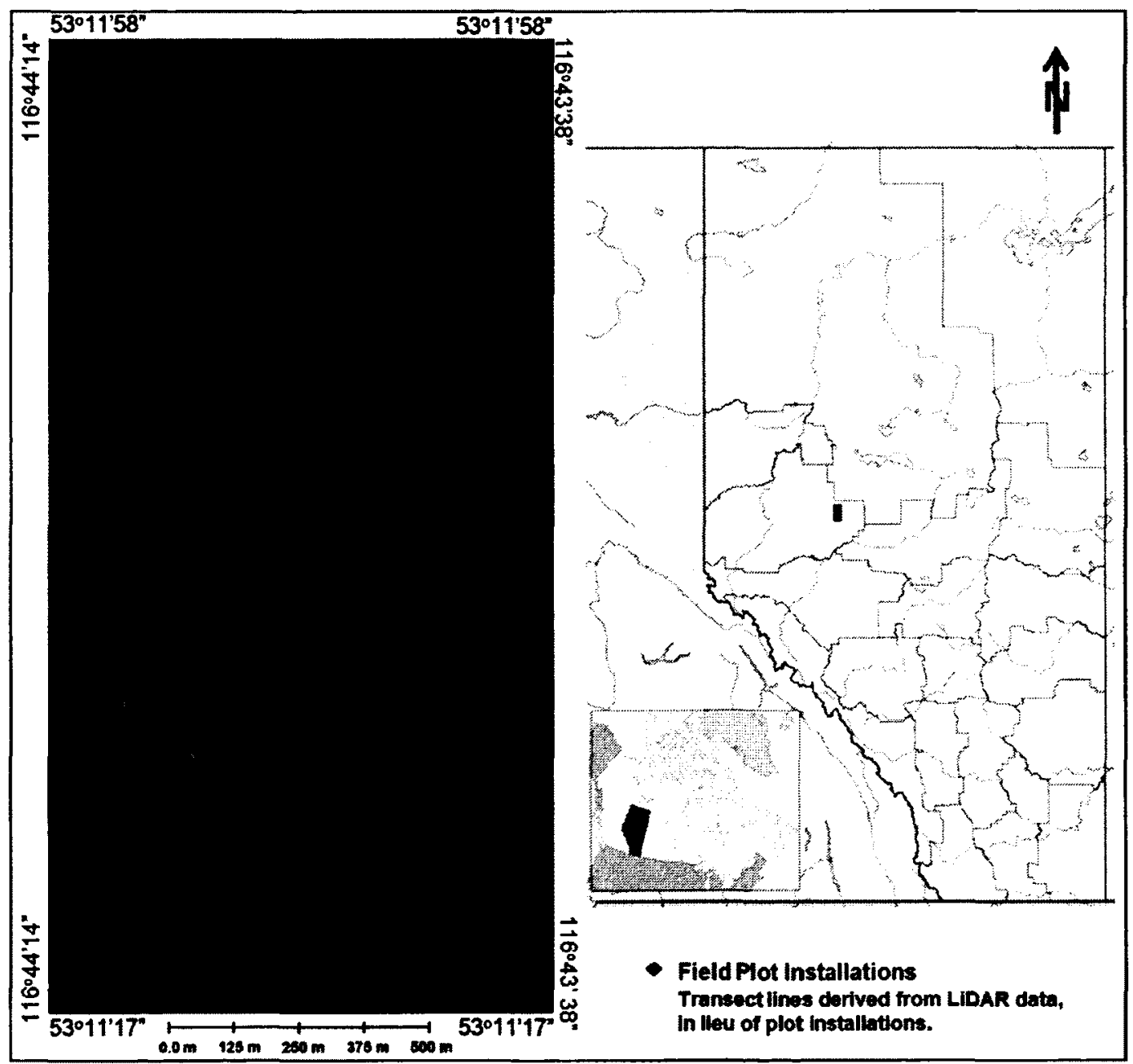

Figure 21. Edson, Alberta research site with six transect lines (red dashed lines) superimposed on optical imagery. Transect line data were derived from LiDAR data, in lieu of plot installations. Transect lines are numbered $1-8$, left to right. 


\subsection{InSAR and PolInSAR Data and Data Processing}

Subsequent sections describe the pre-processing steps carried out in this research and by the vendors, where applicable, for the InSAR and PolInSAR data (Table 3).

Table 3. InSAR and PolInSAR datasets per research site. Accuracies shown are vendor stated values. 'Posting' refers to the distance in the $\mathrm{x}$ or $\mathrm{y}$ direction between data values.

\begin{tabular}{|c|c|c|}
\hline InSAR Data & Elevation Data Specification & $\begin{array}{l}\text { Research Site, Data } \\
\text { Acquisition Date: MM/YY }\end{array}$ \\
\hline $\begin{array}{l}\text { X-HH InSAR } \\
\text { Multiple Take Data } \\
\text { Airborne-single pass } \\
\text { NEXTMap, Intermap }\end{array}$ & $\begin{array}{l}\text { Product: DSM, DTM } \\
\text { Posting: } 5 \mathrm{~m} \\
\text { Vertical accuracy (RMSE): } 1 \mathrm{~m}^{*} \\
\text { Horizontal accuracy (RMSE): } 2 \mathrm{~m}^{*} \\
\text { *Barren and low sloped terrain }\end{array}$ & $\begin{array}{l}\text { Arizona, 09/07 } \\
\text { Morrison, 04/07 } \\
\text { Ely and Intern. Falls, 09/07 } \\
\text { Burnstick Lake, 04/08 } \\
\text { Edson, 04/08 }\end{array}$ \\
\hline $\begin{array}{l}\text { X-HH InSAR } \\
\text { Single Take Data } \\
\text { Airborne-single pass } \\
\text { STAR6, Intermap }\end{array}$ & $\begin{array}{l}\text { Product: DSM } \\
\text { Posting: } 5 \mathrm{~m} \\
\text { Vertical accuracy (RMSE): } 1 \mathrm{~m}^{*} \\
\text { Horizontal accuracy (RMSE): } 2 \mathrm{~m}^{*} \\
\text { *Barren and low sloped terrain }\end{array}$ & $\begin{array}{l}\text { Arizona, 09/07 } \\
\text { Ely and Intern. Falls, 09/07 } \\
\text { Burnstick Lake, 04/08 } \\
\text { Edson, 04/08 }\end{array}$ \\
\hline $\begin{array}{l}\text { C-HH InSAR } \\
\text { Multiple Take Data } \\
\text { Spaceborne-single pass } \\
\text { SRTM, NASA }\end{array}$ & $\begin{array}{l}\text { Product: DSM } \\
\text { Posting: } 30 \mathrm{~m} \\
\text { Vertical accuracy (LE90): } 15 \mathrm{~m} \\
\text { Horizontal accuracy (<E90): } 15 \mathrm{~m}\end{array}$ & $\begin{array}{l}\text { Arizona, 02/00 } \\
\text { Morrison, 02/00 } \\
\text { Ely and Intern. Falls, 02/00 } \\
\text { Burnstick Lake, 02/00 } \\
\text { Edson, 02/00 }\end{array}$ \\
\hline $\begin{array}{l}\text { L-Quad PolInSAR } \\
\text { Single Take Data } \\
\text { Airborne-single pass } \\
\text { TOPOSAR-L, Intermap }\end{array}$ & $\begin{array}{l}\text { Product: DSM, DTM } \\
\text { Posting: } 5 \mathrm{~m} \\
\text { Vertical accuracy (RMSE): } 5 \mathrm{~m}^{*} \\
\text { Horizontal accuracy (RMSE): } 2 \mathrm{~m}^{*} \\
\text { *Barren and low sloped terrain }\end{array}$ & $\begin{array}{l}\text { Burnstick Lake, 04/08 } \\
\text { Edson, 08/08 }\end{array}$ \\
\hline
\end{tabular}

\subsubsection{X-HH InSAR - NEXTMap}

The data for this research were provided by Intermap Technologies, a Canadianbased company that operates several airborne single-pass across-track InSAR X-HH 
( $3 \mathrm{~cm}$ wavelength; horizontal polarization) sensors mounted in airborne platforms (e.g., King Air, Learjet 36). These systems collect nationwide (e.g. all of Germany, all of United States) orthorectified radar imagery and InSAR elevation data (Intermap, 2011; Mercer, 2004). The data were acquired in the standard STAR system configuration for the Intermap NEXTMap program as presented in Figure 22.

\begin{tabular}{|c|c|}
\hline Sensor & STAR \\
\hline Piation & Leajel 364 \\
\hline Flying Heinht & $10,000 \mathrm{~m}$ \\
\hline Speed & $700 \mathrm{~km} / \mathrm{hr}$ \\
\hline Wavelength & $3 \mathrm{~cm} X-8$ and \\
\hline Frequency & $9.8 \mathrm{GHz}$ \\
\hline Polarization & HH \\
\hline $\begin{array}{l}\text { Interferometis } \\
\text { Baseline }\end{array}$ & $1 \mathrm{~m}$ \\
\hline Incidance Angla & $\begin{array}{l}\text { Centered on } 45^{\circ} \\
\text { Ran }\end{array}$ \\
\hline DSNUDTM Posting & $5 \mathrm{~m}$ \\
\hline ORI Pixel size & $1.25 \mathrm{~m}$ \\
\hline Homzontre Acoutacy & $2 \mathrm{~m}$ \\
\hline Yertical Acturacy & $1 \mathrm{~m}$ \\
\hline
\end{tabular}

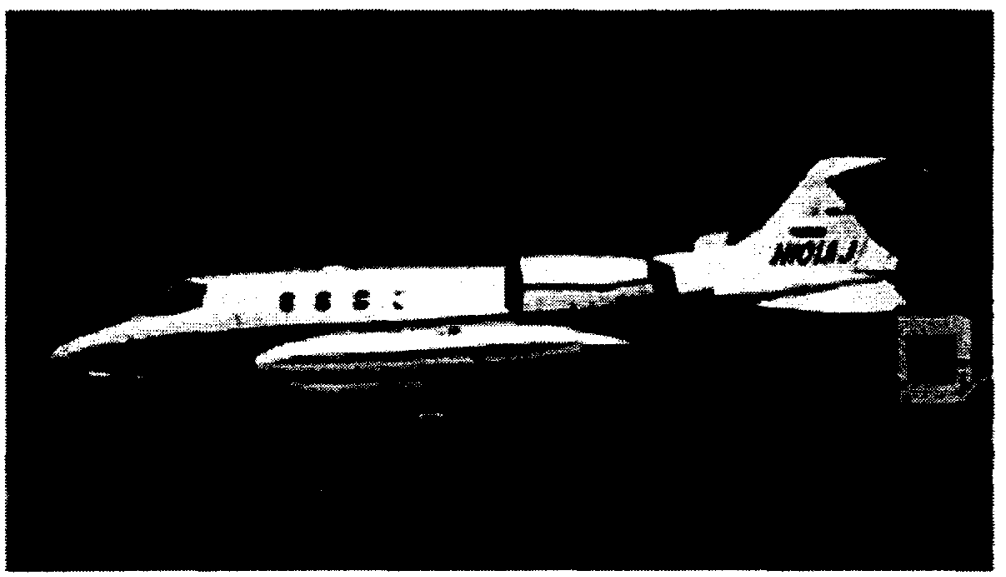

Figure 22. Intermap InSAR specifications for the data used in this research. Typical swath is $10 \mathrm{~km}$ wide and $1200 \mathrm{~km}$ long, allowing for the collection of two flight lines per sortie (approximately 5 hours in the air).

Under the author's supervision, the InSAR data were interferometrically processed (IP) by Intermap's IP specialists using proprietary software that included averaging of multiple InSAR flight lines (from overlapping flight lines and tie lines) where possible, and filtering of the interferogram to reduce phase noise using a Guassian filter. Reference ground elevation points were used as seed points to assist with pahse unwrapping, to provide elevations that link ground elevations to the interferogram. This process created InSAR data that required merging and editing to produce the final NEXTMap DSM and DTM products with a $5 \mathrm{~m}$ ground sampling distance (GSD) in grid 
format using horizontal datum NAD83, geoid Geoid99 and georeferenced to latitude and longitude in decimal degrees and seconds. Edge matching was performed using elevations of tie lines (Figure 23, blue strips), which run perpendicular to the primary flight lines, and are collected as reference elevation data. The primarily flight line strip data (Figure 23, orange and green strips) were adjusted to match the elevations of the tie line and the edge of the adjacent primary flight line strip data. Intermap performed quality assurance checks on the NEXTMap data.

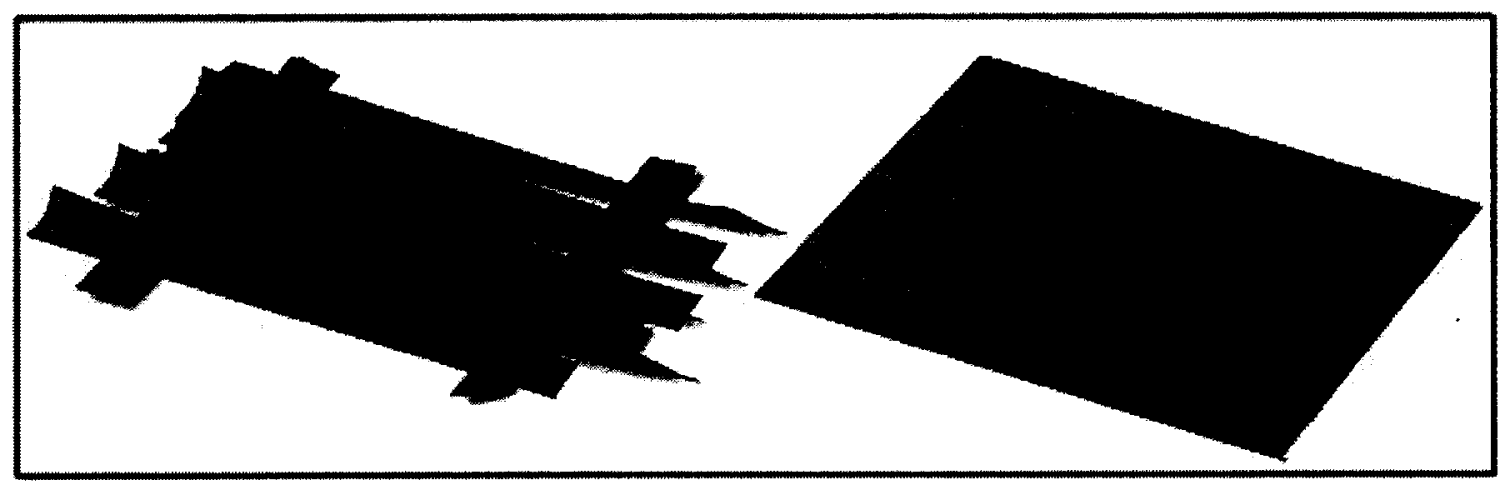

Figure 23. NEXTMap X-HH InSAR DSM data collection of primary (green and orange single take data strips) and tie (blue single take strips) flight line strips that are merged to derived the final DSM given in the right mosaic.

DSM data editing, required to produce the commercial NEXTMap products used in this research, was conducted by Intermap and included the following steps. DSM data were cut into manageable sizes, on the order of 7.5 " tiles, which are the standard map area used by the USGS that cover approximately $150 \mathrm{~km} \times 150 \mathrm{~km}$. Each tile elevation point ( $5 \mathrm{~m}$ posting) is the average of all elevations derived from the overlapping data acquisitions for that point. Spikes (anomalous high elevation values) and wells (anomalous low elevation values) in the DSM data were removed if their difference with 
surrounding elevations exceeded $25 \mathrm{~m}$. All voids in the data were populated with tie line and / or overlapping flight-line data where possible, and recalculated using NED ancillary data (data are tied and warped to the DSM bare ground), or interpolated where no ancillary data were available. All water bodies were smoothed to the elevation of the surrounding shoreline. For example, lakes of $400 \mathrm{~m}$ or more in length were flattened and set to a constant elevation. Single line streams up to $20 \mathrm{~m}$ in width were delineated using $3 \mathrm{D}$ vectors, whereas double line streams greater than $20 \mathrm{~m}$ wide were collected as $3 \mathrm{D}$ polygons. Both types of streams were stepped down in height to match the surrounding water levels to maintain monotonicity (e.g. water flowing downstream).

Additional processing was applied to create the digital terrain model (DTM) where elevations of features such as vegetation and buildings were removed, based on a set of edit rules described in the Intermap Handbook (Intermap, 2011). The DTM in barren areas had been "smoothed" using proprietary three dimensional editing tools to remove noise (up to $30 \mathrm{~cm}$ ) in the DSM data. The DSM and DTM data have a specification of $1 \mathrm{~m}$ vertical RMSE in regions of flat to moderate slope in unobstructed terrain (Intermap, 2011), however, these data have not been evaluated in vegetated cover and on slopes greater than 10 degrees (part of this research). The NEXTMap DSM and DTM data for all sites were received as 32-bit floating $5 \mathrm{~m}$ ground sample distance posted grids in geographic coordinates. They were accompanied by Orthorectified Radar Images (ORIs) showing backscatter magnitude. The InSAR DSM was used to orthorectify the SAR imagery (Madsen et al., 1993; Rosen et al., 1994). The ORI has a final pixel size of $1.25 \mathrm{~m}$ (in range and azimuth) and an estimated horizontal RMSE of $2 \mathrm{~m}$ under test conditions in which corner reflectors are deployed in flat, unobstructed areas 
and their coordinates precisely measured using differential GPS techniques (Intermap, 2011). The ORI was received as an 8-bit magnitude GeoTIFF image in geographic coordinates.

The non-commercial raw unedited X-HH InSAR DSM data, hereafter referred to as the single take X-HH InSAR data (Table 3), for the primary flight lines covering each site, but Morrison (these data were not recoverable from the vendor) were also obtained for all research sites. Each primary flight line, or strip of data represented elevation data from a single flight, thus there was no merging of the DSM data from multiple flights lines (Figure 21). Furthermore, the single take InSAR maintain the range of incidence angles across swath (e.g. from NR to FR), which is lost in the multi-takes InSAR data. The single take data were important to include in this research to test the inherent accuracy of the InSAR DSM without the added merging of DSM data from overlapping flight lines and DSM editing as described above (Section 3.2.1) and to determine if incidence angle ranges affected the vertical accuracy of the derived canopy height. These tests were conducted against the in situ (US sites), National geodetic survey (NGS; U.S, sites), and LiDAR (U.S. and Canadian Sites) bare ground reference measurements and tree height measurements.

\subsubsection{C-HH InSAR - SRTM}

The Shuttle Radar Topography Mission (SRTM) C-HH InSAR data were selected for this research because the SRTM program is another source of large area InSAR data. DSMs generated from these data have been found to have accuracies that may be suitable for distinguishing broad vegetation height classes representative of ground 
vegetation/none, shrubs/small trees, and mature forest (Kellndorfer et al., 2004; Walker et al., 2007; Sexton et al., 2009).

The SRTM sensor (C-Band) was flown on board the Space Shuttle Endeavour during mission STS-99 (Figure 24). It was a single InSAR mission that operated from February 11-22, 2000, making it the world's first and to-date only single-pass spaceborne InSAR to acquire spatially-continuous elevation information over $80 \%$ of the Earth's land mass (Rabus et al., 2003). SRTM utilized two SAR antennae with a fixed-baseline of 60 $\mathrm{m}$ at an altitude of $233 \mathrm{~km}$ and an orbit inclination angle of $57^{\circ}$, collecting data between $60^{\circ} \mathrm{N}$ and $57^{\circ} \mathrm{S}$ lines of latitude (Hensley et al., 2000). The C-band antennae were operated in two-beam ScanSAR mode (Bamler and Just, 1993) such that four narrow but overlapping sub-swaths were generated sequentially with incidence angles ranging between $30^{\circ}$ and $60^{\circ}$ (Hensley et al., 2000). Of the Earth's land mass covered by SRTM, 99.97\% was mapped with at least one Shuttle overpass, $94.59 \%$ with at least two passes, $49.25 \%$ with at least three passes, and $24.10 \%$ with at least four passes. The C-band InSAR data were interferometrically processed by the Jet Propulsion Laboratory (JPL, Pasadena (A) and made available to the public via the National Map Seamless Data Distribution System administered by the USGS (http://seamless.usgs.gov). The interferometric processing included averaging of multiple data acquisitions where possible, and filtering of the interferogram to reduce phase noise and improve the phase unwrapping process (Hensley et al., 2000; Smith and Sandwell, 2003).

Similar DSM finishing techniques performed on the X-HH InSAR data provided by Intermap were performed on the SRTM data. The SRTM data were segmented into 1 degree cells (equivalent to 64 of the Intermap 7.5" tiles) comprised of elevations 
generated by averaging all data from the multiple passes that fell within that cell. The National Geospatial-Intelligence Agency (NGA) performed the quality assurance checks and carried out several additional editing steps (Slater et al., 2006). First, spikes and wells were removed if they exceeded $100 \mathrm{~m}$ compared to surrounding elevations. Second, small voids (16 contiguous posts or less) were filled by interpolation of surrounding elevations. Large voids were left in the data. Third, the ocean elevation was set to $0 \mathrm{~m}$, lakes of 600 $\mathrm{m}$ or more in length were flattened and set to a constant height, rivers over $183 \mathrm{~m}$ wide were delineated and monotonically stepped down in height, and islands were depicted if they had a major axis exceeding $300 \mathrm{~m}$ or their relief was greater than $15 \mathrm{~m}$. The C-band DSM in the United States has a $30 \mathrm{~m}$ ground sampling distance (GSD) and a $90 \mathrm{~m}$ GSD in Canada, both with specifications of $16 \mathrm{~m}$ absolute vertical height accuracy, a $10 \mathrm{~m}$ relative vertical height accuracy (at a local scale of ca. $200 \mathrm{~km}$ ), and $20 \mathrm{~m}$ absolute horizontal accuracy, all at the $90 \%$ confidence level (Rabus et al., 2003; Smith and Sandwell, 2003; Rosen et al., 2001a, 2001b).

\begin{tabular}{ll}
\hline Sensor & SRTM \\
Platform & Space Shuttle STS-99 \\
Flying Height & $233 \mathrm{~km}$ \\
Wavelength & $5.8 \mathrm{~cm} \mathrm{C-Band}$ \\
Frequency & $5.3 \mathrm{GHz}$ \\
Polarization & $\mathrm{HH}$ \\
Interferometric & $60 \mathrm{~m}$ \\
Baseline & $57^{\circ}$ \\
Incidence Angle & $30 \mathrm{~m} \mathrm{U}$. S.; $90 \mathrm{~m}$ World \\
DSM/DTM Posting & $30 \mathrm{~m} \mathrm{U}$. S.; $90 \mathrm{~m}$ World \\
ORI Pixel Size & $16 \mathrm{~m}$ \\
Horizontal Accuracy & $16 \mathrm{~m}$ \\
Vertical Accuracy & 16
\end{tabular}

Figure 24. SRTM single-pass C-HH InSAR platform specifications. This system mapped approximately $80 \%$ of the Earth's landmass in eleven days. 


\subsubsection{L-Quad PolInSAR - TOPOSAR}

In 2007, Intermap Technologies developed the world's first airborne single-pass, fully polarimetric, interferometric sensor (referred to as PollnSAR or Pol-InSAR in the literature) operating in L-Band $(22 \mathrm{~cm}, 1.325 \mathrm{GHz})$ to create bare-earth DTMs and to determine forest canopy heights (Figure 25). This system, called TopoSAR-L, is an adaptation of the TopoSAR System previously described by Maune (2007). TopoSARL's resolution of $1.1 \mathrm{~m}$ in range and $0.5 \mathrm{~m}$ in azimuth allows the derivation of orthorectified images (ORI) with a $1.25 \mathrm{~m}$ posting. Two L-Band logarithmic periodictype antennas (an array of varying length dipole antennas with broadband characteristics where the directional properties of the antenna can be determined) are mounted at the ends of a rigid beam that runs through the aircraft's baggage compartment, forming a geometric baseline of $3.5 \mathrm{~m}$ length when operated in ping-pong mode, where each antenna transmits and receives separately. In addition, a non-ping-pong mode (only one antenna transmits and both receive) adds a second interferometric baseline of $1.75 \mathrm{~m}$.

\begin{tabular}{ll}
\hline Sensor & TOPOSAR \\
Platform & Gulfstream Twin \\
Commander 695
\end{tabular}

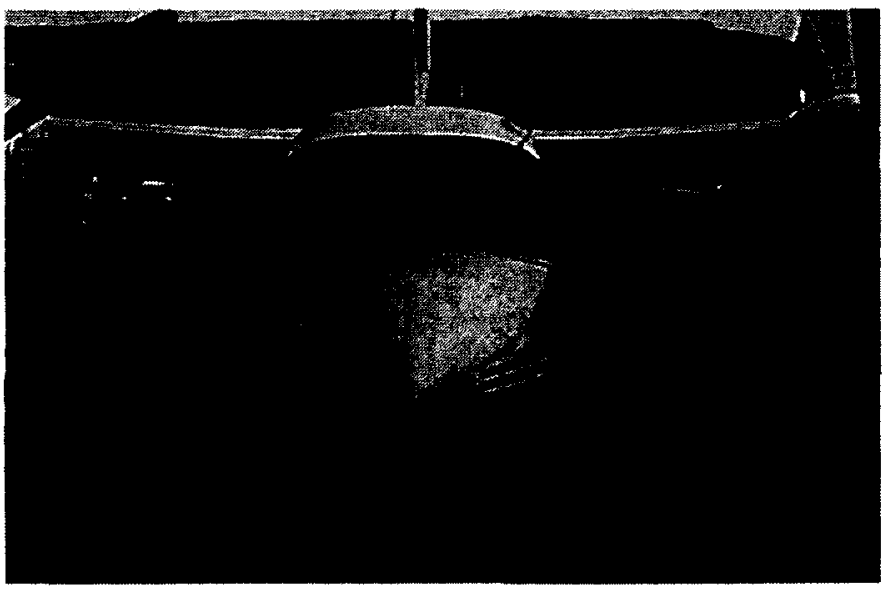

Figure 25. Single-pass L-Quad PollnSAR TOPOSAR platform specifications. Typical swath size is $5 \mathrm{~km}$ wide and $200 \mathrm{~km}$ long. 
As such, the system can effectively be considered a "multi-baseline" sensor which further increases its sensitivity with respect to penetration, as shorter baselines will penetrate vegetation more than longer baselines (Mercer et al., 2009a; 2009b). 32-bit floating $5 \mathrm{~m}$ posted DSM and DTM data in geographic coordinates were created for the Alberta research sites only, as described in sedtion 2.4. The DTM data underwent editing such as water body flattening, removal of spikes and wells, etc., that were applied to the $\mathrm{X}-\mathrm{HH}$ InSAR (NEXTMap) as described is Section 3.2.1. .

\subsection{Ancillary Data}

There were a number of additional data sets (referred to as ancillary data sets) over the research analyzed and thus utilized in this research. The list of the ancillary data sets (Table 4) utilized in this research and the processing techniques performed on each are described in detail in the following sections. These data sets were used to compare with the research results for the multi-frequency InSAR and PolInSAR derived vegetation classification and canopy height estimates presented in Chapter 4. Ideally, the in situ, NGS survey, and LiDAR reference data, as well as the ancillary data sets should be should be collected at or near the same dates and under the same conditions as the InSAR/PolInSAR data to mitigate the effects of temporal differences between datasets being compared. In reality, however, these ideal conditions are rare, and not possible for this research. The impact of the differences in data collection dates is addressed in Chapters 5 (Results) and 6 (Discussion. To partially compensate for the lack of ideally collocated data sets, observations used for comparisons to the airborne sensors, which was the focus of this research, are limited to those that are within a few months and of high to medium resolution. 
Table 4. Ancillary data available for given research sites.

\begin{tabular}{|c|c|c|}
\hline Ancillary Data & Data Products & Research Site \\
\hline $\begin{array}{l}\text { National Land Cover } \\
\text { Database (NLCD) }\end{array}$ & $\begin{array}{l}\text { National Land cover classification } \\
\text { Pixel: } 30 \mathrm{~m} \text {; 15m RMSE } \\
\text { Horizontal Accuracy: } 15 \mathrm{~m} \text { RMSE }\end{array}$ & $\begin{array}{l}\text { Arizona, Morrison, } \\
\text { International Falls, Ely } \\
(2006)\end{array}$ \\
\hline $\begin{array}{l}\text { LANDFIRE Canopy } \\
\text { Height }\end{array}$ & $\begin{array}{l}\text { Product: Canopy Height Models } \\
\text { Posting: } 30 \mathrm{~m} \\
\text { Vertical accuracy: not published } \\
\text { Horizontal accuracy: not published }\end{array}$ & $\begin{array}{l}\text { Arizona, Morrison, } \\
\text { International Falls, Ely } \\
(2001)\end{array}$ \\
\hline $\begin{array}{l}\text { National Geodetic } \\
\text { Survey (NGS) }\end{array}$ & $\begin{array}{l}\text { Product: X, Y, Z reference point } \\
41,322 \text { Survey Grade irregularly } \\
\text { spaced points } \\
\text { Vertical accuracy: } 30 \mathrm{~cm} \text { RMSE } \\
\text { Horizontal accuracy: } 15 \mathrm{~cm} \text { RMSE }\end{array}$ & $\begin{array}{l}\text { Arizona, Morrison, } \\
\text { International Falls, Ely } \\
(1999-2009)\end{array}$ \\
\hline $\begin{array}{l}\text { US National } \\
\text { Elevation Dataset } \\
\text { (NED) }\end{array}$ & $\begin{array}{l}\text { Product: Digital Terrain Model } \\
\text { Posting: } 10-30 \mathrm{~m} \\
\text { Vertical Accuracy: } 2.4-7.3 \mathrm{~m} \text { RMSE }\end{array}$ & $\begin{array}{l}\text { Arizona, Morrison, } \\
\text { International Falls, Ely } \\
(1975-2007)\end{array}$ \\
\hline LiDAR Data & $\begin{array}{l}\text { Product: Digital Terrain Model \& } \\
\text { Digital Surface Model } \\
\text { Posting: } 2 \mathrm{~m} \\
\text { Vertical accuracy: } 20 \mathrm{~cm} \\
\text { Horizontal accuracy: } 30 \mathrm{~cm}\end{array}$ & $\begin{array}{l}\text { Arizona, Morrison, } \\
\text { International Falls, } \\
\text { Ely, Burnstick Lake, } \\
\text { Edson (2007) }\end{array}$ \\
\hline $\begin{array}{l}\text { Optical Aerial } \\
\text { Imagery }\end{array}$ & $\begin{array}{l}\text { Product: Orthorectified Aerial } \\
\text { Imagery } \\
\text { Pixel: } 2 \mathrm{~m} \\
\text { Horizontal accuracy: } 2 \mathrm{~m}\end{array}$ & \begin{tabular}{|l} 
Burnstick Lake \\
(2008), Edson (2007)
\end{tabular} \\
\hline $\begin{array}{l}\text { National Agriculture } \\
\text { Imagery Program } \\
\text { (NAIP) }\end{array}$ & $\begin{array}{l}\text { Product: Orthorectified Aerial } \\
\text { Imagery } \\
\text { Pixel: } 1 \mathrm{~m} \\
\text { Horizontal accuracy: } 1 \mathrm{~m}\end{array}$ & $\begin{array}{l}\text { Arizona, Morrison, } \\
\text { International Falls, Ely } \\
(2007)\end{array}$ \\
\hline
\end{tabular}

\subsubsection{National Land Cover Database (NLCD)}

The 2006 USGS National Land Cover Data (called NLCD2006) is the current land cover data set available for all the U.S. sites (Fry et al., 2011). They were generated 
from 2006 Landsat 5 and 7 data and consist of sixteen land cover classes and 10 canopy closure (vegetation density) classes at a $30 \mathrm{~m}$ pixel size. NLCD2006 is based primarily on the unsupervised classification of Landsat Enhanced Thematic Mapper+ (ETM+) 2006 satellite data (Fry et al., 2011). Full class descriptions were published in Homer et al. (2004; 2007). A formal accuracy assessment of the NLCD2006 land cover change product is planned for 2011. The NLCDs for each research site were downloaded. This data set was compared to the $2007 \mathrm{X}-\mathrm{HH}$ InSAR derived land cover classification presented in this research.

\subsubsection{LANDFIRE Canopy Height}

LANDFIRE is a multi-agency project to provide spatially explicit forest fuel characteristics for fire modeling purposes. The LANDFIRE program generated canopy height data across the conterminous United States using the same mapping zone approach as NLCD (i.e. $30 \mathrm{~m}$ grid; Ryan et al., 2006; LANDFIRE, 2010). Canopy height for the dominant vegetation within a $30 \mathrm{~m}$ grid size cell is recorded in the Existing Vegetation Height (EVH) layer. The canopy height is generated separately for tree, shrub, and herbaceous vegetation using training data and other layers. EVH is determined by the average height weighted by species cover and based on the existing vegetation type (EVT). Decision tree models using field reference data and Landsat, elevation, and ancillary data are developed separately for each life form. Decision tree relationships are used to generate vegetation specific height class layers, which are merged into a single composite EVH layer. The LANDFIRE elevation models were downloaded for all U.S. sites. This data set, collected in 2001, was considered a good match with the C-HH SRTM data collected in 2000 , however, given that the X-HH InSAR data were acquired 
in 2007 and 2008, temporal differences in vegetation are expected to play a role in the comparison of the LANDFIRE data with the derived canopy height estimates presented in this research.

\subsubsection{National Geodetic Survey (NGS)}

The National Geodetic Survey (NGS) provides the public with survey-grade control information such as latitude, longitude, height, and quality of the survey reference point across the United States with a vertical accuracy of $30 \mathrm{~cm}$ (NOAA, 2011). 41,322 NGS points were available across the conterminous states and used in accuracy assessment of the X-HH InSAR DTM data as illustrated in Figure 26.

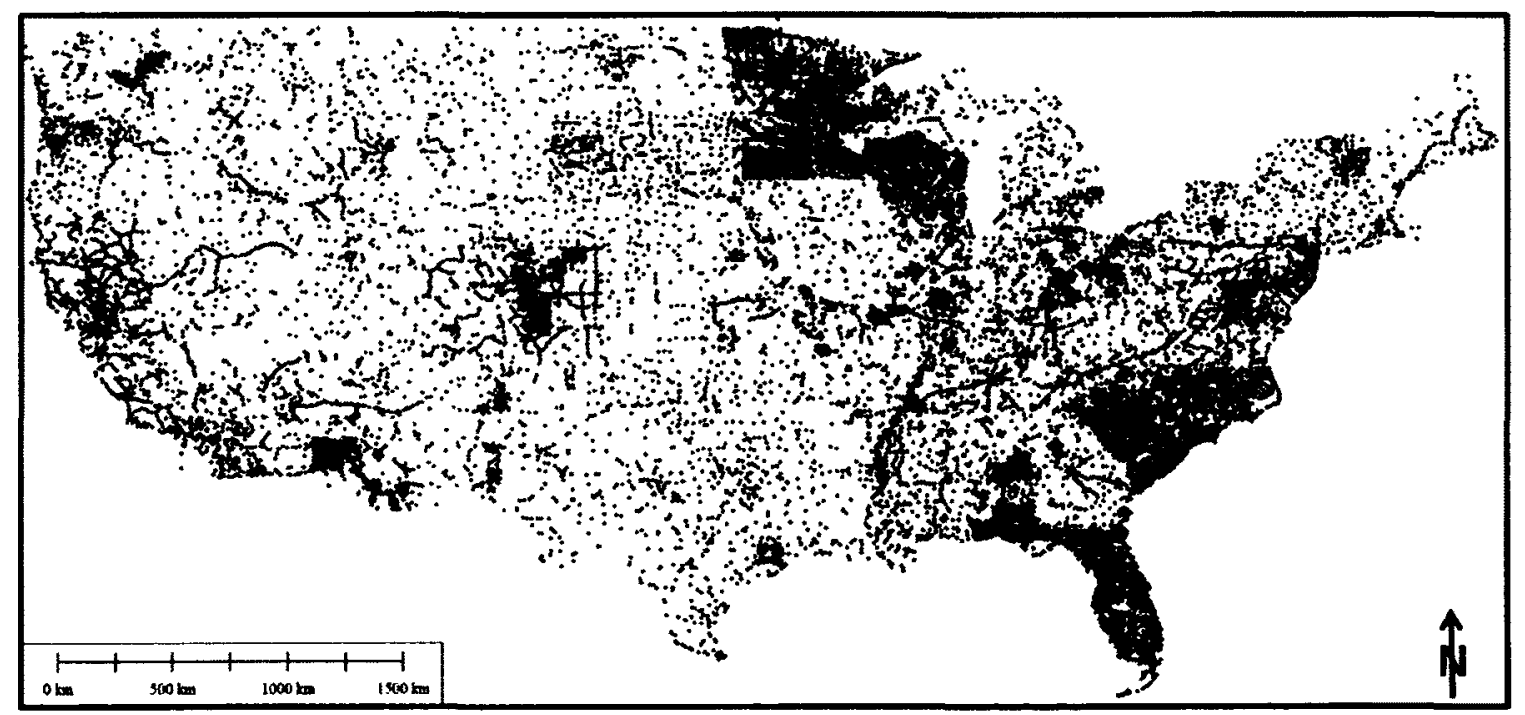

Figure 26. Distribution of the 41,322 US National Geodectic Survey points (NGS, 2003).

The extents of each of the four U.S. research sites were used to extract validation points representing bare ground elevations in barren and vegetated land cover from the NGS database of 41,322 points (Figure 26; NGS, 2003). A total of 313 NGS points (39- 
Ely; 14 - International Falls; 89 - Arizona; 171 - Morrison) fell within the research site extents. These data sets were used to assess the vertical accuracy of the InSAR and PolInSAR DEMs.

\subsubsection{US National Elevation Dataset (NED)}

The United States National Elevation Data (NED) is a DTM (representing bare ground elevations) in geographic co-ordinates which, for the conterminous U.S. The NED data have a horizontal datum of NAD83, a vertical datum of NAVD88, a resolution of $10 \mathrm{~m}$ and $30 \mathrm{~m}$, and a specified accuracy of $2.4 \mathrm{~m}$ to $7.3 \mathrm{~m}$ RMSE (U.S. Geological Survey, 2004; Gesch et al., 2002; Carabajal and Harding, 2005; 2006).

The NED database is the result of the maturation of the USGS effort to provide 1:24,000-scale DTM data for the conterminous U.S. NED is a dynamic dataset that is updated bimonthly to incorporate the best available (e.g. aerial photo, contour maps, LiDAR, etc.) Digital elevation data, which were reorganized and combined into a seamless dataset designed to cover all United States territory. As more 1/3 arc second (10 m) data coverage is obtained it is integrated into the dataset. Comparing NED data with NGS geodetic control points, the overall absolute vertical accuracy was found to be 2.44 m RMSE (NED, 2011); i.e., much better than the expected accuracy given above. The NED data across the United States ranged in age, with a mean age of 25 years. The variation in age differences between the NED and the X-HH/C-HH InSAR data may contribute to the differences in the vertical accuracy assessments presented in this research, as discussed further in Chapters 5 and 6 . Nonetheless, the NED dataset is widely used and thus deemed to be worthwhile to compare against the X-HH InSAR DTM data of this research. 


\subsubsection{LiDAR Data}

LiDAR data for the two Canadian sites were collected by Terrapoint Inc. using its Mid-Range LiDAR system. It is a $2 \mathrm{D}$ laser scanner that produces $8-20$ points $/ \mathrm{m}^{2}$ coverage with stated $95 \%$ confidence vertical accuracy of $0.20 \mathrm{~m}$ on vegetated surfaces and $0.30 \mathrm{~m}$ horizontal accuracy over flat to rolling terrain, which was the case for these research sites (Terrapoint, 2010). The bare ground DTM data were provided as a $2 \mathrm{~m}$ posting 32-bit floating grid. The $1 \mathrm{~m}$ posting original LiDAR point cloud data were also processed by Intermap to derive a DSM by taking the highest point within a $5.6 \mathrm{~m}$ search radius, representing canopy height. This DSM was then resampled to $2 \mathrm{~m}$ posting to correspond with the LiDAR DTM. Three hundred and seventy-two points (181 - Edson; 191 - Burnstick Lake) were extracted from the LiDAR DSM to compare to the InSAR derived canopy height estimates.

LiDAR data for portions of the Ely, International Falls, and Arizona sites became available in 2009 by the United States Geological Survey (USGS; http://nationalmap.usgs.gov). These data were visually inspected for completeness to ensure that any gaps between flight lines or loss of signal represented less than $5 \%$ of required collection area. Areas of open water with a corresponding signal loss were corrected to the best estimate of water level at time of collection. The vertical accuracy of the LiDAR data was tested by the USGS, showing that for a total of 85 control points within the research sites listed above, the average error between the bare earth LiDAR coverage and the control was $-0.005 \mathrm{~m}$ with a RMSE of $0.11 \mathrm{~m}$. The addition of these LiDAR data allowed for collection of additional bare ground measurements within barren 
and vegetated land cover for use as reference data in the X-HH InSAR derived DTM assessment.

\subsubsection{Optical Aerial Photography}

Colour aerial photos were available for the two Alberta research sites and used to verify the land cover classification. The Edson imagery was collected in September 2007 with a $0.4 \mathrm{~m}$ pixel size (Valtus, 2008). This imagery was collected at approximately the same time as the LiDAR, X-HH band InSAR, and L-band PolInSAR data, and thus, was deemed suitable to compare to the X-HH InSAR derived land cover classification and the X-, C-, and L-band derived canopy height estimations. The Burnstick imagery was collected in April 2008 with a $0.5 \mathrm{~m}$ pixel size (Valtus, 2008). There were a change in vegetation cover from the time of InSAR/PolInSAR data and aerial imagery data collections, which is discussed further in the Results and Discussions Chapters.

\subsubsection{National Agriculture Image Program (NAIP) Imagery}

Under the United States National Agriculture Imagery Program (NAIP) digital ortho-aerial imagery during the agricultural growing seasons in the continental U.S. is collected (NAIP, 2011). This imagery is made available to the public within one year of collection. It is collected during "leaf-on" time periods at $1 \mathrm{~m}$ GSD with a horizontal accuracy that matches within six meters of photo-identifiable ground control points, which are used during image inspection. All imagery is inspected for horizontal accuracy and tonal quality. Natural colour (Red, Green and Blue, or RGB) 2007 NAIP imagery in .UTM coordinates and NAD 83 datum were acquired for the continental United States to assist in classification of the NGS reference points and in selection of field plot locations. This imagery was collected at approximately the same time as the X-HH band InSAR and 
the field data and thus suitable to compare to the X-HH InSAR derived land cover classification and CHMs.

\subsection{Summary}

This chapter presented an overview of the six research sites emphasizing the physical characteristics of each site and why they were selected for this research. The six sites covered arid, semi-arid, temperate, and Boreal transition ecozones providing a unique opportunity to assess the applicability of the proposed vegetation type and canopy height estimation method over varied eco-regions. The research sites also varied in topography from flat to undulating low-lying landscapes to mountains which also allowed for testing of the applicability of the presented methods over varied terrain conditions. Finally, the presence of five vegetation classes across the research sites allowed for testing of the applicability of the presented methods over varied vegetation types. The rich data sets, diverse vegetation types, varied terrain conditions, and diverse eco-regions provided a unique opportunity to conduct multiple comparative analyses between research sites, vegetation types, and data types, which has been lacking in the literature. 


\section{CHAPTER FOUR: METHODS}

This chapter describes the methodology carried out to meet the three research objectives outlined in Chapter one. The methodology was divided into five phases discussed in detail in subsequent sections, 4.1) reference data collection, 4.2) InSAR and PollnSAR DTM assessment, 4.3) InSAR and PolInSAR $h_{\text {spc }}$ assessment, 4.4) development of method for canopy height estimation, and 4.5) canopy height estimation performance assessment.

\subsection{Reference Data Collection}

The reference data collection and processing for field plots, NGS, and LiDAR data used in assessment of the DTMs are explained in sections 4.1.1.- 4.1.3 and in Tables 5 -7. These data were used to assess the derived vegetation cover maps and canopy height estimates derived from InSAR and PolInSAR data, as described in Chapter 3.

\subsubsection{Field Plot Installation - U.S. Sites}

Field programs for the Arizona, Minnesota (Ely, International Falls), and Colorado sites were conducted in February-March 2008, July-August 2008, and February 2007 , respectively. Due to time and budget constraints, field time was limited to 30 days in Arizona, 19 days in Minnesota, and 4 days in Colorado. Variations in the time spent in the field resulted in different area bounds for each site. Moreover, the Arizona site had the largest number of plot installations compared to the other U. S. sites due to available resources. Field data collection was not conducted over the Canadian sites due to the availability of LiDAR data, which was comparable in accuracy to the U.S. in situ data.

There were temporal differences between the field collections, NGS data, InSAR/PolInSAR/LiDAR data acquisitions, and ancillary data dates. The time elapsed 
between the field data/LiDAR reference data and the airborne X-HH InSAR and L-Quad PolInSAR data collections was approximately 2, 3, 5, and 10 months for the two Alberta sites, the Colorado site, the Arizona site, and the two Minnesota sites, respectively. While it is best to have the field collections conducted at the same time as the remotely sensed data collections, the time separation between the field and InSAR data collections was not considered to be important.

The NGS data (representing bare ground elevations) collection dates, however, span the 10 years before the airborne InSAR/PolInSAR data collection dates, which required checking the NGS reference point locations against available 2007 NAIP imagery to ensure that the landscapes were suitable surrounding the NGS reference points. The ancillary photo imagery over the two Alberta sites was 5 years older than the PolInSAR data collections and differences were noted when comparing the derived land classified maps to the photo. This was not a concern because the field data, rather than the photo imagery, were used in the land cover classification methods presented in this research. The greatest separation in time with the field data collections was for the SRTM InSAR data that were acquired in 2000 . Given the focus of this research was on the airborne X-HH InSAR and L-Quad PolInSAR data, and that the C-band data were only compared due to their availability globally, corrections to account for vegetation growth from 2000, when SRTM data were collected, to 2007 were not considered.

The goals of the field program were to: (1) acquire survey-grade, bare-ground elevation measurements in open areas and beneath vegetation canopy to serve as reference data for accuracy assessment of InSAR derived DTMs, (2) measure tree and shrub canopy heights to serve as reference data for the accuracy assessment of the InSAR 
derived canopy height estimates, and (3) inventory vegetation type to serve as reference data for the accuracy assessment of the InSAR derived vegetation cover maps.

The NLCD, NAIP, NGS reference points, and NEXTMap X-HH InSAR DTM data were utilized to select candidate field plot locations that were modified in the field to non-random locations within $100 \mathrm{~m}$ of roads for easy access (Figures $16-21$ ). This allowed for quick inventory and measurement, and provided a larger number of plot samples than would have been possible through random selection. Based on visual assessment, selected plot locations were uniform in vegetation cover and species and representative of their assigned class (Table 2) over a circular area of approximately 2830 $\mathrm{m}^{2}$ (30 m radius).Photos of representative vegetation classes are presented in Figure 27. Directional photographs were collected to provide insight into the view of the sky to the GPS antenna, and the surrounding vegetation cover (Figure 28).

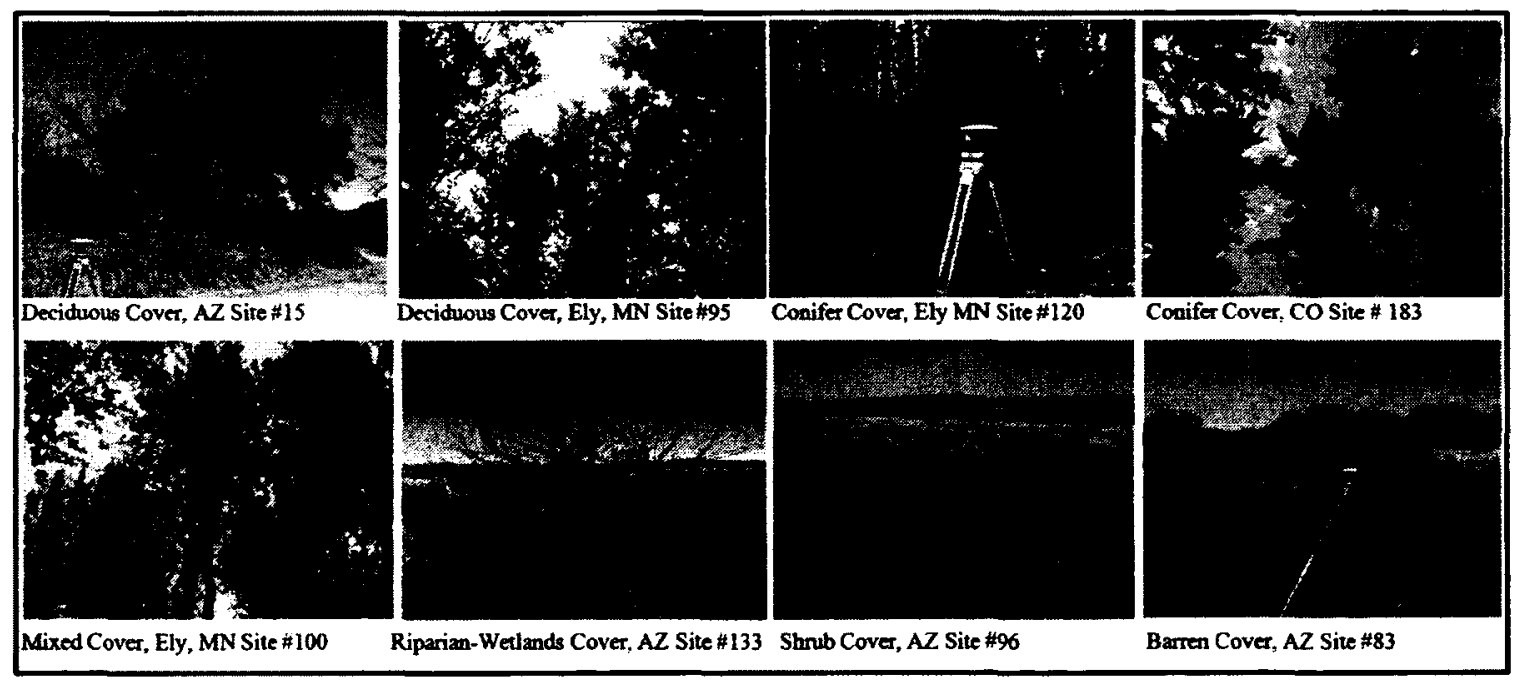

Figure 27. Photographs of the field plot conditions for the five vegetation types investigated in this research. 


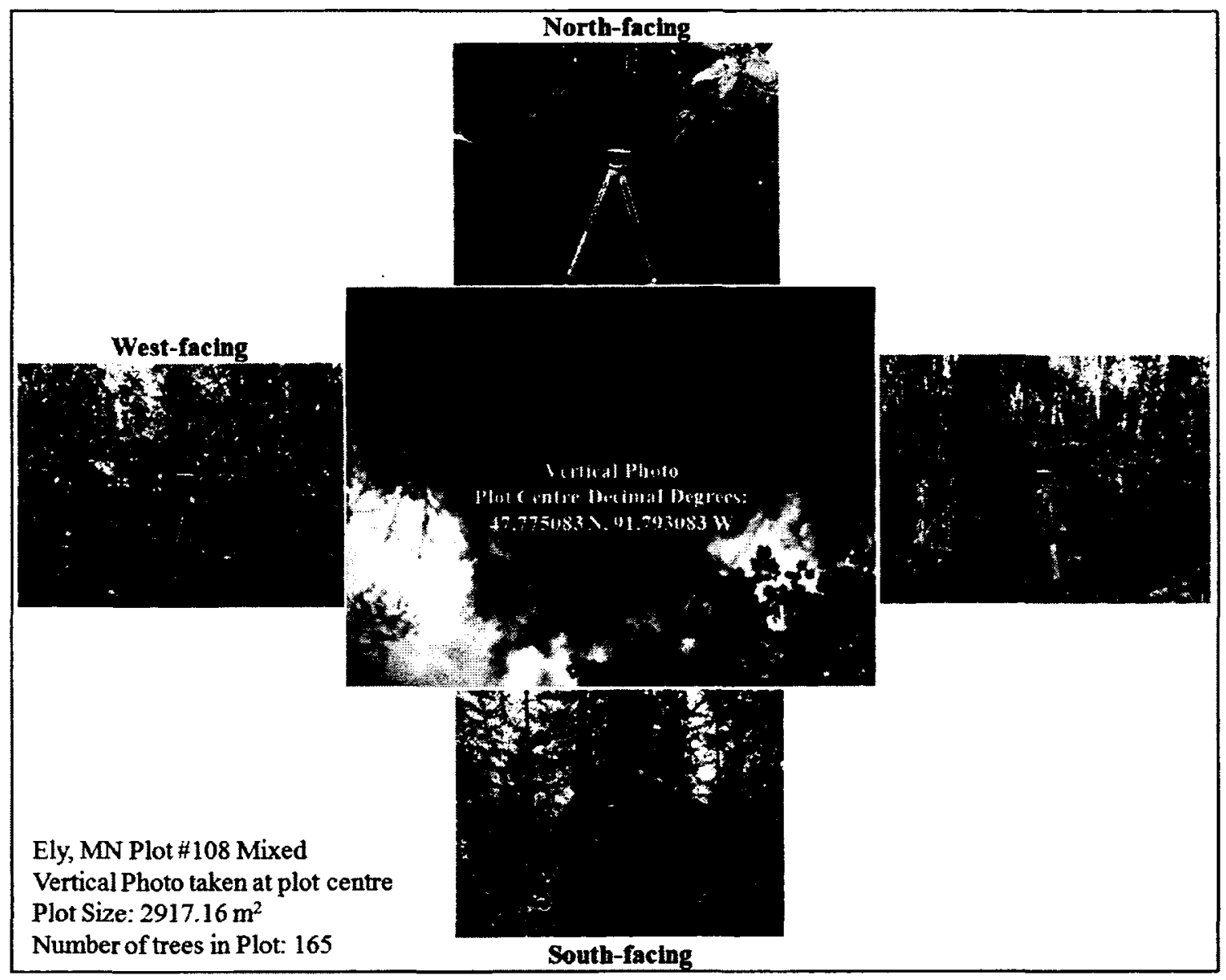

Figure 28. Sample field plot directional photographs for the north, south, east, and west facing locations.

A centre coordinate for each planned plot was loaded in a handheld Leica 500, dual-frequency L1/L2 survey-grade Global Positioning System (GPS) receiver to navigate to the location. This was paired with a Leica AT502 antenna and a surveyor tripod GPS system and used in the field to measure the final selected centre coordinates. Real-time kinematic GPS (RTK-GPS), which delivers instantaneous point coordinates with centimeter-level accuracy, was used to collect the bare ground measurements (Dominy and Duncan. 2001.). The RTK positioning uses a static GPS receiver as a reference station located at a known point (Farrell et al., 1999). Another receiver was 
used as the rover to collect the survey measurement at the location of interest. The logging rate of the GPS antenna was set to 30 seconds with a minimum occupation time of 5 minutes. This process is more efficient when two people are conducting the survey. Both receivers make observations of the GPS signals at the same time and a radio data link between the two receivers permits data to be sent from the reference to rover, where the calculation of coordinates ( $\mathrm{x}, \mathrm{y}$, and $\mathrm{z}$ location) is carried out. Expected vertical accuracy of this setup was 10-20 cm (Dominy and Duncan. 2001).

In the vegetated plot sites, one receiver was used and the GPS antenna was attached to the top of a $2 \mathrm{~m}$ pole, which allowed it to communicate with satellites that were lower on the horizon. The logging rate was set at 30 seconds, with a minimum occupation time of 15 minutes for each measured point. This process required the GPS measurements to be differentially post-processed. In addition, extending the time of data collection in vegetated land cover, the GPS antenna was positioned in canopy gaps, when possible, to provide better results (Weilin et al., 2008).

A vertical accuracy of $10 \mathrm{~cm}$ for the plot centre in shrub and medium-dense forest, and $10-30 \mathrm{~cm}$ in dense forest, based on testing against other survey reference pins, was achieved. The horizontal accuracy was better than $50 \mathrm{~cm}$ regardless of the vegetation class based on testing against NGS data. For each plot, a thorough documentation procedure was followed. Metadata included point number, location, directions to point, and references to the point (for finding and/or re-establishment if so required). The overstory vegetation cover for the dominant vegetation classes (Table 2) within the circular plots was visually estimated in $10 \%$ intervals to assist in the validation of the InSAR-derived vegetation type analysis. Table 5 provides the number of bare 
ground in situ GPS measurement locations, LiDAR reference measurements, and NGS reference points stratified by vegetation class for all research sites.

Table 5. Number of in situ, NGS, and LiDAR reference bare ground measurement locations per vegetation type and research site.

\begin{tabular}{|r|r|r|r|r|r|r|r|}
\hline $\begin{array}{c}\text { Site \& Reference } \\
\text { Type }\end{array}$ & Barren & Shrub & Deciduous & Conifers & Mixed & Wetlands & $\begin{array}{c}\text { Site } \\
\text { Total }\end{array}$ \\
\hline Ely: in situ & 5 & 4 & 4 & 5 & 2 & 0 & \\
\hline NGS & 9 & 7 & 9 & 7 & 7 & 0 & \\
\hline LiDAR & 77 & 78 & 77 & 100 & 75 & 45 & \\
\hline Total & 91 & 89 & 90 & 112 & 84 & 45 & 511 \\
\hline Int. Falls: in situ & 5 & 1 & 2 & 3 & 1 & 1 & \\
\hline NGS & 6 & 5 & 8 & 9 & 5 & 5 & \\
\hline LiDAR & 30 & 30 & 60 & 100 & 55 & 65 & \\
\hline Total & 41 & 36 & 70 & 112 & 61 & 71 & 391 \\
\hline NGS & 12 & 11 & 25 & 30 & 25 & 30 & \\
\hline Lridona: in situ & 20 & 35 & 9 & 6 & 12 & 12 & \\
\hline Total & 100 & 250 & 122 & 100 & 122 & 100 & \\
\hline NGS & 296 & 156 & 136 & 159 & 142 & 1021 \\
\hline Morrison: in situ & 5 & 2 & 2 & 2 & 2 & 0 & \\
\hline NiDAR & 100 & 150 & 150 & 100 & 150 & 60 & \\
\hline Total & 114 & 159 & 163 & 111 & 169 & 75 & 791 \\
\hline Edson LiDAR & 100 & 0 & 50 & 45 & 54 & 0 & 249 \\
\hline $\begin{array}{r}\text { Burnstick Lake } \\
\text { LiDAR }\end{array}$ & 100 & 0 & 50 & 64 & 54 & 60 & 328 \\
\hline Reference Total & 578 & 580 & 579 & 580 & 581 & 393 & 3291 \\
\hline
\end{tabular}

Subplots of $15 \mathrm{~m}$ radius within the main plots were used for measurement of dominant tree heights, diameter at breast height (DBH) and the number of trees within the plot (Table 6). Subplot centre positions were measured using the same survey-grade GPS as described in section 4.1.1. Tree and shrub canopy heights were measured with an 
Abney hand spirit level or clinometer with an expected accuracy of better than $0.5 \mathrm{~m}$ (e.g. $2.5 \%$ for a $20 \mathrm{~m}$ tree height) when the observer has a clear view of the tree being measured (Dominy and Duncan. 2001; Neil, 2005; Abney, 2007). Mean canopy height was taken as the average of the measured tree heights for three trees within each subplot. The subplot coordinates $(x, y, z)$ were taken as the centre location for the three trees and used to represent the canopy height measurements for assessment of the vertical accuracy of the InSAR derived canopy height (Sections 4.3 and 4.5). The number of tree heights per research site stratified by vegetation type is presented in Table 6 .

Table 6. Number of tree height observations per vegetation class for the six sites.

\begin{tabular}{|l|r|r|r|r|r|r|r|}
\hline \multicolumn{1}{|c|}{ Site } & Reference & Shrub & Deciduous & Conifers & Mixed & Wetlands & Total \\
\hline Ely & in situ & 24 & 126 & 150 & 24 & 0 & 324 \\
\hline Inter. Falls & in situ & 24 & 66 & 36 & 36 & 18 & 180 \\
\hline Arizona & in situ & 648 & 66 & 96 & 36 & 162 & 1008 \\
\hline Morrison & in situ & 66 & 66 & 36 & 36 & 0 & 204 \\
\hline Edson & LiDAR & 0 & 93 & 293 & 200 & 0 & 586 \\
\hline Burnstick & LiDAR & 0 & 150 & 150 & 150 & 0 & 450 \\
\hline Total & & 762 & 567 & 761 & 482 & 180 & 2752 \\
\hline
\end{tabular}

\subsubsection{NGS Reference Points}

The available NGS reference points, as discussed in Section 3.6.3., were used in combination with the field plot installations to achieve an equal number of bare ground measurements within the shrub, deciduous, conifers, mixed, and wetlands vegetation classes within the U.S. sites. The combined in situ and NGS reference data provided $70-$ 
72 bare ground reference measurements per vegetation type, with the exception of the Wetlands class, with 63 reference measurements (Table 5).

In addition to the research site NGS reference data, there were 73,155 NGS reference points with associated X-HH InSAR NEXTMap derived DTM points for the conterminous United States. This rich data set presented a unique opportunity to assess the vertical accuracy of the X-HH InSAR NEXTMap derived DTM, The NED DTM, and the SRTM InSAR DSM data over a large geographic extent, covering approximately eight million square $\mathrm{km}$. Using the NLCD, each NGS reference point was assigned a land cover type, according to Table 2 (Holmer et al., 2004). Of the 73,155 NGS reference points, 41,322 NGS fell within the barren, shrub, deciduous, conifers, mixed, and wetlands classes. Given that the accuracy of the NLCD is not published, each of the NGS classes was verified using the NAIP imagery and adjusted as necessary. In addition, the NGS reference points were also assigned a slope class as described in 4.2 .4 (Table 7).

Table 7. 41,322 NGS reference points per land cover class and slope class.

\begin{tabular}{|c|r|r|r|r|r|r|}
\hline Slope & Barren & \multicolumn{1}{|c|}{ Shrub } & Deciduous & Conifers & Mixed & Wetlands \\
\hline$\leq 10^{\circ}$ & 25,228 & 2,770 & 1,593 & 1,252 & 1,415 & 1,402 \\
\hline $11-29^{\circ}$ & 2,969 & 928 & 568 & 443 & 499 & 494 \\
\hline$\geq 30^{\circ}$ & 790 & 349 & 187 & 148 & 166 & 121 \\
\hline Total & 28,987 & 4,047 & 2,348 & 1,843 & 2,080 & 2,017 \\
\hline
\end{tabular}

\subsubsection{LiDAR Reference Measurements}

LiDAR bare ground elevation data for all six research sites were utilized as reference measurements for the vertical accuracy assessment of the X-HH InSAR 
NEXTMap DTM and L-Quad PolInSAR DTMs. The number of bare ground LiDAR reference sites per land cover class and per research site is shown in Table 5. The total reference data (3291 in situ + NGS + LiDAR data points) yield a range of 578 - 581 bare ground reference measurements per vegetation type, with the exception of the Wetlands class, which had 393 reference measurements.

High resolution LiDAR first return DSM data with a RMSE vertical accuracy of $10 \mathrm{~cm}$ were available for the two Canadian sites. The $10 \mathrm{~cm}$ RMSE was considered accurate enough for use as tree height reference data. For that reason, field plots were not installed at the Canadian sites. Tree heights (number of height values given in Table 6) for these sites were extracted from the LiDAR DSM - LiDAR DTM (i.e., the LiDAR derived canopy height estimation (CHE)) using eight transects as illustrated in Figures 20 and 21. The transect spacing and sample point spacing along each transect was $100 \mathrm{~m}$ The canopy height at each sample point was extracted from the LiDAR CHE and used as reference data in the accuracy assessment of InSAR derived vegetation scattering phase centre height and canopy height estimates.

\subsection{Research Objective 1: X-HH InSAR and L-Quad PollnSAR Derived DTM Vertical Accuracy Assessments}

The NEXTMap X-HH InSAR DTM data have a published vertical accuracy specification of $1 \mathrm{~m} \mathrm{RMSE}$ in unobstructed areas (e.g. barren land cover) on slopes less than ten degrees (Intermap, 2011). Although satisfactory results for these DTMs have been reported in the literature (e.g., Andersen et al., 2006; Dowman et al., 2003; Downman and Fischer, 2003), a comprehensive X-HH InSAR DTM accuracy assessment in a diverse set of regions with a range of vegetation types and slopes had not been 
conducted. Given the requirement of an accurate DTM for the intended derivation of $h_{\mathrm{spc}}$ as an estimate of canopy height, the vertical accuracy assessment of the InSAR derived DTMs across this range of conditions was made a focus of the initial stage of this research. Moreover, the availability of the world's first single-pass L-Quad PolInSAR derived DTM data over the Canadian sites presented an excellent opportunity to evaluate its vertical accuracy in comparison to LiDAR DTM reference data as this L-Band system does not yet have published vertical accuracy specifications.

The following sections present several accuracy analyses comprised of comparisons of the X-HH InSAR DTM, L-Quad PolInSAR DTM, SRTM C-HH InSAR DSM, and NED DTM against in situ, LiDAR, and NGS reference elevation data. Note: Hereafter, 'DEM' is used as a general term when DTMs (e.g., X-HH InSAR, NED, and L-Quad PolInSAR) and DSM data (e.g., SRTM C-HH) are compared in the same section, table, or figure. Where applicable these analyses included all reference data combined, reference data stratified by vegetation type, and reference data stratified by slope class. Statistics computed in these analyses include the root mean square error (RMSE) and the mean error. The difference between the DEM data and the reference data is the basis for all statistical analysis, as given by the following:

$$
\begin{aligned}
& =\left\lfloor z D E M-z_{\text {reference }}\right\rfloor \\
& x=\left\lfloor z D E M-z_{\text {reference }}\right\rfloor
\end{aligned}
$$

Where:

$z_{\text {DEM }}$ the elevation height for a given $x-y$ location of the DEM being analyzed against the reference data 
$\mathrm{z}_{\text {reference }} \quad$ elevation height for the same $\mathrm{x}-\mathrm{y}$ location in the reference elevation data

When one elevation data set is compared to a reference data set, the root mean square (RMS) of the pairwise difference the two data sets can serve as a measure how far on average the error is from 0 . The RMS error (RMSE) is then the expected vertical error within the estimated InSAR/PolInSAR dataset compared to the reference elevation (e.g. in situ, NGS, and LiDAR reference data). RMSE, as given by equation (12), was computed in all DEM analysis.

$$
x_{R M S}=\sqrt{\frac{x_{1}^{2}+x_{2}^{2}+\ldots \ldots x_{n}^{2}}{n}}
$$

Where:

$$
\begin{array}{ll}
\mathbf{x} & \text { sample point } \\
\mathrm{n} & \text { number of sample points }
\end{array}
$$

The mean error (bias) of the data is the sum of the residuals in the dataset divided by the number of sample points given by equation (13). Positive mean errors represent locations where the InSAR/PolInSAR DEM elevation was above the NGS reference point elevation, and, conversely, negative errors occur at locations where the InSAR/PolInSAR DEM elevation was below the NGS reference point elevation.

$$
\bar{x}=\frac{\sum x}{n}
$$

Where: 


$$
\begin{array}{cl}
\sum x & \text { sum of the residuals } \\
n & \text { number of sample points }
\end{array}
$$

\subsubsection{Vertical Accuracy Assessment of DEMs: All Reference Data Combined - Six Research Sites}

A total of 3,291 bare ground measurements (combined in situ measurements, NGS, and LiDAR reference points (Table 5)) located in the six research sites were utilized as reference data to assess the vertical accuracy of the DEM data sets (X-HH InSAR DTM (Section 3.2.1.), SRTM DSM (Section 3.2.2), and L-Quad PolInSAR DTM (Section 3.2.3), NED DTM (Section 3.3.4)) where available. Given the varied reference sample size and geographic extents between the six research sites, two methods were used to calculate RMS and mean errors for all data combined: 1) to give equal weight to each site, overall vertical accuracy was calculated as the average of the RMSE and mean error of each research site; 2) to weight the sites by the number of samples, all measurements were combined to derive an overall vertical accuracy, expressed in RMS and mean errors, this value being biased by the site with the most samples (Arizona). A cumulative frequency plot, which shows the percentage of observations in a data set that are less than or equal to particular values, was generated for the overall vertical accuracy assessment of the DEM data using all data combined.

\subsubsection{Vertical Accuracy Assessment of DEMs: All Reference Data Combined - Across Conterminous U.S.}

The vertical accuracies of the X-HH InSAR DTM, NED DTM, and SRTM DSM data covering the conterminous U.S. were assessed against the 41,322 NGS reference 
points (Figure 26). Overall RMSE and mean error were calculated as the average for these points and as above, a cumulative frequency plot was generated.

\subsubsection{Vertical Accuracy Assessment of DEMs: Stratified by Barren and Five Vegetation Cover Classes: Six Research Sites and Conterminous U.S. Site}

To assess whether or not vegetation cover impacted the vertical accuracy of the four DEM data sets, the reference data were stratified based on the barren land cover and five vegetation classes (Table 2) to derive an overall RMSE and mean error per vegetation class for the six research sites and conterminous U.S. sites.

\subsubsection{Vertical Accuracy Assessment of DEMs: Stratified by Slope: U.S. Research}

\section{Sites and Conterminous US. Site}

The impact of slope on the DEM data sets was assessed by stratifying the reference data by slope for both the six research sites data and for the conterminous U.S. data. Ideally, the slope maps should come from the reference data, however, the combined in situ and NGS point data were not dense enough to derive detailed slope maps so they were created for the four U.S. study sites and conterminous United States using the NEXTMap InSAR DTM data. These maps were aggregated into three slope classes which represented flat $\left(\leq 10^{\circ}\right)$, moderate $\left(11-29^{\circ}\right)$ and steep $\left(\geq 30^{\circ}\right)$ terrain. Slope values and DEM elevations were extracted for each reference measurement (from combined in situ and NGS) $\mathrm{x}-\mathrm{y}$ location and used to calculate RMSE and mean error.

\subsubsection{Vertical Accuracy Assessment of DEMs: All Data Combined - Canadian}

\section{Research Sites}

The vertical accuracy of the DEM data was assessed against the reference data (Table 9) along 16 transect lines (Figures 20 and 21) for the two Canadian sites. The 
overall RMSE vertical accuracy and mean error were calculated as the average of all reference data combined for each site because the reference point data locations were widely distributed across the two sites.

\subsubsection{Vertical Accuracy Assessment of DEMs: Stratified by Barren Land and Five Vegetation Classes - Canadian Research Sites}

The impact of vegetation cover on vertical accuracy of the DEM data was assessed against the reference data stratified by available vegetation classes (Table 9) to derive an overall RMSE and mean error per vegetation class for the two Canadian sites. These sites were located in flat terrain with slopes $<10^{\circ}$ thus, the effect of slope on the derived DTM was not assessed.

\subsection{Research Objective 2: Derivation of Scattering Phase Centre Height and Evaluation of its Accuracy as an Estimate of Canopy Height}

The scattering phase centre height, $h_{s p c}$, is a weighted average of the location and strength of all the incoming SAR signals in a given range interval that is processed (often called a range bin; Andersen et al., 2006; Kellndorfer et al., 2004). $h_{\text {spc }}$ is also averaged horizontally, where, for example, trees with a cone-shaped crown will exhibit an "average structural height" rather than a top height (Woodhouse et al., 2003; Balzter et al., 2007a).

The X-HH InSAR $h_{s p c}$ was estimated by subtracting an accurate DTM from the InSAR DSM data (Figure 29). This approach was selected because, first, the X-HH sensor operates at short wavelength so the majority of the scattering comes from the upper portion of the canopy (Izzawati et al., 2006; Kellndorfer et al., 2004; Balzter et al., 2007a; Walker et al., 2007; Andersen et al., 2008) providing a reasonable estimation of 
canopy height, and second, because accurate DTM data were available for all six research sites. SRTM C-HH InSAR data, which is also a short wavelength SAR sensor, used to derive $h_{\text {spc }}$ by subtracting the X-HH InSAR DTM data from the SRTM DSM data.

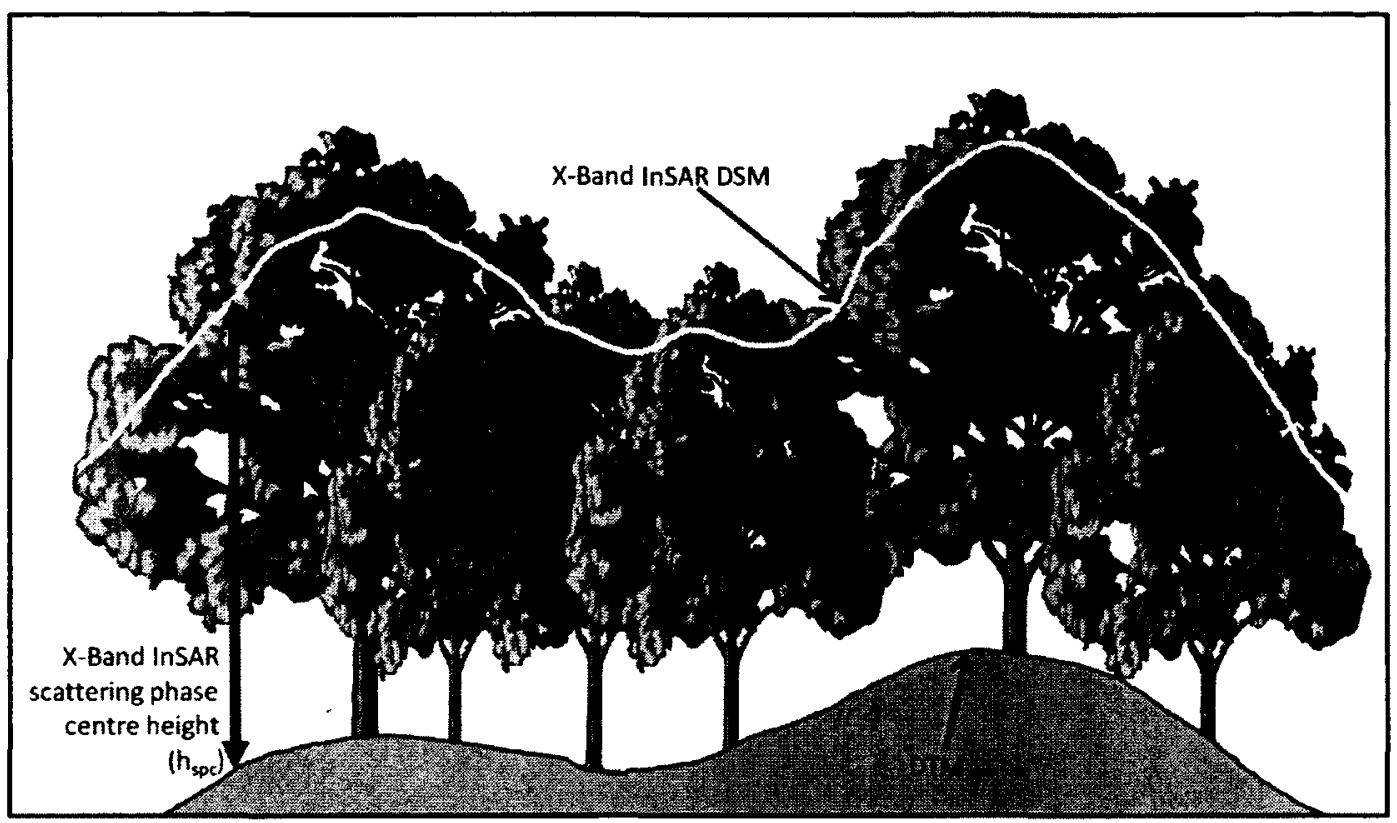

Figure 29. Scattering phase centre height $\left(\mathrm{h}_{\mathrm{spc}}\right)$ was calculated by subtracting the InSAR DTM height (red line) from the InSAR DSM height (yellow line).

Combined with effects of vegetation type and density, wavelength, and local incidence angle on canopy penetration, it is expected that use of $h_{s p c}$ as an estimate of canopy height will result in significant under-estimation of canopy height. Thus, the specific aim of research objective $\# 2$ was to assess magnitude and variation of the canopy height underestimation using $h_{\mathrm{spc}}$ to develop correction factors that account for penetration into the canopy to be applied in the proposed canopy height estimation 
method (Section 4.4). Given that the C-HH InSAR SRTM data were available for all research sites they were also included in this analysis.

The $\mathrm{X}$ - and $\mathrm{C}$-band $\mathrm{h}_{\mathrm{spc}}$ data sets were compared to in situ and LiDAR canopy height reference data for the U.S. and Canadian sites, respectively. In the case of the LBand PollnSAR data for the two Canadian sites, the L-band PolInSAR DSM data, created using the RVoG method, were subtracted from the LiDAR DTM data and the LQuad PollnSAR edited DTM data and compared to the LiDAR reference canopy height measurements. These analyses of X-, C- and L-band $h_{\text {spc }}$ as an estimate of canopy height were performed separately for each research site, and stratified by barren land cover and five vegetation types. Statistics computed in these analyses include the root mean square error (RMSE) and the mean error as described in Section 4.2.

\subsection{Research Objective 3: Refinement of Canopy Height Estimation Based on}

Adjustments to $h_{\text {spe }}$ for Vegetation Type and Proximity to Vegetation

\section{Discontinuities}

The process to derive $h_{s p c}$ creates the height of features above the ground by removing topographic heights above mean sea level (Figure 29). At X-band, however, signal penetration beneath the ground surface can occur, resulting in negative $h_{\text {spc }}$ values. For the X-HH InSAR NEXTMap data, less than 0.03 percent of the $h_{\text {spc }}$ values were negative (e.g. DSM-DTM in barren land cover). This proportion was considered small enough (1-2 millimetre range) to assign the negative values a value of $0.0 \mathrm{~m}$ in the $h_{\text {spc }}$ estimates for all research sites.

The proposed method for derivation of empirical X-HH InSAR canopy height estimates is illustrated in Figure 30. The method corrects for the attenuation (penetration) 
of microwave radiation in vegetation canopies, height discontinuities at vegetation boundaries with non-vegetated surfaces, and gaps or openings within the canopy. The method is comprised of four main components: 1 ) the derivation of $h_{\mathrm{spc}}$ (sections 4.3);2) land cover classification to map the classes listed in Table 2 (section 4.4.1.); 3) application of land cover dependent bias correction factors to $h_{\mathrm{spc}}$ values (section 4.4.2.); and 4) application of correction factors using buffers at vegetation discontinuities to account for SAR signal attenuation (section 4.4.3). The four components and the accuracy assessment plan (section 4.4.4.) are discussed below.

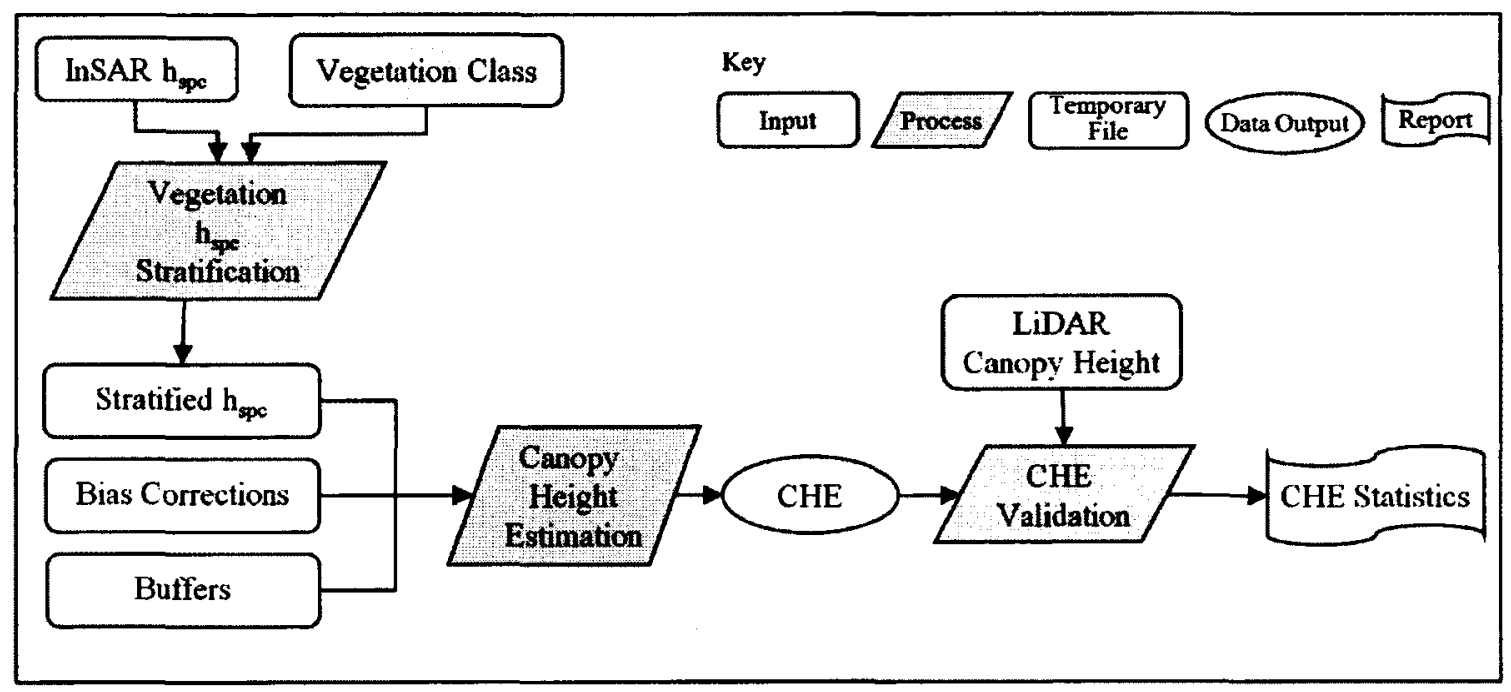

Figure 30. Flowchart illustrating the data and processes used to derive and validate the canopy height estimates.

\subsubsection{Land Cover Classification}

There is compelling evidence in the literature that suggests that vegetation type is an important two dimensional parameter that improves biophysical parameter modeling (Dobson et al., 1992; Ranson et al., 1993; Andersen et al., 2008). Classifying SAR 
imagery from InSAR and PolInSAR sensors into forest/non-forest as well as structural classes has proven feasible and is widely reported in the literature (Askne et al., 1997; Dobson et al., 1992; Balzter et al., 2001). It is also intuitive that the microwave signal interactions would respond differently to changes in biophysical parameters for species with varied structural and dielectric properties (Izzawati et al., 2006; Andersen et al., 2006). Therefore, an important aspect of the canopy height estimation method presented in this research is the corporation of vegetation type (Table 2; Figure 28). Another important aspect was the incorporation of the InSAR and PolInSAR $h_{s p c}$ data as a rough estimate of canopy height, which provides additional information useful in land cover classification.

Object-based classification was selected over pixel-based methods for reasons given in Section 2.5.1. It was implemented using the ENVI object-based classification software (ENVI, 2007) multiple data inputs, image segmentation, and a land cover rule set (Table 8) as illustrated in Figure 31. 


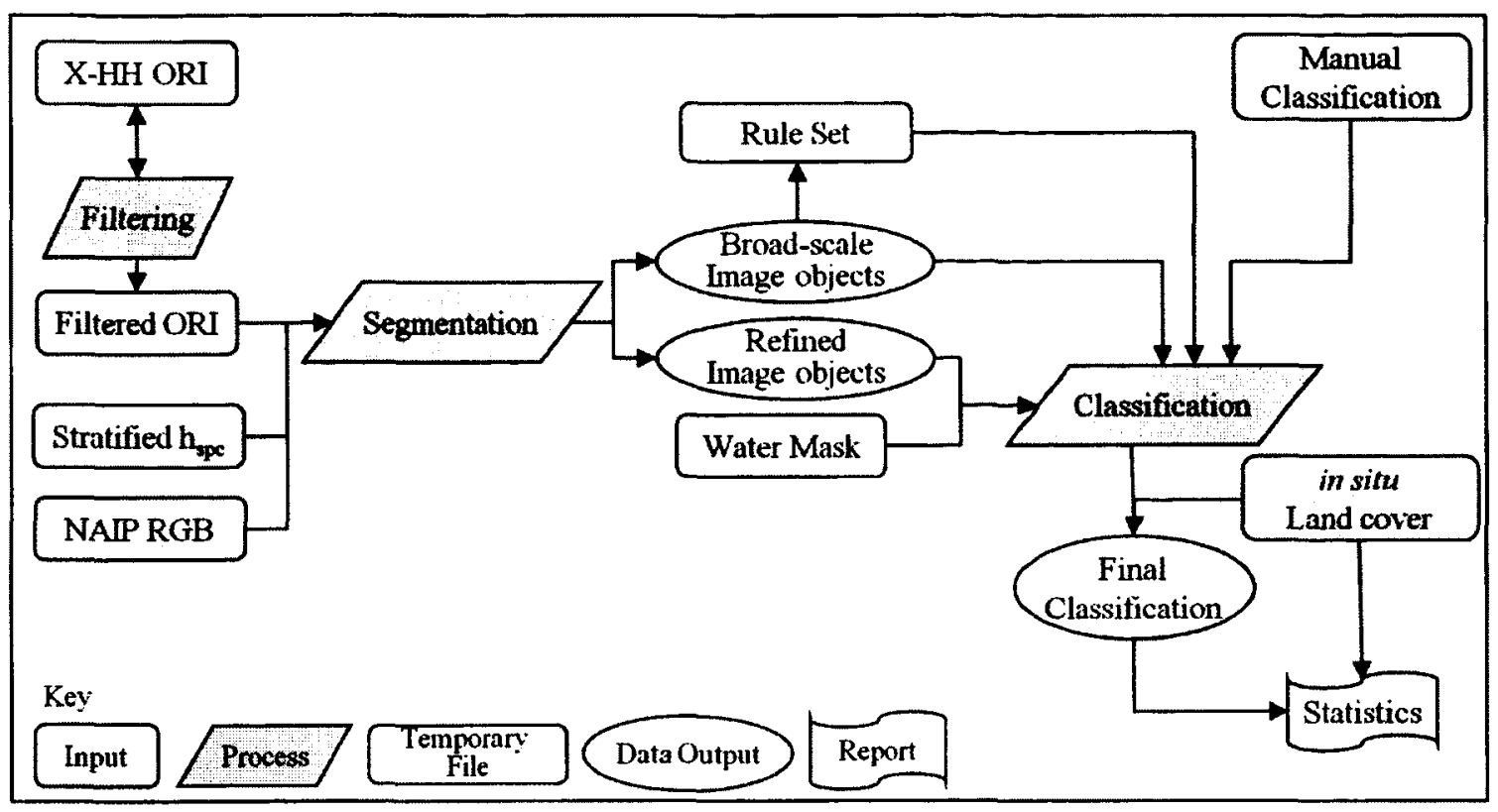

Figure 31. Land cover object-based classification process flow.

The process flow required three remotely sensed data input; 1) SAR imagery, 2) NAIP imagery, and 3) InSAR derived $h_{\text {spe. }}$ Preliminary data processing steps of the SAR imagery and $h_{\text {spc }}$ data were required prior to segmentation and land cover classification. First, the SAR imagery was optimized for land cover classification by applying a speckle suppression filter. A vast array of radar filters are available, but for land cover classification, Quegan et al. (2000) concluded, that the most appropriate is simple adaptive averaging as in a gamma filter. A gamma filter removes high frequency noise (speckle), while preserving high frequency features (edges). Therefore, a 3 by 3 boxcar gamma filter was applied. Second, the $h_{\text {spc }}$ data were reclassified to derive three relative vegetation height classes: 1) $0-2 \mathrm{~m}$ (barren/grass), 2) $2.1 \mathrm{~m}-4.9 \mathrm{~m}$ (shrub), and 3) greater than $5 \mathrm{~m}$ (deciduous, conifers, wetlands, and mixed). 
The filtered ORI, re-classified $h_{\text {spc }}$ and NAIP imagery were used as inputs to the segmentation process. The ENVI Zoom algorithm, which employs the Full LambdaSchedule algorithm created by Robinson et al. (2002), was used to segment the data. This algorithm is an edge-based segmentation algorithm that requires one input parameter (scale level) to create region means (a raster file) in which each segment is assigned the mean band value of all pixels in that region. Two scales of segmentation were of interest: a broader scale distinguishing larger forests and grasslands from one another as large homogenous objects, and a more detailed scale at which trees can be distinguished as conifers and deciduous objects.

Segmentation was first performed using the filtered SAR imagery to segment the image pixels into image objects based on similarity of image tone and texture. Segmentation was also performed on the three-height class $h_{\text {spc }}$ data segments to separate vegetation/non-vegetation objects. A water mask, created from the InSAR derived ORI data provided by Intermap, was incorporated to refine the segments and filter out unwanted water features from the segmentation results. This refinement step was performed prior to classification. The ENVI feature extraction process or object-based classification was performed next. Using a sequential rule base (Table 8), where classes are sequentially defined by a rule sets, attributes are assigned to the land cover classes of interest. The attributed segments were utilized to classify the data into land cover classes outlined in Table 2.

The sequential rules are presented in Table 8. They were derived using three criteria, based on the input data set. First, the training in situ land cover data set was used to identify barren land cover and the five vegetation classes (Table 2) evaluated in this 
research. Histograms of the distribution of the SAR digital numbers were derived for the training land cover types to determine the digital number (DN) range per land cover class. The DN ranges per land cover class are listed in Table 8. Significant differences overall in DN values per barren land cover and five vegetation classes did not existed; consequently, additional criteria were required for the classification process to be successful. Second, the three $h_{\mathrm{spc}}$ data elevation height classes assisted in the separation of barren, shrub, and trees (deciduous, conifers, wetlands, and mixed forest). Third, the training in situ land cover data set were used to identify barren land cover and the five vegetation classes (Table 2) within the NAIP imagery, where histograms of the RGB classes were derived to determine their DN range per land cover class (listed in Table 8).

The refined segmented layers, sequential rule set and the reference data were used to manually delineate the land cover classes listed in Table 2, based on visual interpretation of the image data and field observations at the training sites. The use of a rule set has substantial advantages for land use classification because of its flexibility, nonparametric nature, and ability to handle nonlinear relations between features and classes (Benz et al., 2004). The barren and grass classes were grouped together to simplify the classification maps. The land cover objects were then randomly split equally into training and accuracy assessment data sets. Table 9 provides the number of reference data sets per land cover class. 
Table 8. Sequential rule set used in land cover classification. Digital number is denoted as DN.

\begin{tabular}{|c|c|}
\hline Cover & Rule Set \\
\hline Water & Intermap's water mask was used to mask out water. \\
\hline Barren & $\begin{array}{l}\text { ORI DN range of } 35-165, \text { a } h_{\text {spc }} \text { range of }<2 \mathrm{~m} \text {, a NAIP RGB range of } 162- \\
230 \mathrm{DN} \text { \{red\}, 162-230 DN \{green], and 134-199 DN \{blue }\}\end{array}$ \\
\hline Urban & $\begin{array}{l}\text { ORI DN range of } 20-200, a h_{\text {spc }} \text { of } 0-25 \mathrm{~m} \text {, a NAIP RGB range of } 142-254 \\
\text { \{red\}, } 154-253 \text { green\}, and } 157-249 \text { blue } \text { and slope }<10^{\circ}\end{array}$ \\
\hline Grass & $\begin{array}{l}\left.\text { ORI DN range of } 23-63, a h_{s p c} \text { of }<2 \mathrm{~m} \text {, a NAIP RGB range of } 44-61 \text { red }\right\} \\
80-103 \text { green }\} \text {, and } 65-81\{\text { blue }\} \text { and slope }<10^{\circ}\end{array}$ \\
\hline $\begin{array}{l}\text { Wetlands } \\
\text { Riparian }\end{array}$ & $\begin{array}{l}\text { ORI DN range of } 180-230, \text { a } \mathrm{h}_{\mathrm{spc}} \text { of }>5 \mathrm{~m} \text {, a NAIP RGB range of } 142-254 \\
\text { \{red\}, 154-253 \{green\}, and 157-249 \{blue\} and slope }<10^{\circ}\end{array}$ \\
\hline Deciduous & $\begin{array}{l}\text { ORI DN range of } 23-63, a h_{s p c} \text { of }>5 \mathrm{~m} \text {, a NAIP RGB range of } 44-61\{\text { red }\} \text {, } \\
80-103 \text { green\}, and } 65-81 \text { blue }\}\end{array}$ \\
\hline Conifers & $\begin{array}{l}\left.\text { ORI DN range of 2-79, a } h_{\mathrm{spc}} \text { of }>5 \mathrm{~m} \text {, a NAIP RGB range of } 3-15 \text { red }\right\} \\
39-63 \text { green }\} \text {, and } 40-52 \text { \{blue }\}\end{array}$ \\
\hline Shrub & $\begin{array}{l}\text { ORI DN range of } 52-110, \mathrm{~h}_{\mathrm{spc}} \text { of } 2.1-4.9 \mathrm{~m} \text {, a NAIP RGB range of } 28-43 \\
\text { \{red\}, 76-96 \{green\}, and } 40-52 \text { \{blue }\end{array}$ \\
\hline Mixed & Else Mixed Forest \\
\hline
\end{tabular}


Table 9. Number of land cover reference observations from the in situ observations and from interpretation of high resolution optical imagery shown per vegetation type and research site.

\begin{tabular}{|r|r|r|r|r|r|r|}
\hline $\begin{array}{r}\text { Site \& Reference } \\
\text { Type }\end{array}$ & Barren & Shrub & Deciduous & Conifers & Mixed & Wetlands \\
\hline Ely: in situ & 35 & 36 & 36 & 45 & 18 & 0 \\
\hline Optical & 15 & 30 & 24 & 10 & 37 & 45 \\
\hline Int. Falls: in situ & 35 & 3 & 6 & 6 & 3 & 3 \\
\hline Optical & 15 & 17 & 34 & 29 & 22 & 17 \\
\hline Arizona: in situ & 35 & 105 & 75 & 90 & 75 & 90 \\
\hline Optical & 15 & 40 & 35 & 20 & 35 & 50 \\
\hline Morrison: in situ & 35 & 15 & 6 & 6 & 6 & 0 \\
\hline Optical & 15 & 50 & 24 & 24 & 24 & 45 \\
\hline Edson: Optical & 50 & 25 & 50 & 45 & 60 & 0 \\
\hline Burnstick: Optical & 50 & 15 & 50 & 65 & 60 & 60 \\
\hline
\end{tabular}

Following classification, thematic map accuracy was assessed using reference data that were set aside and standard error matrices (or confusion matrices; Story and Congalton, 1986; Foody, 2002; 2004). Common error statistics were calculated, namely: overall accuracy, class Producer's Accuracy (PA; 100\% - errors of omission) and class User's Accuracy (UA; 100\% - errors of commission) and Cohen's Kappa; Fleiss and Cohen, 1969; Congalton, 1991; 2007; Foody, 2004; Jensen 2005). 


\subsubsection{Refinement of $h_{\text {spe }}$ Canopy Height Estimates within the Canopy and at Vegetation Boundaries and Gaps Using Vegetation Dependent Correction Factors Applied Using Buffers}

The $\mathrm{h}_{\text {spc }}$ can be between $50 \%$ (interior canopy) to $80 \%$ (edge of canopy) below the canopy height surface (Figure 15) in X-band InSAR data (Andersen et al., 2008; Woodhouse et al., 2006). The $\mathrm{h}_{\text {spc }}$ is affected by signal attenuation but there are other factors that also relate to the amount of backscattered energy received from various parts of the canopy and potentially from the ground. For example, in a closed canopy, if the amount of ground backscatter return is small, the recovered canopy height is in the upper half of the canopy at X-band (Andersen et al., 2006; Izzawati et al., 2006; Balzter et al., 2007a), resulting in an underestimation in canopy height. In regions of large canopy gaps, sparse forest, or at the forest-ground boundaries there will be even greater ground scattering contributions compared to the interior region of the canopy (Woodhouse et al., 2006; Balzter at al., 2007b) leading to an even lower $h_{\text {spc }}$ or lower derived canopy height.

Therefore, to minimize the vertical error in InSAR and PolInSAR derived $h_{\text {spc }}$ canopy height estimates in these conditions, vegetation type dependent correction factors were calculated using in situ canopy height measurements, and applied to the $h_{\text {spc }}$ data within the interior of the canopy and at the edges of vegetation canopy-barren land boundaries, which includes within gaps located in the forest canopy. This was accomplished by first establishing the vegetation dependent bias correction factors, and second, by applying these corrections using buffers and the land cover classification maps, as discussed in detail in Sections 4.4.2.1, and 4.4.2.2., respectively. 


\subsubsection{Creation of Vegetation Dependent Correction Factors}

The vegetation dependant bias correction factors for shrub, deciduous, coniferous, mixed, and wetlands canopies were estimated by comparing the in situ tree height measurements to the X-HH InSAR $h_{\mathrm{spc}}$ located within the vegetation canopy and at vegetation - bare ground boundary edges. These measurements were used to establish an average correction factor for each vegetation type as presented in Table 10.

Table 10. Buffers and attenuation bias correction factors for vegetation types.

\begin{tabular}{|l|r|r|r|r|}
\hline $\begin{array}{l}\text { Vegetation } \\
\text { Type }\end{array}$ & $\begin{array}{c}\text { \# of in } \\
\text { situ tree } \\
\text { heights }\end{array}$ & $\begin{array}{c}\text { Interior } \\
\text { Buffer Bias } \\
\text { Factor }\end{array}$ & $\begin{array}{c}\text { Middle } \\
\text { Buffer Bias } \\
\text { Factor }\end{array}$ & $\begin{array}{c}\text { Exterior } \\
\text { Buffer Bias } \\
\text { Factor }\end{array}$ \\
\hline Shrub & 25 & 1.9 & 2.1 & 2.3 \\
\hline Deciduous & 25 & 1.5 & 1.7 & 1.9 \\
\hline Conifers & 25 & 1.2 & 1.4 & 1.6 \\
\hline Mixed & 25 & 1.4 & 1.7 & 2.0 \\
\hline Wetlands & 25 & 1.1 & 1.3 & 1.5 \\
\hline
\end{tabular}

\subsubsection{Application of Vegetation Dependent Correction Factors}

Buffers of consistent widths were required to apply the vegetation dependant correction factors within the canopy, and at edges and gaps. Three buffers were created: 1) interior, 2) middle, and 3) exterior, illustrated as green, blue, and red polygons, respectively, in Figure 32. The interior buffer represents the interior of the canopy that is away from the edges. Using reference data, the InSAR ORI, and the land cover classification maps, the interior buffers were located 12 pixels (12 pixels $* 1.25 \mathrm{~m}$ resolution $\sim 15 \mathrm{~m}$ or 3 elevation postings $(5 \mathrm{~m} * 3=15 \mathrm{~m})$ from the edge of vegetation polygons, as illustrated by the green centre polygon in Figure 32 . The middle (blue, 
Figure 32) and the exterior buffers (red, figure 32) were arbitrarily located at 2 (8 pixels) and 1 (4 pixels) elevation postings from the interior polygon edge. The buffers were automatically created removing the need to generate them manually. The variable correction factors (Table 10) were multiplied by the derived $\mathrm{h}_{\text {spc }}$ height for each pixel in each buffer.

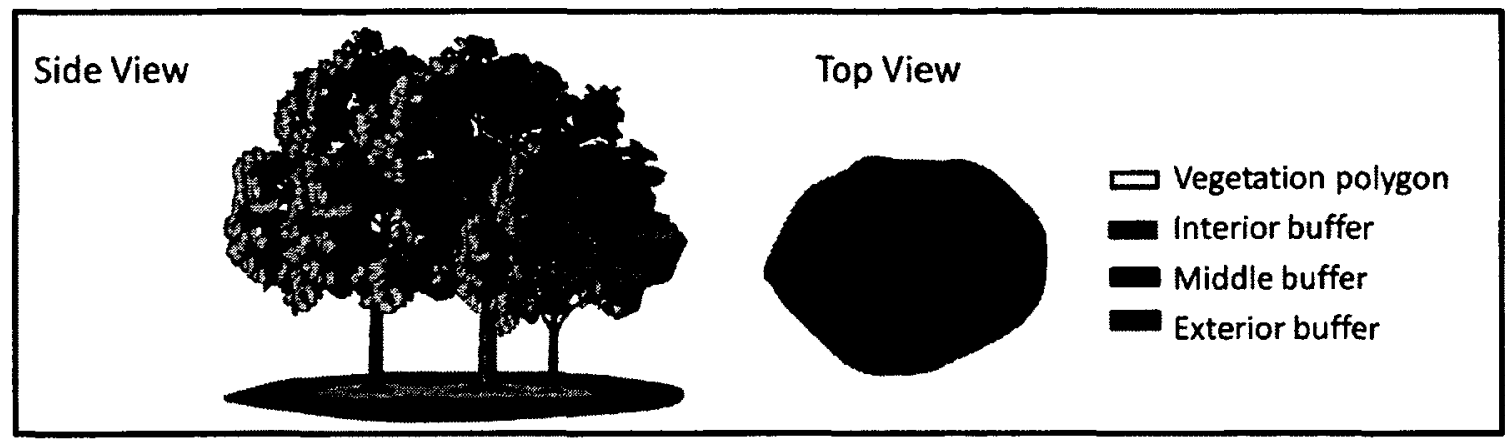

Figure 32. Vegetation buffers illustrated.

\subsubsection{Canopy Height Estimation Vertical Accuracy Assessment}

The output from the above processes produced the final canopy height estimates as shown in Figure 1. The performance of this method over the vegetation classes, terrain types, and environments of the datasets of this research was evaluated by comparing estimated canopy heights to those from the in situ and LiDAR reference vegetation measurements, using the same error measures listed previously.

\subsection{Performance of the Canopy Height Estimation in Sloped Terrain and Effects of Variations in Incidence Angle}

The side-looking viewing geometry of InSAR/PolInSAR (Figure 2; from Near Range [NR] to Mid-Range [MR] to Far Range [FR]) may result in variations in retrieved bare ground elevations (e.g. DTM) and canopy height measurements (Andersen et al., 
2006; Izzawati et al., 2006; Woodhouse et al., 2006). Section 4.2 addressed the effect of terrain slope on the InSAR derived DTM data. In this section, the impact of terrain slope and incidence angle on the proposed canopy height estimation (CHE) is addressed. The different bio-geophysical characteristics of the six research sites and the availability of multi-frequency (X-, C-, and L-band) data provided a unique opportunity to examine these impacts as described in the following two sections.

\subsubsection{Performance of the CHE over a Range of Terrain Slopes}

The effect of terrain slope on the X-HH InSAR derived canopy height given by $h_{\text {spc }}$ estimates and the refined CHE data were evaluated using slope maps derived from XHH InSAR DTM and LiDAR DTM data for the U. S. sites and Canadian sites, respectively. Slope was calculating using ArcGIS software spatial analyst Surface Analysis slope package. The slope maps were stratified as flat $\left(<10^{\circ}\right)$, moderate $\left(11-29^{\circ}\right)$ and steep $\left(\geq 30^{\circ}\right)$. The number of $h_{\text {spc }}$ and CHE data samples per slope, incidence angle (NR, MD, and FR), and land cover classes are provided in Table 11.

Table 11. Number of $h_{\text {spc }}$ and CHE data samples per slope, incidence angle, and land cover class.

\begin{tabular}{|l|l|r|r|r|r|r|}
\hline Slope & Incidence Angle & Shrub & Deciduous & Conifers & Mixed & Wetlands \\
\hline$\leq 10^{\circ}$ & NR & 197 & 132 & 202 & 111 & 38 \\
\hline $11^{\circ}-29^{\circ}$ & NR & 31 & 30 & 28 & 33 & 29 \\
\hline$\geq 30^{\circ}$ & NR & 5 & 6 & 11 & 11 & 0 \\
\hline$\leq 10^{\circ}$ & MR & 235 & 141 & 181 & 125 & 40 \\
\hline $11^{\circ}-29^{\circ}$ & MR & 37 & 29 & 45 & 21 & 15 \\
\hline$\geq 30^{\circ}$ & MR & 6 & 9 & 27 & 3 & 0 \\
\hline$\leq 10^{\circ}$ & FR & 158 & 128 & 180 & 134 & 43 \\
\hline $11^{\circ}-29^{\circ}$ & FR & 22 & 20 & 36 & 5 & 15 \\
\hline$\geq 30^{\circ}$ & FR & 5 & 6 & 15 & 3 & 0 \\
\hline
\end{tabular}




\subsubsection{Performance of the Canopy Height Estimation over a Range of Incidence}

\section{Angles}

For the X-band airborne InSAR sensor used in this research, the incidence angle ranged from $35^{\circ}$ to $55^{\circ}$, centred on $45^{\circ}$. Changes in incidence angle due to SAR sensor viewing geometry changes the relative contributions from canopy and ground surfaces and thus, affect the overall retrieved canopy height. The incidence angle was not known for the NEXTMap X-HH InSAR and SRTM C-HH InSAR data because these data were created from merging multiple data acquisitions at varying incidence angles (Figure 23). However, single-data take X-HH InSAR strip data, which represent data from one flightline pass where the incidence angle range across swath (NR to FR) was maintained, were available for five of the six research sites.

To assess the impact of incidence angle on the ability of X-HH InSAR to derive accurate canopy height, therefore, the single-data take $\mathrm{X}-\mathrm{HH}$ InSAR derived $\mathrm{h}_{\mathrm{spc}}$ data were created by subtracting the reference DTM data from the single-data take DSM data for the Arizona (X-HH InSAR), two Minnesota (X-HH InSAR), and Edson and Burnstick Lake (X-HH InSAR) sites. Single take data were not available for the Colorado site, and thus, excluded from this analysis. The canopy height values for each $\mathrm{x}-\mathrm{y}$ in situ and LiDAR CHE reference canopy height location, stratified by three incidence angles $(\mathrm{NR}=$ $35^{\circ}, \mathrm{MR}=45^{\circ}$, and $\mathrm{FR}=55^{\circ}$ ) and by vegetation type (shrub, deciduous, coniferous, mixed, and wetlands) were extracted from both the single- and multi-data take $h_{\text {spc }}$ data (Section 4.3). All height values were classified based on slope data to ensure that only those values that represented terrain slopes $\leq 10^{\circ}$ were used; otherwise, the effects of incidence angle cannot be evaluated independently. The root mean square and mean 
errors were computed. The number of data samples per NR, MR, and FR and per research site, in flat terrain with slopes less than $10^{\circ}$ is listed in Table 12.

Table 12. Number of data samples per near- (NR), mid- (MR), and far-range (FR) per research site, in flat terrain with slopes less than $10^{\circ}$.

\begin{tabular}{|l|c|r|r|r|r|r|}
\hline \multicolumn{1}{|c|}{ Site } & $\theta$ & \multicolumn{1}{c|}{ Shrub } & Deciduous & Conifers & Mixed & Wetlands \\
\hline \multirow{4}{*}{ Ely } & NR & 9 & 24 & 22 & 6 & 0 \\
\cline { 2 - 7 } & MR & 6 & 31 & 31 & 9 & 0 \\
\cline { 2 - 7 } & FR & 5 & 49 & 29 & 5 & 0 \\
\hline \multirow{2}{*}{$\begin{array}{l}\text { International } \\
\text { Falls }\end{array}$} & NR & 10 & 27 & 15 & 14 & 8 \\
\cline { 2 - 7 } Arizona & MR & 8 & 29 & 15 & 16 & 7 \\
\hline \multirow{4}{*}{ Edson } & NR & 154 & 19 & 29 & 0 & 0 \\
\cline { 2 - 7 } & MR & 184 & 21 & 31 & 0 & 0 \\
\cline { 2 - 7 } & FR & 139 & 18 & 27 & 0 & 0 \\
\hline \multirow{3}{*}{$\begin{array}{l}\text { Burnstick } \\
\text { Lake }\end{array}$} & NR & 0 & 33 & 82 & 64 & 0 \\
\cline { 2 - 7 } & MR & 0 & 35 & 85 & 64 & 0 \\
\cline { 2 - 7 } & FR & 0 & 22 & 87 & 64 & 0 \\
\cline { 2 - 7 } & MR & 0 & 45 & 45 & 45 & 0 \\
\cline { 2 - 7 } & FR & 0 & 45 & 45 & 45 & 0 \\
\hline
\end{tabular}

Given that the single take data were available over most of the five sites assessed above, the effect of incidence angle on InSAR derived $h_{\text {spc }}$ was investigated further by comparing transect lines running along the length of the single take data to see if the impact of merging multiple takes reduce the effect of incidence angle on the derived canopy heights. This was accomplished by extracting $h_{s p c}$ values, along three transects located $1 \mathrm{~km}\left(\mathrm{NR}=35^{\circ}\right), 5 \mathrm{~km}\left(\mathrm{MR}=45^{\circ}\right)$, and $9 \mathrm{~km}\left(\mathrm{FR}=55^{\circ}\right)$ across the single-data take swath in the range direction (Figure 33), from the single- and multi takes X/L InSAR data. The canopy height values (e.g. given by $h_{\text {spc }}$ ) were compared to each other using the 
RMS difference (RMSD) and mean difference. RMSD was calculated since neither the single- nor multi takes data were considered as reference data; i.e., this was not an accuracy assessment. $R^{2}$ values were also tabulated. The results for all site data combined were tabulated as a weighted average based on the number of samples per site, since they were not equal at each site.

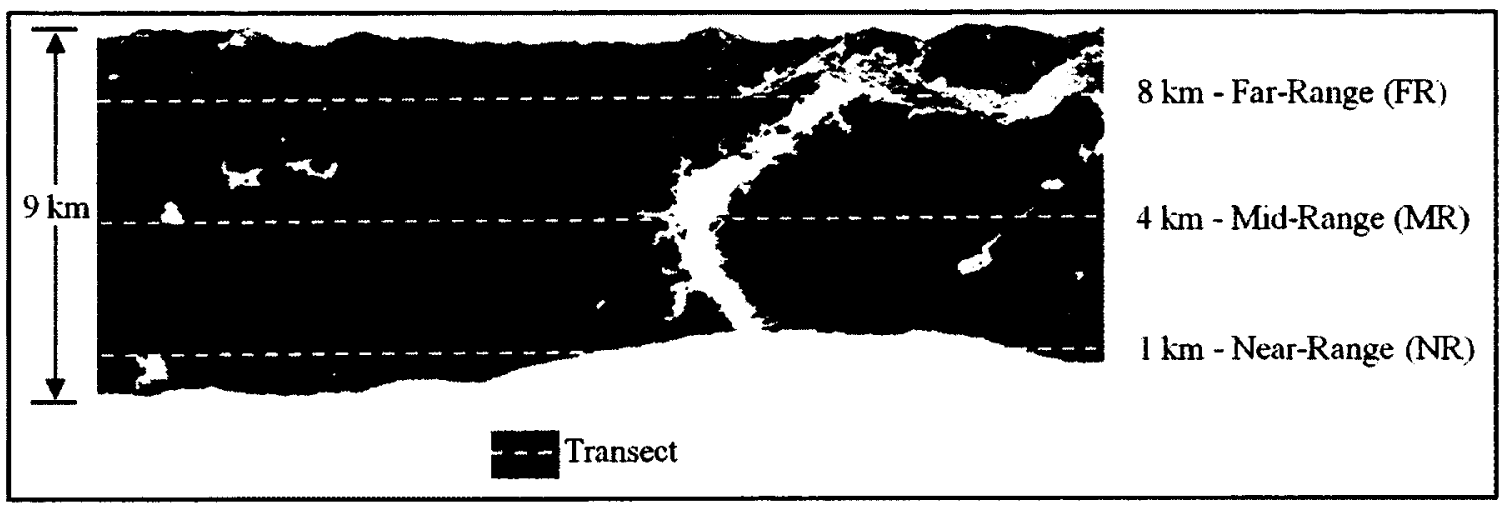

Figure 33. Transect (dashed lines) positions in near-, mid-, and far-range for one strip of X-HH InSAR data (e.g. single-data take). Example presented here is from the International Falls, MN site.

The goal was to select transects that were common to more than one flight line of data (e.g. single-data take) in order to compare the same transect in NR, MR, and FR. The $\mathrm{h}_{\mathrm{spc}}$ value at each sample point (spaced $50 \mathrm{~m}$ apart; tabulated in Table 13) along all transects with slopes less than $10^{\circ}$ was extracted from both the single-data take and the NEXTMap X-HH InSAR (multi-data takes) and the L-Quad PolInSAR (multi-data takes) data. 
Table 13. Number of data samples per near- (NR), mid- (MR), and far-range (FR) per research site, in flat terrain with slopes less than $10^{\circ}$.

\begin{tabular}{|l|r|r|r|r|}
\hline Study Area & \multicolumn{1}{|c|}{$\begin{array}{c}\text { \# of } \\
\text { Image Strips }\end{array}$} & $\begin{array}{c}\text { \# NR } \\
\text { Samples }\end{array}$ & $\begin{array}{c}\text { \# MR } \\
\text { Samples }\end{array}$ & $\begin{array}{c}\text { \# FR } \\
\text { Samples }\end{array}$ \\
\hline Ely & 3 & 927 & 1111 & 2762 \\
\hline International Falls & 2 & 804 & 504 & 404 \\
\hline Arizona & 3 & 1320 & 1318 & 1923 \\
\hline Burnstick Lake & 1 & 403 & 403 & 403 \\
\hline Edson & 1 & 535 & 535 & 0 \\
\hline
\end{tabular}

Transects were also created running across (NR - FR) single take swaths from (Figure 34) and the $h_{\text {spc }}$ value at each sample point (spaced $50 \mathrm{~m}$ apart) was extracted from the single- and multi takes X-HH InSAR data to create profiles comparing similar vegetation classes across the three incidence angle locations. The number NR, MR, and FR plots per research site, in flat terrain with slopes less than $10^{\circ}$ is listed in Table 14.

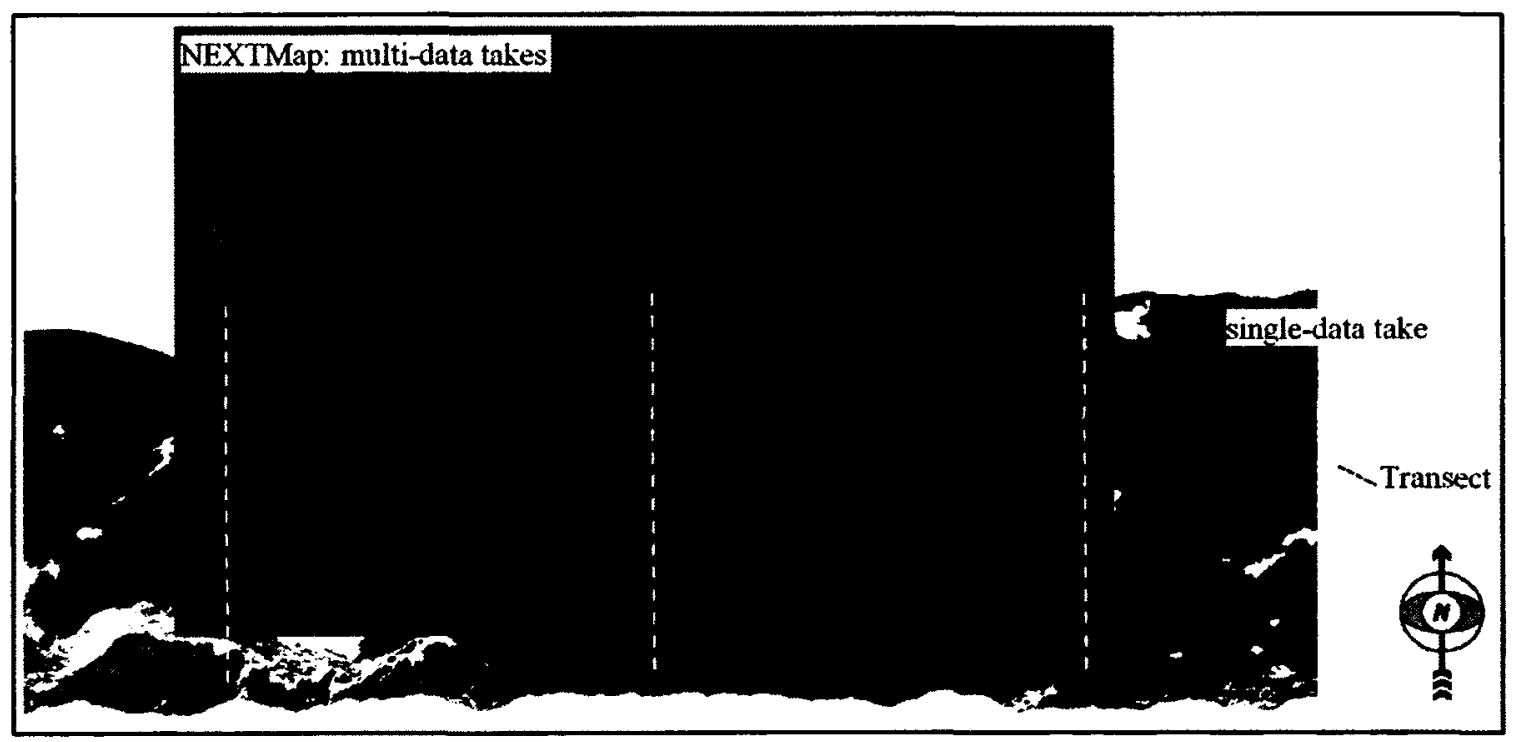

Figure 34. Transect line (dashed line) running across one strip (single-data take data) swath in the range direction. Example presented here is from the International Falls, MN site. 
Table 14. Number of across-swath transects per site.

\begin{tabular}{|l|c|c|c|}
\hline Study Area & $\begin{array}{c}\text { \# of } \\
\text { Image Strips }\end{array}$ & $\begin{array}{c}\text { Swath } \\
\text { Coverage }\end{array}$ & $\begin{array}{c}\text { \# of Profiles per } \\
\text { strip }\end{array}$ \\
\hline Ely & 1 & NR-MR-FR & 3 \\
\hline International Falls & 2 & MR-FR & 2 \\
\hline Arizona & 2 & NR-MR-FR & 3 \\
\hline Edson & 1 & NR_MR & 1 \\
\hline Burnstick Lake & 1 & NR-MR & 1 \\
\hline
\end{tabular}

\subsection{Summary}

This chapter provided a description of the reference data (in situ, NGS, LiDAR) collection methods for use in evaluating the produced land cover classification and canopy height estimates across the six research sites. The methodology to refine scattering phase centre height that can be derived from InSAR and PolInSAR data by correcting for signal penetration into the vegetation canopy as well as at or near vegetation non-vegetation cover boundaries was summarized in this chapter. Also outlined was the analysis conducted in this research to meet the research objectives and to set the stage for the results and discussion chapters that follow. 


\section{CHAPTER FIVE: RESULTS}

This chapter presents the results for the three research objectives. First, the evaluation of the vertical accuracy assessment of X-HH InSAR DTM, L-Quad PolInSAR DTM, and C-HH InSAR DSM data is discussed in Section 5.1. Second, the results of the vertical accuracy assessment of X-HH InSAR, L-Quad PolInSAR, and C-HH InSAR scattering phase centre height as an estimate of canopy height is presented in Section 5.2, including stratification by vegetation type, research site, and incidence angle. Third, assessments of land cover classification accuracy and the final canopy height estimation, which includes the corrections to $h_{\mathrm{spc}}$ based on vegetation class and gap/edge position, are presented in Section 5.3. The latter analysis is stratified by vegetation type, research site, and terrain slope. Recall, that hereafter, 'DEM' is used as a general term when DTMs (e.g., X-HH InSAR, NED, and L-Quad PolInSAR) and DSM data (e.g., SRTM C-HH) are compared in the same section, table, or figure. This chapter is concluded with a summary in Section 5.4 .

\subsection{Research Objective 1: DEM Vertical Accuracy Assessment}

This section presents the results of comparisons of the DEM products against reference data (presented in Table 5) and the implications of the findings on the overall research aim of canopy height estimation from InSAR and PolInSAR data.

\subsubsection{DEM Vertical Accuracy Assessments - All Reference Data Combined}

\subsubsection{Six Research Sites}

The DEM overall vertical accuracy assessment results for the six research sites are presented in Table 15. Combining all available in situ, NGS, and LiDAR reference data (Table 5) into one validation data set, the overall vertical accuracy, calculated as the 
average of the site RMSE and mean errors (rows corresponding to sites in Table 15), is given in the second last row of Table 15 and labeled: All*.

Table 15. DEMs vertical accuracy assessment against combined in situ, NGS, and LiDAR reference data for the six research sites.

\begin{tabular}{|c|c|c|c|c|c|c|c|c|c|}
\hline \multirow{2}{*}{$\begin{array}{l}\text { \# of } \\
\text { Ref. }\end{array}$} & \multirow{2}{*}{ Site } & \multicolumn{2}{|c|}{ X-HH DTM } & \multicolumn{2}{|c|}{ L-Quad DTM } & \multicolumn{2}{|c|}{ C-HH DSM } & \multicolumn{2}{|c|}{ NED DTM } \\
\hline & & $\begin{array}{c}\text { RMSE } \\
\text { (m) }\end{array}$ & $\begin{array}{l}\mathrm{ME} \\
(\mathrm{m})\end{array}$ & $\begin{array}{l}\text { RMSE } \\
\text { (m) }\end{array}$ & $\begin{array}{l}\text { ME } \\
(\mathrm{m})\end{array}$ & $\begin{array}{l}\text { RMSE } \\
\text { (m) }\end{array}$ & $\begin{array}{l}\mathrm{ME} \\
(\mathrm{m})\end{array}$ & $\begin{array}{c}\text { RMSE } \\
\text { (m) }\end{array}$ & $\begin{array}{l}\mathrm{ME} \\
(\mathrm{m})\end{array}$ \\
\hline 511 & Ely & 1.20 & 0.71 & N/A & N/A & 7.43 & 7.09 & 2.38 & 1.78 \\
\hline 391 & Int. Falls & 1.09 & 1.32 & N/A & N/A & 6.69 & 4.29 & 2.32 & 1.64 \\
\hline 1021 & Arizona & 0.66 & 0.17 & N/A & N/A & 5.35 & 2.09 & 2.45 & 1.34 \\
\hline 791 & Morrison & 0.78 & 0.21 & N/A & N/A & 4.30 & 3.32 & 2.72 & 1.91 \\
\hline 249 & Burnstick & 1.09 & 0.76 & 3.59 & 1.29 & 5.94 & 4.20 & $\mathrm{~N} / \mathrm{A}$ & N/A \\
\hline 328 & Edson & 1.13 & 0.83 & 3.83 & 1.33 & 6.24 & 5.11 & $\mathrm{~N} / \mathrm{A}$ & N/A \\
\hline 3291 & All* & 0.99 & 0.67 & 3.71 & 1.31 & 5.99 & 4.35 & 2.47 & 1.67 \\
\hline 3291 & All** & 0.72 & 0.37 & $\mathrm{~N} / \mathrm{A}$ & $\mathrm{N} / \mathrm{A}$ & 6.99 & 4.35 & 2.07 & 1.35 \\
\hline \multicolumn{10}{|c|}{ * Vertical RMSE calculated as the average of six site RMSE value } \\
\hline \multicolumn{10}{|c|}{$\begin{array}{l}\text { ** All measurements from all sites were combined to derive an overall vertical } \\
\text { RMSE accuracy, this value being biased by the site with the most samples (Arizona) } \\
\text { and biased because the dominant land covers at the Arizona site are Barren and }\end{array}$} \\
\hline
\end{tabular}

The RMSE and mean error of the X-HH InSAR DTM, the focal data of this research, were $0.99 \mathrm{~m}$ and $0.67 \mathrm{~m}$, respectively. Using site average values eliminates bias that would occur if all individual point errors were simply averaged because the numbers of samples were not equal for each site. For example, the Arizona site had double the number of samples compared to the Ely site, and it was comprised mostly of open barren 
terrain and shrub vegetation on low sloped terrain, which is considered a favorable landscape for InSAR techniques, producing generally low vertical error. This is reflected in the higher X-HH InSAR vertical accuracy calculated from all samples (0.72 m RMSE) irrespective of site (Table 15, last row: All**). Note, the NED data were not available for the Canadian sites and the L-Quad PolInSAR DTM data were not available for the U.S. sites as shown in Table 15. The cumulative error plot presented in Figure 35 indicates that X-HH, NED, C-HH, and L-Quad DEMs have an absolute vertical accuracy of better than $1 \mathrm{~m}$ for $88 \%, 67 \%, 46 \%$, and $38 \%$ of their elevation data, respectively, for all data combined over the research sites, where applicable.

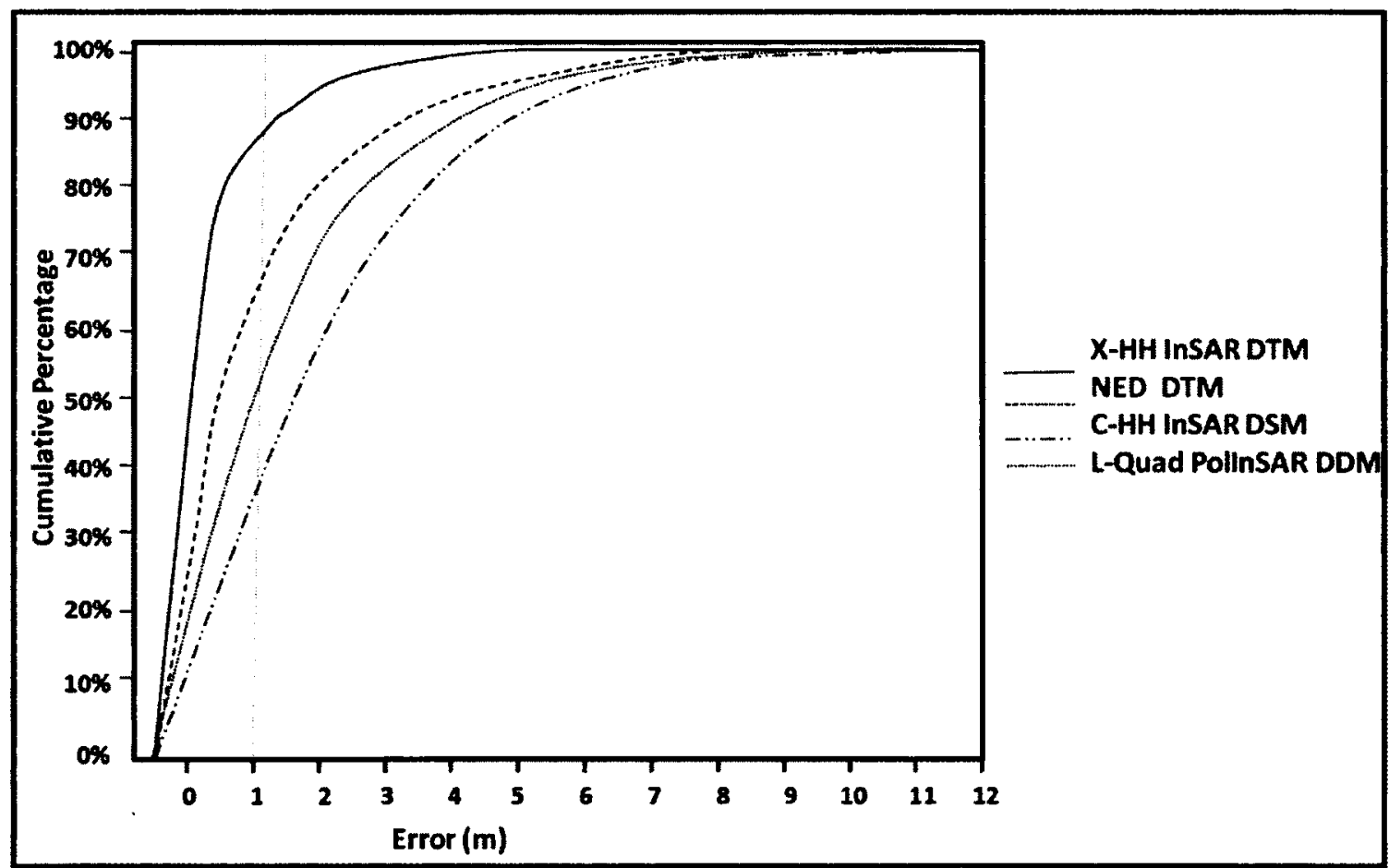

Figure 35. Cumulative distribution of the absolute value of individual point vertical errors for the X-HH InSAR DTM, NED DTM and SRTM C-HH InSAR DSM for the six research sites compared to the reference data. 
The mean errors (mean of the $\{D E M$ - reference data $\}$ point values or the central location of the residual error distribution) for all DEM data sets were positive, indicating that their elevations were on average higher than the reference elevations. This is expected because the presence of surface features in the InSAR/PolInSAR data will inflate the apparent mean error. Therefore, the mean value does not reflect errors in the DEM, but the extent to which surface features are present in the region being evaluated and the noise of the InSAR/PolInSAR sensors, in the order of about $30 \mathrm{~cm}$. Another possible explanation for the reference data being on average lower elevation than the InSAR DEMs is that part of the reference data was comprised of NGS elevations, which used the NAD27 geoid, whereas the DEM data used the NAD83 geoid. The relationship between NAD27 and NAD83 includes a change in the reference ellipsoid as well as modeling of the NAD27 distortions which exhibit regional trends in certain areas and regions where the distortions appear random. Given the variability and complexity of the distortions, it is of practical importance to simplify the transformation, thereby rendering both the distortion and ellipsoid changes to within acceptable tolerances (e.g. within 0.18 m; Lister, 2005; Mulcare, 2004). Existing geocoded images may then be transformed and knowledge of the incurred positional error taken into account.

In the case of the InSAR/PolInSAR data, these DEM accuracy results are expected because of the size of the SAR footprint (e.g. SAR pulse main lobe) and the general effect of land cover on the output DEMs. The elevation value for any InSAR/PollnSAR DSM posting or sample (e.g. square footprint somewhat larger than the DSM ground sample distance) results from a combined signal of many scattering objects. In open barren areas, the SAR signal can penetrate beneath the Earth's surface when it is a dry 
porous medium like dry sand, which would result in lower than bare earth scatterers contributing to the overall GSD. In contrast, raised objects, such as shrubs and trees located within the SAR pulse footprint, contribute to the overall elevation value measured for the given GSD in the DSM; which may be transferred to the derived DTM. Finally, the noise associated with the X-HH InSAR sensor is in the order of $30 \mathrm{~cm}$ (Intermap, 2011). The DTM is derived from the DSM data, by smoothing the DSM data over barren and grass terrain, resulting in higher than bare ground elevations overall. The $\mathrm{X}-\mathrm{HH}$ InSAR and $\mathrm{C}-\mathrm{HH}$ InSAR RMSE and mean errors are highest in the dense vegetation sites (two $\mathrm{MN}$, and two $\mathrm{AB}$ sites) possibly due to lesser ground scattering contributions compared to that than of the sparser vegetation cover of the $\mathrm{CO}$ and $\mathrm{AZ}$ sites.

These X-HH InSAR DTM vertical accuracy results were better than expected because the 3291 bare-earth elevation reference measurements were taken on slopes ranging from $0^{\circ}$ to just less than $30^{\circ}$, with one third of those beneath vegetated canopy (or in obstructed terrain). The published specification of the X-HH InSAR DTM data is $1 \mathrm{~m}$ RMSE for low sloped $\left(<10^{\circ}\right)$ and unobstructed terrain (barren and open land cover; Intermap, 2011), whereas the RMSE values for the Colorado and Arizona sites, which were comprised mostly of barren and short vegetation, were $0.78 \mathrm{~m}$ and $0.66 \mathrm{~m}$, respectively.

At the time of this research, there were no published NEXTMap X-HH InSAR DTM specifications for obstructed land cover located on $>10^{\circ}$ terrain slopes. However, it was anticipated that land cover type (barren or unobstructed versus vegetation/buildings or obstructed) and terrain slope, would have a significant effect on DEM vertical accuracies (Andersen et al., 2006; Izzawati et al., 2006; Woodhouse et al., 2003). The 
impact of vegetation type and terrain slope is further investigated in Sections 5.3.1. and

\section{1 .3 , respectively.}

The vertical accuracy for the L-Quad PolInSAR DTM data for the two Canadian sites was worse than that for the $\mathrm{X}-\mathrm{HH}$ InSAR data. This contrasts with theoretical expectations that L-band SAR signals should penetrate further into vegetation canopy and receive a greater portion of ground scattering than $X$-band $S A R$, which should result in better bare ground elevations or DTM data. However, these results concur with those presented in the literature (Rowland and Balzter, 2003; Zhang et al., 2008; Mercer et al., 2009a; 2009b). Reasons for these findings are presented in the discussion Section 6.2.

It was expected that the C-HH InSAR SRTM DSM would perform the worst of all DEMs being compared. Three possible reasons for this are as follows. 1) SRTM data have a GSD of $30 \mathrm{~m}$ for the U.S. sites and $90 \mathrm{~m}$ for the Canadian sites, which is coarser compared to the X-HH InSAR (5 m GSD), L-Quad PolInSAR (5 m GSD), and NED (10 m GSD) DTMs. The coarse GSD of the SRTM data would result in fewer "bare earth" elevations, especially through continuous vegetation canopy cover. 2) The SRTM data represent a DSM (not a DTM) where remnants of elevations of features above the ground (e.g. trees, buildings, shrubs) could be present in the DSM. 3) The SRTM data were older (2000, Figure 36) than the NEXTMap data (2007-2008; Figure 36), possibly leading to errors due to ground elevation changes in the years between SRTM and reference data acquisitions. These results concur with performance evaluations by the U. S. National Intelligence Agency (NGA), the USGS, and the SRTM project team which have shown an absolute vertical error of $5 \mathrm{~m}$ (Rosen et al., 2001a; 2001b; Smith and Sandwell, 2003; Sun et al., 2003). These results are better than the published SRTM 
specifications of $16 \mathrm{~m}$ vertical accuracy (Rabus et al., 2003). As expected, the errors at the two Canadian sites are similar to the two MN sites and the errors for these four sites are greater than for the $\mathrm{CO}$ and $\mathrm{AZ}$ sites. The Canadian and $\mathrm{MN}$ sites all have dense forest cover, whereas the $\mathrm{CO}$ and $\mathrm{AZ}$ sites do not. This indicates that it is not the coarser resolution of the Canadian data ( $90 \mathrm{~m}$ GSD) but dense vegetation that is the main cause of the higher errors at the Canadian and MN sites than at the $\mathrm{CO}$ and $\mathrm{AZ}$ sites.

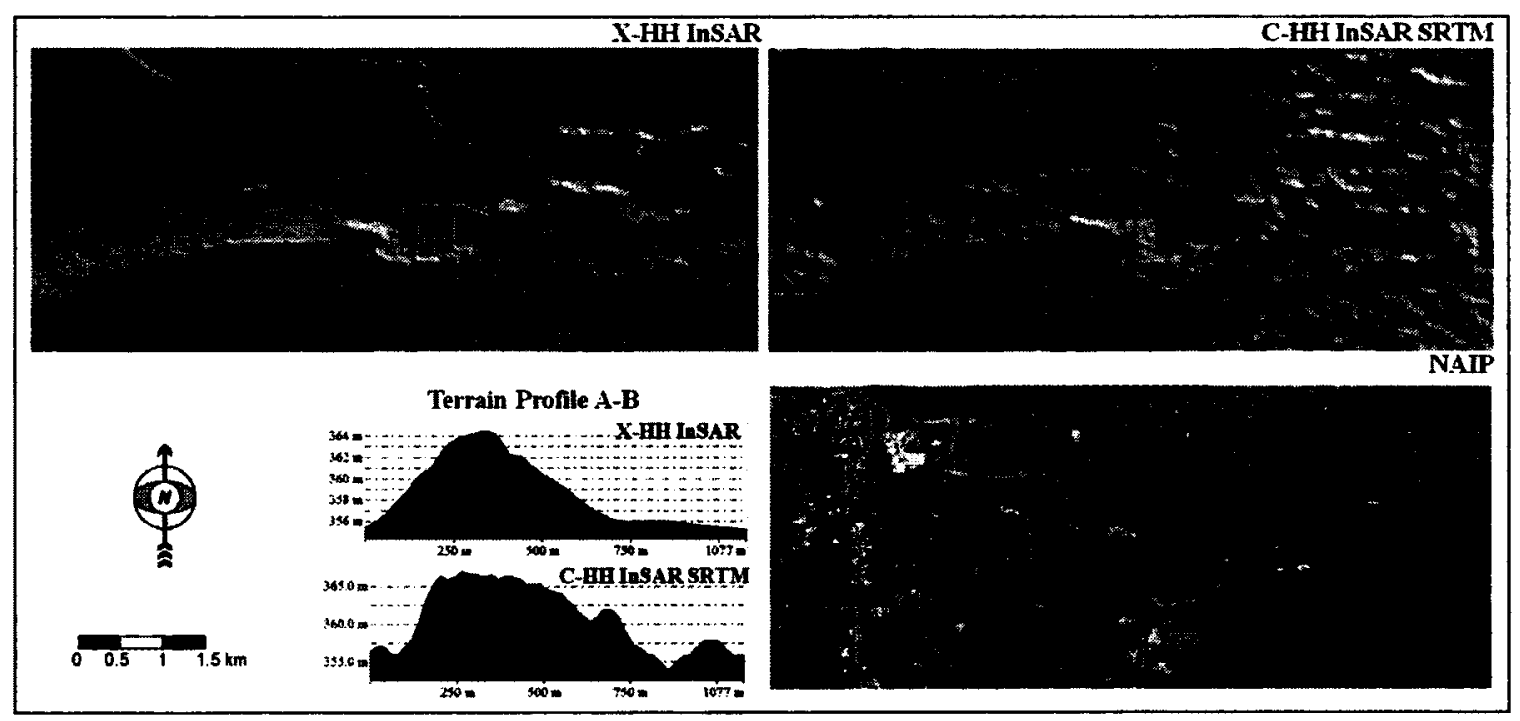

Figure 36. Comparison of DEM data for the International Falls, MN research site. Top left: 2007 X-HH InSAR DTM; top right: 2000 SRTM DSM; bottom left: elevation profiles for each data set over the A-B transect; bottom right: 2007 NAIP image.

The NED data vertical elevation errors presented in Table 15 are supported in the literature (Kellndorfer et al., 2004; Walker et al., 2007). In contrast to the X-HH InSAR DTM, the NED mean errors were not higher in the more forested MN sites, most likely due to the data collection methods were different (e.g. contours, photogrammetry, and 
LiDAR; NED, 2003) However, NED errors were two to three times greater than the XHH InSAR DTM errors. Like the SRTM data set, perhaps the age of the $10 \mathrm{~m}$ GSD NED DTM played a key role in vertical accuracy errors, compared to the X-HH InSAR data. The NED DTM data age ranges between 15 - 40 years older than the X-HH InSAR DTM, therefore, temporal and spatial resolution (5 m GSD InSAR DTM versus $10 \mathrm{~m}$ GSD NED DTM) differences could account for the lower overall vertical accuracy of the NED DTM in comparison to the X-HH InSAR DTM. Figure 37 shows example DTM data for the International Falls site that demonstrates differences between the X-HH InSAR DTM (collected in 2007) and NED DTM (collected in1986). A change in terrain landscape (resulting from top soil infill) and elevation values has occurred at the location of the profile labeled A-B.

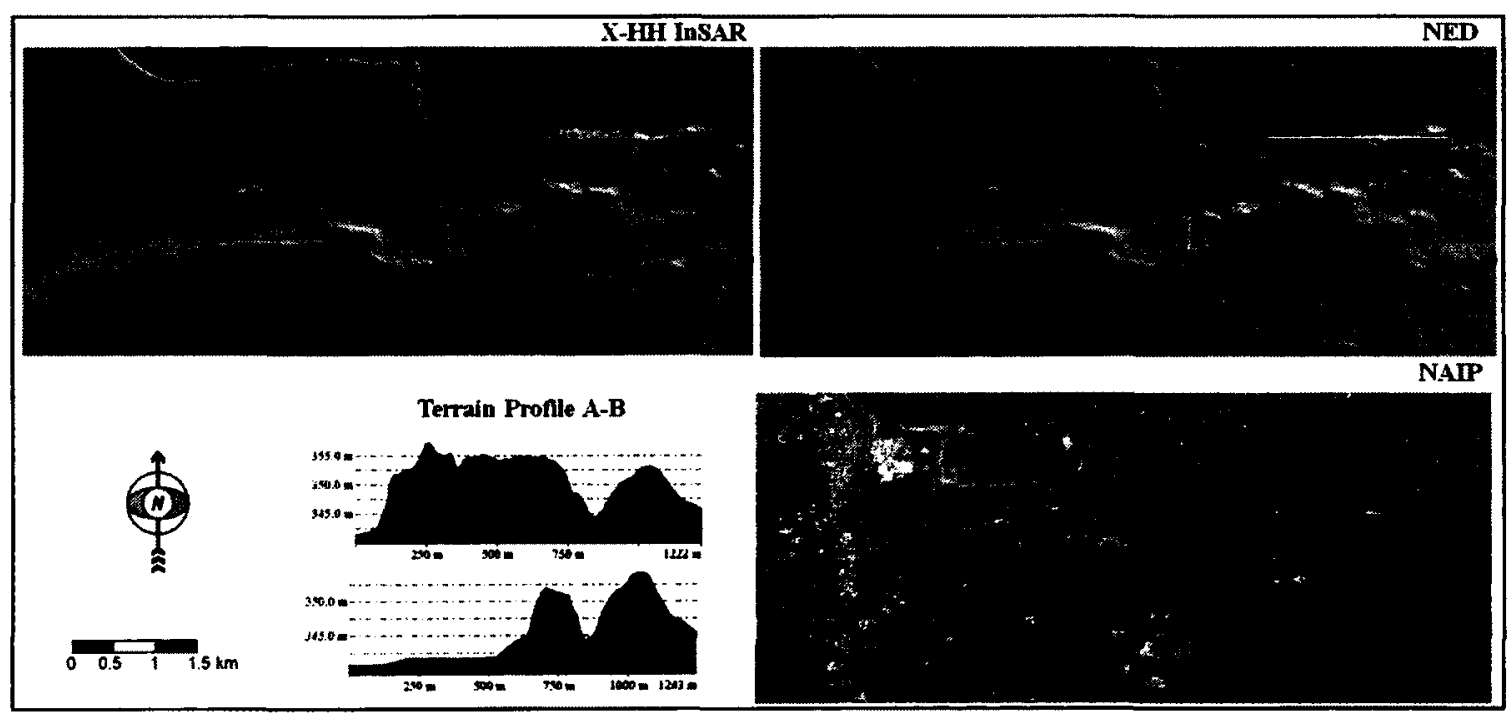

Figure 37. Comparison of DTM data for the International Falls, MN site. Top left: 2007 X-HH InSAR DTM; top right: 1986 NED DTM; bottom left: elevation profiles for each data set over the A-B profile; bottom right: 2007 NAIP data. 
Another possible explanation for the vertical accuracy error differences between the NED DTM and X-HH InSAR data could be that the method used to derive the NED DTM ranged from digitizing contours from topographic maps to extraction of sparse bare ground elevation points collected using stereo photogrammetry to incorporating LiDAR bare ground data, whereas the X-HH InSAR data are created from one method that generated a seamless dense grid of elevation values.

\subsubsection{Across the Conterminous U.S.}

Using NGS reference data (41,322 survey grade reference samples) for the conterminous U.S., the vertical accuracies of the X-HH InSAR DTM, C-HH InSAR DSM, and NED DTM were assessed over a much larger geographic extent than at the individual research sites, covering approximately 8 million $\mathrm{km}^{2}$. Only areas of barren, shrub, deciduous, conifers, mixed, or wetlands land cover types (as extracted from NLCD and NAIP were assessed. Table 16 presents the vertical RMS and mean errors calculated from all 41,322 NGS reference points illustrated in Figure 26.

Table 16. DEMs vertical accuracy assessment against 41,322 NGS reference elevations for the conterminous United States over terrain slopes less than $30^{\circ}$.

\begin{tabular}{|c|c|r|r|r|r|r|}
\hline \multirow{2}{*}{$\begin{array}{c}\text { \# NGS } \\
\text { Samples }\end{array}$} & \multicolumn{2}{|c|}{ X-HH InSAR DTM } & \multicolumn{2}{c|}{ C-HH InSAR SRTM } & \multicolumn{2}{c|}{ NED DTM } \\
\cline { 2 - 7 } & $\begin{array}{c}\text { RMSE } \\
(\mathrm{m})\end{array}$ & $\begin{array}{c}\text { Mean } \\
\text { Error (m) }\end{array}$ & $\begin{array}{c}\text { RMSE } \\
(\mathrm{m})\end{array}$ & $\begin{array}{c}\text { Mean } \\
\text { Error (m) }\end{array}$ & $\begin{array}{c}\text { RMSE } \\
(\mathrm{m})\end{array}$ & $\begin{array}{c}\text { Mean } \\
\text { Error (m) }\end{array}$ \\
\hline 41,322 & 1.08 & 0.31 & 4.22 & 0.25 & 3.37 & 0.52 \\
\hline
\end{tabular}


Across the broader region, the errors are slightly higher (but still always positive for all DEMs) than those presented for the six research sites above. One explanation could an even distribution of NGS reference points among land cover classes across the U.S. compared to a larger proportion of open and shrub vegetation class samples located at the $\mathrm{AZ}$ and $\mathrm{CO}$ sites analyzed in the research site vertical accuracy assessment.

The X-HH InSAR DTM overall vertical accuracy is slightly higher than the Intermap $1 \mathrm{~m}$ RMSE published specification. As stated previously, the published specification for NEXTMap is for low sloped $\left(10^{\circ}\right)$, unobstructed terrain (open and barren), whereas the $41,322 \mathrm{NGS}$ reference points were taken on slopes ranging from $0^{\circ}$ to $30^{\circ}$, with one quarter of those beneath vegetated canopy (or obstructed terrain). Thus, these results are better overall than expected given the $1 \mathrm{~m}$ RMSE specification. The SRTM DSM performed better than the assessment of the six research sites and achieved better accuracies than the published specification of $16 \mathrm{~m}$ absolute vertical height at a 90\% confidence level (Rabus et al., 2003; Smith and Sandwell, 2003; and Rosen et al., 2001a; 2001b). The NED achieved slightly higher errors than those presented for the research sites and worse than the $2.44 \mathrm{~m}$ often quoted in the literature (NED, 2011).

The cumulative error plot (Figure 38) indicates that the X-HH InSAR DTM, NED DTM and SRTM C-HH DSM have a vertical accuracy smaller than $1 \mathrm{~m}$ for $89 \%, 71 \%$, and $39 \%$ of their elevation data, respectively. These results trend well with the results of the six research sites presented in Figure 35. 


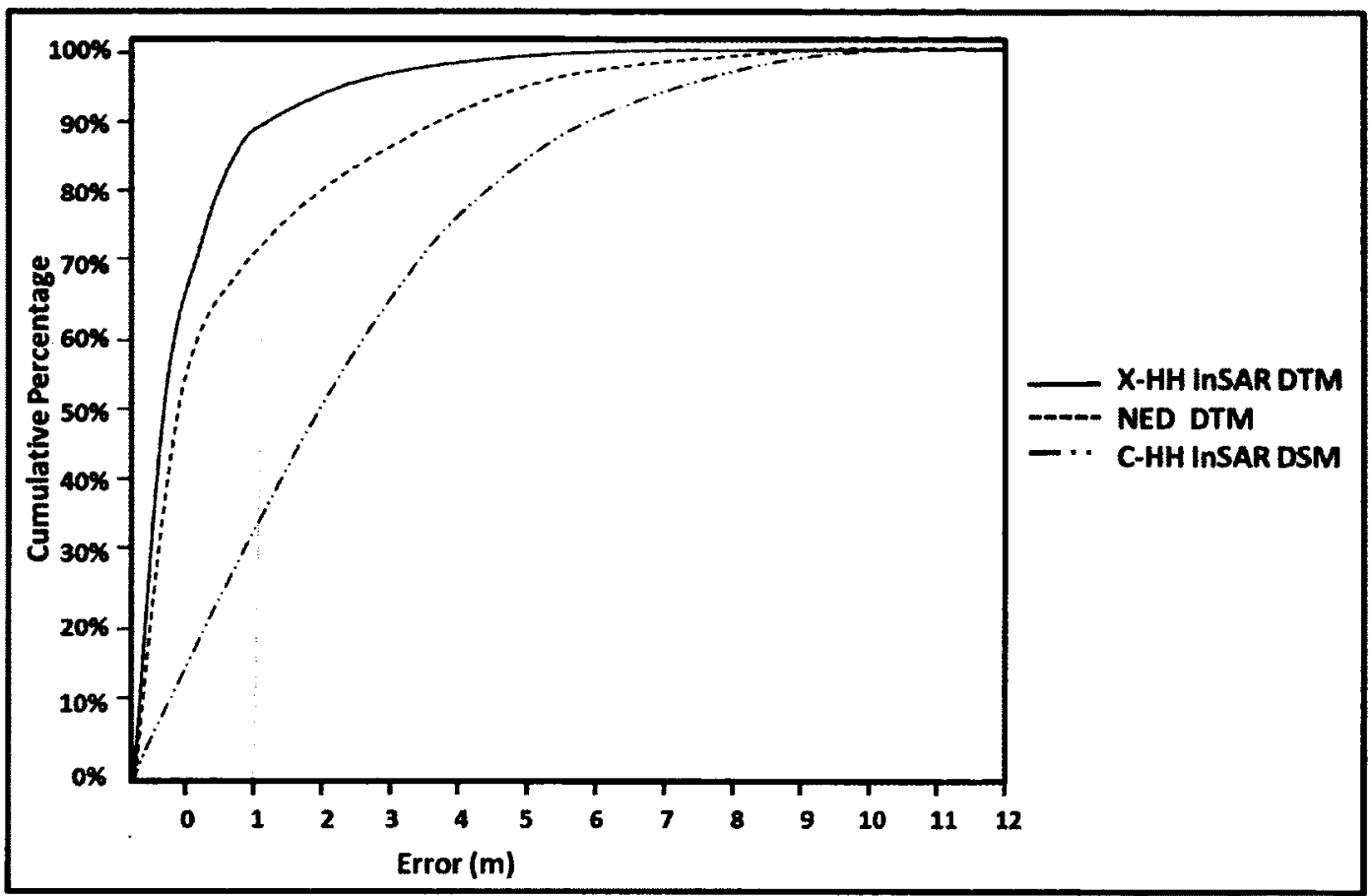

Figure 38. Cumulative distribution of the vertical error for the X-HH InSAR DTM, NED DTM and SRTM C-HH InSAR DSM for the conterminous U.S. Error was calculated through comparison with NGS data.

Given the large geographic area analyzed, these findings are promising, indicating that the X-HH InSAR derived DTM data are suitable for inclusion in canopy height modelling presented in sections 5.2 and 5.3.

\subsubsection{DEMs Vertical Accuracy Assessment - Stratified by Barren and Five Vegetation Classes}

The DEMs were analyzed to quantify vegetation class dependent errors in the ground surface elevation data. Barren and vegetation land cover classes were mapped using the methods described in Section 4.4.2. Section 5.1.2.1 presents the results for the six research sites and Section 5.1.2.2 presents the results for conterminous United States. 


\subsubsection{Six Research Sites}

The results for the six research sites stratified by land cover (barren, shrub, deciduous, conifers, mixed, and wetlands) over all terrain slopes $\left(0^{\circ}-30^{\circ}\right)$, are presented in Table 17.

Table 17. DEMs vertical accuracy assessment against reference measurements stratified by land cover at the six sites for all terrain slopes.

\begin{tabular}{|c|c|c|c|c|c|c|c|c|c|}
\hline \multirow[b]{2}{*}{$\begin{array}{c}\text { \# of } \\
\text { Ref. } \\
\text { Samples }\end{array}$} & \multirow[b]{2}{*}{$\begin{array}{l}\text { Land } \\
\text { Cover }\end{array}$} & \multicolumn{2}{|c|}{ X-HH DTM } & \multicolumn{2}{|c|}{ L-Quad DTM } & \multicolumn{2}{|c|}{ C-HH DTM } & \multicolumn{2}{|c|}{ NED DTM } \\
\hline & & $\begin{array}{l}\text { RMSE } \\
\text { (m) }\end{array}$ & $\begin{array}{l}\text { Mean } \\
\text { Error } \\
(\mathrm{m})\end{array}$ & $\begin{array}{l}\text { RMSE } \\
\text { (m) }\end{array}$ & $\begin{array}{c}\text { Mean } \\
\text { Error } \\
(\mathrm{m})\end{array}$ & $\begin{array}{l}\text { RMSE } \\
\text { (m) }\end{array}$ & $\begin{array}{l}\text { Mean } \\
\text { Error } \\
(m)\end{array}$ & $\begin{array}{l}\text { RMSE } \\
\text { (m) }\end{array}$ & $\begin{array}{l}\text { Mean } \\
\text { Error } \\
(\mathrm{m})\end{array}$ \\
\hline 578 & $\overline{\text { Barren }}$ & 0.63 & 0.17 & $\overline{3.11}$ & 1.89 & $\overline{3.7}$ & 0.97 & $\overline{3.49}$ & 0.81 \\
\hline 580 & Shrub & 0.94 & 0.28 & N/A & $\mathrm{N} / \mathrm{A}$ & 4.5 & 1.63 & $\overline{1.11}$ & $\overline{0.04}$ \\
\hline 529 & Deciduous & 2.23 & 0.82 & 3.59 & 3.24 & $\overline{5.13}$ & 1.14 & 3.15 & 0.68 \\
\hline 516 & Conifers & 2.21 & 0.79 & 3.89 & 2.33 & 6.16 & 2.08 & 2.61 & 0.83 \\
\hline 527 & Mixed & 3.17 & 1.53 & 3.01 & 2.87 & $\overline{6.64}$ & 0.98 & 3.56 & $\overline{0.08}$ \\
\hline 288 & Wetlands & 1.73 & 0.59 & 3.99 & 1.71 & 4.82 & 1.34 & 2.31 & 0.78 \\
\hline
\end{tabular}

As expected, accuracy was generally higher for barren land cover than for the vegetation classes, with the exception of the NED and L-Quad data. It was expected that X-HH InSAR DTM vertical accuracy in barren land cover would be better than in vegetated land cover because of the interactions of X-band radar with vegetation canopies described in section 2.6.2. These DTM data had also been edited to remove elevations of features above the ground; however, it is evident that some residual error still exists. 
Similar effects were found for the other two radar-based DEMs. On the other hand, the NED data methodology extracts bare ground elevations from contours, stereo-optical viewing, and photogrammetry, or from last return LiDAR data which represent bare ground elevations rather than feature surface elevations. Therefore, the NED DTM accuracy is not markedly poorer in vegetated cover compared to barren areas.

The results of the X-HH InSAR DTM vertical assessment in barren terrain presented in this research agree with several other previous studies using similar data that have found accuracies ranging from $0.17-1.1 \mathrm{~m}$ (Dowman and Fischer (2003), Dowman et al. (2003), Mercer (2004)). In contrast to the X-HH and SRTM C-HH DEMs, the vertical accuracy for the L-Quad DTM data in barren terrain (Table 17) was about the same as for the vegetated areas. Much of the PolInSAR RVoG technique research and validation efforts presented in the literature to date relate to the extraction of tree height rather than bare ground elevations (e.g., Zhang et al. (2008) and references therein) rather than bare ground elevations. Additional research and testing of L-Quad RVoG technique are therefore required to optimize the phase coherence to derive a better bare earth elevation estimates. The SRTM C-HH InSAR DSM and NED DTM RMSEs for barren land cover were approximately four times greater than that of the X-HH InSAR DTM. As discussed previously, a possible reason for this could be could be the differences in GSD and the age of the NED and SRTM data, both being over 10 years older than the NGS reference data.

The overall X-HH InSAR DTM vertical accuracy over shrub vegetation was less than $1 \mathrm{~m}$. This was expected since the relatively open structure of shrub vegetation (i.e., space between stems) compared to other vegetation classes likely allows greater 
penetration of microwave pulses to the ground resulting in greater ground contributions in the DSM data used to derive the DTM data. Furthermore, the bulk of the shrub vegetation samples were in semi-arid (Colorado) and arid (Arizona) eco-zones where the lack of moisture causes the microwave signals to penetrate more than in areas where moisture content is higher. Finally, while the X-HH InSAR data for all other sites were collected during leaf-on conditions, some of the Arizona site data, where there were a large number of the in situ shrub plot installations, were collected during leaf-off conditions (Figure 39). This could result in greater contributions from the ground and a lower overall DSM height compared to leaf-on conditions; however, literature regarding a comparison of signal attenuation in leaf-on and leaf-off X-HH InSAR DSM data is lacking in the literature. This phenomenon affected only a small portion of the data and was therefore not a significant contribution to the overall error

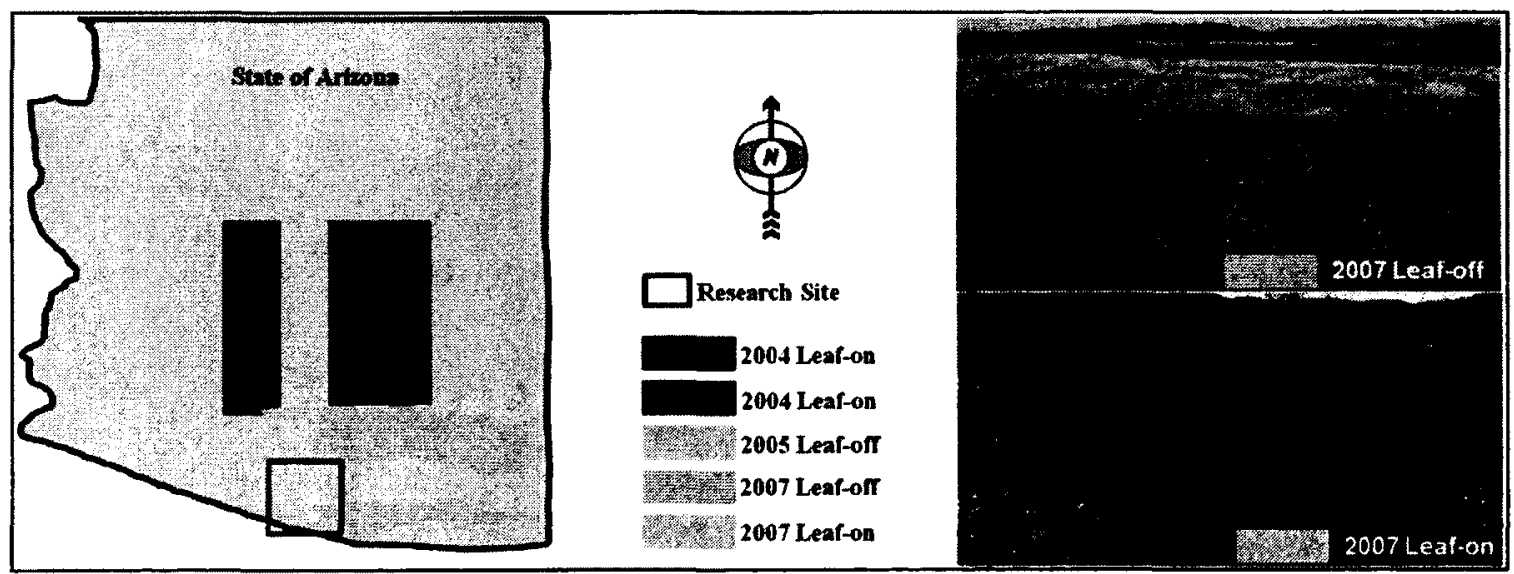

Figure 39. Data collection conditions for the Arizona research site (red box) where shrub plot installations over vegetation samples were observed. Top right photo is an example of leaf-off shrub; lower right photo is an example of leaf-on shrub vegetation. 
Shrub vegetation cover was not large enough (less than $0.5 \%$ ) in the Alberta sites, thus the L-Quad PolInSAR DTM accuracy was not assessed for this vegetation class. The SRTM C-HH DSM followed similar trends to the X-HH InSAR DTM vertical accuracy results, where the barren land cover performed better than the shrub vegetation cover. The NED data performed better in the shrub vegetation than in barren land, which was unexpected and difficult to explain without additional assessments. The mixed vegetation class had the greatest RMSE, possibly due to the dense canopy formed by integration of conifer and deciduous tree crowns, which have differing morphologies. Wetlands vegetation had the lowest RMSE amongst these classes because its vegetation was less dense than in the forest classes, resulting in greater signal interaction with the ground and vegetation.

The X-HH InSAR DTM RMSE errors range from $1.73 \mathrm{~m}$ to $3.17 \mathrm{~m}$ for deciduous, conifers, mixed and wetlands vegetation, thereby indicating that the $\mathrm{X}-\mathrm{HH}$ InSAR DTM data are a reliable measure of ground topography and thus, suitable for use in the canopy height estimation method presented in this research.

\subsubsection{Across the Conterminous U.S.}

The vertical DEM accuracies for the conterminous United States stratified by land cover over terrain slopes of $0^{\circ}-30^{\circ}$ are presented in Table 18. These results follow the pattern found for the six research sites (Table 16). For example, accuracy was poorer in regions covered by vegetation in comparison to barren land cover and the mean errors were positive for all land cover and data types indicating that their elevations were on average higher than the reference elevations. NED DTM and SRTM C-HH InSAR DSM 
RMSE values for barren land cover were four times greater than that of the X-HH InSAR DTM (see explanation in 5.1.3). Overall, the results presented provide confidence that X-HH InSAR derived DTM data are accurate in barren and vegetated land cover and suitable as a datum from which a canopy height estimates can be derived.

Table 18. DEMs vertical accuracy assessment against 41,322 NGS reference elevations for the conterminous United States stratified by land cover type.

\begin{tabular}{|c|c|c|c|c|c|c|c|}
\hline \multirow[b]{2}{*}{$\begin{array}{l}\text { Land } \\
\text { Cover } \\
\text { Type }\end{array}$} & \multirow[b]{2}{*}{$\begin{array}{l}\text { \# NGS } \\
\text { Points }\end{array}$} & \multicolumn{2}{|c|}{$\begin{array}{c}\text { X-HH InSAR } \\
\text { DTM }\end{array}$} & \multicolumn{2}{|c|}{$\begin{array}{c}\text { C-HH InSAR } \\
\text { DSM } \\
\end{array}$} & \multicolumn{2}{|c|}{ NED DTM } \\
\hline & & $\begin{array}{c}\text { RMSE } \\
\text { (m) }\end{array}$ & $\begin{array}{l}\text { Mean } \\
\text { Error } \\
(\mathrm{m})\end{array}$ & $\begin{array}{c}\text { RMSE } \\
(\mathrm{m})\end{array}$ & $\begin{array}{l}\text { Mean } \\
\text { Error } \\
(\mathrm{m})\end{array}$ & $\begin{array}{c}\text { RMSE } \\
(\mathrm{m})\end{array}$ & $\begin{array}{c}\text { Mean } \\
\text { Error } \\
(\mathrm{m})\end{array}$ \\
\hline Barren & 28,987 & 0.71 & 0.05 & 3.80 & 0.49 & 3.55 & 0.25 \\
\hline Shrub & 4,047 & $\overline{0.94}$ & 0.75 & 5.35 & 1.77 & 2.38 & 0.56 \\
\hline Deciduous & 2,348 & 2.16 & 0.97 & 5.40 & 0.81 & 2.30 & 0.62 \\
\hline Conifers & 1,843 & 2.29 & 0.98 & 6.25 & 2.14 & 2.48 & 0.63 \\
\hline Mixed & 2,080 & 2.57 & 1.21 & 4.61 & 0.98 & 2.79 & 0.39 \\
\hline Wetlands & 2,017 & 1.93 & 0.69 & 4.38 & 1.52 & 2.17 & 0.71 \\
\hline
\end{tabular}

\subsubsection{DEM Vertical Accuracy Assessment - Stratified by Slope}

\subsubsection{Six Research Sites}

The vertical accuracy assessment for the research sites stratified by slope for all land cover classes is presented in Table 19. Slopes ranged between $0^{\circ}$ and $30^{\circ}$ in the U.S. sites while for the $\mathrm{AB}$ sites they were less than $10^{\circ}$ and thus excluded from the slope assessment. As expected, the RMS and mean errors increased with increasing terrain slope for all data types. As in the two previous analyses, mean errors were consistently positive indicating a positive bias in elevation estimates compared to the bare ground 
reference data. The RMSE errors for slopes greater than or equal to $30^{\circ}$ were greater than $6 \mathrm{~m}$ for all data types; however, less than one percent of the area of the six research sites was on terrain slopes greater than $30^{\circ}$.

Table 19. DEMs accuracy stratified by terrain slope at the four U.S. research sites, all data combined.

\begin{tabular}{|l|r|r|r|r|r|r|r|}
\hline \multirow{2}{*}{ Slope } & \multirow{2}{*}{$\begin{array}{c}\text { \# Ref. } \\
\text { Samples }\end{array}$} & \multicolumn{2}{|c|}{ X-HH InSAR DTM } & \multicolumn{2}{c|}{ C-HH InSAR DSM } & \multicolumn{2}{|c|}{ NED DTM } \\
\cline { 3 - 8 } & & $\begin{array}{c}\text { RMSE } \\
(\mathrm{m})\end{array}$ & $\begin{array}{c}\text { Mean } \\
\text { Error } \\
(\mathrm{m})\end{array}$ & $\begin{array}{c}\text { RMSE } \\
(\mathrm{m})\end{array}$ & $\begin{array}{c}\text { Mean } \\
\text { Error } \\
(\mathrm{m})\end{array}$ & $\begin{array}{c}\text { RMSE } \\
(\mathrm{m})\end{array}$ & $\begin{array}{c}\text { Mean } \\
\text { Error } \\
(\mathrm{m})\end{array}$ \\
\hline$\leq 10^{\circ}$ & 2613 & 1.18 & 0.04 & 3.56 & 0.60 & 2.43 & 0.19 \\
\hline $11-29^{\circ}$ & 420 & 3.42 & 0.17 & 7.23 & 3.61 & 4.65 & 2.01 \\
\hline$\geq 30^{\circ}$ & 253 & 6.07 & 1.78 & 13.95 & 7.15 & 6.90 & 2.97 \\
\hline
\end{tabular}

\subsubsection{Across the Conterminous U.S.}

The vertical accuracy assessment for the conterminous United States stratified by slope for all land cover classes is presented in Table 20. The same trends were evident as for the research site analysis above with accuracies similar to those of Table 19.

Table 20. DEMs accuracy stratified by terrain slope over the conterminous United States.

\begin{tabular}{|c|r|r|r|r|r|r|r|}
\hline \multirow{2}{*}{ Slope } & \multirow{2}{*}{$\begin{array}{c}\text { \# Ref. } \\
\text { Samples }\end{array}$} & \multicolumn{2}{|c|}{\begin{tabular}{c} 
X-HH InSAR DTM \\
\cline { 3 - 8 }
\end{tabular}} & $\begin{array}{c}\text { C-HH InSAR } \\
\text { RSM }\end{array}$ & \multicolumn{2}{|c|}{ NED DTM } \\
\hline$\leq 10^{\circ}$ & 37190 & 1.17 & 0.28 & 4.01 & 0.63 & 3.37 & 0.32 \\
\hline $11-29^{\circ}$ & 3306 & 2.75 & 1.57 & 6.11 & 3.45 & 4.18 & 2.22 \\
\hline$\geq 30^{\circ}$ & 826 & 5.28 & 1.78 & 12.33 & 3.90 & 6.15 & 1.13 \\
\hline
\end{tabular}




\subsection{Research Objective 2: Assessment of X-HH InSAR, L-Band PolInSAR, and SRTM C-HH InSAR $h_{\text {spe }}$ as an Estimate of Canopy Height}

The previous section demonstrated the ability of X-and L-band InSAR/PolInSAR as a reliable source of DTM data. The X-HH InSAR DTM and L-Quad PollnSAR DTMs, where available, were used in conjunction with the X-/C-/L-Band digital surface models (DSM) to derive scattering phase centre heights $\left(h_{\mathrm{spc}}\right)$. The $h_{\mathrm{spc}}$ values were then compared to field measured or LiDAR canopy heights as described in section 4.3. The results of the visual and vertical accuracy assessments of the performance of the $\mathrm{X}-/ \mathrm{C}-/ \mathrm{L}-$ Band $h_{\text {spc }}$ as a first estimation of canopy height over a range of SAR incidence angles are presented in sections 5.2.1 - 5.2.4.

\subsubsection{Visual Comparison of InSAR and PolInSAR $h_{\text {spe }}$ Surfaces}

Three dimensional (3D) perspective views for $\mathrm{X}-, \mathrm{C}-$, and $\mathrm{L}-\mathrm{band} \mathrm{h}_{\mathrm{spc}}$ data compared to the LiDAR derived canopy height model (CHM) for a section of the Edson $\mathrm{AB}$ research site are illustrated in Figure 40 . The 3D views clearly illustrate the variation in detail of the canopy structure over dense coniferous forest for data with different resolutions or ground sampling distance (GSD). As expected, the LiDAR CHE, with $2 \mathrm{~m}$ GSD, provides the greatest detail, whereas the $90 \mathrm{~m}$ GSD C-band SRTM data produced a smooth rendition of the forest canopy, offering little detail about canopy structure. The X- and L-band data sets differ in canopy structure detail possibly because the shorter X-band wavelength interacts mostly with twigs and branches of the upper canopy compared to the L-band data which penetrates more into the canopy and interacts with tree trunks in addition to twigs and branches. 


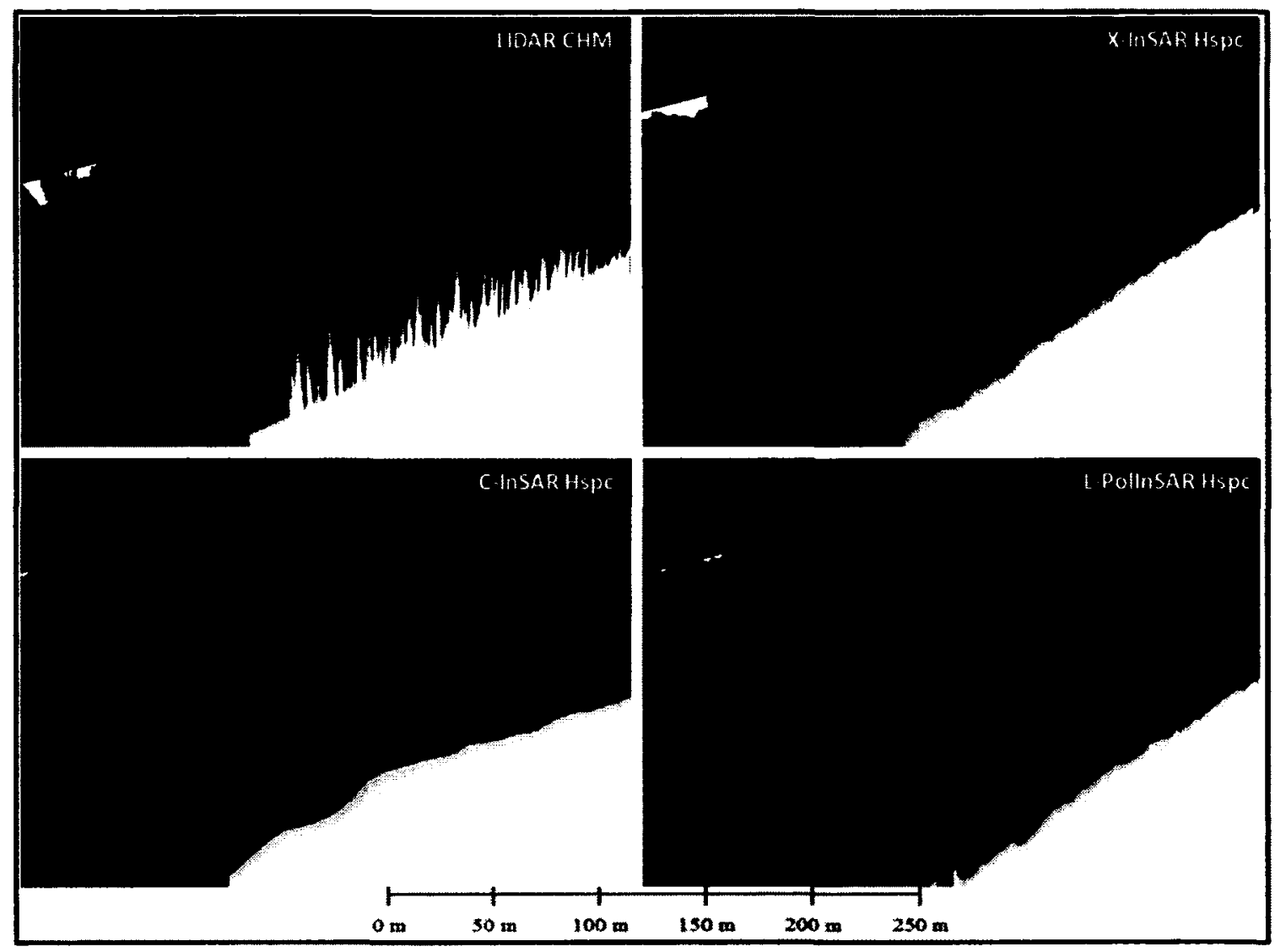

Figure 40. 3-D perspective view of $\mathrm{h}_{\mathrm{spc}}$ for a section of conifers and mixed forests within the Edson, AB study site. LiDAR CHM (Top Left), X-HH InSAR $h_{\text {spc }}$ (Top Right), CHH InSAR $h_{\text {spc }}$ (Bottom Left), and the L-Band PolInSAR $h_{\text {spc }}$ (Bottom Right).

The X-HH InSAR and L-Quad PolInSAR $h_{s p c}$ maps for the six research sites are presented in Figures $41-46$ (X-band) and $45-46$ (L-Band). An elevation of zero (blue on the $h_{\text {spc }}$ maps) may represent water or barren land cover. 


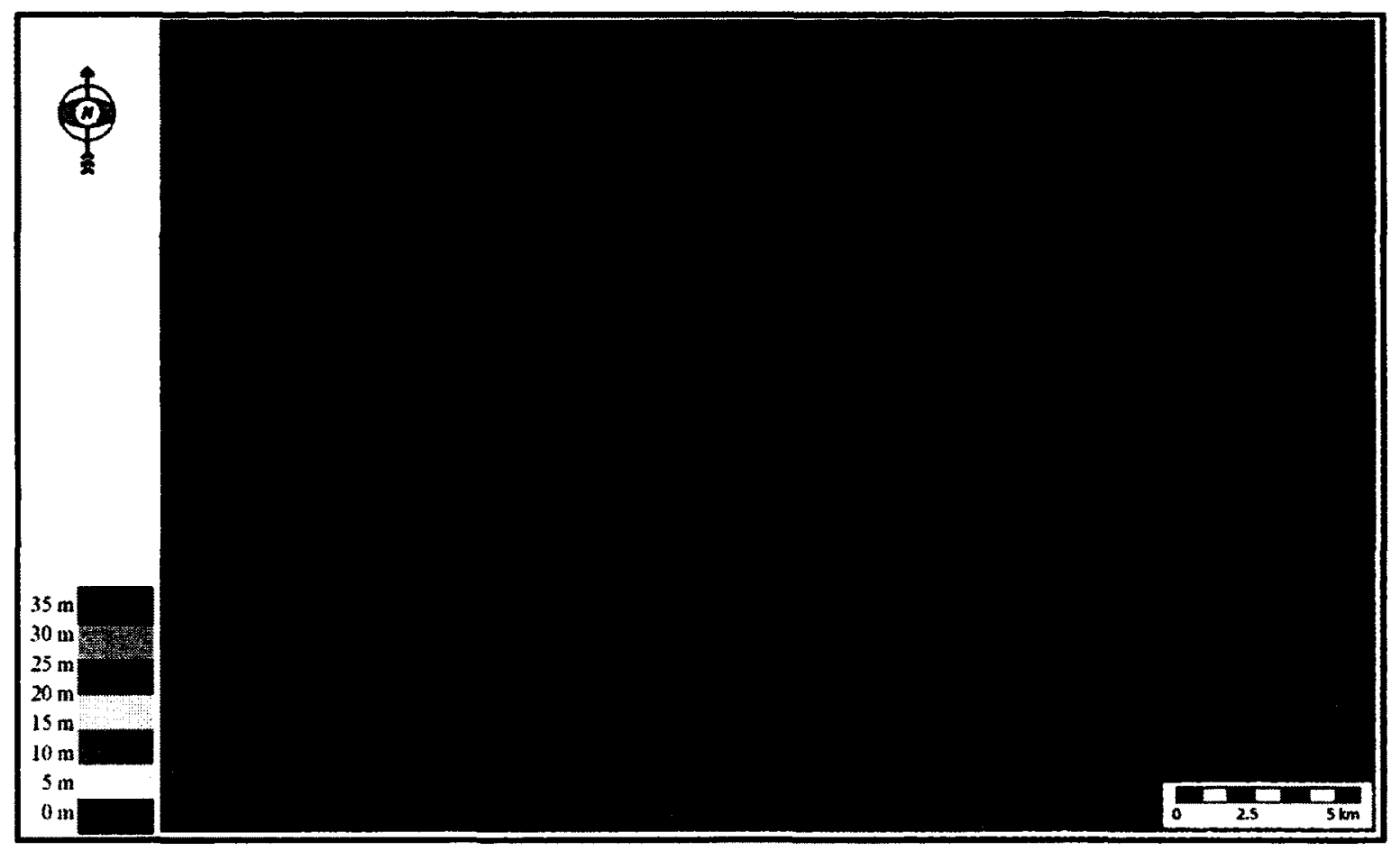

Figure 41. Ely research site X-HH InSAR derived $\mathrm{h}_{\mathrm{spc}}$.

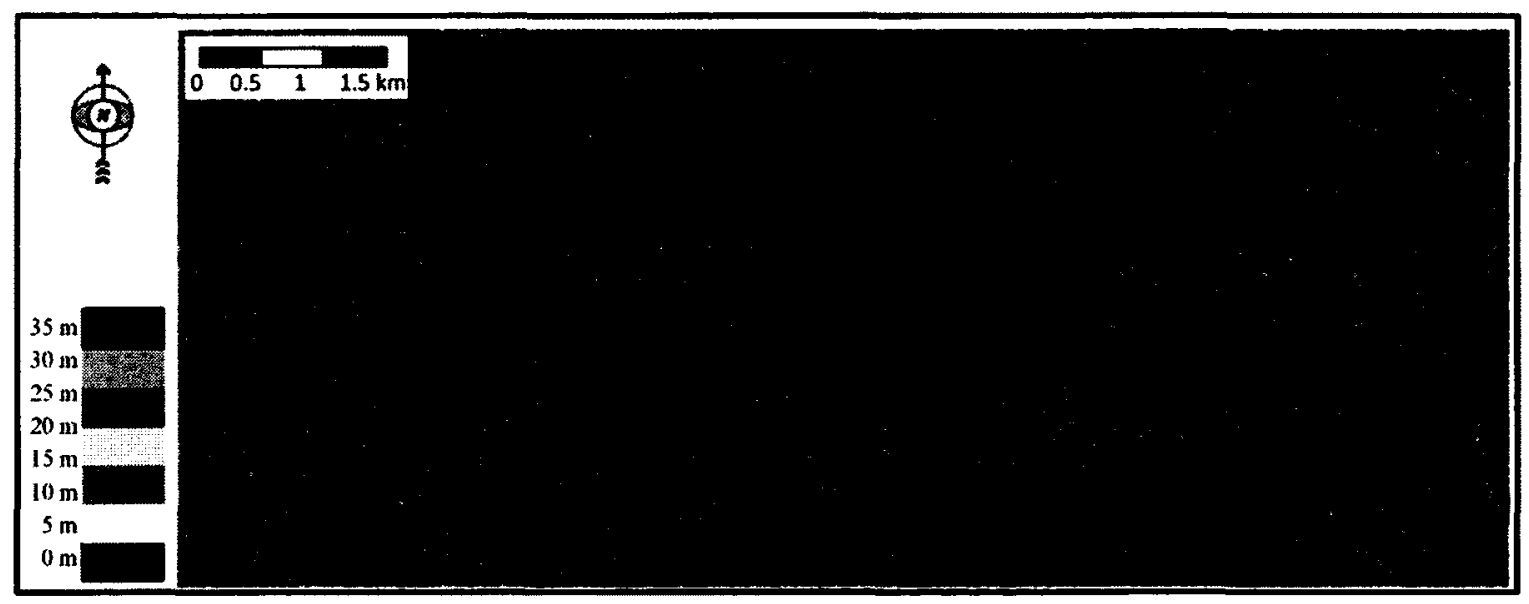

Figure 42. International Falls research site X-HH $\operatorname{InSAR}$ derived $h_{\text {spc }}$. 


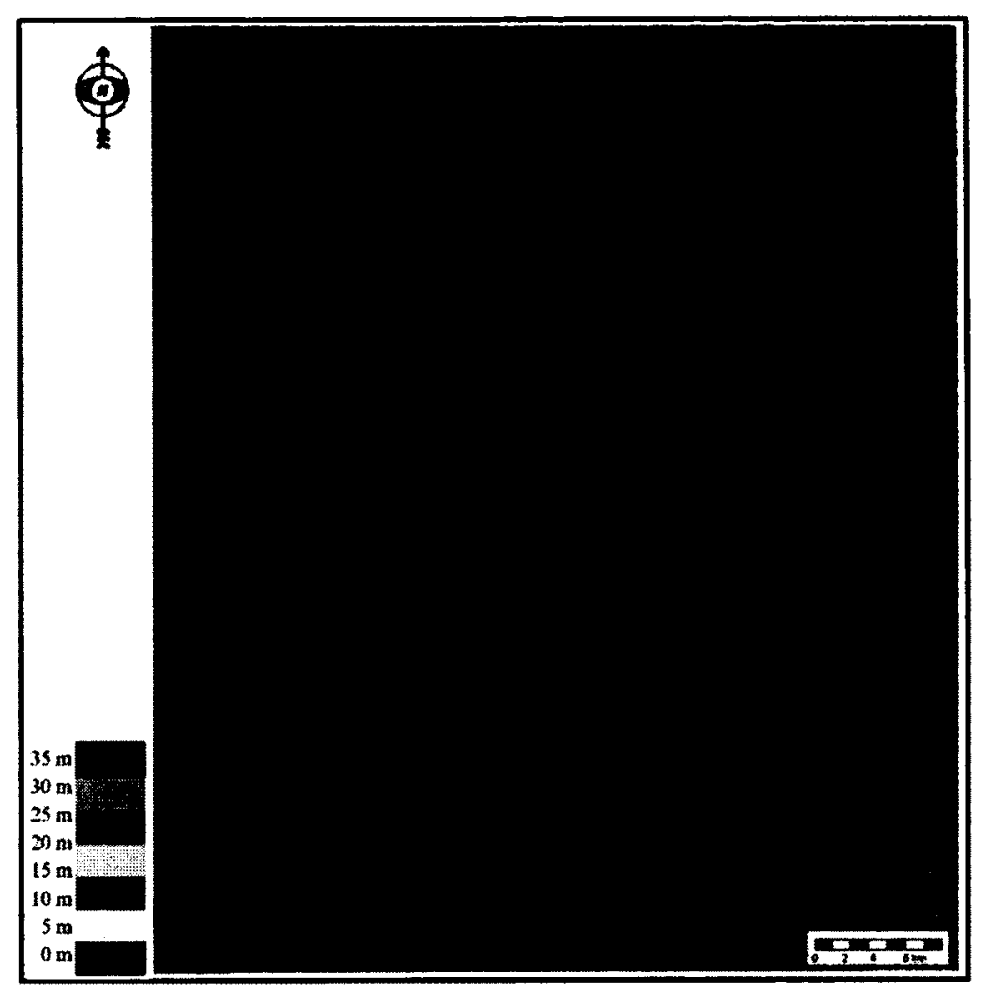

Figure 43. Colorado research site X-HH $\operatorname{InSAR}$ derived $h_{\mathrm{spc}}$.

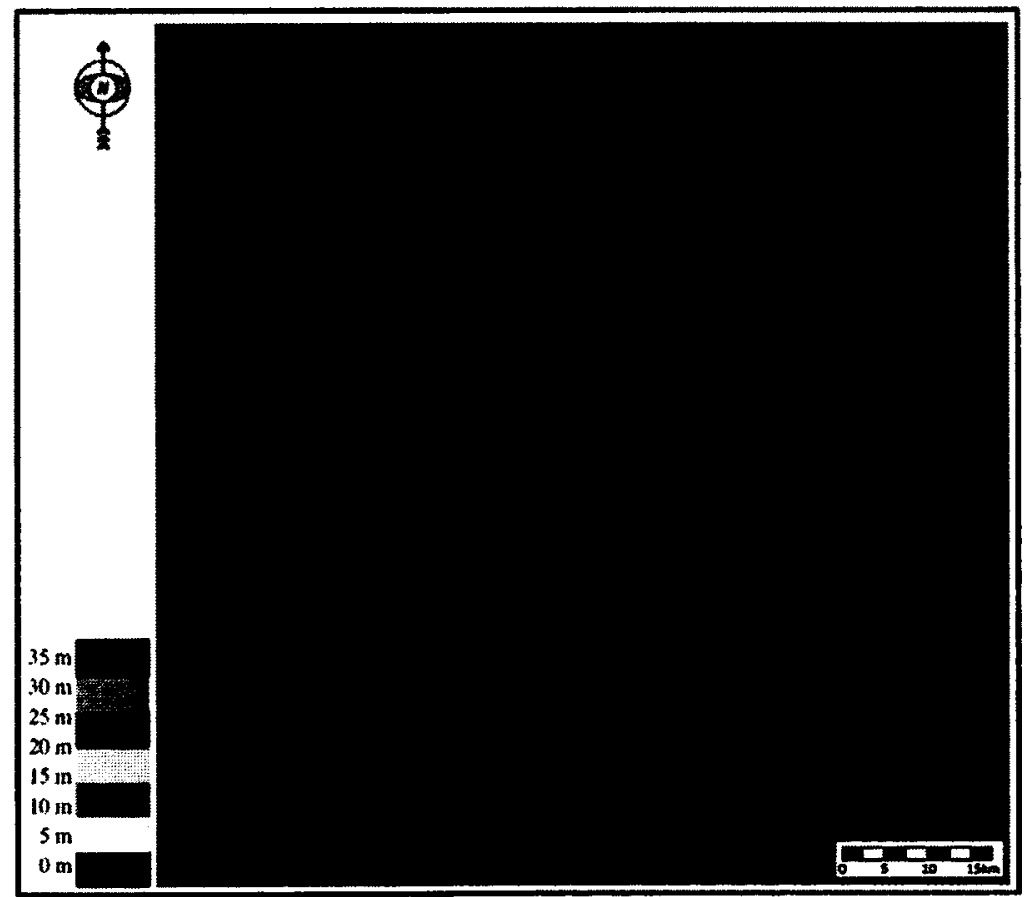

Figure 44. Arizona research site X-HH InSAR derived $h_{\text {spc. }}$ 


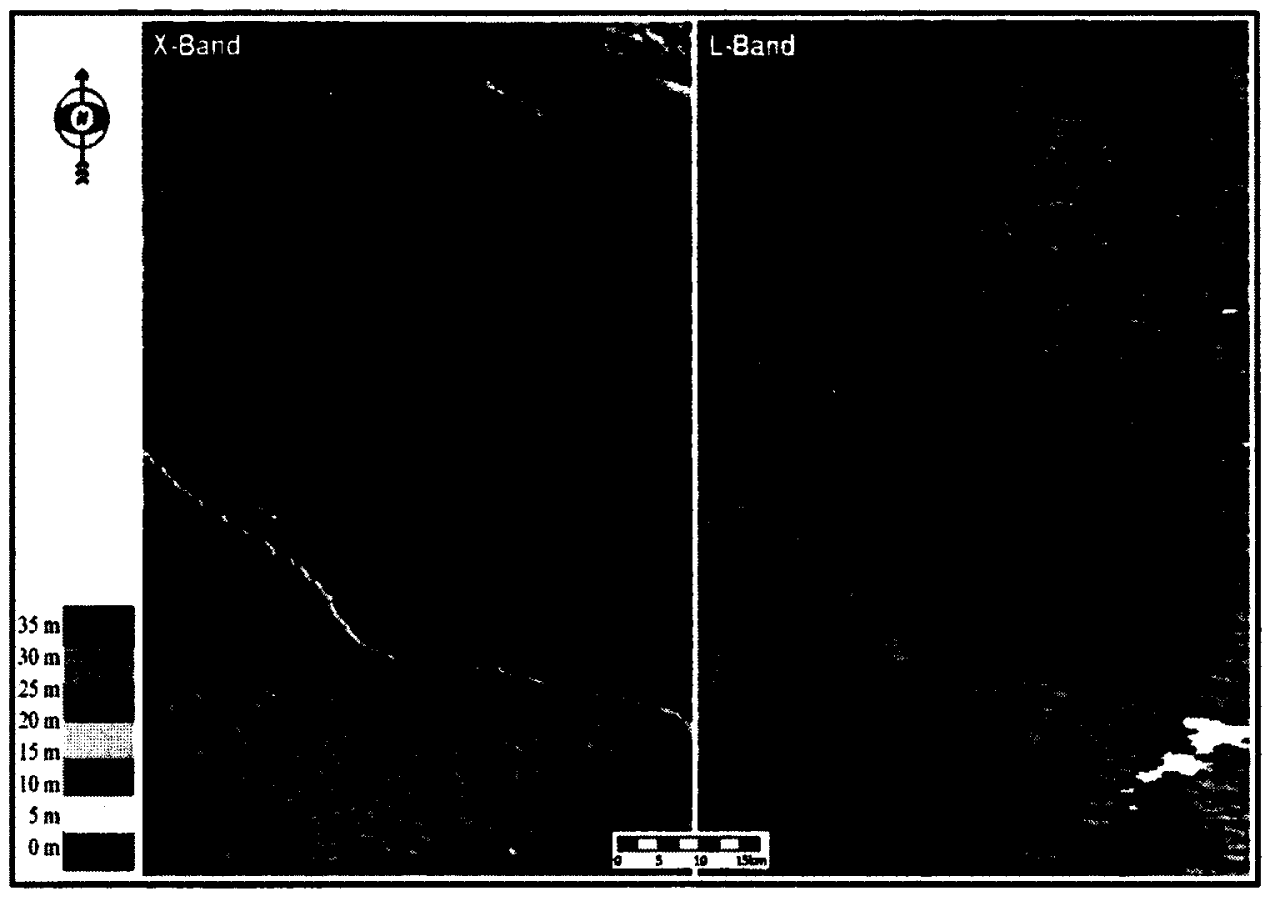

Figure 45. Edson research site X-HH InSAR (left image) and L-Quad PollnSAR (right image) derived $h_{\text {spc }}$.

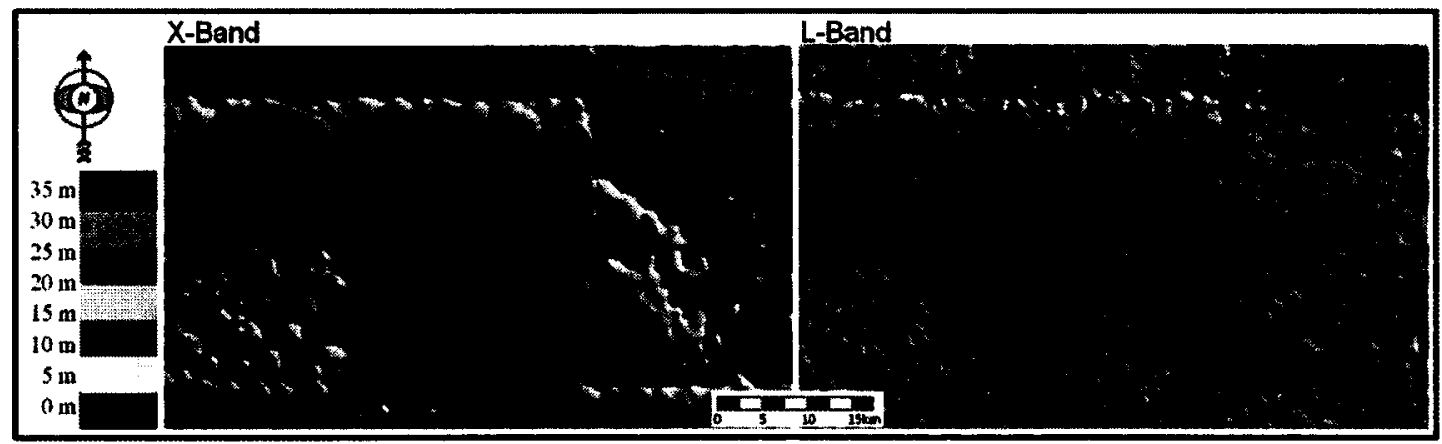

Figure 46. Burnstick Lake research site X-HH InSAR (left image) and L-Quad PollnSAR (right image) derived $h_{\text {spc }}$.

5.2.2. X-HH InSAR, L-Quad PolInSAR, and C-HH SRTM InSAR hpe as an

\section{Estimate of Canopy Height - Stratified by Vegetation Type}

The results of the vertical accuracy assessment of the $h_{\text {spc }}$ derived from the three InSAR data sets as an estimate of canopy height over all research sites and stratified by 
vegetation type are given in Tables 21 (RMSE and mean errors) and 22 (percentage of canopy height retrieved). The mean errors were negative for all data sources and land cover categories indicating that $h_{\text {spc }}$ consistently under-estimated canopy height for all vegetation types.

Table 21. X-HH InSAR, L-Band PolInSAR and SRTM C-HH InSAR derived $\mathrm{h}_{\mathrm{spc}}$ vertical error assessment against in situ and LiDAR canopy height for all research sites (where applicable), stratified by vegetation type. Mean tree height for all sites are given in column 3 for comparison with X-, and C-band errors given in columns 4 and 5. Mean tree height for the two Alberta sites is given in column 6 for comparison with L-Band height estimate errors shown in column 7.

\begin{tabular}{|c|c|c|c|c|c|c|c|c|c|}
\hline \multirow[b]{2}{*}{$\begin{array}{c}\text { \# ref. } \\
\text { samples }\end{array}$} & \multirow[b]{2}{*}{$\begin{array}{c}\text { land cover } \\
\text { type }\end{array}$} & \multirow{2}{*}{$\begin{array}{l}\text { mean } \\
\text { tree } \\
\text { height } \\
(\mathrm{m})\end{array}$} & \multicolumn{2}{|c|}{ X-Band } & \multicolumn{2}{|c|}{ C-Band } & \multirow{2}{*}{$\begin{array}{l}\text { mean } \\
\text { tree } \\
\text { height } \\
(\mathrm{m}) \text { in } \\
\text { Alberta }\end{array}$} & \multicolumn{2}{|c|}{ L-Band } \\
\hline & & & $\begin{array}{l}\text { RMSE } \\
\text { (m) }\end{array}$ & $\begin{array}{l}\text { Mean } \\
\text { Error } \\
\text { (m) }\end{array}$ & $\begin{array}{c}\text { RMSE } \\
\text { (m) }\end{array}$ & $\begin{array}{l}\text { Mean } \\
\text { Error } \\
\text { (m) }\end{array}$ & & $\begin{array}{l}\text { RMSE } \\
\text { (m) }\end{array}$ & $\begin{array}{c}\text { Mean } \\
\text { Error } \\
\text { (m) }\end{array}$ \\
\hline 762 & Shrub & 4 & 1.91 & -0.79 & 3.27 & -2.29 & $\overline{\text { N/A }}$ & N/A & N/A \\
\hline 567 & Deciduous & $\overline{16}$ & 6.81 & -2.92 & 6.30 & $\overline{-3.48}$ & 17 & 4.87 & -3.97 \\
\hline 761 & Conifers & $\overline{24}$ & 6.96 & -2.45 & 6.27 & -3.59 & 27 & 5.12 & -4.40 \\
\hline 482 & Mixed & 14 & 6.62 & -2.76 & 6.01 & -3.49 & 14 & 8.01 & -2.98 \\
\hline 180 & Wetlands & 7 & 5.40 & -2.61 & 5.48 & -3.54 & N/A & N/A & $\overline{\mathrm{N} / \mathrm{A}}$ \\
\hline
\end{tabular}

While the X-HH InSAR RMSE $h_{\text {spc }}$ error is lower for shrub than forest/wetlands types, its relative error (relative to measured height) is poorer; for example, for shrub 
vegetation with average height of $4 \mathrm{~m}$, the relative error is $47.8 \%$ compared to deciduous (42.6\%) and conifers (29.0\%). Wetlands vegetation performed the worst with a relative error of $77.1 \%$ (Table 22).

Table 22. X-HH InSAR, L-Band PollnSAR and SRTM C-HH InSAR derived $h_{\text {spc }}$ relative error and canopy height estimate stratified by vegetation type for all data combined.

\begin{tabular}{|r|l|r|r|r|}
\hline \multirow{2}{*}{$\begin{array}{c}\text { \# ref. } \\
\text { samples }\end{array}$} & \multirow{2}{*}{$\begin{array}{c}\text { land cover } \\
\text { type }\end{array}$} & \multicolumn{1}{c|}{ X-Band } & L-Band & \multicolumn{1}{c|}{ C-Band } \\
\cline { 3 - 5 } & relative error & relative error & relative error \\
\hline 762 & Shrub & $47.8 \%$ & N/A & $81.75 \%$ \\
\hline 567 & Deciduous & $42.6 \%$ & $28.07 \%$ & $39.38 \%$ \\
\hline 761 & Conifers & $29.0 \%$ & $18.96 \%$ & $33.00 \%$ \\
\hline 487 & Mixed & $47.3 \%$ & $58.04 \%$ & $42.93 \%$ \\
\hline 180 & Wetlands & $77.1 \%$ & N/A & $78.29 \%$ \\
\hline
\end{tabular}

The L-Quad PolInSAR $h_{\text {spc }}$ performed worse than the X-HH InSAR $h_{\text {spc }}$ for the mixed vegetation class and significantly better for the deciduous and coniferous classes. It was expected that the L-band $h_{\text {spc }}$ would perform worse for all vegetation classes because it should penetrate further into vegetation canopy resulting in a lower $h_{\text {spc }}$. However, with its multi-polarized data and better separation of ground and volume scattering features, it was recognized that the L-Quad data may possibly create a better DSM than the X-HH InSAR data. Site differences also play a role in these results. For the Canadian sites, which were the only sites with L-Quad data, the deciduous and coniferous vegetation cover was of greater density and taller compared the same classes at the four U.S. research sites. Taller trees and greater density may account for less signal 
attenuation and better estimates of canopy height (Izzawati et al., 2006; Woodhouse et al., 2006). Consequently, the L-Quad results are from tall and dense Canadian sites only, whereas the X-HH results are averaged over all size sites, including the US sites which were not as dense and probably had greater error. The mixed vegetation class average height was about equal across all sites, but tree density was not. Mixed forests were denser at the U.S. sites, which could result in a decrease in signal penetration and a lower relative error or a better estimate of canopy height when averaged with the Canadian sites.

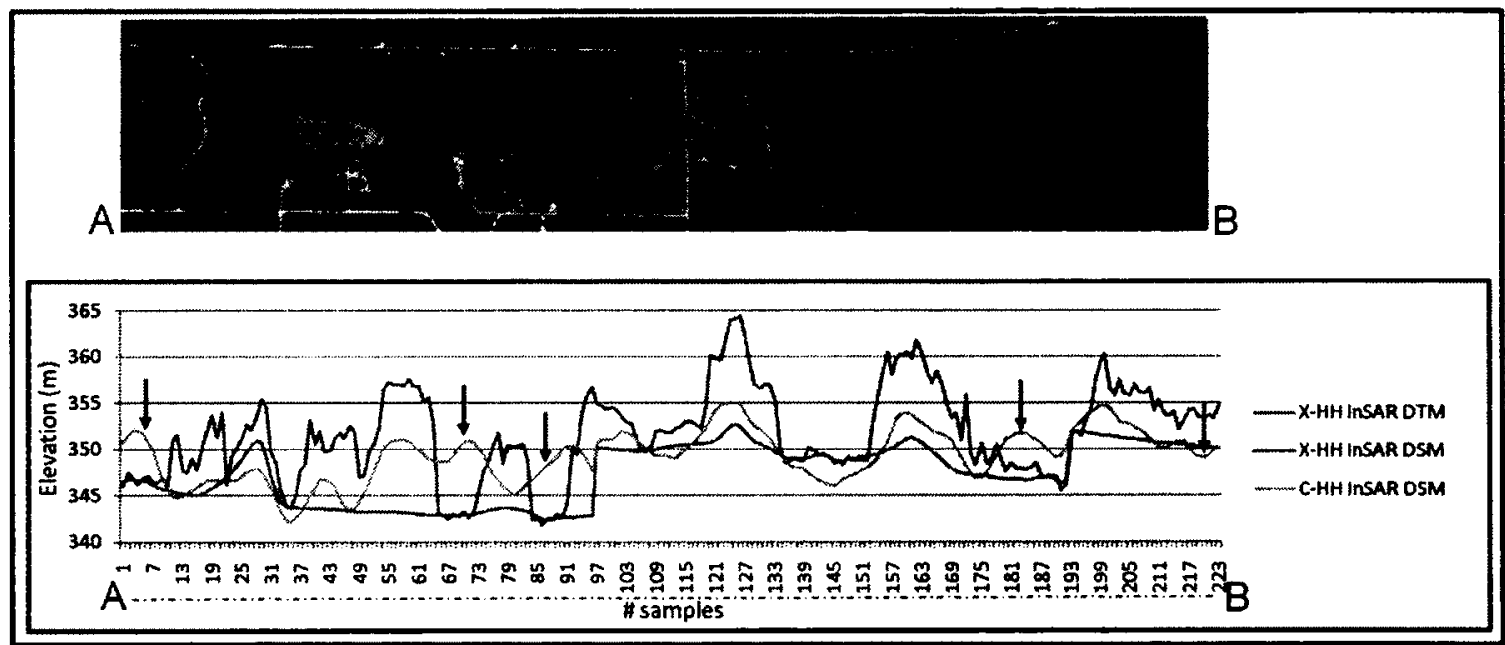

Figure 47. Profile comparisons of X-HH InSAR DSM (red line), C-HH InSAR DSM (green line), and the X-HH InSAR DTM (blue line) over barren and vegetated land cover at the International Falls site. Arrows indicate regions where the C-band DSM is higher than the shorter wavelength X-band DSM.

An unexpected outcome was that the X-HH InSAR $h_{\text {spc }}$ RMSE was greater for all 3 forest classes compared to C-HH InSAR $h_{\text {spc }}$. In other words, the shorter wavelength X- 
band penetrated the vegetation canopy more than the C-band for these three classes (Figure 47, locations at black arrows) yielding better estimates of canopy height. One reason for the greater penetration at X-band could be the difference in GSD between the X-HH (5 m) and C-HH InSAR (30 m - U.S. sites and $90 \mathrm{~m}$ - Canadian sites) data, such that the X-band data are providing more detailed canopy height and terrain heights (peaks and valleys) compared to the more generalized C-band data. Another reason could be due to the systematic bias in the C-band SRTM DSM data as suggested by Becek (2008) and Viergever et al. (2008) in explaining similar results. Although, on average, these results indicate that the $\mathrm{X}$-band signal penetrated deeper into canopy than C-Band, the differences are marginal. Since X- and L-band data were the focus of this research, further investigation into this C-band anomaly was not conducted.

\subsubsection{X-HH InSAR, L-Quad PollnSAR and C-HH InSAR Assessment of $h_{\text {spc }}$ as an Estimate of Canopy Height - Stratified by Research Site \\ The RMS and mean errors of the canopy heights given by X-, C-, and L-band $h_{s p c}$} data per research site and stratified by vegetation type are presented in Tables $23-28$. The X-HH InSAR $h_{\text {spc }}$ performs better than the C-HH InSAR $h_{\text {spc }}$ in all five vegetation types for the U.S. sites (Tables 23-26), but worse for two (deciduous, coniferous) of the three vegetation classes in the Canadian sites (Tables 27 and 28). Similar results were found for the L-Quad PolInSAR $h_{\mathrm{spc}}$. Possible explanations for these findings are presented below the tables. As in the previous analysis (Table 21), the mean errors were negative for all research sites, data sources, and land cover categories indicating that the $\mathrm{h}_{\mathrm{spc}}$ consistently under-estimated canopy height regardless of research site location. 
Table 23. X-HH InSAR and SRTM C-HH InSAR derived $h_{\text {spc }}$ error assessment against in situ canopy height for International Falls, stratified by vegetation type.

\begin{tabular}{|r|l|r|r|r|r|r|}
\hline \multirow{2}{*}{$\begin{array}{l}\text { \# in situ } \\
\text { Samples }\end{array}$} & \multirow{2}{*}{$\begin{array}{c}\text { Land Cover } \\
\text { Type }\end{array}$} & $\begin{array}{c}\text { Average } \\
\text { Tree Height } \\
(\mathrm{m})\end{array}$ & $\begin{array}{c}\text { RMSE } \\
(\mathrm{m})\end{array}$ & $\begin{array}{c}\text { Mean } \\
\text { Error }(\mathrm{m})\end{array}$ & $\begin{array}{c}\text { RMSE } \\
(\mathrm{m})\end{array}$ & $\begin{array}{c}\text { Mean } \\
\text { Error }(\mathrm{m})\end{array}$ \\
\hline 24 & Shrub & 4.0 & 1.94 & -0.87 & 3.09 & -2.12 \\
\hline 66 & Deciduous & 15.0 & 6.87 & -2.55 & 7.23 & -3.42 \\
\hline 36 & Conifers & 15.5 & 6.87 & -2.93 & 9.02 & -2.55 \\
\hline 36 & Mixed & 14.6 & 6.62 & -2.76 & 7.06 & -3.38 \\
\hline 18 & Wetlands & 7.2 & 3.68 & -1.76 & 4.11 & -2.96 \\
\hline
\end{tabular}

Table 24. X-HH InSAR and SRTM C-HH InSAR derived $h_{\text {spc }}$ error assessment against in situ canopy height for Ely, stratified by vegetation type.

\begin{tabular}{|r|l|r|r|r|r|r|}
\hline \multirow{2}{*}{$\begin{array}{l}\text { \# in situ } \\
\text { Samples }\end{array}$} & \multirow{2}{*}{$\begin{array}{c}\text { Land Cover } \\
\text { Type }\end{array}$} & \multirow{2}{*}{$\begin{array}{c}\text { Average } \\
\text { Tree Height } \\
(\mathrm{m})\end{array}$} & $\begin{array}{c}\text { X-HH InSAR } \\
(\mathrm{m})\end{array}$ & $\begin{array}{c}\text { Mean } \\
\text { Error (m) }\end{array}$ & $\begin{array}{c}\text { RMSE } \\
(\mathrm{m})\end{array}$ & $\begin{array}{c}\text { Mean } \\
\text { Error (m) }\end{array}$ \\
\hline 24 & Shrub & 4.1 & 1.91 & -0.69 & 3.01 & -2.31 \\
\hline 126 & Deciduous & 14.1 & 6.23 & -2.55 & 6.30 & -3.48 \\
\hline 150 & Conifers & 15.2 & 6.92 & -2.83 & 8.48 & -2.73 \\
\hline 24 & Mixed & 14.7 & 6.57 & -2.69 & 7.06 & -3.38 \\
\hline
\end{tabular}

Table 25. X-HH InSAR and SRTM C-HH InSAR derived $\mathrm{h}_{\text {spc }}$ error assessment against in situ canopy height for Arizona, stratified by vegetation type.

\begin{tabular}{|c|c|c|c|c|c|c|}
\hline \multirow{2}{*}{$\begin{array}{l}\text { \# in situ } \\
\text { Samples }\end{array}$} & \multirow{2}{*}{$\begin{array}{c}\text { Land Cover } \\
\text { Type }\end{array}$} & \multirow{2}{*}{$\begin{array}{l}\text { Average } \\
\text { Tree Height } \\
\text { (m) }\end{array}$} & \multicolumn{2}{|c|}{$\mathrm{X}$-HH InSAR } & \multicolumn{2}{|c|}{ C-HH InSAR } \\
\hline & & & $\begin{array}{l}\text { RMSE } \\
\text { (m) }\end{array}$ & $\begin{array}{c}\text { Mean } \\
\text { Error }(\mathrm{m})\end{array}$ & $\begin{array}{c}\text { RMSE } \\
(\mathrm{m})\end{array}$ & $\begin{array}{c}\text { Mean } \\
\text { Error }(\mathrm{m})\end{array}$ \\
\hline 648 & Shrub & 4.3 & 1.84 & -0.78 & 3.87 & -2.58 \\
\hline 66 & Deciduous & 15.2 & 6.51 & -2.55 & 7.13 & -3.31 \\
\hline 96 & Conifers & 15.5 & 6.49 & -2.93 & 8.69 & -2.15 \\
\hline 36 & Mixed & $\overline{14.4}$ & $\overline{6.43}$ & -2.76 & 6.87 & -3.18 \\
\hline 162 & Wetlands & 6.1 & 3.11 & -2.76 & 4.51 & -3.12 \\
\hline
\end{tabular}


Table 26. X-HH InSAR and SRTM C-HH InSAR derived $h_{\mathrm{spc}}$ error assessment against in situ canopy height for Colorado, stratified by vegetation type.

\begin{tabular}{|c|c|c|c|c|c|c|}
\hline \multirow{2}{*}{$\begin{array}{l}\text {.\# in situ } \\
\text { Samples }\end{array}$} & \multirow{2}{*}{$\begin{array}{c}\text { Land Cover } \\
\text { Type }\end{array}$} & \multirow{2}{*}{$\begin{array}{l}\text { Mean } \\
\text { Tree Height } \\
\text { (m) }\end{array}$} & \multicolumn{2}{|c|}{ X-HH InSAR } & \multicolumn{2}{|c|}{ C-HH InSAR } \\
\hline & & & $\begin{array}{l}\text { RMSE } \\
\text { (m) }\end{array}$ & $\begin{array}{c}\text { Mean } \\
\text { Error }(\mathrm{m})\end{array}$ & $\begin{array}{c}\text { RMSE } \\
\text { (m) }\end{array}$ & $\begin{array}{c}\text { Mean } \\
\text { Error (m) }\end{array}$ \\
\hline 66 & Shrub & 4.2 & 1.91 & -0.83 & 3.12 & -2.16 \\
\hline 66 & Deciduous & 15.1 & 6.01 & -2.69 & 9.09 & -3.29 \\
\hline 36 & Conifers & 13.9 & 7.33 & -2.98 & 7.65 & -3.43 \\
\hline 36 & Mixed & 14.5 & 6.67 & -2.84 & 6.99 & -3.60 \\
\hline
\end{tabular}

Table 27. X-HH InSAR, SRTM C-HH InSAR and L-Band PolInSAR derived $\mathrm{h}_{\text {spc }}$ error assessment against LiDAR CHM for Edson, stratified by vegetation type.

\begin{tabular}{|c|c|c|c|c|c|c|c|c|}
\hline \multirow{2}{*}{$\begin{array}{c}\text { \# in situ } \\
\text { or } \\
\text { LiDAR } \\
\text { CHE } \\
\text { Samples }\end{array}$} & \multirow{2}{*}{$\begin{array}{c}\text { Land Cover } \\
\text { Type }\end{array}$} & \multirow{2}{*}{$\begin{array}{c}\text { Mean } \\
\text { Tree } \\
\text { Height } \\
\text { Range } \\
\text { (m) }\end{array}$} & \multicolumn{2}{|c|}{ X-HH InSAR } & \multicolumn{2}{|c|}{ C-HH InSAR } & \multicolumn{2}{|c|}{$\begin{array}{c}\text { L-Quad } \\
\text { PolInSAR }\end{array}$} \\
\hline & & & $\begin{array}{l}\text { RMSE } \\
\text { (m) }\end{array}$ & $\begin{array}{l}\text { Mean } \\
\text { Error } \\
\text { (m) }\end{array}$ & $\begin{array}{l}\text { RMSE } \\
\text { (m) }\end{array}$ & $\begin{array}{c}\text { Mean } \\
\text { Error } \\
\text { (m) }\end{array}$ & $\begin{array}{l}\text { RMSE } \\
\text { (m) }\end{array}$ & $\begin{array}{c}\text { Mean } \\
\text { Error } \\
\text { (m) }\end{array}$ \\
\hline 93 & Deciduous & 18.4 & 5.63 & -1.73 & 4.11 & -2.12 & 5.38 & -3.97 \\
\hline 293 & Conifers & 28.7 & 8.35 & -1.83 & 6.89 & -1.89 & 8.69 & -4.40 \\
\hline 200 & Mixed & 14.5 & 5.67 & -1.82 & 5.29 & -2.16 & 5.82 & -2.98 \\
\hline
\end{tabular}

Table 28. X-HH InSAR, SRTM C-HH InSAR and L-Band PolInSAR derived $\mathrm{h}_{\text {spc }}$ error assessment against LiDAR CHM for Burnstick Lake, stratified by vegetation type.

\begin{tabular}{|c|l|c|c|c|c|c|c|c|}
\hline $\begin{array}{c}\text { \# in situ } \\
\text { or } \\
\text { LiDAR } \\
\text { CHE } \\
\text { Samples }\end{array}$ & Land Cover & $\begin{array}{c}\text { Mean } \\
\text { Tree } \\
\text { Teight } \\
\text { Range } \\
(\mathrm{m})\end{array}$ & \multicolumn{2}{|c|}{$\begin{array}{c}\text { X-HH InSAR } \\
\text { RMSE } \\
(\mathrm{m})\end{array}$} & $\begin{array}{c}\text { Mean } \\
\text { Error } \\
(\mathrm{m})\end{array}$ & $\begin{array}{c}\text { C-HH InSAR } \\
\text { RMSE } \\
(\mathrm{m})\end{array}$ & $\begin{array}{c}\text { Mean } \\
\text { Error } \\
(\mathrm{m})\end{array}$ & $\begin{array}{c}\text { L-Quad } \\
\text { PolInSAR } \\
(\mathrm{m})\end{array}$ \\
\hline 150 & Deciduous & 16.3 & 6.33 & -2.98 & 4.02 & -2.60 & $\begin{array}{c}\text { Mean } \\
\text { Error } \\
(\mathrm{m})\end{array}$ \\
\hline 150 & Conifers & 25.3 & 7.76 & -2.14 & 5.98 & -1.91 & 8.11 & -4.29 \\
\hline 150 & Mixed & 13.8 & 5.39 & -1.81 & 4.12 & -1.71 & 5.72 & -2.71 \\
\hline
\end{tabular}


Shrub vegetation $h_{\text {spc }}$ errors relative to field measured height were similar across the U.S. sites for X-HH (RMSE 43-50\% of actual height) and C-HH InSAR (RMSE $75-97 \%$ of actual height). There is little research published on the analysis of shrub canopy cover, thus these findings are relatively new. Given the difference in eco-regions (in particular moisture content) the variability of the relative error of $h_{\mathrm{spc}}$ is low, and this rendered it suitable for the application of a correction model to account for signal attenuation, as presented in section 5.3.

Deciduous vegetation X-HH InSAR $h_{\text {spc }}$ relative errors were similar for the U.S. sites $(\sim 43-49 \%)$ but errors were lower at Burnstick (34.4\%) and Edson (34.5\%). The deciduous canopies at all sites were of similar densities; however, they differed in tree height. Deciduous trees at the Canadian sites were taller $(16.3 \mathrm{~m}-18.4 \mathrm{~m})$ than those at the U.S. sites (14.1 m to $15.2 \mathrm{~m}$ ). An increase in tree height is usually accompanied by an increase in crown size, thus, reducing the gaps between the trees (in terms of X-band), which may account for the differences. These results indicating that there is less signal attenuation in tall dense deciduous forest are also supported in the literature (Izzawati et al., 2006; Woodhouse et al., 2006).

Likewise, $\mathrm{X}-\mathrm{HH}$ InSAR $h_{\text {spc }}$ coniferous vegetation relative errors were similar across the U.S. sites ( 42-46\%), but much lower at Burnstick (29.1\%) and Edson (33.0\%). The density of the conifer tree canopies was greater at the Canadian sites than at the U.S. sites resulting in less signal penetration and a higher detected $h_{\text {spc }}$. The U.S. site relative errors were similar to U.S. deciduous errors, but slightly better than at the Canadian sites; this was unexpected. The conical conifer crown structure (Figure 48) is known to produce less backscatter from the upper tips of the crown compared to 
deciduous crowns which exhibit a more rounded shape (Izzawati et al., 2006; Woodhouse et al., 2006). This could possibly lead to a lower retrieved $h_{\text {spc }}$ over coniferous vegetation than for deciduous trees as presented in Izzawati et al. (2006). The Canadian conifers were dense and tall; both parameters might have resulted in lower overall errors as reported by Izzawati et al. (2006) over dense conifers.

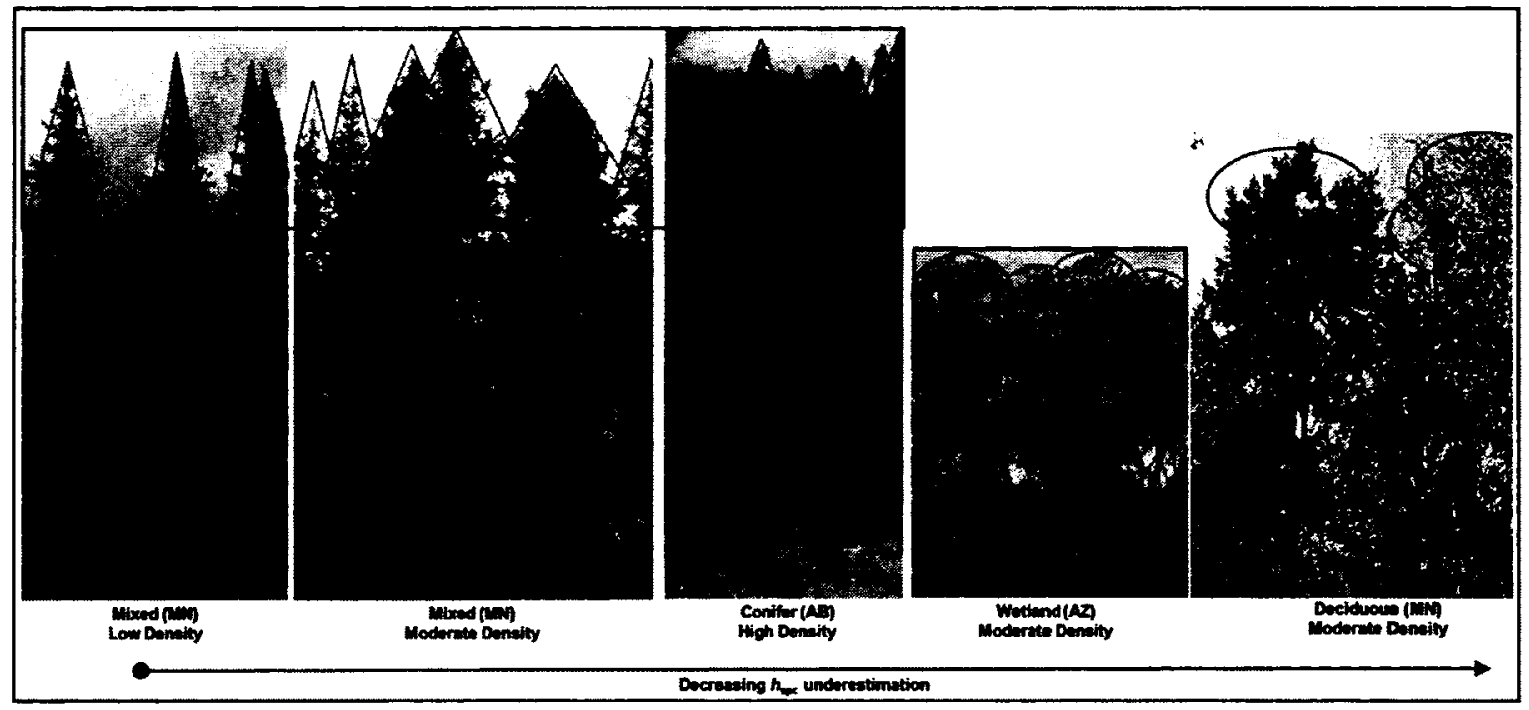

Figure 48. Structure and density examples for mixed, conifers, wetlands, and deciduous vegetation cover. Wetlands and deciduous vegetation cover have better canopy height estimates than the coniferous forests, possibly due to the vegetation structure.

$\mathrm{X}-\mathrm{HH}$ InSAR $\mathrm{h}_{\mathrm{spc}}$ over mixed vegetation followed similar trends across the U.S. sites (relative error $~ 43-46 \%$ ) and slightly lower at Burnstick (39.1\%) and Edson (41.1\%). These results show a clear trend for this vegetation type, which is promising for the application of a signal attenuation correction factor across all research sites, as presented in section 5.3. The $h_{\text {spc }}$ values derived from the $\mathrm{X}-, \mathrm{C}-$, and L-band InSAR 
DEMs for three transect lines covering approximately $666 \mathrm{~m}$ in length at the Edson research site, depicted in Figure 49, and are compared to LiDAR CHE reference data. The number of postings of the input X-HH InSAR DSM, C-HH InSAR DSM, L-Quad PolInSAR $h_{\text {spc }}$ data, and LiDAR CHE data are approximately $133,7,133$, and 332 , respectively.

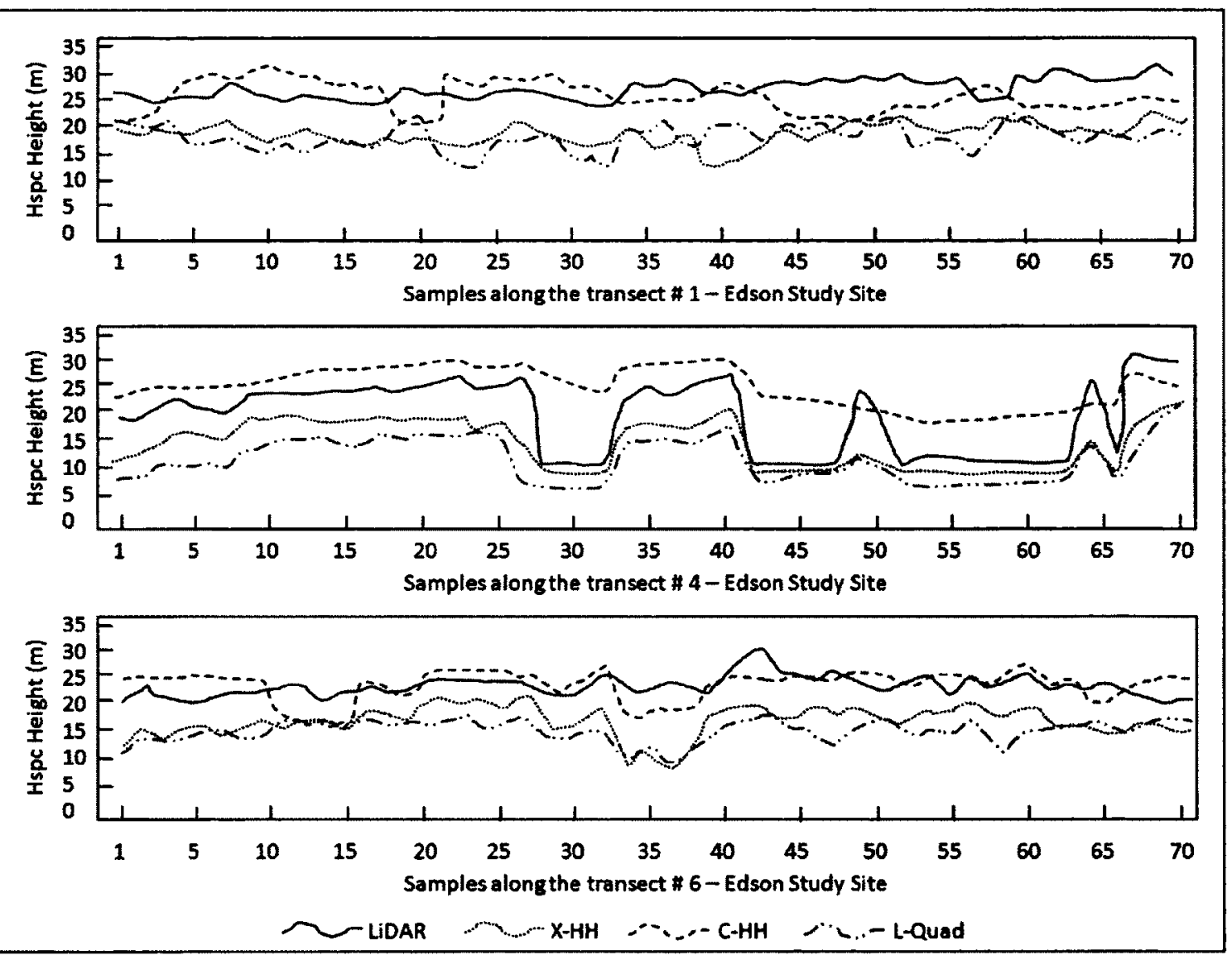

Figure 49. Comparison of LiDAR canopy height, X-HH InSAR $\mathrm{h}_{\mathrm{spc}}$, SRTM C-HH InSAR $h_{\text {spc }}$, and L-Quad PolInSAR $h_{\text {spc }}$ for three transects (\#1, \#4, and \#6, $1.3 \mathrm{~km}$ in length, Figure 21) at the Edson research site. 
As found in the error analysis (Table 22), it is evident that SRTM C-HH InSAR $\mathrm{h}_{\mathrm{spc}}$ (yellow line), despite over-estimating canopy height in many places (especially on Transect 4), provides better overall estimates of canopy height than X-HH InSAR $h_{s p c}$ (pink line). The reason for this is not understood at this time since, in theory, C-band should penetrate vegetation more than X-band. However, the X-and L-band data follow the LiDAR CHE better overall, compared to the C-band data which does not detect large gaps as well (e.g., Transect 4). The X-/L-band results indicate potential for bias correction using the $\mathrm{X}$ - and L-band SAR data sets more so than the C-band data set because separate bias factors can be applied for each land cover (vegetation) type as classified using these higher resolution data, whereas the coarse resolution SRTM C-HH $\mathrm{h}_{\mathrm{spc}}$ values appear to be much less sensitive to cover type variations such as those along Transect 4 .

\subsubsection{Performance of $h_{s p e}$ as an Estimate of Canopy Height over a Range of Incidence Angles}

\subsubsection{Incidence Angle Analysis of Single- and Multi-Takes X-HH $\operatorname{InSAR} \mathbf{h}_{\text {spe }}$ as an}

\section{Estimate of Canopy Height}

The results of the incidence angle analysis comparing the X-HH InSAR singleand multi-data take derived $h_{\text {spc }}$ data against in situ and LiDAR measurements of canopy height in flat terrain $\left(<10^{\circ}\right)$ stratified by vegetation class and incidence angle (given by the single data take transects) are presented in Tables 29 - 33 for all site data, and stratified by research site (excluding the Colorado site where single-take data were not available). The results for the multi take InSAR (NEXTMap) for all data combined, in

most cases, supported the theory that in NR (steep incidence angles, e.g. $\theta=35^{\circ}$ ), greater 
exposure of the lower vegetation canopy structure leads to greater canopy penetration, greater volume scattering if there is understory, or if little to no understory, greater double bounce, and a decrease in the amount of volume scattering contributions higher up in the canopy. This scenario results in a lower overall scattering phase centre height $\left(\mathrm{h}_{\mathrm{spc}}\right)$ or greater canopy height underestimation in the single-data take InSAR data. The opposite effect occurs in the FR, where at shallow incidence angles $\left(\theta=55^{\circ}\right)$ there is an increase in more relative volume scattering from the upper canopy, little to no ground scattering contributions, resulting in more accurate canopy height estimates.

Table 29. Single- and multi- (NEXTMap) takes InSAR-derived $h_{\text {spc }}$ error assessment against in situ canopy height for the Ely site, stratified by vegetation type and incidence angle range for $\leq 10^{\circ}$ terrain slope. ${ }^{*}$ Multi-takes InSAR incidence angle is not known due to the combining of multiple flight lines (or takes) to generate the final output.

\begin{tabular}{|l|c|l|r|r|r|r|}
\hline \multirow{3}{*}{$\begin{array}{c}\text { Type (mean tree } \\
\text { height in metres) }\end{array}$} & $\begin{array}{c}\# \\
\text { in situ }\end{array}$ & $\theta$ & \multicolumn{2}{c|}{$\begin{array}{c}\text { X-HH InSAR } \\
\text { (Single Take) }\end{array}$} & \multicolumn{2}{c|}{$\begin{array}{c}\text { X-HH InSAR } \\
\text { (Multi Take) }\end{array}$} \\
\cline { 3 - 7 } & & & $\begin{array}{c}\text { RMSE } \\
\text { (m) }\end{array}$ & $\begin{array}{c}\text { Mean } \\
\text { Error (m) }\end{array}$ & $\begin{array}{c}\text { RMSE } \\
\text { (m) }\end{array}$ & $\begin{array}{c}\text { Mean Error } \\
\text { (m) }\end{array}$ \\
\hline \multirow{5}{*}{ Shrub (4.1) } & 9 & NR & 2.89 & -2.31 & 1.92 & -0.69 \\
\hline & 6 & MR & 2.99 & -2.52 & 1.89 & -0.54 \\
\cline { 2 - 7 } & 5 & FR & 2.74 & -2.99 & 1.91 & -0.63 \\
\hline \multirow{5}{*}{ Deciduous (14.1) } & 24 & NR & 7.32 & -3.48 & 6.24 & -2.43 \\
\hline & 31 & MR & 7.79 & -3.24 & 6.11 & -2.33 \\
\cline { 2 - 7 } & 49 & FR & 7.17 & -3.29 & 6.31 & -2.11 \\
\hline & 22 & NR & 8.48 & -2.73 & 6.29 & -2.83 \\
\cline { 2 - 7 } & 31 & MR & 7.99 & -2.33 & 6.27 & -2.99 \\
\cline { 2 - 7 } & 29 & FR & 8.41 & -2.99 & 6.12 & -2.18 \\
\hline \multirow{5}{*}{ Mixed (14.7) } & 6 & NR & 7.21 & -3.05 & 6.42 & -2.21 \\
\cline { 2 - 7 } & 9 & MR & 7.33 & -3.25 & 6.32 & -2.43 \\
\cline { 2 - 7 } & 5 & FR & 7.45 & -3.19 & 6.33 & -2.19 \\
\hline
\end{tabular}


Table 30. Single- and multi- (NEXTMap) takes InSAR-derived $\mathrm{h}_{\mathrm{spc}}$ error assessment against in situ canopy height for the International Falls site, stratified by vegetation type and incidence angle range for $\leq 10^{\circ}$ terrain slope. ${ }^{*}$ Multi-takes InSAR incidence angle is not known due to the combining of multiple flight lines (or takes) to generate the final output.

\begin{tabular}{|c|c|c|c|c|c|c|}
\hline \multirow{2}{*}{$\begin{array}{l}\text { Type (mean tree } \\
\text { height in meters) }\end{array}$} & \multirow{2}{*}{$\begin{array}{c}\# \\
\text { in situ }\end{array}$} & \multirow{2}{*}{$\theta$} & \multicolumn{2}{|c|}{$\begin{array}{l}\text { X-HH InSAR } \\
\text { (Single Take) }\end{array}$} & \multicolumn{2}{|c|}{$\begin{array}{l}\text { X-HH InSAR } \\
\text { (Multi Take)* }\end{array}$} \\
\hline & & & $\begin{array}{l}\text { RMSE } \\
(\mathrm{m})\end{array}$ & $\begin{array}{c}\text { Mean } \\
\text { Error }(\mathrm{m})\end{array}$ & $\begin{array}{l}\text { RMSE } \\
(\mathrm{m})\end{array}$ & $\begin{array}{l}\text { Mean Error } \\
\text { (m) }\end{array}$ \\
\hline \multirow[b]{2}{*}{ Shnob } & 10 & NR & 2.29 & -2.01 & 1.86 & -0.83 \\
\hline & 8 & MR & 2.33 & -2.21 & 1.68 & -0.71 \\
\hline \multirow[b]{2}{*}{ Deciduous (15.1) } & 27 & NR & 8.12 & -3.12 & 6.44 & -2.15 \\
\hline & 29 & MR & 8.01 & -2.97 & 6.51 & -2.34 \\
\hline \multirow[b]{2}{*}{ Conifers (15.5) } & 15 & NR & 9.02 & -2.22 & 6.35 & -2.93 \\
\hline & 15 & MR & 8.89 & -2.11 & 6.24 & -2.77 \\
\hline \multirow[b]{2}{*}{ Mixed (14.6) } & 14 & NR & 7.06 & -3.38 & 6.52 & -2.26 \\
\hline & 16 & MR & 7.26 & -2.87 & 6.12 & -2.13 \\
\hline \multirow[b]{2}{*}{ Wetlands (7.2) } & 8 & NR & 4.11 & -2.96 & 3.11 & -1.46 \\
\hline & 7 & MR & 3.99 & -2.19 & 3.01 & -1.35 \\
\hline
\end{tabular}

Table 31. Single- and multi- (NEXTMap) takes InSAR-derived $\mathrm{h}_{\mathrm{spc}}$ error assessment against in situ canopy height for the Arizona site, stratified by vegetation type and incidence angle range for $\leq 10^{\circ}$ terrain slope. ${ }^{*}$ Multi-takes InSAR incidence angle is not known due to the combining of multiple flight lines (or takes) to generate the final output.

\begin{tabular}{|c|c|c|c|c|c|c|}
\hline \multirow{2}{*}{$\begin{array}{l}\text { Type (mean } \\
\text { tree height in } \\
\text { metres) }\end{array}$} & \multirow{2}{*}{$\begin{array}{c}\# \\
\text { in situ }\end{array}$} & \multirow{2}{*}{$\theta$} & \multicolumn{2}{|c|}{$\begin{array}{l}\text { X-HH InSAR } \\
\text { (Single Take) }\end{array}$} & \multicolumn{2}{|c|}{$\begin{array}{l}\text { X-HH InSAR } \\
\text { (Multi Take)* }\end{array}$} \\
\hline & & & $\begin{array}{l}\text { RMSE } \\
(\mathrm{m})\end{array}$ & $\begin{array}{l}\text { RMSE } \\
(\mathrm{m})\end{array}$ & $\begin{array}{l}\text { RMSE } \\
(\mathrm{m})\end{array}$ & $\begin{array}{c}\text { Mean } \\
\text { Error }(\mathrm{m})\end{array}$ \\
\hline \multirow{3}{*}{$\begin{array}{l}\text { Shrub } \\
(4.3)\end{array}$} & 154 & NR & 2.18 & 2.18 & 1.77 & -0.75 \\
\hline & 184 & MR & 2.11 & 2.11 & 1.71 & -0.73 \\
\hline & 139 & FR & 2.15 & 2.15 & 1.74 & -0.74 \\
\hline \multirow{3}{*}{$\begin{array}{l}\text { Deciduous } \\
\text { (15.2) }\end{array}$} & 19 & NR & 6.84 & 6.84 & 6.25 & -2.45 \\
\hline & 21 & MR & 6.63 & 6.63 & 6.05 & -2.37 \\
\hline & 18 & FR & 6.74 & 6.74 & 6.15 & -2.41 \\
\hline \multirow{3}{*}{ Conifers (15.5) } & 29 & NR & 8.34 & 8.34 & 6.23 & -2.81 \\
\hline & 31 & MR & 8.08 & 8.08 & 6.04 & -2.72 \\
\hline & 27 & FR & 8.21 & 8.21 & 6.13 & -2.77 \\
\hline
\end{tabular}


Table 32. Single- and multi- (NEXTMap) takes InSAR-derived $h_{\text {spc }}$ error assessment against LiDAR canopy height for the Edson site, stratified by vegetation type and incidence angle range for $\leq 10^{\circ}$ terrain slope. * Multi-takes InSAR incidence angle is not known due to the combining of multiple flight lines (or takes) to generate the final output.

\begin{tabular}{|l|c|l|r|r|r|r|}
\hline \multirow{2}{*}{$\begin{array}{c}\text { Type (mean } \\
\text { tree height in } \\
\text { metres) }\end{array}$} & \multirow{2}{*}{$\begin{array}{c}\text { LiDAR } \\
\text { CHE }\end{array}$} & \multirow{2}{*}{$\theta$} & \multicolumn{2}{c|}{$\begin{array}{c}\text { X-HH InSAR } \\
\text { (Single Take) }\end{array}$} & \multicolumn{2}{c|}{$\begin{array}{c}\text { X-HH InSAR } \\
\text { (Multi Take) }\end{array}$} \\
\cline { 3 - 7 } & & & $\begin{array}{c}\text { RMSE } \\
(\mathrm{m})\end{array}$ & $\begin{array}{c}\text { RMSE } \\
(\mathrm{m})\end{array}$ & $\begin{array}{c}\text { RMSE } \\
(\mathrm{m})\end{array}$ & $\begin{array}{c}\text { Mean } \\
\text { Error (m) }\end{array}$ \\
\hline \multirow{2}{*}{$\begin{array}{l}\text { Deciduous } \\
(18.4)\end{array}$} & 33 & NR & 8.12 & 8.12 & 4.99 & -3.28 \\
\cline { 2 - 7 } & 30 & MR & 5.75 & 5.75 & 5.79 & -3.22 \\
\cline { 2 - 7 } & 30 & FR & 5.37 & 5.37 & 4.86 & -2.98 \\
\hline \multirow{3}{*}{ Conifers (28.7) } & 100 & NR & 8.44 & 8.44 & 4.91 & -2.33 \\
\cline { 2 - 7 } & 100 & MR & 8.77 & 8.77 & 4.86 & -2.84 \\
\cline { 2 - 7 } & 83 & FR & 8.74 & 8.74 & 4.76 & -3.83 \\
\hline \multirow{3}{*}{ Mixed (14.5) } & 68 & NR & 7.41 & 7.41 & 5.03 & -2.12 \\
\cline { 2 - 7 } & 61 & MR & 7.54 & 7.54 & 5.61 & -2.54 \\
\cline { 2 - 7 } & 63 & FR & 7.32 & 7.32 & 5.47 & -2.41 \\
\hline
\end{tabular}

Table 33. Single- and multi- (NEXTMap) takes InSAR-derived $h_{\text {spc }}$ error assessment against LiDAR canopy height for the Burnstick Lake site, stratified by vegetation type and incidence angle range for $\leq 10^{\circ}$ terrain slope. ${ }^{*}$ Multi-takes InSAR incidence angle is not known due to the combining of multiple flight lines (or takes) to generate the final output.

\begin{tabular}{|l|c|l|r|r|r|r|}
\hline $\begin{array}{c}\text { Type (mean } \\
\text { tree height in } \\
\text { metres) }\end{array}$ & \multirow{2}{*}{$\begin{array}{c}\text { LiDAR } \\
\text { CHE }\end{array}$} & $\theta$ & \multicolumn{2}{|c|}{$\begin{array}{c}\text { X-HH InSAR } \\
\text { (Single Take) }\end{array}$} & \multicolumn{2}{c|}{$\begin{array}{c}\text { X-HH InSAR } \\
\text { (Multi Take) }\end{array}$} \\
\cline { 4 - 8 } & & & $\begin{array}{c}\text { RMSE } \\
(\mathrm{m})\end{array}$ & $\begin{array}{c}\text { RMSE } \\
(\mathrm{m})\end{array}$ & $\begin{array}{c}\text { RMSE } \\
(\mathrm{m})\end{array}$ & $\begin{array}{c}\text { Mean } \\
\text { Error (m) }\end{array}$ \\
\hline \multirow{3}{*}{$\begin{array}{l}\text { Deciduous } \\
(16.3)\end{array}$} & 47 & NR & 7.34 & 7.34 & 4.42 & -2.12 \\
\cline { 2 - 8 } & 43 & MR & 5.75 & 5.75 & 5.09 & -2.03 \\
\cline { 2 - 8 } & 51 & FR & 5.37 & 5.37 & 4.26 & -2.87 \\
\hline \multirow{3}{*}{ Conifers (25.3) } & 49 & NR & 7.63 & 7.63 & 4.35 & -2.24 \\
\cline { 2 - 8 } & 50 & MR & 8.77 & 8.77 & 5.53 & -2.97 \\
\cline { 2 - 8 } & 45 & FR & 8.74 & 8.74 & 5.43 & -2.94 \\
\hline \multirow{3}{*}{ Mixed (13.8) } & 46 & NR & 6.70 & 6.70 & 4.46 & -2.97 \\
\cline { 2 - 8 } & 49 & MR & 7.41 & 7.41 & 5.72 & -2.31 \\
\cline { 2 - 8 } & 52 & FR & 7.02 & 7.02 & 5.74 & -2.24 \\
\hline
\end{tabular}




\subsubsection{Incidence Angle Effects on the $h_{\text {spe }}$ as an Estimate of Canopy Height -All Data Combined and Stratified by Research Site}

The results of the incidence angle analysis comparing transect lines that run parallel to the single-data take X-HH InSAR derived DSM (Figure 33) against the multidata takes X-HH InSAR derived DSM (NEXTMap) data in flat terrain $\left(<10^{\circ}\right)$ are presented in Table 34 for all site data combined and stratified by range class into NR, MR, and FR, respectively. The RMS difference (RMSD) was calculated since neither the $\mathrm{X}-\mathrm{HH}$ InSAR single- nor multi-data takes data were considered as reference data; i.e., this is not an accuracy assessment. The $R^{2}$ values were also tabulated. These results were tabulated as a weighted average based on the number of samples per site, since they were not equal at each site.

Overall, the single take data demonstrated a strong correlation to the multi takes data from NR to FR. This is an expected result and concurs with results presented by Woodhouse et al. (2006) and Andersen et al. (2008). The $R^{2}$ values also increased from NR to FR, indicating a greater correlation between the single take InSAR and multi take InSAR moving across the swath. This means that absolute height estimate accuracy is best in the NR using either using single-data take derived $h_{\text {spc }}$ or the CHE (multi-data take data), but single-data take derived $h_{\text {spc }}$ data are more related to the NEXTMap multi-take data (from which the CHE is derived) in the far range. The mean differences shown in Table 34 are all negative; meaning that on average, single-data take derived $h_{\text {spc }}$ was slightly lower than NEXTMap $h_{\text {spc }}$. However, the mean differences were low (ranging from 10.18 to -0.39 ) indicating little if any bias. 
Table 34. $h_{\mathrm{spc}}$ comparison for 19,561 sample points located along transect lines of slopes less than $10^{\circ}$ in the NR $\left(\theta=35^{\circ}\right), \operatorname{MR}\left(\theta=45^{\circ}\right)$, and FR $\left(\theta=55^{\circ}\right) \cdot \mathrm{h}_{\text {spc }}$ was generated from single-data take X-HH InSAR and compared to multi-data takes X-HH InSAR (NEXTMap) for all site data combined in weighted averages based on samples per site.

\begin{tabular}{|l|r|r|r|r|r|r|}
\hline $\begin{array}{c}\text { Incidence } \\
\text { Angle }\end{array}$ & \# Strips & $\begin{array}{c}\text { \# transect } \\
\text { samples }\end{array}$ & $\begin{array}{c}\text { \# Void } \\
\text { samples }\end{array}$ & $\begin{array}{c}\text { RMSD } \\
(\mathrm{m})\end{array}$ & $\begin{array}{c}\text { Mean } \\
\text { Difference } \\
(\mathrm{m})\end{array}$ & $R^{2}$ \\
\hline NR & 11 & 5557 & 148 & 2.61 & -0.18 & 0.82 \\
\hline MR & 9 & 7144 & 207 & 2.01 & -0.36 & 0.86 \\
\hline FR & 6 & 6860 & 185 & 1.32 & -0.39 & 0.97 \\
\hline
\end{tabular}

Given the range of eco-regions, canopy heights, vegetation classes, and canopy densities among the six research sites, more detailed comparison of the $\mathrm{X}-, \mathrm{C}-$, and Lband $h_{\mathrm{spc}}$ data stratified by research site as well as by vegetation type was conducted (Table 35), to determine if similar results prevailed. They did for the mean differences for all sites. However, the effect of incidence angle on RMSD and $R^{2}$ was site-dependent. The trend of an increase in agreement (decrease in mean difference) between single- and multi take data from NR to MR to FR, as presented in Table 35, was not found at all sites. In the case of the Arizona site, the differences increase slightly from NR to MR to FR. At the International Falls site, where only NR and MR data were available, the NR single take $\mathrm{X}-\mathrm{HH} \mathrm{h}_{\mathrm{spc}}$ data were more similar to the multi take data than were the MR data. These results were unexpected. Could this mean that X-HH InSAR derived $h_{\text {spc }}$ is sometimes closer to multi-pass data averaged data in the NR and sometimes closer in the FR? Additional information about how the multi takes data were mosaic ked together is needed to make this conclusion. 
Table 35. Comparison of $h_{\text {spc }}$ for sample points located along transect lines of slopes less than $10^{\circ}$ in the NR $\left(\theta=\left(35^{\circ}\right)\right.$, MR $\left(\theta=45^{\circ}\right)$, and FR $\left(\theta=55^{\circ}\right)$ generated from X-HH InSAR (single-data take) and NEXTMap X-HH InSAR (multi-data takes).

\begin{tabular}{|c|c|c|c|c|c|c|c|}
\hline $\begin{array}{c}\text { Research } \\
\text { Site }\end{array}$ & $\begin{array}{c}\text { Incidence } \\
\text { Angle }\end{array}$ & $\begin{array}{c}\# \\
\text { Strips }\end{array}$ & $\begin{array}{c}\# \\
\text { transect } \\
\text { samples }\end{array}$ & $\begin{array}{l}\text { \# Void } \\
\text { samples }\end{array}$ & $\begin{array}{c}\text { RMSD } \\
\text { (m) }\end{array}$ & $\begin{array}{c}\text { Mean } \\
\text { Difference } \\
(\mathrm{m})\end{array}$ & $R^{2}$ \\
\hline \multirow{3}{*}{ Ely } & NR & 2 & 1656 & 37 & 4.01 & -0.77 & 0.81 \\
\hline & MR & 3 & 1416 & 93 & 2.97 & -0.48 & 0.71 \\
\hline & FR & 2 & 1973 & 81 & 0.96 & -0.58 & 0.99 \\
\hline \multirow{2}{*}{$\begin{array}{l}\text { International } \\
\text { Falls }\end{array}$} & NR & 1 & 323 & 11 & 1.65 & -0.25 & 0.51 \\
\hline & $\mathrm{MR}$ & 1 & 306 & 11 & 2.87 & -0.37 & 0.61 \\
\hline \multirow{3}{*}{ Arizona } & NR & 6 & 2640 & 81 & 1.04 & -0.03 & 0.96 \\
\hline & MR & 3 & 4484 & 89 & 1.15 & -0.03 & 0.99 \\
\hline & FR & 3 & 4484 & 89 & 1.27 & -0.23 & 0.99 \\
\hline \multirow{3}{*}{$\begin{array}{l}\text { Burnstick } \\
\text { Lake }\end{array}$} & NR & 1 & 403 & 6 & 4.13 & -1.87 & 0.59 \\
\hline & $\overline{\mathrm{MR}}$ & 1 & 403 & 9 & 3.98 & -1.43 & 0.67 \\
\hline & $\overline{F R}$ & $\overline{1}$ & 403 & 15 & 3.64 & -1.27 & 0.73 \\
\hline \multirow{2}{*}{ Edson } & NR & 1 & 535 & 13 & 5.51 & -2.20 & 0.47 \\
\hline & $\overline{\mathrm{MR}}$ & 1 & $\overline{535}$ & 5 & 4.74 & -1.97 & 0.52 \\
\hline
\end{tabular}

One possible reason for these findings could be attributed to slight heading changes along a single flight line (Figures 23 and 50) due to the long flight lines of NEXTMap resulting in a curved data strip. Although each single-data take is tied to ground control, minor heading changes along the length of a flight line strip (typically $600-1200 \mathrm{~km}$ in length) will occur as illustrated in Figure 23 (orange, green, or blue strip) and in the profile along the length of a section of a flight line strip of data over the Ely, MN research site presented in Figure 50. Another possible reason is that it may be that at one site the multi 
take data stitched together NR or FR data in the same area, producing a multi take image that still shows a range effect. In other sites it is possible that the multi take data averages NR and FR data of the same pixels from different single-data take images.

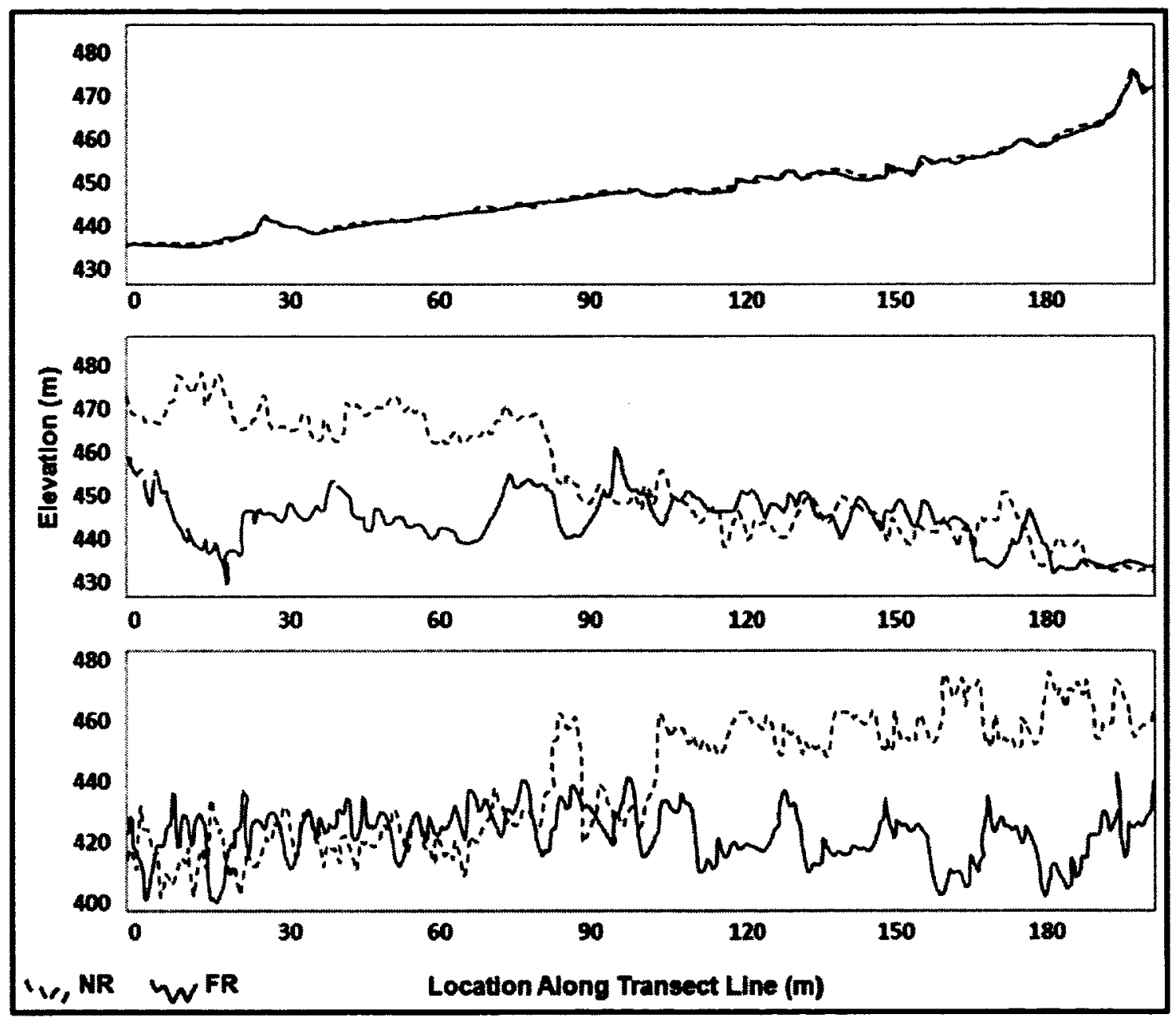

Figure 50. Three examples of X-HH airborne flight line twisting.

The top graph in Figure 50 illustrates a strong correlation between the NR (dashed line) and FR (solid line) for two flight line strips (that have been controlled using ground control) over the same transect line. The middle and bottom graphs for a transect line 
located both in the NR and FR do not correlate well. In the middle graph, the beginning of the transect (left side of the graph, starting at number 1 does not compare well in NR and FR, but they begin to converge at about data point $\# 81$ approximately $54 \mathrm{~km}$ from the start of data collection for the NR pass and at $104 \mathrm{~km}$ for the FR pass. The bottom graph shows a strong correlation between NR and FR profiles along the same transect line at the beginning, but they begin to separate from each other at about data point \#169 approximately, $68 \mathrm{~km}$ from the start of data collection for the NR line (pass \#1) and at $134 \mathrm{~km}$ for the blue line (pass \#2).

The results of the profiles for transects running across the single take data (from NR to FR; Figure 34) compared to the multi-data takes X-HH InSAR and L-Quad PolInSAR data to compare similar ground vegetation classes across the three incidence angle locations are presented in Table 36 and Figures $51-53$.

Table 36. Comparison of $\mathrm{h}_{\mathrm{spc}}$ for combined sample points located along transect lines running across swath from NR - MR - FR of slopes less than $10^{\circ}$ generated from X-HH InSAR (single-data take) and NEXTMap X-HH InSAR (multi-data takes).

\begin{tabular}{|l|r|r|r|r|r|}
\hline \multirow{3}{*}{ Research Site } & $\begin{array}{c}\text { Strip } \\
\text { Number }\end{array}$ & $\begin{array}{c}\# \\
\text { transect } \\
\text { samples }\end{array}$ & $\begin{array}{c}\text { RMSD } \\
(\mathrm{m})\end{array}$ & $\begin{array}{c}\text { Mean } \\
\text { Difference } \\
(\mathrm{m})\end{array}$ & \multicolumn{1}{c|}{$R^{2}$} \\
\hline \multirow{3}{*}{ Ely } & 1 & 82 & 0.90 & 0.20 & 0.91 \\
\cline { 2 - 6 } & 2 & 107 & 0.78 & 0.34 & 0.96 \\
\cline { 2 - 6 } & 3 & 111 & 0.93 & 0.37 & 0.96 \\
\hline International & 1 & 51 & 2.55 & -0.17 & 0.60 \\
\cline { 2 - 6 } Falls & 2 & 51 & 2.52 & -0.06 & 0.90 \\
\hline \multirow{3}{*}{ Arizona } & 1 & 152 & 1.16 & -0.09 & 0.88 \\
\cline { 2 - 6 } & 2 & 151 & 2.05 & 0.10 & 0.92 \\
\cline { 2 - 7 } & 3 & 150 & 1.03 & -0.03 & 0.86 \\
\hline
\end{tabular}


The theory of an increase in agreement between single and multi takes data from NR to MR to FR was not found at all sites. In fact, the opposite was found at all research sites analyzed. In all cases, the differences increased slightly from NR to MR and significantly in the FR. Furthermore, the correlation or RMSD proved to be better than the results presented in Table 35. One possible reason for this could be the location of the transect line across swath, rather than along swath where there is an increase in error along the length of the flight line as discussed in Figure 50.

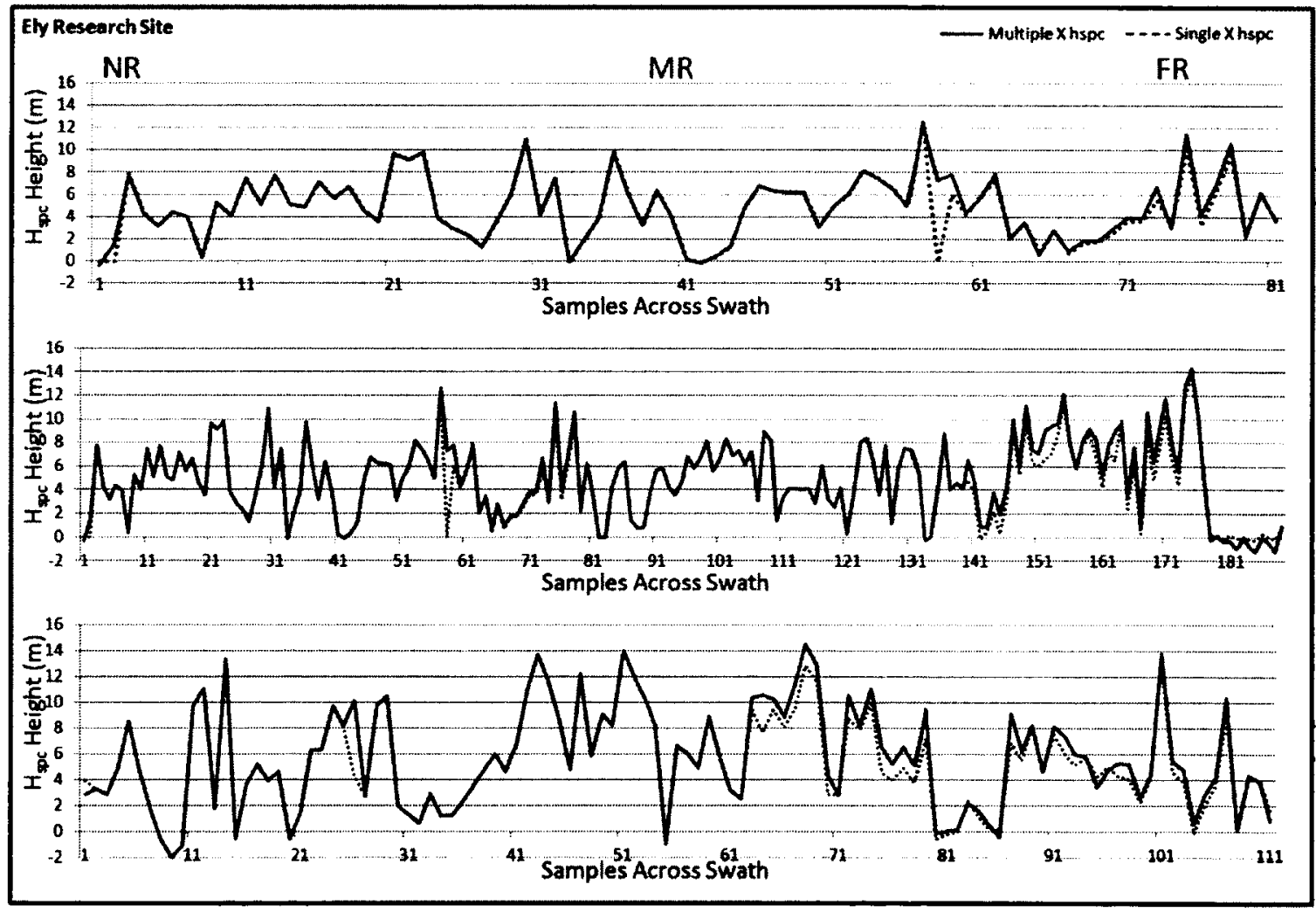

Figure 51. Three profiles located across one swath (NR-MR-FR) over single-data take $h_{\text {spc }}$ data) compared to multi-data takes X-HH InSAR derived $h_{\text {spc }}$ data for the Ely site. 


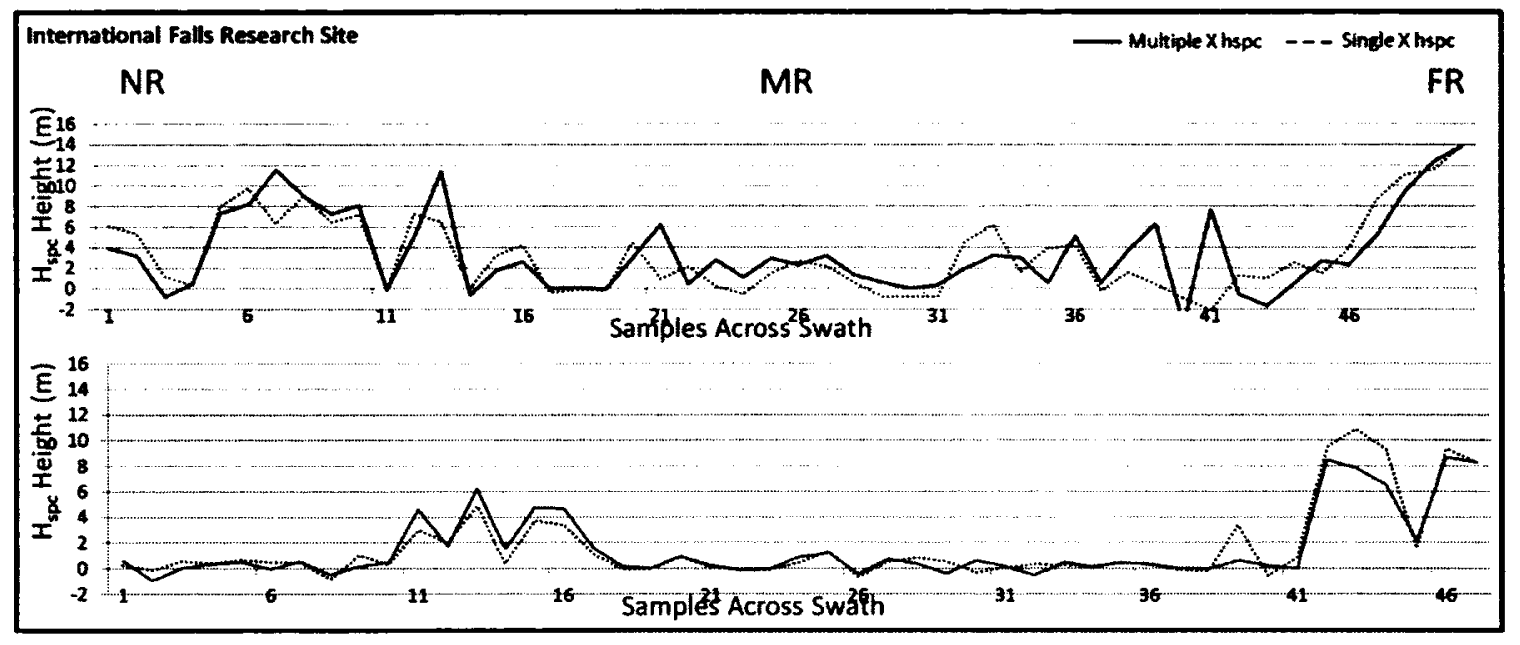

Figure 52. Two profiles located across one swath (MR-FR) over single-data take $h_{\text {spc }}$ data) compared to multi-data takes X-HH InSAR $h_{\text {spc }}$ data for the International Falls site.

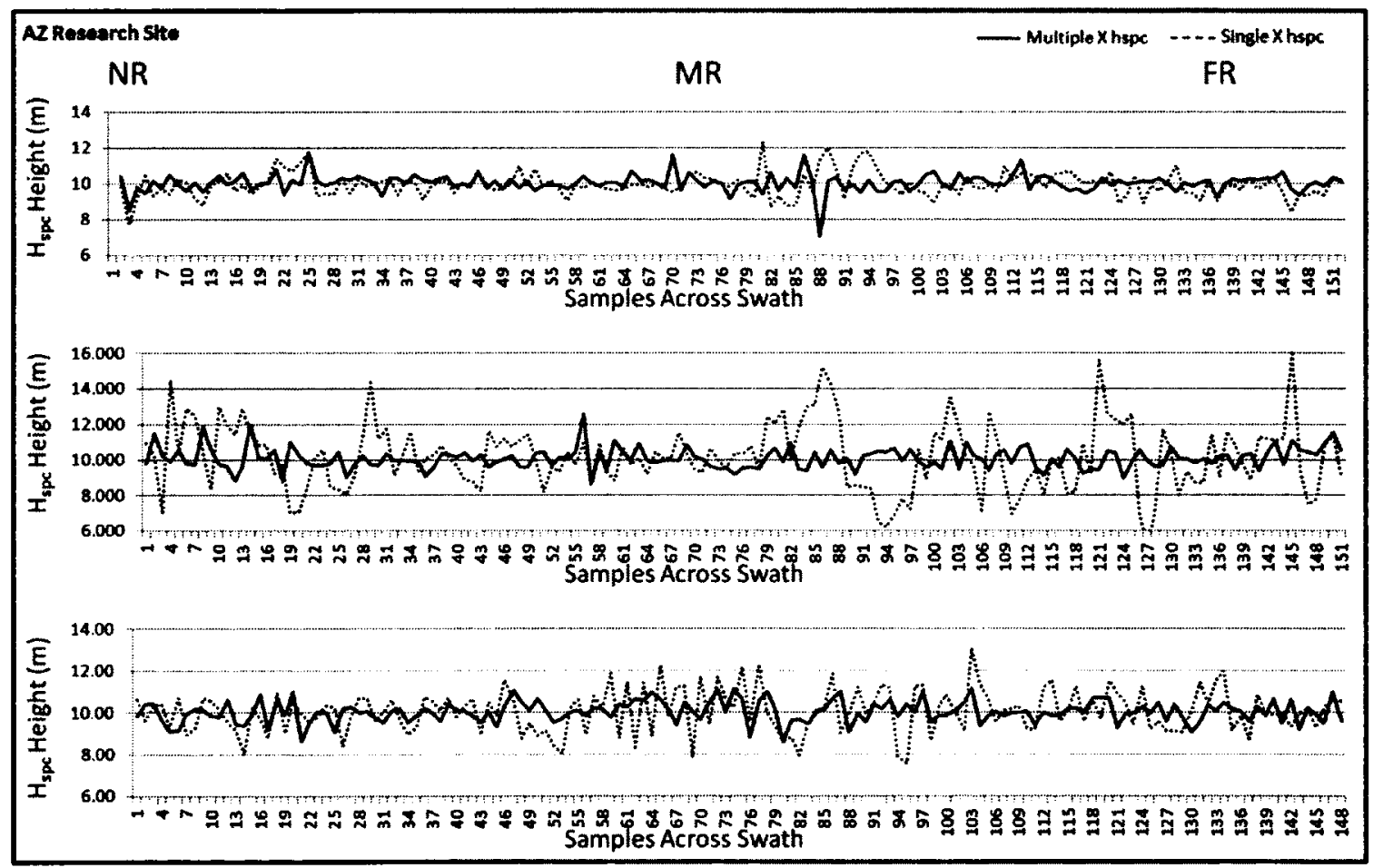

Figure 53. Three profiles located across one swath (NR-MR-FR) over single-data take $h_{\text {spc }}$ data) compared to multi-data takes X-HH InSAR derived $h_{\text {spc }}$ data for the Arizona site. 


\subsection{Research Objective 3: Assessment of Refined InSAR and PolInSAR Canopy}

\section{Height Estimates}

The derived canopy height estimates (CHE) presented in this research are based on $\mathrm{h}_{\mathrm{spc}}$ derived from InSAR and PolInSAR data as a representation of canopy height and refined through the application of attenuation bias correction factors that account for signal penetration into the canopy for shrub, deciduous, conifers, mixed, and wetlands vegetation classes. Consequently, accurate mapping of these classes, as well as barren areas, is a pre-requisite to implementation of the correction.

The CHE presented here is also based on corrections made for gaps within a vegetation canopy and at vegetation-barren boundaries, using variable buffers. Section 5.3.1 provides a visual assessment of the vegetation cover maps followed by a quantitative accuracy assessment of the land cover classification results for all data combined and stratified by research site. The results of the addition of variable buffer correction factors to the proposed CHE for all data combined stratified by vegetation class and by research site are presented in Section 5.3.2. The results of the assessment of the performance of the proposed canopy height estimation methodology over a range of SAR incidence angles and terrain slopes are discussed in Section 5.3.3.

\subsubsection{Land Cover Classification Assessment}

\subsubsection{Visual Assessment of Land Cover Classification Maps}

The land cover classification maps derived from X-HH InSAR data (using $h_{\mathrm{spc}}$ and orthorectified radar imagery brightness as inputs) for the six research sites are presented in Figures $54-59$. Using visual interpretation of NAIP imagery as a reference, there are evident discrepancies between these maps and the NLCD for the U.S. sites. The 
X-band data show a greater amount of conifers than the NLCD for all sites (Figures 5457) and, in general, deciduous forest is separated better from coniferous forest than in the NLCD. Further, the X-HH maps depict more barren and less urban land cover than the NLCD. For example, the urban area in the upper right corner of Figure 54 is well classified using the X-HH InSAR but the NLCD over estimates its area. This is probably a result of resolution as the X-HH InSAR maps have a GSD of $5 \mathrm{~m}$ compared to $30 \mathrm{~m}$ for NLCD; i.e., the X-HH InSAR data can provide much greater detail on other classes such as grass, trees and water within urban areas.

Water was also classified incorrectly or under represented by the NLCD in several areas, including some small ponds, water treatment ponds, and rivers/river inlets. The NLCD overestimates wetlands coverage; for example in Figure 55, much of the wetlands classified area is actually forest, and many open water bodies are classified as wetlands. It should be noted, however, that some of the water bodies in the centre of Figure 56 are misclassified as grass in the X-HH InSAR map. In the Arizona site, where wetlands are predominantly riparian, the X-HH data identify two of the major areas better than NLCD but several other streams with vegetation that are visible in the NAIP imagery were missed by both maps.

The X-HH InSAR classification for the Burnstick Lake, AB site did not correlate well with the ancillary aerial optical data (Figure 57) due to temporal differences between the two image collections (e.g. X-HH InSAR 2007; Optical Imagery 2008). The X-HH InSAR classification for the Edson, AB site correlated well with the optical data (Figures 58). The dense vegetation cover juxtaposed to barren land provided an excellent example for the promise of using $h_{\mathrm{spc}}$ to separate vegetation types from non-vegetation. 


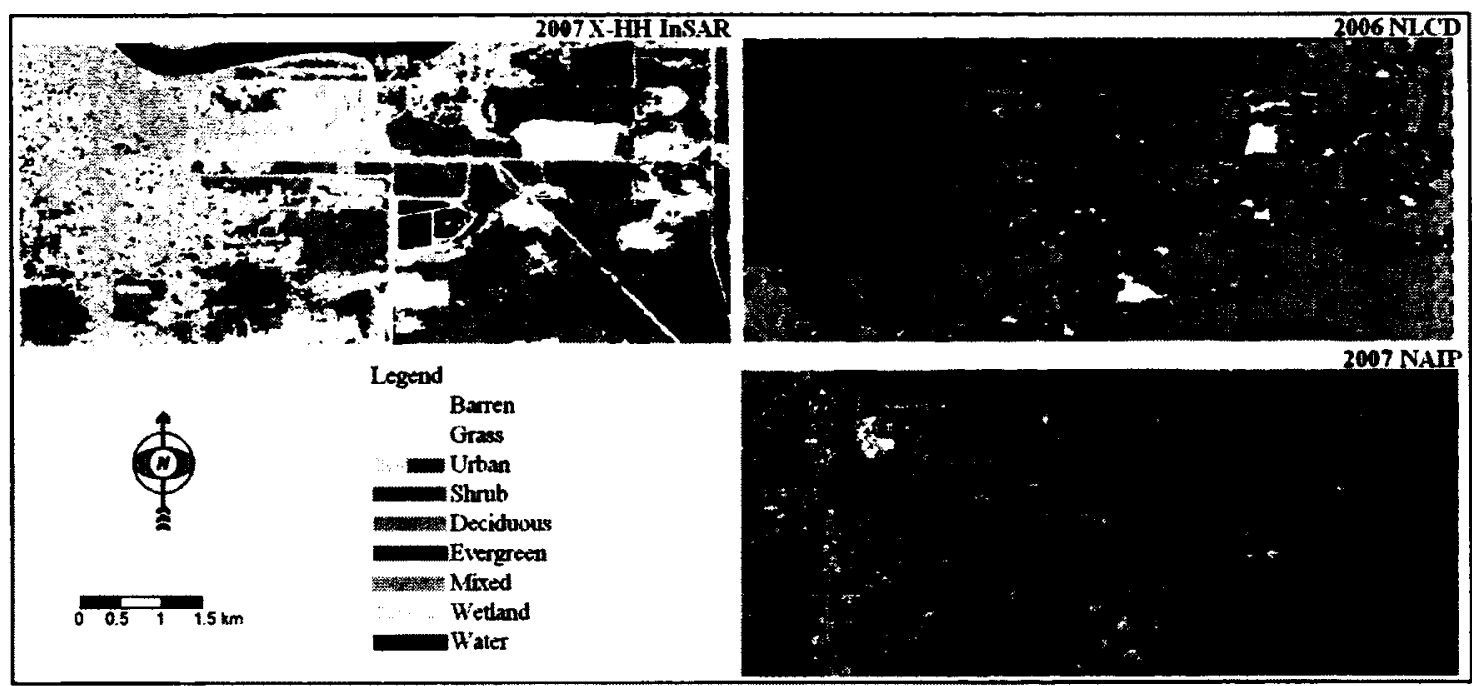

Figure 54. International Falls X-HH InSAR derived land cover map (top left); NLCD (top right); NAIP imagery (bottom right).

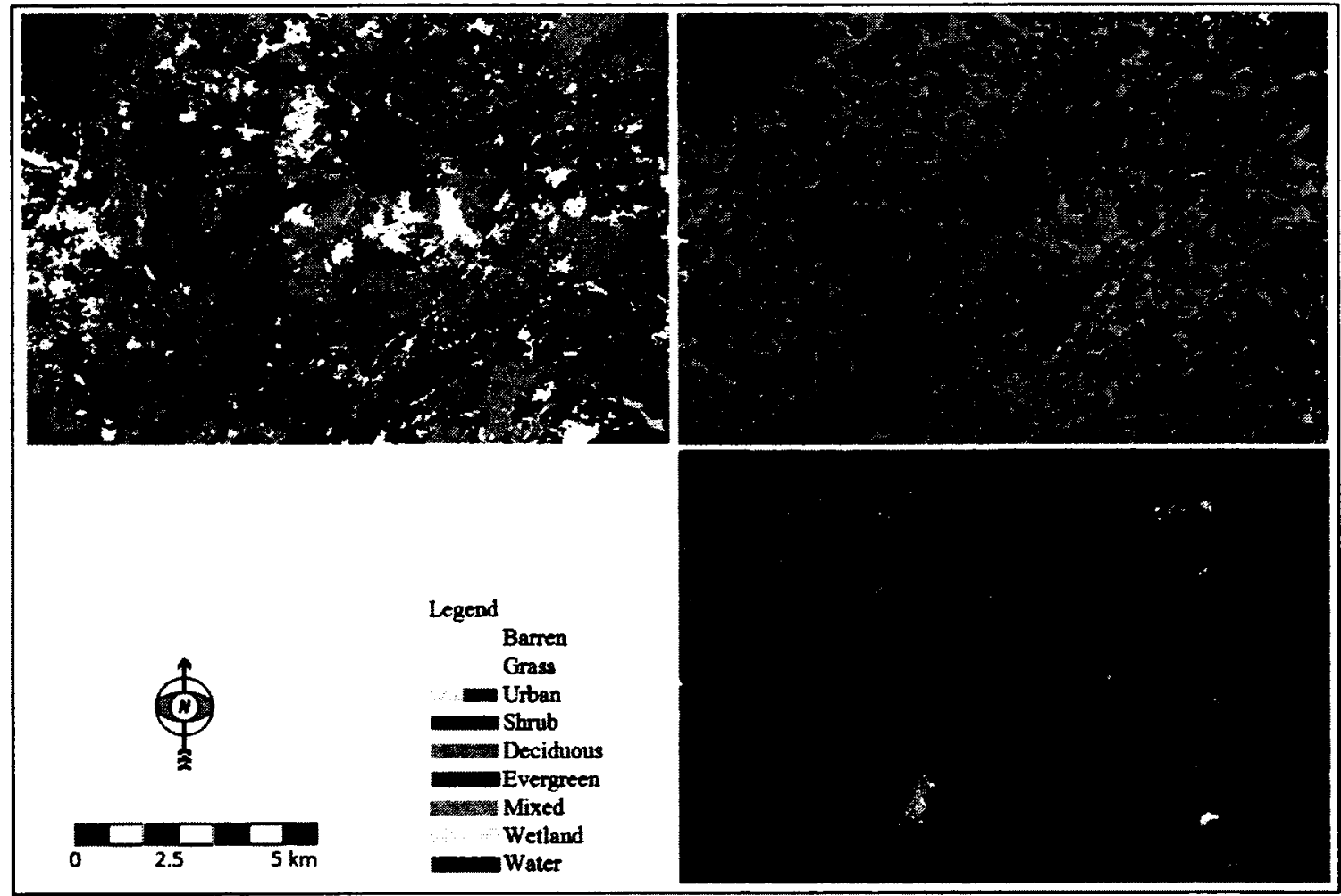

Figure 55. Ely X-HH InSAR derived land cover map (top left); NLCD (top right); NAIP imagery (bottom right). 


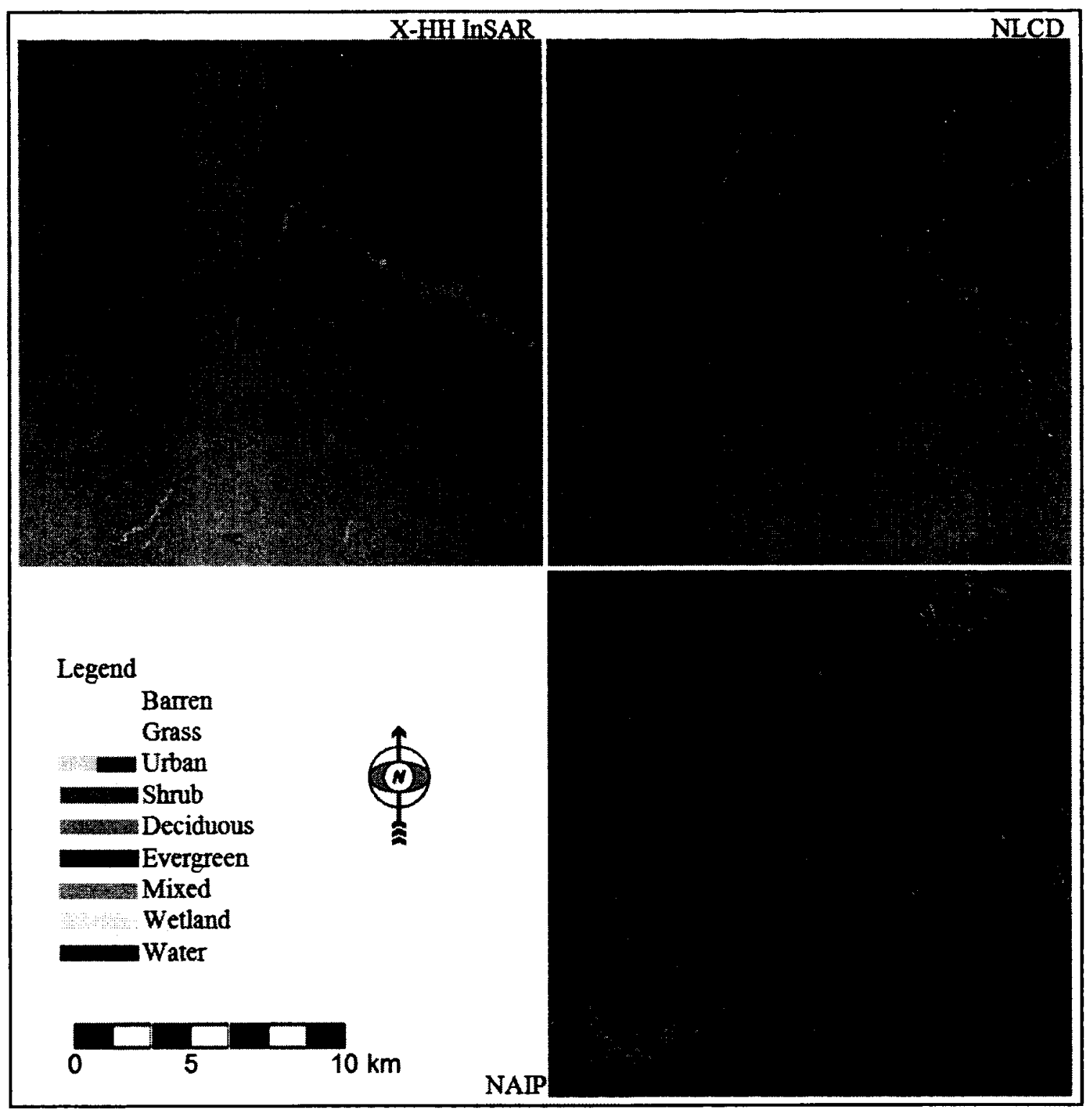

Figure 56. Arizona X-HH InSAR derived land cover map (top left); NLCD (top right); NAIP imagery (bottom right). 


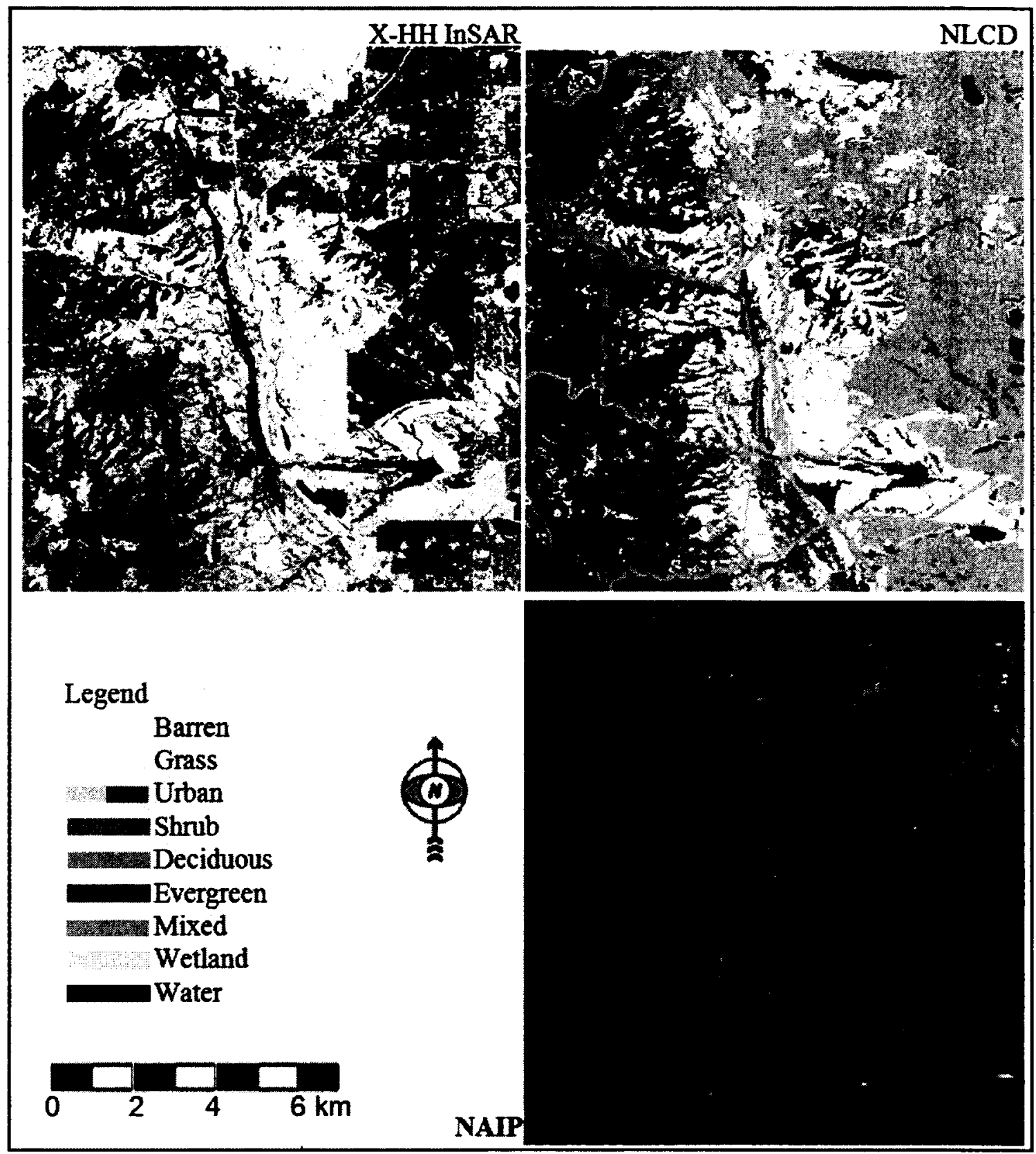

Figure 57. Colorado X-HH InSAR derived land cover map (top left); NLCD (top right); NAIP imagery (bottom right). 


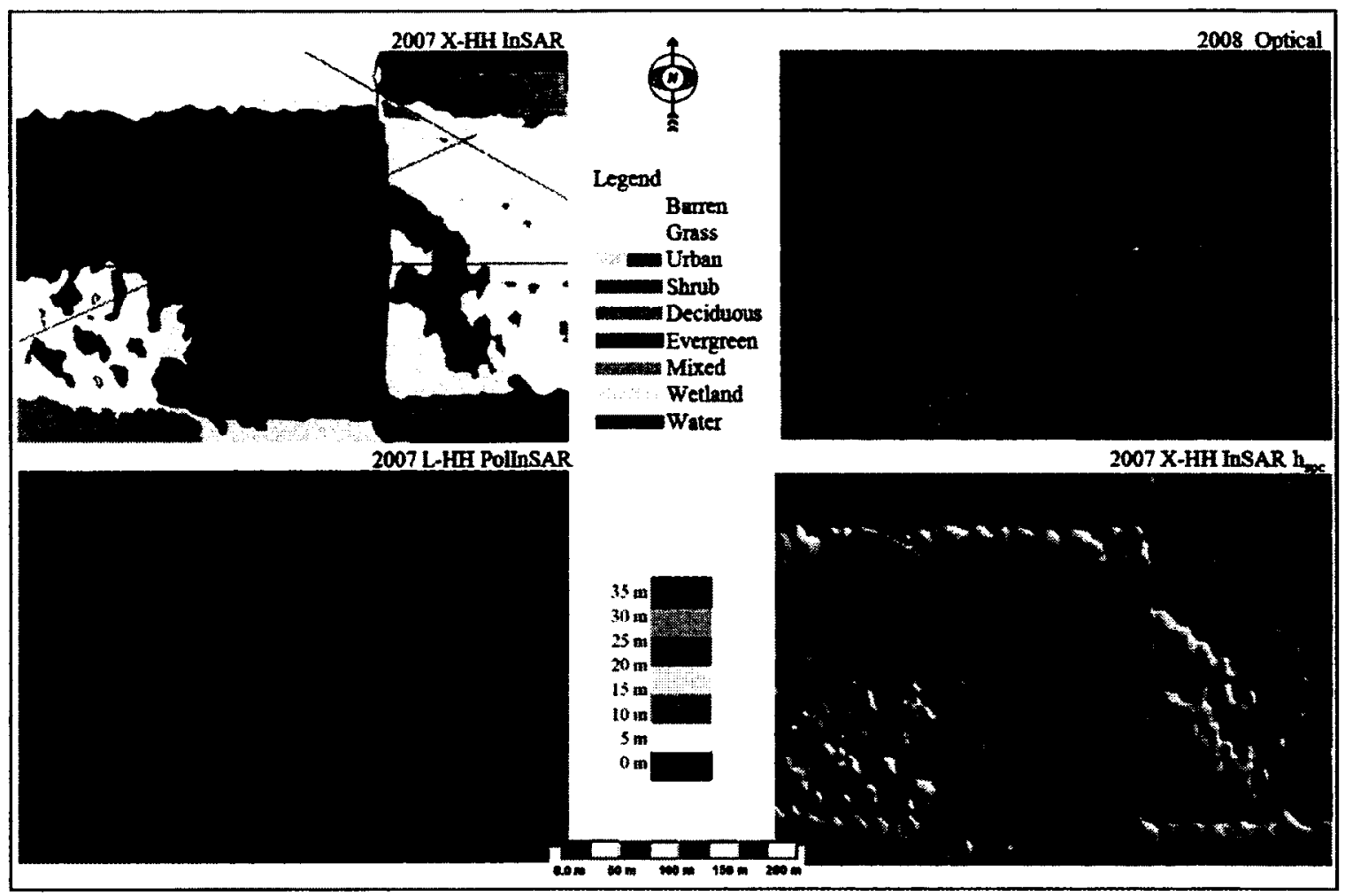

Figure 58. Burnstick Lake 2007 X-HH InSAR derived land cover map (top left) differs in time from the 2008 Google Earth (top right) optical image, showing a deforested patch of land that was a forest at the time of the InSAR data collection. The L-HH InSAR imagery (bottom left) and the 2007 X-HH InSAR scattering phase centre height (bottom right image) correlate well with the land cover classification. The Google imagery does not correlate well with X-HH derived InSAR land cover classification, due to the temporal differences. 


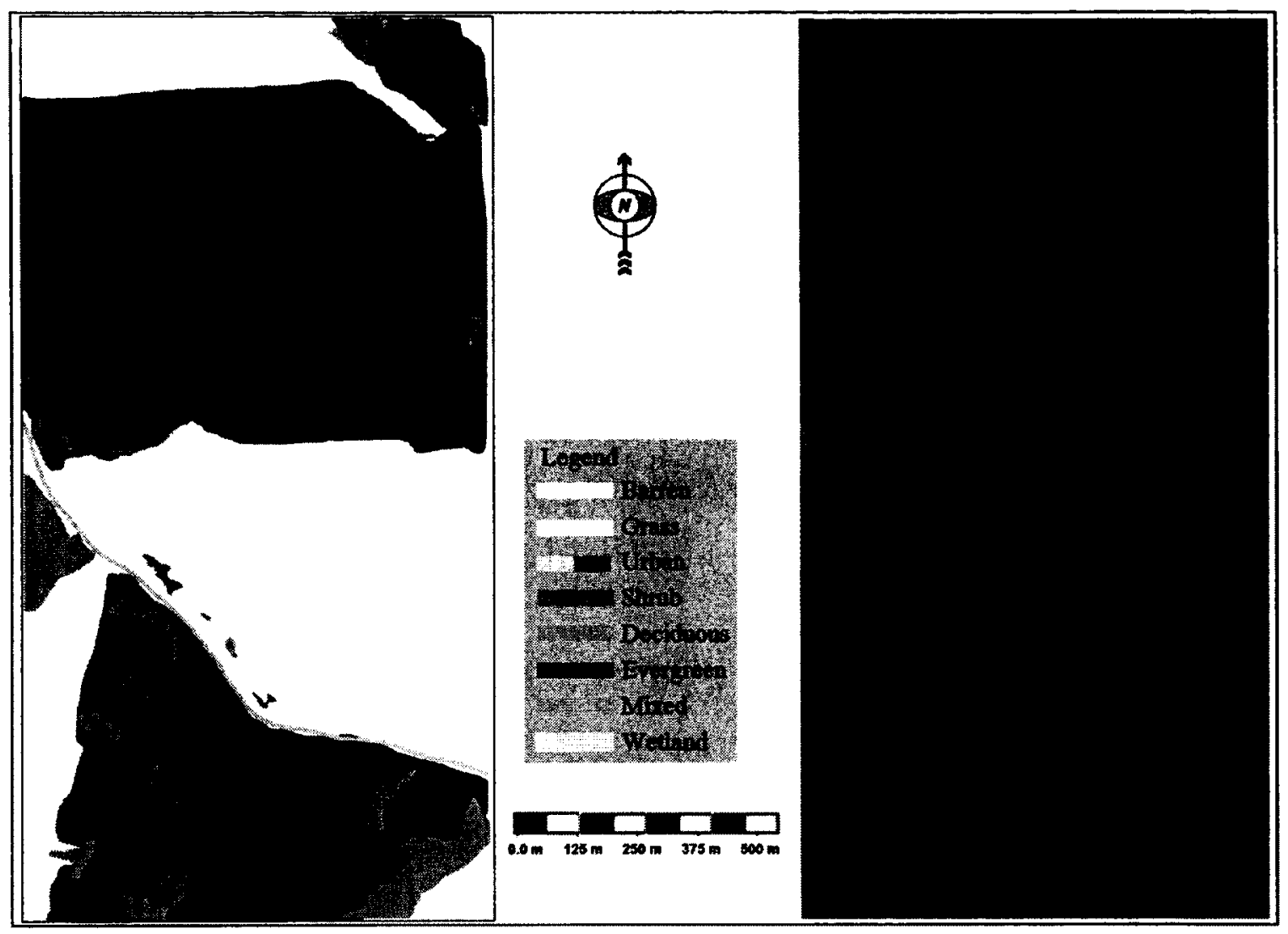

Figure 59. Edson X-HH InSAR derived land cover map (left); aerial photography supplied by Valtus (right).

\subsubsection{Quantitative Assessment of Land Cover Classification - Stratified by Research Site}

The X-HH InSAR derived land cover classifications were assessed against in situ observations (Table 37, U.S. sites) and visual interpretation of high resolution optical imagery (Table 39, Canadian sites) using error matrices. For comparison, the 2006 NLCD maps were assessed against the same reference data for the U.S. sites (Table 38). The average PA and average UA for each class in the U.S. sites were calculated from the PAs and UAs of each class at each site. The diagonal elements of each error matrix contain the number of samples correctly identified for each class. In addition, Cohen's 
Kappa statistics were generated because it takes into account the agreement occurring by chance (Fleiss and Cohen, 1969). The results of these analyses are presented in detail in Sections 5.3.1.2.1. and 5.3.1.2.2., for the U.S. and the Canadian research sites, respectively.

\subsection{U. S. Research Sites}

The X-HH InSAR derived classification results are presented in Table 37. Five of the six land cover classes had both producer and user accuracies greater than $86.6 \%$ at all sites. The overall accuracy range for the four sites was $86.8 \%-92.1 \%$ (kappa results ranged from $86.8 \%-90.2 \%$ ), which represents a significant improvement over the 2006 NLCD (44.0\% - 65.0\%; kappa - 31.6\% - 56.8\%, Table 38). This was expected because of the differences in resolution of the data sets (X-HH InSAR - $5 \mathrm{~m} ; \mathrm{NLCD}-30 \mathrm{~m})$ and because of the addition of the canopy height estimates given by $h_{\mathrm{spc}}$ to the object-based classification method, which is a new approach.

The class most confused was mixed forest, possibly due to the diverse structure of the forest elements (e.g. deciduous and conifer mixture). Of the vegetation classes, shrub had the highest accuracy, most likely due to the inclusion of $h_{s p c}$ as a discriminating variable; as it was much lower than for the other four vegetation classes. The $\mathrm{X}-\mathrm{HH}$ InSAR derived classification results are encouraging as the land cover maps play a critical role in the proposed $\mathrm{CHE}$. 
Table 37. X-HH InSAR land cover classification accuracy assessment, U.S. sites (Decid $=$ Deciduous). The reference data are in the rows; classified data are in the columns.

\begin{tabular}{|c|c|c|c|c|c|c|c|c|c|}
\hline Ely & Barren & Shrub & Decid & Conifers & Mixed & Wetlands & Total & PA (\%) & Kappa (\%) \\
\hline Barren & 50 & 0 & 0 & 0 & 0 & 0 & 50 & 100 & \\
\hline Shrub & 2 & 61 & 0 & 0 & 2 & 1 & 66 & 92.4 & \\
\hline Decid & 0 & 0 & 54 & 2 & 2 & 2 & 60 & 90.0 & \\
\hline Conifers & 0 & 0 & 3 & 50 & 2 & 0 & 55 & 92.1 & \\
\hline Mixed & 0 & 0 & 2 & 2 & 48 & 3 & 55 & 86.2 & \\
\hline Wetlands & 0 & 3 & 0 & 0 & 3 & 39 & 45 & 86.7 & \\
\hline Total & 52 & 64 & 59 & 54 & 57 & 45 & 331 & & \\
\hline UA (\%) & 96.2 & 95.3 & 91.5 & 92.6 & 84.2 & 86.7 & & 91.2 & 89.5 \\
\hline IF & Barren & Shrub & Decid & Conifers & Mixed & Wetlands & Total & $\mathrm{PA}(\%)$ & Kappa (\%) \\
\hline Barren & 49 & 1 & 0 & 0 & 0 & 0 & 50 & 98.0 & \\
\hline Shrub & 0 & 18 & 0 & 0 & 1 & 1 & 20 & 90.0 & \\
\hline Decid & 0 & 0 & 22 & 2 & 1 & 0 & 25 & 88.0 & \\
\hline Conifers & 0 & 0 & 0 & 23 & 1 & 1 & 25 & 92.0 & \\
\hline Mixed & 0 & 0 & 1 & 1 & 23 & 0 & 25 & 92.0 & \\
\hline Wetlands & 0 & 1 & 1 & 0 & 1 & 16 & 19 & 84.2 & \\
\hline Total & 49 & 20 & 24 & 26 & 27 & 18 & 164 & & \\
\hline UA (\%) & 100 & 93.2 & 90.7 & 92.4 & 89.0 & 92.3 & & 92.1 & 90.2 \\
\hline Arizona & Barren & Shrub & Decid & Conifers & Mixed & Wetlands & Total & PA (\%) & Kappa (\%) \\
\hline Barren & 48 & 2 & 0 & 0 & 0 & 0 & 50 & 96.0 & \\
\hline Shrub & 0 & 135 & 0 & 0 & 1 & 9 & 145 & 93.1 & \\
\hline Decid & 0 & 4 & 97 & 2 & 7 & 0 & 110 & 88.2 & \\
\hline Conifers & 0 & 0 & 7 & 96 & 6 & 1 & 110 & 87.3 & \\
\hline Mixed & 0 & 1 & 6 & 6 & 92 & 5 & 110 & 83.6 & \\
\hline Wetlands & 0 & 3 & 2 & 0 & 6 & 129 & 140 & 92.1 & \\
\hline Total & 48 & 145 & 112 & 104 & 112 & 144 & 665 & & \\
\hline UA (\%) & 100.0 & 93.1 & 86.6 & 92.3 & 82.1 & 89.6 & & 89.8 & 87.5 \\
\hline Colorado & Barren & Shrub & Decid & Conifers & Mixed & Wetlands & Total & PA (\%) & Kappa (\%) \\
\hline Barren & 44 & 6 & 0 & 0 & 0 & 0 & 50 & 88.0 & \\
\hline Shrub & 3 & 61 & 0 & 0 & 1 & 0 & 65 & 93.8 & \\
\hline Decid & 0 & 1 & 26 & 1 & 2 & 0 & 30 & 86.7 & \\
\hline Conifers & 0 & 0 & 2 & 26 & 2 & 0 & 30 & 86.7 & \\
\hline Mixed & 0 & 0 & 1 & 2 & 25 & 2 & 30 & 83.3 & \\
\hline Wetlands & 0 & 2 & 0 & 0 & 2 & 41 & 45 & 91.1 & \\
\hline Total & 47 & 70 & 29 & 29 & 32 & 43 & 250 & & \\
\hline UA (\%) & 93.6 & 87.1 & 89.7 & 89.7 & 78.1 & 95.3 & & 89.2 & 86.8 \\
\hline
\end{tabular}


Table 38. NLCD land cover classification accuracy assessment, U.S. sites (Decid = Deciduous). The reference data are in the rows; classified data are in the columns.

\begin{tabular}{|c|c|c|c|c|c|c|c|c|c|}
\hline Ely & Barren & Shrub & Decid & Conifers & Mixed & Wetlands & Total & PA (\%) & Карра (\%) \\
\hline Barren & 21 & 11 & 0 & 0 & 0 & 18 & 50 & 42.0 & \\
\hline Shrub & 14 & 32 & 8 & 7 & 0 & 5 & 66 & 48.5 & \\
\hline Decid & 0 & 0 & 38 & 9 & 1 & 12 & 60 & 63.3 & \\
\hline Conifers & 0 & 0 & 6 & 39 & 2 & 8 & 55 & 70.9 & \\
\hline Mixed & 2 & 5 & 6 & 7 & 29 & 6 & 55 & 52.7 & \\
\hline Wetlands & 19 & 9 & 6 & 0 & 0 & 11 & 45 & 24.4 & \\
\hline Total & 56 & 57 & 64 & 62 & 32 & 60 & 331 & & \\
\hline UA (\%) & 37.5 & 56.1 & 91.5 & 62.9 & 84.2 & 18.3 & & 51.4 & 41.6 \\
\hline IF & Barren & Shrub & Decid & Conifers & Mixed & Wetlands & Total & PA (\%) & Kappa (\%) \\
\hline Barren & 38 & 3 & 5 & 0 & 2 & 0 & 50 & 76.0 & \\
\hline Shrub & 3 & 2 & 6 & 0 & 2 & 7 & 20 & 10.0 & \\
\hline Decid & 0 & 3 & 12 & 2 & 0 & 10 & 25 & 48.0 & \\
\hline Conifers & 0 & 0 & 7 & 3 & 0 & 15 & 25 & 12.0 & \\
\hline Mixed & 0 & 0 & 5 & 0 & 8 & 12 & 25 & 32.0 & \\
\hline Wetlands & 0 & 3 & 6 & 0 & 3 & 13 & 19 & 52.0 & \\
\hline Total & 41 & 11 & 41 & 3 & 17 & 57 & 170 & & \\
\hline UA (\%) & 92.7 & 18.2 & 29.3 & 100 & 47.1 & 22.8 & & 44.7 & 32.5 \\
\hline Arizona & Barren & Shrub & Decid & Conifers & Mixed & Wetlands & Total & PA (\%) & Kappa (\%) \\
\hline Barren & 22 & 22 & 1 & 0 & 3 & 2 & 50 & 44.0 & \\
\hline Shrub & 4 & 114 & 12 & 0 & 6 & 9 & 145 & 78.6 & \\
\hline Decid & 0 & 23 & 67 & 3 & 11 & 6 & 110 & 60.9 & \\
\hline Conifers & 3 & 32 & 5 & 68 & 2 & 0 & 110 & 61.8 & \\
\hline Mixed & 0 & 31 & 2 & 0 & 72 & 33 & 110 & 65.5 & \\
\hline Wetlands & 2 & 41 & 5 & 1 & 2 & 89 & 140 & 63.6 & \\
\hline Total & 31 & 235 & 92 & 72 & 96 & 139 & 665 & & \\
\hline UA (\%) & 71.0 & 48.5 & 72.8 & 94.4 & 75 & 64.0 & & 65.0 & 56.8 \\
\hline Colorado & Barren & Shrub & Decid & Conifers & Mixed & Wetlands & Total & PA (\%) & Kappa (\%) \\
\hline Barren & 26 & 11 & 0 & 10 & 0 & 3 & 50 & 52.0 & \\
\hline Shrub & 7 & 35 & 0 & 15 & 0 & 8 & 65 & 53.9 & \\
\hline Decid & 2 & 3 & 9 & 16 & 0 & 0 & 30 & 30.0 & \\
\hline Conifers & 2 & 8 & 1 & 18 & 1 & 0 & 30 & 60.0 & \\
\hline Mixed & 2 & 5 & 4 & 12 & 7 & 0 & 30 & 23.3 & \\
\hline Wetlands & 0 & 14 & 3 & 11 & 2 & 15 & 45 & 33.3 & \\
\hline Total & 39 & 76 & 17 & 82 & 10 & 26 & 250 & & \\
\hline UA (\%) & 83.9 & 46.0 & 53.0 & 22.8 & 22.8 & 57.7 & & 44.0 & 31.60 \\
\hline
\end{tabular}


Combining the X-HH InSAR land cover maps for the U.S. sites into a single error matrix (Table 39) indicates that five of the six land cover classes had both producer and user accuracies greater than $86.5 \%$. The average accuracy was $89.7 \%$ (kappa $=87.6 \%$ ), which represents a significant improvement over the 2006 NLCD (54.9\%; kappa = $45.4 \%)$.

Table 39. X-HH InSAR and NLCD land cover classification accuracy assessment for all data combined, U.S. sites (Decid = Deciduous). The reference data are in the rows; classified data are in the columns.

\begin{tabular}{|c|c|c|c|c|c|c|c|c|c|}
\hline $\mathrm{X}-\mathrm{HH}$ & Barren & Shrub & Decid & Conifers & Mixed & Wetlands & Total & PA (\%) & Kappa (\%) \\
\hline Barren & 191 & 9 & 0 & 0 & 0 & 0 & 200 & 95.5 & \\
\hline Shrub & 5 & 275 & 0 & 0 & 5 & 11 & 296 & 92.9 & \\
\hline Decid & 0 & 8 & 209 & 9 & 12 & 2 & 240 & 87.1 & \\
\hline Conifers & 0 & 0 & 16 & 199 & 13 & 2 & 230 & 86.5 & \\
\hline Mixed & 0 & 1 & 10 & 11 & 188 & 10 & 220 & 85.5 & \\
\hline Wetlands & 0 & 9 & 3 & 0 & 12 & 226 & 250 & 90.4 & \\
\hline Total & 196 & 302 & 238 & 219 & 230 & 251 & 1436 & & \\
\hline UA (\%) & 97.5 & 91.1 & 87.8 & 90.9 & 81.7 & 90.0 & & 89.7 & 87.6 \\
\hline NLCD & Barren & Shrub & Decid & Conifers & Mixed & Wetlands & Total & PA (\%) & Kappa (\%) \\
\hline Barren & 91 & 57 & 4 & 16 & 3 & 29 & 200 & 45.5 & \\
\hline Shrub & 28 & 183 & 26 & 22 & 8 & 29 & 296 & 61.8 & \\
\hline Decid & 0 & 31 & 135 & 27 & 17 & 30 & 240 & 56.2 & \\
\hline Conifers & 5 & 41 & 21 & 135 & 5 & 23 & 230 & 58.7 & \\
\hline Mixed & 4 & 13 & 19 & 19 & 116 & 51 & 220 & 52.7 & \\
\hline Wetlands & 21 & 65 & 18 & 11 & 7 & 128 & 250 & 51.2 & \\
\hline Total & 149 & 390 & 221 & 230 & 156 & 290 & 1436 & & \\
\hline UA (\%) & 61.1 & 49.2 & 61.1 & 58.7 & 74.4 & 44.1 & & 54.9 & 45.4 \\
\hline
\end{tabular}


As with the previous analysis (Tables 36 and 37) mixed forest was most confused and the shrub class had the highest accuracy. These results are encouraging considering the research sites represent different eco-regions and several vegetation types, and given only two data inputs, $\mathrm{X}-\mathrm{HH}$ intensity and $\mathrm{X}-\mathrm{HH} \operatorname{InSAR}$ derived $\mathrm{h}_{\mathrm{spc}}$.

In comparison, the NLCD maps, for all U.S. sites combined, had an overall accuracy of approximately $54.6 \%$, often confusing the vegetation classes with errors of omission and commission being distributed amongst these classes (Table 38). It was unexpected to see five of the six classes with producer's and user's accuracies of less than $60 \%$. Confusion between barren land and shrub classes, underestimation of the coniferous class, and overestimating the shrub class were evident in the NLCD results.

\subsection{Canadian Research Sites}

Results of the X-HH InSAR derived land cover maps for the two Canadian sites, compared against visually interpreted high-resolution optical reference data are presented in Table 40. Results indicate that all but the user's accuracy for deciduous forest at Edson were greater than $89.1 \%$. The coniferous results are impressive and slightly better than those from the U.S. research sites. One possible explanation for this could be due to the greater density of all forest vegetation classes compared to the same vegetation types found at the U.S. sites. The land cover map for Edson was more accurate than for Burnstick Lake, possibly due to the greater density in vegetation at Edson compared to Burnstick Lake, where the results indicate that all but the user's accuracy for shrub vegetation were greater than $85.2 \%$. 
Table 40. X-HH InSAR land cover classification accuracy for the Canadian sites (Decid $=$ Deciduous). The reference data are in the rows; classified data are in the columns.

\begin{tabular}{|c|c|c|c|c|c|c|c|c|c|}
\hline Edson & Barren & Shrub & Decid & Conifers & Mixed & \multicolumn{2}{|c|}{ Total } & PA (\%) & Kappa (\%) \\
\hline Barren & 46 & 2 & 0 & 0 & 2 & & 50 & 92.0 & \\
\hline Shrub & 2 & 22 & 0 & 0 & 1 & & 25 & 88.0 & \\
\hline Decid & 0 & 1 & 44 & 2 & 3 & & 50 & 88.0 & \\
\hline Conifers & 0 & 0 & 3 & 41 & 1 & & 45 & 91.1 & \\
\hline Mixed & 0 & 0 & 4 & 4 & 52 & & 60 & 86.7 & \\
\hline Total & 48 & 25 & 51 & 47 & 59 & & 230 & & \\
\hline UA $(\%)$ & 95.8 & 88.0 & 86.3 & 87.2 & 59 & & & 89.1 & 86.2 \\
\hline Burnstick & Barren & Shrub & Decid & Conifers & Mixed & Wetlands & Total & PA (\%) & Kappa (\%) \\
\hline Barren & 46 & 2 & 0 & 0 & 2 & 0 & 50 & 92.0 & \\
\hline Shrub & 2 & 12 & 0 & 0 & 0 & 0 & 15 & 86.7 & \\
\hline Decid & 0 & 1 & 44 & 2 & 3 & 0 & 50 & 88.0 & \\
\hline Conifers & 0 & 0 & 2 & 60 & 1 & 2 & 65 & 92.3 & \\
\hline Mixed & 0 & 0 & 4 & 2 & 52 & 3 & 61 & 85.3 & \\
\hline Wetlands & 0 & 05 & 1 & 2 & 3 & 51 & 57 & 89.5 & \\
\hline Total & 48 & 16 & 51 & 66 & 61 & 56 & 298 & & \\
\hline UA (\%) & 95.8 & 81.3 & 86.3 & 90.9 & 85.2 & 91.1 & & 89.3 & 86.8 \\
\hline
\end{tabular}

\subsubsection{Accuracy Assessment of the Refined X-HH InSAR and L-Quad PollnSAR Canopy Height Estimates (CHE)}

\subsubsection{CHE - All Data Combined, Stratified by Vegetation Type}

Accuracies of the X-HH InSAR canopy height estimates given by the proposed CHE (Figure 30) prior to/and after the application of the gap/edge corrections, stratified by vegetation type for all research sites are presented in Table 41 . The results show that implementation of the gap/edge corrections significantly improved the canopy height estimates in all vegetation classes. 
Table 41. X-HH InSAR derived canopy height estimate error at vegetation canopy gaps and vegetation non-vegetation canopy boundaries with and without gap/edge corrections applied: error assessment is against in situ canopy height measurements.

\begin{tabular}{|l|c|r|r|}
\hline \multicolumn{2}{|c|}{ Field Observations } & CHE RMSE (m) & CHE RMSE (m) \\
\hline Vegetation Cover & $\begin{array}{c}\text { \# Gap/edge } \\
\text { Samples }\end{array}$ & $\begin{array}{c}\text { no gap/edge } \\
\text { correction applied }\end{array}$ & $\begin{array}{c}\text { gap/edge correction } \\
\text { applied }\end{array}$ \\
\hline Shrub & 133 & 2.69 & 1.00 \\
\hline Deciduous & 26 & 9.98 & 1.93 \\
\hline Conifers & 32 & 13.5 & 1.85 \\
\hline Mixed & 20 & 9.78 & 1.65 \\
\hline Wetlands & 24 & 7.06 & 1.26 \\
\hline
\end{tabular}

The error assessment of the X-HH InSAR and L-Quad PolInSAR canopy height estimates are compared to all reference data, for all research sites, stratified by vegetation class is presented in Table 42. These adjusted X-and L-band canopy height estimates were significantly more accurate than using the scattering phase centre height alone (Table 21) as an estimate of canopy height, although the mean error for all classes was negative indicating that, on average, canopy height was still underestimated.

Table 42. X-HH InSAR and L-Band PolInSAR derived canopy height error assessment for all research sites stratified by vegetation type. Reference data were: in situ (U.S. sites) and LiDAR (Canadian sites) canopy height measurements.

\begin{tabular}{|c|l|c|c|c|c|c|c|}
\hline \multirow{2}{*}{$\begin{array}{c}\text { \# ref. } \\
\text { samples }\end{array}$} & $\begin{array}{l}\text { land cover } \\
\text { type }\end{array}$ & $\begin{array}{c}\text { mean tree } \\
\text { height }(\mathrm{m})\end{array}$ & $\begin{array}{c}\text { RMSE } \\
(\mathrm{m})\end{array}$ & $\begin{array}{c}\text { Mean } \\
\text { Error }(\mathrm{m})\end{array}$ & $\begin{array}{c}\text { mean tree } \\
\text { height }(\mathrm{m})\end{array}$ & $\begin{array}{c}\text { RMSE } \\
(\mathrm{m})\end{array}$ & $\begin{array}{c}\text { Mean } \\
\text { Error } \\
(\mathrm{m})\end{array}$ \\
\hline 762 & Shrub & 4 & 0.97 & -0.61 & N/A & N/A & N/A \\
\hline 567 & Deciduous & 16 & 1.53 & -0.40 & 17 & 1.98 & -2.11 \\
\hline 761 & Conifers & 24 & 1.23 & -0.22 & 27 & 2.17 & -1.80 \\
\hline 482 & Mixed & 14 & 1.31 & -0.32 & 14 & 2.21 & -2.30 \\
\hline 180 & Wetlands & 7 & 0.93 & -0.16 & N/A & N/A & N/A \\
\hline
\end{tabular}


Table 43 lists the average percentage of canopy height represented by the proposed CHEs for X-band and L-Band, for each class. Overall, both data types underestimate canopy height, with L-band PolInSAR performing slightly poorer for the forest classes at the Canadian sites than the X-band InSAR for the same classes over all six sites. The results presented in Tables 42 and 43 are averaged over all sites. The variability among sites is addressed in Section 5.4.3.

Table 43. Percentage of canopy height retrieved by the X-HH InSAR and L-Band PolInSAR CHEs for all research sites combined, stratified by vegetation type.

\begin{tabular}{|c|l|r|r|r|r|r|r|}
\hline \multirow{2}{*}{$\begin{array}{c}\text { \# ref. } \\
\text { samples }\end{array}$} & $\begin{array}{c}\text { land cover } \\
\text { type }\end{array}$ & $\begin{array}{c}\text { mean } \\
\text { tree } \\
\text { height } \\
(\mathrm{m})\end{array}$ & $\begin{array}{c}\text { X-Band } \\
\text { relative } \\
\text { error }\end{array}$ & $\begin{array}{c}\text { canopy } \\
\text { height } \\
\text { retrieved }\end{array}$ & $\begin{array}{c}\text { mean } \\
\text { tree } \\
\text { height } \\
(\mathrm{m})\end{array}$ & $\begin{array}{c}\text { L-Band } \\
\text { relative } \\
\text { error }\end{array}$ & $\begin{array}{c}\text { canopy } \\
\text { height } \\
\text { retrieved }\end{array}$ \\
\hline 762 & Shrub & 4 & $24.25 \%$ & $75.75 \%$ & N/A & N/A & N/A \\
\hline 567 & Deciduous & 16 & $9.56 \%$ & $90.44 \%$ & 17 & $11.65 \%$ & $88.35 \%$ \\
\hline 761 & Conifers & 24 & $5.13 \%$ & $94.88 \%$ & 27 & $8.04 \%$ & $91.96 \%$ \\
\hline 482 & Mixed & 14 & $9.36 \%$ & $90.64 \%$ & 14 & $15.79 \%$ & $84.21 \%$ \\
\hline 180 & Wetlands & 7 & $13.29 \%$ & $86.71 \%$ & N/A & N/A & N/A \\
\hline
\end{tabular}

\subsubsection{CHE - All Data Combined, Stratified by Research Site}

The accuracies of the X-and L-band (Canadian sites only) CHEs against reference data and against the LANDFIRE CHE (U.S. sites only) and stratified by vegetation type are presented in Tables $44-49$ for each research site. These results include data acquired across the vegetation canopy, including at edges as separately presented above. Like the CHE stratified by vegetation type, (Table 43) the results of the X-HH InSAR and L-Quad PolInSAR CHEs were significantly more accurate than using $h_{\text {spc }}$ alone at all research 
sites and for every vegetation type. The X-HH InSAR derived CHEs at the U.S. sites were more accurate than existing LANDFIRE canopy height data.

As in the previous analysis (Table 43), the mean errors were negative for all vegetation types at all research sites indicating that the $\mathrm{CHE}$ estimator still underestimates canopy height at both X- and L-band. The deciduous class RMSE values for the $\mathrm{AZ}$ and $\mathrm{CO}$ sites were worse than those of the two $\mathrm{MN}$ and two $\mathrm{AB}$ sites. This could possibly be due to the impact of vegetation canopy density, as previously discussed. Similar results were found for coniferous vegetation. In comparison, the LANDFIRE data overestimate canopy height for all five vegetation classes, possibly due to the method in which the LANDFIRE data were created, where one height measurement per vegetation class was typically applied over large geographic extents. Furthermore, the coarse resolution of the LANDFIRE data (GSD $=30 \mathrm{~m}$ ) compared the CHEs presented here ( $5 \mathrm{~m} \mathrm{GSD)}$ would contribute to the greater error in the LANDFIRE data in comparison to the X-band data.

Table 44. X-HH InSAR derived CHE error assessment against in situ canopy height for International Falls, stratified by vegetation type.

\begin{tabular}{|r|l|r|r|r|r|r|}
\hline \multirow{2}{*}{$\begin{array}{r}\text { \# in situ } \\
\text { Samples }\end{array}$} & \multirow{2}{*}{$\begin{array}{c}\text { Land Cover } \\
\text { Type }\end{array}$} & $\begin{array}{c}\text { Mean Tree } \\
\text { Height }(\mathrm{m})\end{array}$ & $\begin{array}{c}\text { RMSE } \\
(\mathrm{m})\end{array}$ & $\begin{array}{c}\text { Mean } \\
\text { Error }(\mathrm{m})\end{array}$ & $\begin{array}{c}\text { XMSE } \\
(\mathrm{m})\end{array}$ & $\begin{array}{c}\text { Mean Error } \\
(\mathrm{m})\end{array}$ \\
\hline 24 & Shrub & 4.0 & 1.05 & -0.12 & 5.95 & -1.81 \\
\hline 66 & Deciduous & 15.1 & 1.38 & -0.09 & 19.16 & -1.73 \\
\hline 36 & Conifers & 15.5 & 1.33 & -0.13 & 19.98 & -2.49 \\
\hline 36 & Mixed & 14.6 & 1.54 & -0.93 & 15.97 & -2.74 \\
\hline 18 & Wetlands & 7.2 & 1.85 & -0.99 & 17.92 & -2.14 \\
\hline
\end{tabular}


Table 45. X-HH InSAR derived CHE error assessment against in situ canopy height for Ely, stratified by vegetation type.

\begin{tabular}{|r|l|r|r|r|r|r|}
\hline \multirow{2}{*}{$\begin{array}{c}\text { \# in situ } \\
\text { Samples }\end{array}$} & \multirow{2}{*}{$\begin{array}{c}\text { Land Cover } \\
\text { Type }\end{array}$} & $\begin{array}{c}\text { Mean Tree } \\
\text { Height }(\mathrm{m})\end{array}$ & $\begin{array}{c}\text { XMSE } \\
(\mathrm{m})\end{array}$ & $\begin{array}{c}\text { Mean } \\
\text { Error }(\mathrm{m})\end{array}$ & $\begin{array}{c}\text { RMSE } \\
(\mathrm{m})\end{array}$ & $\begin{array}{c}\text { Mean Error } \\
(\mathrm{m})\end{array}$ \\
\hline 24 & Shrub & 4.0 & 1.15 & -0.32 & 5.39 & -1.75 \\
\hline 126 & Deciduous & 15.4 & 1.32 & -0.11 & 19.16 & -2.51 \\
\hline 150 & Conifers & 15.2 & 1.29 & -0.34 & 15.00 & -2.19 \\
\hline 24 & Mixed & 14.3 & 1.43 & -0.79 & 18.39 & -2.70 \\
\hline
\end{tabular}

Table 46. X-HH InSAR derived CHE error assessment against in situ canopy height for Arizona, stratified by vegetation type.

\begin{tabular}{|r|l|r|r|r|r|r|}
\hline \multirow{2}{*}{$\begin{array}{l}\text { \# in situ } \\
\text { Samples }\end{array}$} & \multirow{2}{*}{$\begin{array}{c}\text { Land Cover } \\
\text { Type }\end{array}$} & $\begin{array}{c}\text { Mean Tree } \\
\text { Height }(\mathrm{m})\end{array}$ & $\begin{array}{c}\text { RMSE } \\
(\mathrm{m})\end{array}$ & $\begin{array}{c}\text { Mean } \\
\text { Error }(\mathrm{m})\end{array}$ & $\begin{array}{c}\text { RMSE } \\
(\mathrm{m})\end{array}$ & $\begin{array}{c}\text { Mean Error } \\
(\mathrm{m})\end{array}$ \\
\hline 648 & Shrub & 4.3 & 0.77 & -0.02 & 5.82 & -1.73 \\
\hline 66 & Deciduous & 15.2 & 1.84 & -0.21 & 14.00 & -1.84 \\
\hline 96 & Conifers & 15.5 & 1.49 & -0.34 & 19.24 & -1.89 \\
\hline 36 & Mixed & 14.4 & 1.63 & -0.84 & 14.98 & -2.13 \\
\hline 162 & Wetlands & 6.1 & 1.91 & -0.78 & 18.23 & -2.23 \\
\hline
\end{tabular}

Table 47. X-HH InSAR derived CHE error assessment against in situ canopy height for Colorado, stratified by vegetation type.

\begin{tabular}{|c|c|c|c|c|c|c|}
\hline \multirow{2}{*}{$\begin{array}{l}\text { \# in situ } \\
\text { Samples }\end{array}$} & \multirow{2}{*}{$\begin{array}{c}\text { Land Cover } \\
\text { Type }\end{array}$} & \multirow{2}{*}{$\begin{array}{l}\text { Mean Tree } \\
\text { Height (m) }\end{array}$} & \multicolumn{2}{|c|}{ X-HH InSAR } & \multicolumn{2}{|c|}{ LANDFIRE CHE } \\
\hline & & & $\begin{array}{c}\text { RMSE } \\
(\mathrm{m}) \\
\end{array}$ & $\begin{array}{c}\text { Mean } \\
\text { Error (m) }\end{array}$ & $\begin{array}{c}\text { RMSE } \\
\text { (m) }\end{array}$ & $\begin{array}{c}\text { Mean Error } \\
\text { (m) }\end{array}$ \\
\hline 66 & Shrub & 4.2 & 0.89 & -0.11 & 5.37 & -1.68 \\
\hline 66 & Deciduous & 15.1 & 1.92 & -0.31 & 14.12 & -1.83 \\
\hline 36 & Conifers & 13.9 & 1.49 & -0.34 & 20.51 & -2.12 \\
\hline 36 & Mixed & 14.5 & 1.63 & -0.84 & 18.83 & -2.51 \\
\hline
\end{tabular}


Table 48. X-HH InSAR and L-Band PolInSAR derived CHE error assessment against LiDAR CHE for Edson, stratified by vegetation type.

\begin{tabular}{|c|c|c|c|c|c|c|c|c|}
\hline \multirow{2}{*}{$\begin{array}{c}\text { \# in situ } \\
\text { or } \\
\text { LiDAR } \\
\text { CHE } \\
\text { Samples }\end{array}$} & \multirow{2}{*}{$\begin{array}{l}\text { Land } \\
\text { Cover } \\
\text { Type }\end{array}$} & \multirow{2}{*}{$\begin{array}{c}\text { Mean } \\
\text { Tree } \\
\text { Height } \\
\text { Range } \\
\text { (m) }\end{array}$} & \multicolumn{2}{|c|}{ X-HH InSAR } & \multicolumn{2}{|c|}{$\begin{array}{l}\text { L-Quad } \\
\text { PolInSAR }\end{array}$} & \multicolumn{2}{|c|}{$\begin{array}{c}\text { L-Quad } \\
\text { PolInSAR \& } \\
\text { LiDAR DTM }\end{array}$} \\
\hline & & & $\begin{array}{c}\text { RMSE } \\
\text { (m) }\end{array}$ & $\begin{array}{l}\text { Mean } \\
\text { Error } \\
(\mathrm{m}) \\
\end{array}$ & $\begin{array}{c}\text { RMSE } \\
\text { (m) }\end{array}$ & $\begin{array}{c}\text { Mean } \\
\text { Error } \\
(\mathrm{m})\end{array}$ & $\begin{array}{c}\text { RMSE } \\
\text { (m) }\end{array}$ & $\begin{array}{l}\text { Mean } \\
\text { Error } \\
\text { (m) }\end{array}$ \\
\hline 93 & Deciduous & 18.4 & 1.32 & -0.11 & 5.38 & -3.97 & 1.89 & -0.97 \\
\hline 263 & Conifers & 28.7 & 1.12 & -0.21 & 5.11 & -3.21 & 1.64 & -0.45 \\
\hline 200 & Mixed & 14.5 & 1.17 & -0.18 & 5.29 & -3.16 & 1.72 & -0.68 \\
\hline
\end{tabular}

Table 49. X-HH InSAR and L-Band PolInSAR derived CHE error assessment against LiDAR CHE for Burnstick Lake, stratified by vegetation type.

\begin{tabular}{|c|c|c|c|c|c|c|c|c|}
\hline \multirow{2}{*}{$\begin{array}{c}\text { \# in situ } \\
\text { or } \\
\text { LiDAR } \\
\text { CHE } \\
\text { Samples }\end{array}$} & \multirow{2}{*}{$\begin{array}{c}\text { Land Cover } \\
\text { Type }\end{array}$} & \multirow{2}{*}{$\begin{array}{c}\text { Mean } \\
\text { Tree } \\
\text { Height } \\
\text { Range } \\
\text { (m) }\end{array}$} & \multicolumn{2}{|c|}{ X-HH InSAR } & \multicolumn{2}{|c|}{$\begin{array}{l}\text { L-Quad } \\
\text { PolInSAR }\end{array}$} & \multicolumn{2}{|c|}{$\begin{array}{c}\text { L-Quad } \\
\text { PollnSAR \& } \\
\text { LiDAR DTM }\end{array}$} \\
\hline & & & $\begin{array}{l}\text { RMSE } \\
\text { (m) }\end{array}$ & $\begin{array}{l}\text { Mean } \\
\text { Error } \\
(\mathrm{m})\end{array}$ & $\begin{array}{c}\text { RMSE } \\
\text { (m) }\end{array}$ & $\begin{array}{c}\text { Mean } \\
\text { Error } \\
(\mathrm{m})\end{array}$ & $\begin{array}{l}\text { RMSE } \\
\text { (m) }\end{array}$ & $\begin{array}{l}\text { Mean } \\
\text { Error } \\
(\mathrm{m}) \\
\end{array}$ \\
\hline 150 & Deciduous & 16.3 & 1.41 & -0.23 & 5.89 & -3.54 & 2.01 & -0.87 \\
\hline 150 & Conifers & 25.3 & 1.25 & -0.03 & 4.98 & -2.89 & 1.62 & -0.40 \\
\hline 150 & Mixed & 13.8 & 1.37 & -0.12 & 5.21 & -2.96 & 1.82 & -0.73 \\
\hline
\end{tabular}

The X-HH CHE method performed the better than L-Quad PollnSAR CHEs at the Canadian sites, as expected. For the Edson (Table 48) and Burnstick Lake sites (Tables 49) the LiDAR DTM provided a better representation of bare ground than the L-Quad PolInSAR DTM, which resulted in better CHE vertical accuracies when these two data types were used together to estimate canopy height compared to the CHE derived entirely from L-Quad PolInSAR data. 
The deciduous class RMSE values for the Canadian sites were worse than coniferous and mixed vegetation as was the case at the U.S. sites. This could possibly be due to the impact of vegetation canopy density of the conifers and mixed vegetation, as previously discussed.

\subsubsection{Performance of $h_{\text {spe }}$ and the Refined Canopy Height Method over a Range of}

\section{Terrain Slopes}

The impact of terrain slope on $\mathrm{X}-\mathrm{HH}$ InSAR single-data take derived $h_{\mathrm{spc}}$ and the X-HH InSAR multi-data take derived CHE errors for the three slope classes $\left(\leq 10^{\circ}, 11^{\circ}\right.$ $29^{\circ}$, and $>30^{\circ}$ ) in the near, mid, and far range incidence angle classes, and stratified by vegetation type as well as for all vegetation classes combined was assessed using the same error measures listed previously are discussed in this section.

Slope maps derived from X-HH InSAR DTM data (U.S. sites) and L-Quad edited DTM data (Canadian sites) showed that slopes ranged from $0^{\circ}$ to $33^{\circ}$ in the four U.S. sites, whereas they were less than $10^{\circ}$ in the Edson and Burnstick Lake sites. This may account for the better canopy height retrieval at the Canadian sites compared to the U.S. sites. For that reason, the impact of terrain slope was only investigated for the $\mathrm{X}-\mathrm{HH}$ InSAR data in the U.S. sites. The slope maps for these sites are presented in Figures $60-$ 63. The effects of terrain slope on the distribution of $h_{\text {spc }}$ and the refined CHE errors are presented in Tables 50-53. 


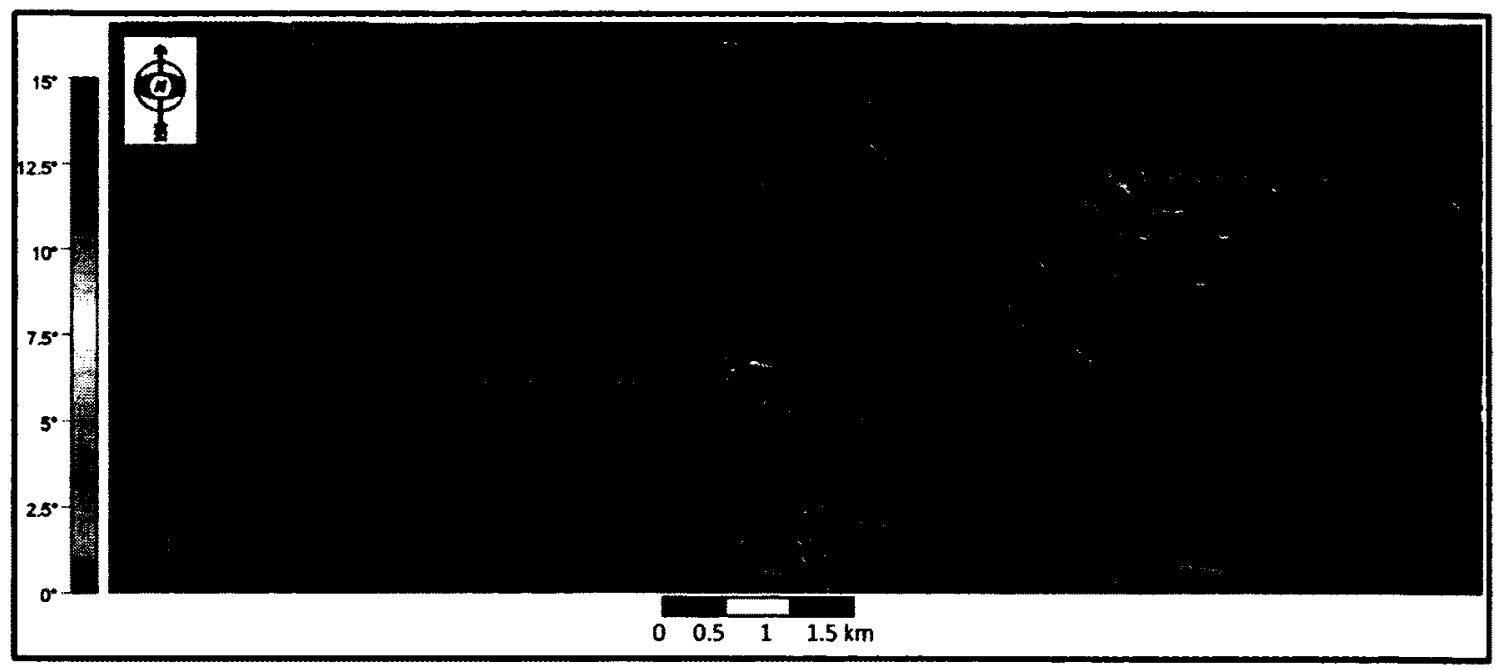

Figure 60. International Falls research site X-HH InSAR DTM derived slope map.

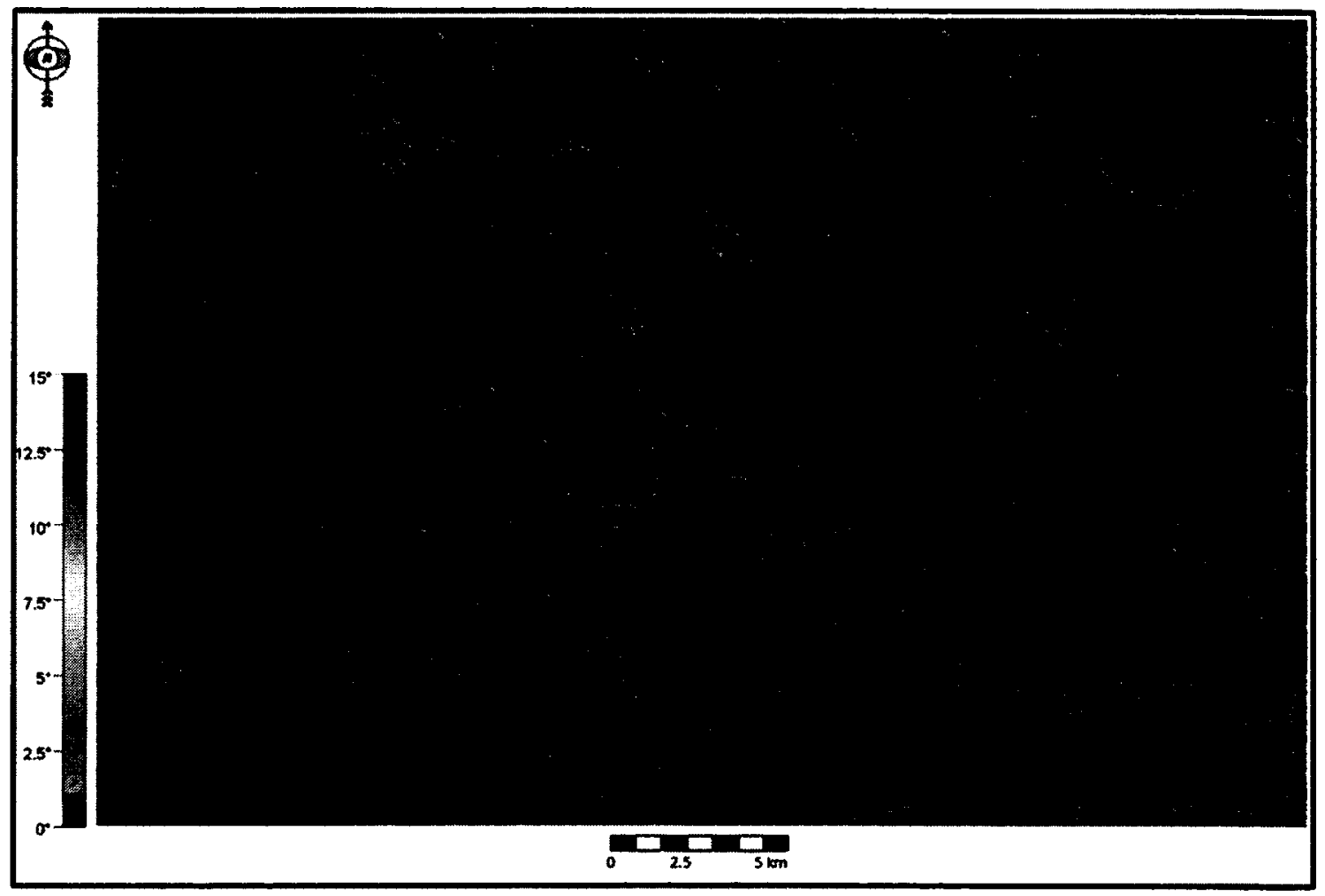

Figure 61. Ely research site X-HH InSAR DTM derived slope map. 


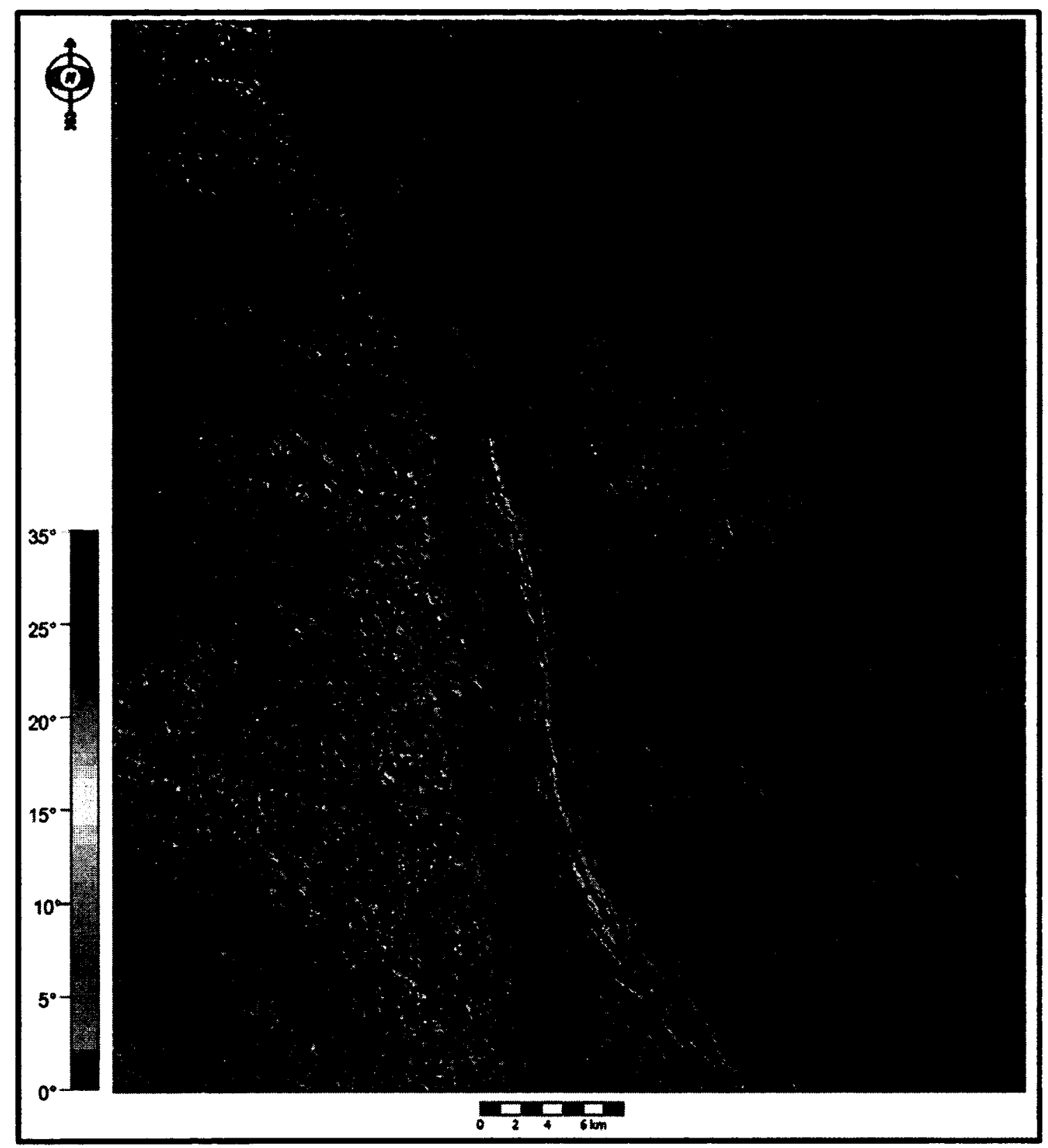

Figure 62. Colorado research site X-HH InSAR DTM derived slope map. 


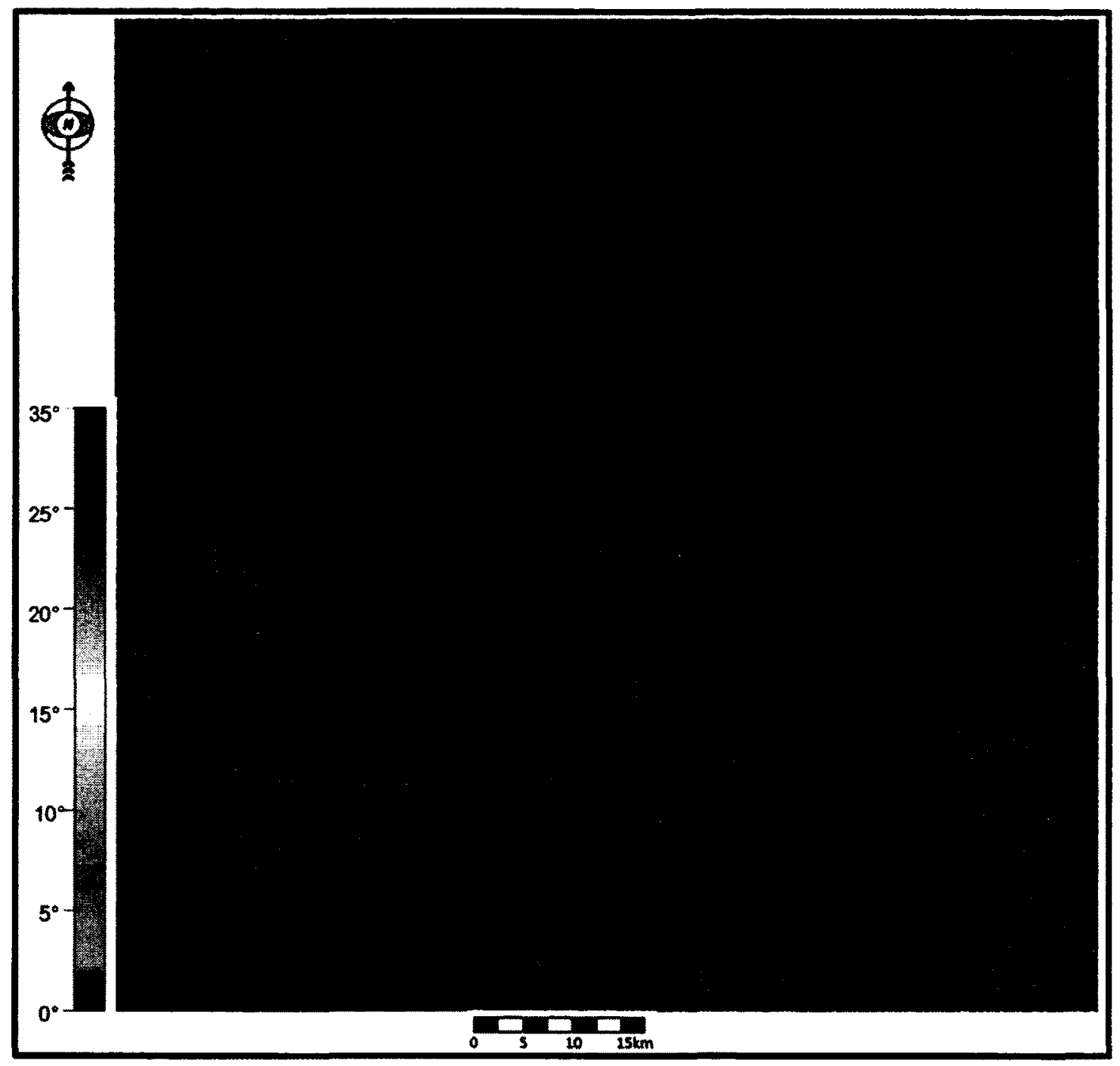

Figure 63. Arizona research site X-HH InSAR DTM derived slope map.

As expected, there is a consistent correlation between terrain slope and vertical error for both X-HH InSAR single- and multi-data takes (NEXTMap) data for all vegetation classes and all incidence angles, where with increasing terrain slope there is an increase in the error. These findings are supported in the literature (Izzawati et al., 2006; Woodhouse et al., 2006; Breidenbach et al., 2008). The single-data take errors were on 
average about 4.3 times greater than those for the CHE data, confirming that multi-data takes mitigate the effect of terrain slope significantly.

However, for both single-data take $h_{s p c}$ and $\mathrm{CHE}$, canopy height estimate error increased from the NR incidence angle to MR, but was then decreased to intermediate values in the far range. Thus, the mid range single-data take $h_{\text {spc }}$ errors were the highest of all incidence angles and all vegetation classes over sloped terrain. It was at first thought that the single take data may contain void data due to decorrelation in phase which would result in lower overall accuracies (Izzawati et al. (2006); Andersen et al. (2006); Woodhouse et al. (2006)). However, the amount of void data was minimal: NR $(0.03 \%)$, MR $(0.03 \%)$ and FR $(0.06 \%)$, so this was not considered a contributing factor. In addition, it may be possible that land cover differences are contributing to the increase in errors. For example, if a given land cover type is the dominant source of error and it is typically found on steeper slopes, then terrain slope may be mistakenly identified as the source of error (Hodgson et al., 2003). On the other hand, as shown in Tables 50-52, all vegetation types, except wetlands, occurred in all slope classes, so the analysis stratified by vegetation class in these tables shows real slope effects. In the case of the multi take InSAR CHE results, the NR and FR may have performed better than the MR data due to the merging of both NR and FR data (or multi-data takes) at flight line strip edges. These results were unexpected. In contrast, the proposed canopy height method errors (last two columns in Tables $50-53$ ), while degrading relatively about the same proportion as the single take data with increasing slope, retained absolute RMSE values less than $3.0 \mathrm{~m}$ at all incidence angles and $2.0 \mathrm{~m}$ or less for the NR data. Thus, in absolute terms they were not as affected by incidence angle. A possible reason for this is that the multi takes data 
used to create NEXTMap imagery, where NR and FR data are merged together, produced similar results.

Table 50. X-HH InSAR derived $\mathrm{h}_{\mathrm{spc}}$ and proposed CHE error stratified by vegetation cover and terrain slope for data located in the near range $\left(30^{\circ}-39^{\circ}\right.$ Incidence angle).

\begin{tabular}{|c|c|c|c|c|c|c|}
\hline \multirow[t]{2}{*}{ \# in situ } & \multirow{2}{*}{$\begin{array}{l}\text { Land } \\
\text { Cover } \\
\text { Type }\end{array}$} & \multirow{2}{*}{$\begin{array}{l}\text { Terrain } \\
\text { Slope }\end{array}$} & \multicolumn{2}{|c|}{$\begin{array}{l}\text { X-HH InSAR Canopy } \\
\text { Height Given by } h_{\text {spc }} \\
\text { (Single Take) }\end{array}$} & \multicolumn{2}{|c|}{$\begin{array}{c}\text { X-HH InSAR CHE } \\
\text { (Multi Take) }\end{array}$} \\
\hline & & & $\begin{array}{c}\text { RMSE } \\
(\mathrm{m})\end{array}$ & $\begin{array}{c}\text { Mean } \\
\text { Error }(\mathrm{m})\end{array}$ & $\begin{array}{c}\text { RMSE } \\
(\mathrm{m})\end{array}$ & $\begin{array}{c}\text { Mean } \\
\text { Error }(m)\end{array}$ \\
\hline 197 & Shrub & $\leq 10^{\circ}$ & 1.01 & -0.57 & 0.67 & -0.39 \\
\hline 132 & Deciduous & $\leq 10^{\circ}$ & 4.92 & -1.87 & 1.03 & -0.38 \\
\hline 202 & Conifers & $\leq 10^{\circ}$ & 5.23 & -1.86 & 0.97 & -0.11 \\
\hline 111 & Mixed & $\leq 10^{\circ}$ & $\overline{4.34}$ & -2.31 & 0.99 & -0.26 \\
\hline 38 & Wetlands & $\leq 10^{\circ}$ & 4.34 & -2.02 & 0.68 & -0.21 \\
\hline 31 & Shrub & $11^{\circ}-29^{\circ}$ & 1.42 & -0.44 & 0.75 & -0.48 \\
\hline 30 & Deciduous & $11^{\circ}-29^{\circ}$ & 6.01 & -1.89 & 1.25 & -0.31 \\
\hline 28 & Conifers & $11^{\circ}-29^{\circ}$ & 6.02 & -1.78 & 0.99 & -0.37 \\
\hline 33 & Mixed & $11-29^{\circ}$ & 5.88 & -1.65 & 1.01 & -0.38 \\
\hline 29 & Wetlands & $11^{\circ}-29^{\circ}$ & 4.83 & -1.69 & 1.08 & -0.49 \\
\hline 5 & Shrub & $>29^{\circ}$ & 2.1 & -0.98 & 1.02 & -1.01 \\
\hline 6 & Deciduous & $>29^{\circ}$ & 6.35 & -2.63 & 1.65 & -0.95 \\
\hline 11 & Conifers & $>29^{\circ}$ & 8.89 & -2.46 & 2.01 & -1.34 \\
\hline 11 & Mixed & $>29^{\circ}$ & 7.68 & -2.87 & 1.58 & -0.79 \\
\hline
\end{tabular}


Table 51. X-HH InSAR derived $h_{\mathrm{spc}}$ and proposed CHE error stratified by vegetation cover and terrain slope for data located in the mid range $\left(40^{\circ}-49^{\circ}\right.$ Incidence angle).

\begin{tabular}{|c|c|c|c|c|c|c|}
\hline \multirow[t]{2}{*}{ \# in situ } & \multirow{2}{*}{$\begin{array}{l}\text { Land } \\
\text { Cover } \\
\text { Type }\end{array}$} & \multirow{2}{*}{$\begin{array}{l}\text { Terrain } \\
\text { Slope }\end{array}$} & \multicolumn{2}{|c|}{$\begin{array}{l}\text { X-HH InSAR Canopy } \\
\text { Height Given by } h_{\text {spc }} \\
\text { (Single Take) }\end{array}$} & \multicolumn{2}{|c|}{$\begin{array}{c}\text { X-HH InSAR CHE } \\
\text { (Multi Take) }\end{array}$} \\
\hline & & & $\begin{array}{c}\text { RMSE } \\
\text { (m) }\end{array}$ & $\begin{array}{l}\text { Mean Error } \\
\text { (m) }\end{array}$ & $\begin{array}{c}\text { RMSE } \\
\text { (m) }\end{array}$ & $\begin{array}{l}\text { Mean Error } \\
\text { (m) }\end{array}$ \\
\hline$\overline{197}$ & Shrub & $\leq 10^{\circ}$ & 1.92 & -0.64 & 1.02 & -0.45 \\
\hline 132 & Deciduous & $\leq 10^{\circ}$ & 5.82 & -2.30 & 1.32 & -0.42 \\
\hline 202 & Conifers & $\leq 10^{\circ}$ & 6.18 & -2.04 & 1.24 & -0.23 \\
\hline 111 & Mixed & $\leq 10^{\circ}$ & 5.78 & -2.84 & 1.19 & -0.32 \\
\hline 38 & Wetlands & $\leq 10^{\circ}$ & 5.43 & -2.59 & 1.01 & -0.21 \\
\hline 31 & Shrub & $11^{\circ}-29^{\circ}$ & 2.11 & -0.69 & 1.12 & -0.63 \\
\hline 30 & Deciduous & $11^{\circ}-29^{\circ}$ & 6.73 & -2.21 & 1.74 & -0.38 \\
\hline 28 & Conifers & $11^{\circ}-29^{\circ}$ & 6.67 & -2.03 & 1.31 & -0.23 \\
\hline 33 & Mixed & $11^{\circ}-29^{\circ}$ & 6.78 & -2.15 & 1.36 & -0.23 \\
\hline 29 & Wetlands & $11^{\circ}-29^{\circ}$ & 5.29 & -2.05 & 1.10 & -0.29 \\
\hline$\overline{5}$ & Shrub & $>29^{\circ}$ & 3.21 & -1.18 & 1.42 & -1.89 \\
\hline$\overline{6}$ & Deciduous & $>29^{\circ}$ & 8.69 & -3.00 & 2.89 & -1.54 \\
\hline 11 & Conifers & $>29^{\circ}$ & 10.53 & -3.54 & 2.47 & -2.19 \\
\hline$\overline{11}$ & Mixed & $>29^{\circ}$ & 9.29 & -3.10 & 2.99 & $\overline{-1.56}$ \\
\hline
\end{tabular}


Table 52. X-HH InSAR derived $h_{\text {spc }}$ and proposed CHE error stratified by vegetation cover and terrain slope for data located in the far range $\left(50^{\circ}-59^{\circ}\right.$ Incidence angle).

\begin{tabular}{|c|c|c|c|c|c|c|}
\hline \multirow[t]{2}{*}{ \# in situ } & \multirow{2}{*}{$\begin{array}{l}\text { Land } \\
\text { Cover } \\
\text { Type }\end{array}$} & \multirow[t]{2}{*}{$\begin{array}{c}\text { Terrain } \\
\text { Slope }\end{array}$} & \multicolumn{2}{|c|}{$\begin{array}{l}\text { X-HH InSAR Canopy } \\
\text { Height Given by } h_{\text {spc }} \\
\text { (Single Take) }\end{array}$} & \multicolumn{2}{|c|}{$\begin{array}{c}\text { X-HH InSAR CHE } \\
\text { (Multi Take) }\end{array}$} \\
\hline & & & $\begin{array}{l}\text { RMSE } \\
\text { (m) }\end{array}$ & $\begin{array}{l}\text { Mean Error } \\
\text { (m) }\end{array}$ & $\begin{array}{l}\text { RMSE } \\
\text { (m) }\end{array}$ & $\begin{array}{l}\text { Mean Error } \\
(\mathrm{m})\end{array}$ \\
\hline 197 & Shrub & $\leq 10^{\circ}$ & 1.59 & -0.66 & $\overline{0.81}$ & -0.51 \\
\hline 132 & Deciduous & $\leq 10^{\circ}$ & 5.42 & -2.31 & 1.21 & -0.32 \\
\hline 202 & Conifers & $\leq 10^{\circ}$ & 5.84 & -2.06 & 1.03 & -0.18 \\
\hline 111 & Mixed & $\leq 10^{\circ}$ & 5.38 & -2.76 & 1.06 & -0.26 \\
\hline 38 & Wetlands & $\leq 10^{\circ}$ & 4.55 & -2.61 & 0.78 & -0.13 \\
\hline 31 & Shrub & $11^{\circ}-29^{\circ}$ & 1.82 & -0.67 & 0.87 & -0.52 \\
\hline 30 & Deciduous & $11^{\circ}-29^{\circ}$ & 6.31 & -2.22 & 1.48 & -0.38 \\
\hline 28 & Conifers & $11^{\circ}-29^{\circ}$ & 6.46 & -2.05 & 1.13 & -0.19 \\
\hline 33 & Mixed & $11^{\circ}-29^{\circ}$ & 6.22 & -2.16 & 1.21 & -0.21 \\
\hline 29 & Wetlands & $11^{\circ}-29^{\circ}$ & 5.10 & -2.09 & 0.87 & -0.10 \\
\hline 5 & Shrub & $>29^{\circ}$ & 2.31 & -1.12 & 1.17 & -1.01 \\
\hline 6 & Deciduous & $>29^{\circ}$ & 8.16 & -3.01 & 1.83 & -0.95 \\
\hline 11 & Conifers & $>29^{\circ}$ & 9.16 & -3.56 & 2.33 & -1.59 \\
\hline 11 & Mixed & $>29^{\circ}$ & 8.93 & -3.11 & 1.59 & -0.99 \\
\hline
\end{tabular}


Table 53. X-HH InSAR derived $h_{\text {spc }}$ and proposed CHE error stratified by terrain slope and incidence angle for all vegetation classes combined.

\begin{tabular}{|c|c|c|c|c|c|c|}
\hline \multirow{2}{*}{$\begin{array}{l}\text { Incidence } \\
\text { Angle } \\
\text { Range }\end{array}$} & \multirow{2}{*}{$\begin{array}{l}\text { Land } \\
\text { Cover } \\
\text { Type }\end{array}$} & \multirow[t]{2}{*}{$\begin{array}{l}\text { Terrain } \\
\text { Slope }\end{array}$} & \multicolumn{2}{|c|}{$\begin{array}{l}\text { X-HH InSAR Canopy } \\
\text { Height Given by } \mathrm{h}_{\text {spc }} \\
\text { (Single Take) }\end{array}$} & \multicolumn{2}{|c|}{$\begin{array}{c}\text { X-HH InSAR CHE } \\
\text { (Multi Take) }\end{array}$} \\
\hline & & & RMSE (m) & $\begin{array}{c}\text { Mean } \\
\text { Error }(\mathrm{m})\end{array}$ & $\operatorname{RMSE}(\mathrm{m})$ & $\begin{array}{c}\text { Mean } \\
\text { Error }(\mathrm{m})\end{array}$ \\
\hline \multirow{3}{*}{ NR } & All & $\leq 10^{\circ}$ & 4.96 & -2.16 & 1.09 & -0.34 \\
\hline & All & $\leq 10^{\circ}$ & 6.28 & -2.60 & 1.45 & -0.41 \\
\hline & All & $\leq 10$ & 5.70 & -2.60 & 1.22 & -0.35 \\
\hline \multirow{3}{*}{ MR } & All & $11^{\circ}-29^{\circ}$ & 4.83 & -1.49 & 1.02 & -0.41 \\
\hline & All & $11^{\circ}-29^{\circ}$ & 5.52 & -1.83 & 1.33 & -0.35 \\
\hline & All & $11^{\circ}-29^{\circ}$ & 5.18 & -1.84 & 1.11 & -0.28 \\
\hline \multirow{3}{*}{ FR } & All & $>29^{\circ}$ & 6.26 & -2.24 & 1.57 & -1.02 \\
\hline & All & $>29^{\circ}$ & 7.93 & -2.71 & 2.44 & -1.80 \\
\hline & All & $>29^{\circ}$ & 7.14 & -2.70 & 1.73 & -1.14 \\
\hline
\end{tabular}

\subsection{Summary}

This chapter provides a summary of the results of the analysis conducted on the proposed empirical methodology to extract vegetation type and canopy height for use with airborne X-band InSAR and L-band PolInSAR over diverse environments and large geographic extents common in North America. The results of analysis of the three key inputs to the proposed canopy height estimation method were summarized.

First, a reliable and accurate DTM is required, therefore, this chapter first evaluated the vertical accuracy of X-band InSAR DTM data over 8 million square kilometers against 41,322 NGS survey-grade reference points across open barren and the five vegetation classes of interest in this research. The overall vertical accuracy results 
presented (Section 5.2.2.2.) indicate an overall vertical accuracy of $1.08 \mathrm{~m}$ over varied land cover classes, slopes up to 23 degrees, and varied eco-systems. This represents the first InSAR DTM analysis of such a large and varied geographic extent.

Second, the results of the vertical accuracy assessment of X-HH InSAR, L-Quad PollnSAR, and C-HH InSAR scattering phase centre height (providing a first estimate of canopy height) were presented, including stratification by vegetation type, research site, and incidence angle. Results indicate that there is significant signal penetration into vegetation canopies, over all vegetation classes evaluated, that must be corrected for in order to retrieve reliable canopy height.

Third, the results of the land cover classification accuracy assessment were presented. They achieved an accuracy of $89.6 \%$ ( $87.9 \%$ Kappa), providing a reliable methodology to extract open/barren, shrub, deciduous, conifers, mixed forest and wetlands land cover classes.

A summary of the results of the proposed empirical methodology to extract canopy height yielded root mean square height errors of $0.93-1.53 \mathrm{~m}$ and $1.98 \mathrm{~m}-2.21$ $\mathrm{m}$ for $\mathrm{X}$ and $\mathrm{L}$ band data respectively, over all vegetation types compared to reference data, which is a substantial improvement over $1.91 \mathrm{~m}-6.96 \mathrm{~m}$ and $4.87 \mathrm{~m}-8.01 \mathrm{~m}$, RMSE for raw X-and L-band derived $h_{\text {spc }}$, respectively. Relative height estimate errors decreased with increasing canopy height and density and consequently errors were generally highest in shrub/wetlands vegetation and lowest in dense coniferous forest. Height estimate error also increased with increasing terrain slope, but effects of incidence angle were mixed. The results of the effects of terrain slope and incidence angle on the derived canopy height estimation methods proposed showed that canopy height given by 
the scattering phase centre height was not significantly affected by SAR viewing geometry when using multi-data takes InSAR data because the increase in InSAR looks or passes mitigated the effect of incidence angle to some degree. Spaceborne sensors have a much less variable incidence angle range over airborne sensors and thus, these findings are promising because they may indicate that the geometry of side looking SAR spaceborne systems may not play a key role in the overall accuracy of scattering phase centre height across a SAR scene. These results of the proposed methodology to derive vegetation type and canopy height estimates using X-HH InSAR and L-Quad PolInSAR data are further discussed in Chapter 6. 


\section{CHAPTER SIX: DISCUSSION}

This research has highlighted a number of important findings on the evaluation of airbome and spaceborne interferometric synthetic aperture radar (InSAR) and airborne polarimetric InSAR (PolInSAR) for vegetation cover and canopy height estimation. These findings are discussed in detail in the following sections 6.1 through 6.3. The benefits (Section 6.4) and the limitations (6.5) of the proposed method for vegetation type and canopy height estimation presented in this research are discussed as well as compared to other SAR canopy height methods presented in the literature. This chapter closes with a summary of the use of airborne InSAR and PolInSAR data for vegetation cover mapping and canopy height estimation (Section 6.6).

\subsection{Vertical Accuracy of the DTMs and DSMs Evaluated in this Research}

\subsubsection{X-HH InSAR DTM - Airborne}

Prior to this study, DTM data from InSAR techniques of any wavelength (e.g. X-, C-, S-, L-, and P-band) had yet to be assessed over large geographic extents, nor for a diverse set of vegetation types (shrub, deciduous, coniferous, mixed, and wetlands) as in the six research sites and the conterminous U.S. data sets of this research.

The vertical accuracy assessment results for the X-HH InSAR DTM data concur with several studies reported in the literature for specific cover types or regions (Table 54, first five rows). They do not, however, agree with Hodgson et al. (2003) and Wallington et al. (2004), due primarily to differences in processing the Intermap derived X-HH InSAR DSM to derive the DTM data. From 1999 to 2002, Intermap utilized a manual editing finishing process to derive a DTM from the InSAR ORI and DSM data. This process worked well for barren terrain, but had limitations in vegetated regions 
where some of the vegetation cover elevations were not removed from the DSM data to create the DTM, leading to errors in the InSAR DTM in vegetated land cover.

Table 54. Key X-InSAR DTM vertical accuracy studies over varied land cover.

\begin{tabular}{|c|c|c|c|c|c|}
\hline Author & $\begin{array}{c}\text { Site, Area } \\
\left(\mathrm{km}^{2}\right)\end{array}$ & Reference Source & Slope & $\begin{array}{l}\text { Cover } \\
\text { Type }\end{array}$ & $\begin{array}{l}\text { DTM Vertical } \\
\text { Accuracy } \\
\text { RMSE (m) } \\
\end{array}$ \\
\hline \multirow{3}{*}{$\begin{array}{l}\text { Wang et al. } \\
(2001)\end{array}$} & \multirow{3}{*}{ U.S. } & \multirow{3}{*}{ LiDAR } & $<10^{\circ}$ & barren & 0.68 \\
\hline & & & $>10^{\circ}$ & barren & 1.33 \\
\hline & & & $>10^{\circ}$ & forest & 3.16 \\
\hline $\begin{array}{l}\text { Downman \& } \\
\text { Fischer (2003) }\end{array}$ & $\begin{array}{l}\text { UK, } \\
200,000\end{array}$ & $\begin{array}{l}\text { photogrammetric and } \\
\text { LiDAR checkpoints }\end{array}$ & $<10^{\circ}$ & barren & 0.83 \\
\hline $\begin{array}{l}\text { Dowman et al. } \\
(2003)\end{array}$ & $\begin{array}{l}\text { UK, } \\
200,000\end{array}$ & $\begin{array}{l}\text { photogrammetric } \\
\text { checkpoints }\end{array}$ & $<10^{\circ}$ & barren & 0.17 \\
\hline Mercer (2004) & UK, 4 & $\begin{array}{l}\text { LiDAR, GPS, \& } \\
\text { photogrammetric } \\
\text { checkpoints }\end{array}$ & $<10^{\circ}$ & barren & $0.5-1.1$ \\
\hline Mercer(2007) & $\begin{array}{l}\text { Europe, } \\
220,000\end{array}$ & Survey check points & $<10^{\circ}$ & barren & 1.00 \\
\hline \multirow{4}{*}{$\begin{array}{l}\text { Hodgson et } \\
\text { al.(2003) }\end{array}$} & \multirow{4}{*}{$\begin{array}{l}\text { U.S., } \\
12\end{array}$} & \multirow{4}{*}{ LiDAR, NGS } & $<14^{\circ}$ & shrub & 4.36 \\
\hline & & & $<14^{\circ}$ & deciduous & 7.95 \\
\hline & & & $<14^{\circ}$ & pine & 5.28 \\
\hline & & & $<14^{\circ}$ & mixed & 10.05 \\
\hline \multirow{3}{*}{$\begin{array}{l}\text { Wallington et al. } \\
\text { (2004) }\end{array}$} & \multirow{3}{*}{$\begin{array}{l}\text { UK, } \\
5\end{array}$} & \multirow{3}{*}{$\begin{array}{l}\text { OSDEM (Ordnance } \\
\text { Survey DEM) }\end{array}$} & $<20^{\circ}$ & barren & 1.01 \\
\hline & & & $<20^{\circ}$ & \begin{tabular}{|l} 
grass \\
\end{tabular} & 1.58 \\
\hline & & & $<10^{\circ}$ & forest & $11.84-14.26$ \\
\hline
\end{tabular}

Hodgson et al. (2003) and Wallington et al. (2004) used data created during this timeframe, which would explain why the data performed well in barren land cover and poor under vegetated land cover. In 2003 , Intermap moved to a semi-automated 3D workflow, which has better 3D tools to "remove" vegetation from the DSM data when 
creating the DTM. Intermap continuously improves the X-HH InSAR derived DTM editing and finishing processes, and the current conterminous United States (e.g. data used in this research) and Europe X-HH InSAR data have been processed using this more robust editing workflow, resulting in improved accuracy as presented in this research and in Mercer (2004). This research found that the vertical accuracy of the X-HH InSAR DTM was lower in regions with slopes less than $10^{\circ}$ compared to regions of terrain slopes greater than $10^{\circ}$. This finding is to be expected and supported in the literature for all types of elevation models (Mercer et al., 2004; Izzawati et al., 2006; Andersen et al., 2006).

Hodgson et al. (2003) found the magnitude of X-HH InSAR DTM error in deciduous vegetation increased with increasing terrain slope. Wang et al. (2001) found that in barren areas RMSE increased from $0.68 \mathrm{~cm}$ in low sloped terrain to $1.33 \mathrm{~m}$ in moderate slopes. Mercer (2004) reported bare ground RMSE on the order of 1.3-1.5 m over flat terrain, while it was $1.7 \mathrm{~m}$ on slopes up to $35^{\circ}$, and $1.6-2.2 \mathrm{~m}$ on mixed terrain (flat and moderately sloped terrain up to $35^{\circ}$ ). The full range of RMSE was $0.8-2.2 \mathrm{~m}$. Dowman and Fischer (2003) and Dowman et al. (2003) assessed $5 \mathrm{~m}$ resolution X-HH InSAR DTM data in the UK against photogrammetric checkpoints and noted that over mixed terrain (hilly, flat) along a road vertical RMSE of the X-HH DTM data degraded from $0.82 \mathrm{~m}$ (flat) to $1.67 \mathrm{~m}$ (hilly). Less than $5 \%$ of the terrain at the six research sites and conterminous U.S. had terrain slopes greater than $30^{\circ}$; thus, the degradation in vertical accuracy of the DTM data as a result of increasing terrain slope was not considered to be significant for mapping of such large areas, and a correction for terrain slope was not required. However, in more rugged terrain, correction for terrain slope may need to be considered and thus, this topic should be further investigated. 
The results presented in this research show that X-HH InSAR derived DTM data can provide accurate bare ground measurements (e.g. DTM data) in barren and vegetated land cover types over very large extents or possibly at global scales. These findings are also encouraging for current and future X-band satellites such as Tandem-X, COSMOSkyMed, and recently released SRTM X-band DSM data that could be used to derive DTM data with a GSD of $12 \mathrm{~m}, 20 \mathrm{~m}$, and $30 \mathrm{~m}$, respectively, on a global basis, provided similar DSM to DTM editing procedures (Section 3.3) are executed. This further implies potential for worldwide DTM and DSM generation from spaceborne platforms for use in canopy height extraction to assess biomass, carbon credits, and climate change on a global basis.

\subsubsection{L-Quad PolInSAR DTM - Airborne}

The other focal data set in this research was the airborne L-Quad-band PolInSAR. Polarimetric SAR is well suited to vegetation mapping because it is sufficiently sensitive to vegetation structure, including both canopy and sub-canopy elements, as well as ground topography (Cloude and Corr, 2003; Zhang et al., 2008; Mercer et al., 2009a; 2009b). PolInSAR at L-band therefore, has the potential to produce a true ground DTM with minimal vegetation bias (Cloude and Papathanassiou, 1997; 1998; Papathanassiou et al., 2005; Woodhouse et al., 2003). However, the empirical findings of this research showed that the PolInSAR RVoG DEM difference derived DTMs were quite noisy when compared to a LiDAR DTM, exhibiting both over and underestimation of terrain elevation on the order of $5 \mathrm{~m}$ RMSE. The L-PolInSAR DTM is even noisier over vegetated terrain however the trends are similar to the X-HH InSAR, LiDAR, and SRTM C-HH InSAR elevation data. The noisy L-band results are possibly due to three reasons. 
First, the longer wavelength L-band SAR signal penetrates deeper into the canopy (double bounce and volume scattering) than the X-band (dominated by volume scattering). Second, the hspc is affected by both 3D forest structural parameters (i.e. canopy density, under-storey, and gaps) and SAR system parameters (i. e. incidence angle, number of data takes). Consequently, the derived hspc produced noisy results. Third, the PolInSAR method and the density of the vegetation at the two Alberta sites result in little to no ground return and therefore, the InSAR phase component is biased and noisy (Zhang et al., 2008).

These results are supported by others (Mercer et al., 2007; Zhang et al., 2008) indicating that further investigation is required to determine how to optimize the RVoG methods to achieve bare ground measurements with higher accuracies. Improvements to the L-Quad PolInSAR DTM derived data were achieved through 3D editing, similar to that performed during the X-band DSM to DTM processing (Section 3.2/1/), reducing the RMSE error to similar levels as for the X-band DTM. These findings are new to the literature because no attempt has been made to edit L-band PolInSAR DTM data and publish the results. Ideally, however, improvements to the RVoG method should, if possible, minimize the requirement for "manual" $3 \mathrm{D}$ editing, to ensure a robust method to derive DTM data at global scales. The analysis presented here utilized single-pass PolInSAR data where temporal decorrelation (as discussed in section 2.2) was not a concern. More representative studies of repeat-pass L-band PolInSAR, where temporal decorrelation may be problematic, are required before we can determine the suitability of L-band PollnSAR data as a reliable source of DTM data and for use in canopy height extraction. 


\subsubsection{C-HH InSAR DSM - Spaceborne}

At a broader scale, this research compared the two airborne data sources with spaceborne C-HH InSAR SRTM data, which are available only as a DSM, however,

freely available for nearly $80 \%$ of the Earth's landmass. The overall vertical accuracy of the SRTM $30 \mathrm{~m}$ GSD DSM data for conterminous U.S. was four times worse than that for the X-HH InSAR DTM 5 m GSD data. This is not surprising given that the coarser the InSAR spatial resolution the more difficult it is to produce accurate bare ground digital elevation models, especially through continuous forest canopy cover where gaps in the forest are rarely detected. SRTM DSM $30 \mathrm{~m}$ GSD data are publicly available for the U.S. only, whereas, SRTM DSM 90 m GSD data are available for the rest of the globe. Findings presented in this research for the $90 \mathrm{~m}$ SRTM DSM data indicate a vertical accuracy six times worse than that of the X-HH InSAR DTM data for the same research sites.

The vertical accuracy of the C-HH InSAR DSM presented in this research concurs with that presented in Carabajal and Harding (2005), Kellndorfer et al. (2004), and Walker et al. (2007). Kellndorfer et al. (2004) found that errors related to soil moisture and roughness were nearly impossible to quantify given the complex nature of SRTM data acquisition and processing (e.g., averaging of multiple data takes), even still, these errors themselves are relatively minor and thus, generally not corrected for. However, they found greater error related to phase noise and vertical offsets (also noted by Viergever et al., 2008 and Becek, 2008). These errors are reasonably well understood and can be minimized, if not removed, using the techniques (e.g. sample averaging) 
described in Kellndorfer et al. (2004). No attempt was made in this research to correct for these errors because the SRTM data were not the main focus of this research.

The SRTM DSM data are deemed to not be suitable for DTM generation and use in CHEs at detailed scales equivalent to the X-HH InSAR or L-Quad PolInSAR DTM data, however, they were assessed in this research to understand how they would perform given they represent an elevation dataset that is available worldwide. In fact, Kellndorfer et al. (2004), Simard et al. (2006), Kenyi et al. (2009) and others have had success in combining the SRTM DSM data with the NED DTM to create an estimation of canopy height (e.g. given by DSM-DTM). Given the free and near global availability of these CHH InSAR data, however, editing to produce a suitable DTM (for example using methods discussed in section 3.3) is possible, and such a DTM could be combined with other free near global DSM data sets such as the unedited SRTM DSM data and the $30 \mathrm{~m}$ GSD ASTER DSM (ASTER DSM is negatively biased and would need to be corrected) and CORINE global land cover (Cruickshank et al., 2000), to derive large extent canopy height estimates (DSM - DTM) using methods similar to those presented in this research.

\subsubsection{U.S. National Elevation Data (NED)}

In some cases, nations make available nation-wide DTM data, which could be used in conjunction with a DSM to derive canopy height (Kellndorfer et al., 2004; Walker et al, 2007; Balzter et al., 2007a; 2007b). The NED data, for example, is constantly being updated (approximately 15\% each year; Maune, 2009) with highresolution LiDAR or photogrammetric data and should improve in accuracy over time. The results of the vertical accuracy assessment of NED against NGS reference data showing better vertical accuracy than that published (U.S. Geological Survey, 1997; 
Gesch et al., 2002) may be indicative of these improvements. These findings also concur with Smith and Roman (2001) who compared NED elevations to NGS control and achieved a RMSE of $2.72 \mathrm{~m}$. Thus, the findings presented in this research indicate that the NED offers a suitable (and freely available) DTM for use in canopy height generation for sites with similar characteristics to those of this research. If they were used in place of the X-HH InSAR DTM, the canopy height estimate vertical accuracy is expected to degrade somewhat, although it may still be sufficient for analysis over large geographic extents.

\subsection{Canopy Height Estimated by InSAR/PolInSAR Scattering Phase Centre Height}

This research has shown that scattering phase centre height given by InSARs (XC-L-Bands) is strongly correlated with field tree height measurements, although it consistently underestimates them. The degree of SAR signal attenuation in forest, wetlands, and shrub vegetation was found to vary with wavelength, incidence angle, terrain slope, vegetation canopy density, and vegetation type (Izzawati et al., 2006; Andersen et al., 2006, Woodhouse et al., 2006). Other factors not investigated in this research, include moisture and climate conditions (Sarabandi and Lin 2000, Kellndorfer et al. 2004).

Comparison of attenuation between $\mathrm{X}, \mathrm{C}$, and $\mathrm{L}$ wavelengths, therefore, has to be done carefully to control for these factors by analyzing the same patch of forest and preferably using single strip data (e.g. no-data merging). If, for example, comparing Cband data in the near range (small incidence angle) to X-band in the far range (large incidence angle), the C-Band may penetrate deeper into the forest canopy and vice-versa. However, the multi-pass processing of both the NEXTMap X-HH and SRTM C-band 
InSAR data does mitigate incidence angle effects somewhat (Kellndorfer et al., 2004; Andersen et al., 2008); this was confirmed in this research by comparing $h_{\text {spc }}$ derived from single-data take X-HH InSAR and multi-data takes NEXTMap X-HH data.

Sections 6.2.1, through to 6.2.3. provide additional discussions on $h_{s p c}$ as an estimate of canopy height for the two airborne datasets (X-HH InSAR, L-Quad PolInSAR), and the spaceborne dataset (C-HH InSAR data), respectively.

\subsubsection{X-HH InSAR $h_{\text {spe }}$ as an Estimate of Canopy Height}

InSAR $h_{\text {spc }}$ as an estimate of canopy height has been reported in the literature with some success in a variety of individual eco-types and land cover categories. Table 55 lists several studies dominant cover type evaluated and the associated height estimate error in RMSE, where available. In all cases, $\mathrm{h}_{\mathrm{spc}}$ underestimated canopy height using $\mathrm{X}$-band InSAR. Furthermore, each study in Table 55 was focused primarily on a single vegetation class (mostly), whereas this research evaluated $h_{\mathrm{spc}}$ for five vegetation classes (shrub, deciduous, conifers, mixed forests, and wetlands), providing greater insight into $\mathrm{X}-/ \mathrm{C}-\mathrm{HH}$ InSARs and L-Quad PolInSAR signal attenuation over various vegetation types. As far as the author is aware, no studies on InSAR height estimation for classes such as shrub and wetlands exist, thus, the findings of this research are new. Moreover, the ecological and vegetation structure diversity of the six research sites provided a unique opportunity to examine, in particular, the X-HH InSAR data under a variety of conditions; this has not yet been conducted in one study.

Despite the expectation that retrieved tree height from X-band InSAR should be near the top of the canopy, within all vegetation classes of this research, and at edges and discontinuities, this assumption was not valid. This result concurs with several previous 
studies (Izzawati et al., 2006; Balzter et al., 2007a; Sexton et al, 2009). Shrub vegetation, with average height of about $4 \mathrm{~m}$ over the sites of this research, had a vertical RMSE of approximately $2 \mathrm{~m}$, thus retrieving approximately $50 \%$ of actual canopy height on average. Wetlands vegetation had a similar relative error. It was unexpected to see approximately $50 \%$ penetration into shrub and wetlands canopies, especially for a short wavelength such as X-band. However, vegetation density was low in these two classes (e.g., less than 150 shrubs per field plot within an area of $2918 \mathrm{~m}^{2}$ ) probably resulting in significant ground surface scattering, which contributed to the low average $h_{\text {spc. }}$. These findings are supported in the literature (Izzawati et al., 2006; Kenyi et al., 2009).

Table 55. Key X-InSAR derived $\mathrm{h}_{\text {spc }}$ canopy height studies.

\begin{tabular}{|l|l|l|l|l|}
\hline \multicolumn{1}{|c|}{ Author } & Veg Type & \multicolumn{1}{|c|}{ InSAR Data } & \multicolumn{1}{c|}{ Reference } & \multicolumn{1}{c|}{$\begin{array}{c}\text { hoc } \\
\text { (m) }\end{array}$} \\
\hline Wallington et al. (2004) & Pine & X-HH NEXTMap & in situ & $5.8 \mathrm{~m}-7.4 \mathrm{~m}$ \\
\hline Izzawati et al. (2006) & Conifer & X-HH NEXTMap & in situ & Not recorded \\
\hline Dutra et al. (2006) & Tropical & X-HH GeoSAR & in situ & Not recorded \\
\hline Hyde et al. (2006) & Conifers & X-HH NEXTMap & in-situ & $8.7 \mathrm{~m}-11.9 \mathrm{~m}$ \\
\hline Balzter et al. (2007a) & Deciduous & X-VV ESAR & LiDAR CHM & $2.9 \mathrm{~m}-4.1 \mathrm{~m}$ \\
\hline Balzter et al. (2007b) & Pine & X-VV ESAR & LiDAR DSM & $3.5 \mathrm{~m}$ \\
\hline Andersen at al. (2008) & Conifers & X-HH NEXTMap & LiDAR CHM & $3.0 \mathrm{~m}$ \\
\hline Sexton et al. (2009) & Conifers & X-HH GeoSAR & in situ & $4.6 \mathrm{~m}$ \\
\hline Kellndorfer et al. (2004) & Pine & C-HH SRTM & in situ & $1.0 \mathrm{~m}-1.8 \mathrm{~m}$ \\
\hline Walker et al (2004) & Pine & C-HH SRTM & in situ & $4.62 \mathrm{~m}-4.90 \mathrm{~m}$ \\
\hline Sexton et al (2009) & Pine/Decid. & C-HH SRTM & in situ & $4.67 \mathrm{~m} / 3.87 \mathrm{~m}$ \\
\hline Zhang et al. (2008) & Mixed & L-PolInSAR & in situ & $8.5 \mathrm{~m}$ \\
\hline
\end{tabular}


If the reference data comprised only canopy height measurements but the radar signal hits both vegetation and ground in the same area, the averaged $h_{\text {spc }}$ for that area will be lower in relation to canopy height than in an area where vegetation is dense and the radar signal does not include ground returns. This is a limitation of InSAR derived $\mathrm{h}_{\mathrm{spc}}$ as an estimate of canopy height over lower density vegetation; it does not perform as well where vegetation is sparse and the InSAR resolution is high.

Deciduous, coniferous, and mixed forest classes with tree heights ranging from $13.1 \mathrm{~m}$ to $15.1 \mathrm{~m}$ (based on in situ and LiDAR reference data canopy heights) for the arid, semi-arid, temperate, and temperate-boreal transition environments had similar relative accuracy (approximately $45 \%$ of measured tree height); whereas taller tree canopies ( $24 \mathrm{~m}$ to $29 \mathrm{~m}$ ) located in the template-boreal transition zone achieved a higher relative accuracy (approximately $70 \%$ ). Others have also reported a correlation between increasing tree height and decreasing canopy height estimate errors (Izzawati et al., 2006; Wallington et al., 2005; Woodhouse et al., 2006). Although it was not specifically measured in this research, it is believed that the generally observed increased crown size that accompanies increased tree height reduces the gaps between the trees and leads to a reduction in X-band signal penetration.

One field design limitation of this research was the omission of the collection of stem density, canopy cover view to the sky, and/or Leaf Area Index (LAI) measurements as they all have significant impacts on signal attenuation (penetration into the canopy) and thus, the derived estimates of canopy height given by $h_{\text {spc. }}$. Additional knowledge is still required to understand further InSAR signal attenuation over vegetation types of varying densities and heights. 
Comparing deciduous and coniferous trees of similar heights (i.e., excluding the tall conifers of the Canadian sites); the accuracy relative to tree height was approximately $44.4 \%$ for coniferous and approximately $46.2 \%$ for deciduous trees. Izzawati et al. (2006) concluded that conical crowns such as those of many conifers have greater signal attenuation than broadleaf crowns, resulting in a greater canopy height underestimation. The results of this research show only a slight difference between coniferous and deciduous trees. A possible reason could be in the averaging of multi-data takes InSAR to derive the NEXTMap X-HH phased derived DSM data used in this research, in comparison to the single-data take X-HH InSAR used in Izzawati et al (2006).

The mixed vegetation class received the greatest errors of the forest classes, primarily due to their variability in vegetation structure. Introducing seasonal data such as a spring (leaf-off) and summer (leaf-on) collection would provide different volume scattering contributions from the deciduous vegetation within the mixed class and therefore, assist in better classification of the class and extraction of canopy height.

One promising aspect of $\mathrm{X}-\mathrm{HH}$ InSAR scattering phase centre height is that, while it is dependent on vegetation type, density, and height, among other parameters, it is predictable across large areas, indicating that it is suitable to apply corrections for signal attenuation that can improve the overall accuracy of retrieved canopy height (see Section 6.3).

\subsubsection{L-Quad PollnSAR $h_{\text {spc }}$ as an Estimate of Canopy Height}

The key idea of the PolInSAR technique is the discrimination between the canopy phase centre and the ground phase centre by combining different polarizations and the subsequent estimation of canopy height by means of the interferometric phase. The major 
contribution to this application has been the Random Volume over Ground (RVoG) model and its inversion procedure (Papathanassiou and Cloude, 2001; 2004; Mercer et al., 2009a; Neumann et al., 2010) to derive canopy height (Cloude and Papathanassiou, 2003). In this research, as expected, the L-PolInSAR data penetrated into the forest canopy more than LiDAR, X-HH InSAR, and the C-HH InSAR data, given its long wavelength. All of the PolInSAR L-Band profiles (Figure 49) followed the trends given by the LiDAR DSM data, indicating that a correction to the L-band DSMs could be applied to account for the radar signal attenuation by the forest canopy. The potential of the PolInSAR technique together with an appropriate model such as the Random Volume Over Ground (RVoG) model (Treuhaft and Siqueira, 2000; Papathanassiou and Cloude, 2001), has demonstrated success for the recovery of canopy height and bare ground elevations beneath vegetation cover as documented in the literature (Hajnsek et al., 2009; Mercer et al., 2009a; 2009b; Huang et al., 2011).

A correction model to account for signal attenuation, like that presented for the $\mathrm{X}$ HH InSAR data, however, would be required to achieve more accurate canopy height estimates than those given by the $h_{\text {spc }}(R V o G$ DSM - RVoG DTM). These results agree with the literature (Cloude and Corr, 2003; Mercer et al., 2007; Zhang et al., 2008), but there is still a need for a deeper understanding of the dependence of the PolInSAR coherence on the vegetation parameters and, consequently, the need for an improved inversion procedure to derive better ground surface elevations.

\subsubsection{C-HH InSAR $h_{\text {spe }}$ as an Estimate of Canopy Height}

The $h_{\text {spe, }}$, given by C-HH InSAR (e.g. C-band DSM - X-band DTM) provided mixed results between the United States and Canadian research sites. The C-HH InSAR 
SRTM results for the United States research sites, with relative height accuracies of $41.7 \%-52.1 \%$ for dense forest canopies (deciduous, conifers, and mixed) are similar to those cited in the literature (Kellndorfer et al., 2004; Walker et al., 2007; Simard et al., 2008; Sexton et al., 2009). The wetlands and shrub relative accuracies were lower (9\% 42.12\%), possibly due to lower density cover, gaps in the forest canopies as discussed previously, and the coarser resolution of the C-band data ( $30 \mathrm{~m}$ compared to the $5 \mathrm{~m}$ for the X-and L-band data). The C-band DSM omits several cleared areas in the Canadian research site areas, mostly likely due to the coarse GSD (90 m).

C-band is expected to penetrate forest canopies to about $50 \%$ of canopy height and should penetrate more than X-band (Carabajal and Harding, 2006; Balzter et al., 2007a; Sexton et al., 2009). The C-Band data were, thus, thought to be suspect for the Canadian study areas because derived $h_{s p c}$ values were higher than those for $\mathrm{X}-\mathrm{HH}$ InSAR. Others have also found this type of anomaly (Becek et al., 2008; Walker et al., 2007; Viergever et al., 2008). These inconsistencies are therefore thought to be most likely caused by SRTM sensor phase noise, mast motion errors (movement of the $60 \mathrm{~m}$ deployable mast that formed the interferometric baseline; Eineder et al., 2001; Hensley et al., 2000; Walker et al., 2007), and/or systematic offset between the C-band, X-/L-band and validation data sets.

Walker et al. (2007) presented error mitigation strategies to compensate for SRTM C-HH InSAR phase noise and motion mast errors when using SRTM data to retrieve canopy height. Due to time constraints and the focus of this research being on the $\mathrm{X}$ - and L-band airborne data, mitigation strategies were, however, not performed in this study, thus, the CHE methodology and testing was not applied to the C-Band data. 
If the SRTM results were caused by a systematic offset between the X-HH InSAR, L-Quad PolInSAR, and the validation datasets, it is anticipated that once this is corrected, the SRTM will provide more reliable results, but they will be worse than the $\mathrm{X}$-band InSAR results. Furthermore, the fact that the X-and L-band DTMs have a negative bias compared to the LIDAR DTM could also be the most likely reason why SRTM performs best at the two Canadian research sites. To produce better estimates of canopy $h_{\text {spc }}$, SRTM C-HH InSAR data would need to be combined with a reliable DTM and would require additional processing steps to correct for sensor phase noise and motion mast errors, to check for systematic offsets, in addition to the application of corrections for signal attenuation, gaps, and discontinuities at vegetation/non-vegetation boundaries. Refinement of $h_{\text {spc }}$ canopy height method would also require the implementation of vegetation dependent correction factors and corrections at canopy gaps and edges.

\subsection{Refinement of $h_{\text {spe }}$ as an Estimate of Canopy Height Using Vegetation Dependent Correction Factors and Corrections at Canopy Gaps and Edges}

Development of empirically based $h_{\text {spc }}$ correction factors for each vegetation type was conducted followed by additional correction within canopy, at gaps and edges. Discussion of the results of these is given in 6.3.1 and 6.3.2, respectively.

\subsubsection{Vegetation Dependent Correction Factors}

The addition of $h_{\text {spc }}$ correction factors based on vegetation type has been shown in this research to provide better estimates of canopy height; few studies have however, reported on this type of correction. These factors were derived empirically from comparison of $h_{\text {spc }}$ with in situ and LiDAR tree measurements for five vegetation classes 
(shrub, coniferous, deciduous, mixed, and wetlands). To implement the corrections, accurate land cover maps for these vegetation classes and a barren class are required. The accuracies achieved using object-based segmentation and classification with $h_{\text {spc }}$ and ORI brightness and texture as inputs were high, being over $87 \%$ for all research sites and classes in all but one case.

The use of InSAR derived $h_{\text {spc }}$ data in land cover object-based classification, as applied in this research, to the author's knowledge has not been conducted in previous studies and should be explored further as it was shown to aid discrimination of several vegetation classes of different heights and structure. The implementation of object-based segmentation and classification techniques with spaceborne and airborne InSAR imagery and InSAR coherence data for the discrimination of vegetated and urban land cover are more common in the literature (e.g., Engdahl and Hyyppa, 2003; Corr et al., 2003; Matikainen et. al., 2006; Huang et al., 2007).

Airborne orthorectified SAR imagery was used in Canada to classify jack pine, black spruce, trembling aspen, and three classes of mixed forest (Saatchi and Rignot, 1997) with good success. Japanese Earth Resources Satellite (JERS-1, 18 m pixels) Lband SAR imagery have been combined with C-band SAR imagery to map forest composition (Kellndorfer et al., 1998), and L-band PALSAR imagery have been used to map land cover (Turkar and Rao, 2008). Given the success to date in using SAR data for land cover classification, coupled with the soon to be global scale of X-band data (from airborne NEXTMap and spaceborne X-band InSAR capable data sets), an automated land cover extraction method is of value for X-band InSAR data. 
Using the X-HH InSAR derived land cover maps, the X-HH InSAR derived canopy height estimates adjusted for $h_{\text {spc }}$ within each of the five vegetation classes were much more accurate than using $h_{s p c}$ alone as an estimate of height and they were also more accurate than the U.S. LANDFIRE canopy height data. Land cover inclusion in the canopy height estimation (CHE) method presented in this research generated canopy height accuracies that approached those obtainable from traditional field survey (approximately $90 \%$ of tree height), and the method can be applied over large areas, as opposed to sample-based ground measurements.

\subsubsection{CHE Refinement within Canopy, in Gaps, and at Canopy Edges Using Buffers}

Canopy height retrieval at discontinuities (e.g., edge of vegetation canopy or gaps within a forest canopy) using interferometry is prone to large errors due to the sidelooking nature (viewing geometry) of InSAR sensors and the contribution of the exposed ground surface and tree trunks on the near-range side of the forest/vegetation stand (Woodhouse et al., 2006; Balzter et al., 2001). As a result, estimated canopy height typically decreases at the edge of vegetation cover (Andersen et al, 2006; Hagberg et al., 1995; Wallington et al., 2004). In a closed canopy, for example, the amount of ground return is small such that $h_{\text {spc }}$ represents the upper half of the canopy. In areas of large gaps or sparse vegetation this changes because, at $\mathrm{X}$-band, $\mathrm{h}_{\mathrm{spc}}$ will be comprised of upper canopy, understory and ground signal contributions in one resolution cell (Hagberg

et al., 1995; Kellndorfer et al., 2004; Izzawati et al., 2006). As a result, $\mathrm{h}_{\text {spc }}$ will be lower than that of a closed canopy.

In this research, the creation of buffers along the inside of vegetation boundaries (derived from the land cover maps) proved to significantly mitigate these edge and gap 
effects (Figure 15). This is an important addition to the canopy height method that has not been reported in the literature; it directly addresses conclusions made by Woodhouse et al. (2006) that the use of operational InSAR products must take into account edge effects, and methods must be employed that seek to minimize their influence, including the effects of incidence angle, tree height, and underlying slope.

The final canopy height estimation results presented in this research were fairly consistent over the six diverse research sites, indicating the potential to apply the proposed canopy height methods over diverse landscapes and regions. The application of the buffers and vegetation bias correction factors were also largely computational rather than manual, thus, making the proposed methods attractive for application over large geographic extents.

\subsection{Impact of Incidence Angle on $h_{\text {spe }}$ as an Estimate of Canopy Height}

The change in incidence angle across swath has the effect of altering proportions of the vegetation canopy-volume scattering and ground scattering contributions received at the SAR sensor. This will affect the surface elevation model (e.g. DSM) generated from InSAR techniques. In general, for example, within a dense forest canopy, at larger incidence angles (also referred to as shallow incidence angles located in the FR), SAR pulses interact more with the vegetation canopy structure and less with the ground surface, thus, decreasing signal penetration into the canopy and providing a better canopy height estimate. In contrast, at smaller incidence angles (also referred to as steep incidence angles located in the NR), the SAR pulse over the dense canopy penetrates more into gaps of various sizes and interacts more with understory, the tree trunks and the ground, leading to an overall decrease in the retrieved canopy height. This phenomenon 
results in variations in canopy height retrieval across single-data take InSAR data as supported in the literature (Izzawati et al., 2006; Woodhouse et al., 2006; Balzter et al., 2007b). In fact, Andersen et al. (2003) presented results that indicate InSAR viewing geometry to be the single most important factor influencing the accuracy of canopy height measurements derived from X-HH InSAR techniques. Their recommendation was to ensure the collection of multi-data take InSAR over single-data take InSAR to achieve the best possible DSM and DTM InSAR data for use in canopy height extraction.

In the preparation of NEXTMap multi-data take data, single-data take data are tied to control and a range quality check $(\mathrm{QC})$ is performed prior to data merging. The purpose of range QC is to examine range profiles (across the swath of a single data strip) of orthogonally overlapping SAR data, detect any errors that are beyond defined specification, model, and correct the errors. There are four known sources of range error that can affect each pass: roll, pitch, yaw, and motion. Of these errors, only motion is common to all similar data takes for a specific mission, whereas, roll, pitch, yaw are unique. For range QC, the specification expressed in linear error at the $90 \%$ (LE90\%) is $1.0 \mathrm{~m}$ in unobstructed, low sloped terrain (which covers $70 \%$ of the Conterminous U.S., for example) for the NEXTMap multi-data take data product. Furthermore, the nominal standard deviation is approximately $0.30 \mathrm{~m}$ absolute difference between highest / lowest peak. In theory, there are no differences between flat and mountainous areas, but there is an understanding that accuracy will degrade in mountains. The process of merging multidata takes results in the reduction of distortions associated with variations in incidence angles, thereby generating a better data set for the extraction of biophysical parameters such as canopy height. 
As expected, the results presented in this research indicate that the large incidence angle range of the airborne X-HH airborne InSAR (e.g. Intermap single-data take X-HH InSAR incidence angle range is $35^{\circ}-55^{\circ}$ ) results in a range of height errors that decrease across swath (from NR to MR to FR), but that this effect is less pronounced in the NEXTMap X-HH InSAR data because it represents a combination of multiple data acquisitions from different incidence angles that have been merged and averaged to create the final InSAR data (Andersen et al., 2008; Intermap, 2011). The improvements from NR to FR were, however, minor, indicating that the multi-data takes InSAR are not impacted by changes in incidence angle in flat terrain due to the aggregation of multiple flight line passes. In the case of the single-data take results, the theory did not hold, though. In some cases the NR accuracy was better than the FR accuracy, and in most cases the MR accuracy was worse than both the NR and FR. Overall, however, the differences were not significant, indicating that that incidence angle range for flat terrain does not play a major role in the canopy height accuracy.

The findings presented here are confirmed in the literature (Andersen et al., 2003; 2008; Woodhouse et al., 2006; Balzter et al., 2007). Andersen et al. (2003) reported similar results, concluding that the combination of several overlapping flight lines of single data takes of multiple look directions significantly improved the vertical accuracy of the derived canopy height. Future airborne data strips would need to undergo a similar process to ensure that rotation of the flight line in the azimuth direction is corrected prior to merging with overlapping strips. Woodhouse et al. (2006) also found an increase of sensor exposure to lower parts of the trees at the discontinuities and the decrease of exposure to the adjacent ground at increasing incidence angles. Balzter et al. (2007a) 
obtained similar results using E-SAR dual frequency InSAR data (X-and L-band) to derive canopy height estimates, by making adjustments to account for InSAR incidence angle variance from NR to FR which improved vertical RMSE from of $4.1 \mathrm{~m}$ (NR) to 2.9 m (FR) compared to LiDAR CHM estimates of $2 \mathrm{~m}$ RMSE.

The results in this research also concur with other studies using SRTM (Kellndorfer et al., 2004), or GeoSAR (Chapman et al., 2000) data. Height retrieval accuracies over $90 \%$ are obtainable when investigating single species (Suarez and Wallington, 2005) or where detailed topographic surfaces are available (Andersen et al., 2008). Furthermore, the area of retrieved $h_{s p c}$ at edges and within gaps of the forest canopy is also affected by variations in incidence angle. As one would expect, the area of edge effect is reduced at shallow (FR) incidence angles due to the higher proportion of volume scattering. These findings support the need for the application of corrections at forest-barren land cover discontinuities, as discussed in section 6.3.2.

\subsection{Impact of Terrain Slope on $h_{\text {spe }}$ and CHE as Estimates of Canopy Height}

This research found that RMS and mean errors in $h_{\text {spc }}$ as an estimate of canopy height consistently increased with increasing terrain slope for both $\mathrm{X}-\mathrm{HH}$ single- and multi-data takes InSAR for all vegetation classes when stratified by incidence angle range (Tables 49-52). This is due to the side looking geometry of SAR sensors where terrain slope affects the SAR backscatter and thus, the derived DSM and DTM elevation data used in the creation of the CHE. This research found that accuracy of the X-HH InSAR DTM was lower in regions with slopes greater than $10^{\circ}$ (Section 6.1.1.). Therefore, slopes greater than $10^{\circ}$ are expected to have DTM errors that would be transferred to the canopy height estimates derived from InSAR. Furthermore, when an InSAR sensor images 
vegetation over sloped terrain, different sections of the forested canopy will be exposed to the signal. The impact of terrain slope on the derived scattering phase centre height and proposed canopy height depends on slope magnitude, the direction the slope faces with respect to the SAR sensors (positive or forward when the terrain faces the SAR sensor, negative or back slope when the terrain faces away from the SAR sensor), and where the area being imaged lies within the radar swath (e.g. NR, MR, or FR). Moreover, the effects of slope and vegetation canopy density are somewhat interrelated and thus, difficult to separate. For example, the steep terrain slopes found at the $\mathrm{AZ}$ and $\mathrm{CO}$ sites that had dense coniferous vegetation actually provided good estimates of canopy height due to a large portion of volumetric scatterers contributing to the overall InSAR signal return, whereas, in flat terrain dominated by shrub the overall error in $h_{\text {spc }}$ estimates of canopy height expressed as RMSE per cent of mean height were relatively worse. These findings are supported in the literature (Izzawati et al., 2006; Andersen et al., 2008).

Findings presented here provide a confirmation of previous studies that terrain slope affects the accuracy of X-HH InSAR derived canopy height estimation when InSAR is generated from a single-data take data (Izzawati et al., 2006; Andersen et al., 2008, Breidenbach et al., 2008). When using single-data take data, terrain slope corrections could improve accuracies and should be further investigated. While the effect of terrain slope was evident in both the single- and multi-data takes X-HH InSAR data, it was less pronounced in the multi-data takes data (e.g. NEXTMap X-HH InSAR). These results concur with the literature on multi-data take spaceborne X-band (Andersen et al., 2006) and C-band InSAR (Walker et al., 2007; Kellndorfer et al., 2004; Andersen et al., 2004). Andersen et al. (2008) results concur with what is presented in this research. They 
found an increase in random error in the height measurements as the slope increases. Their findings conclude that terrain slope will influence vertical accuracy of InSAR canopy height estimation when InSAR is generated from a single-data take data, yet multi-data takes InSAR data errors related to terrain slope were largely mitigated when using InSAR DEMs derived from multiple-passes. Furthermore, the influence of terrain slope on X-band height measurements was sensitive to the relationship between the SAR viewing geometry and incidence angle (Izzawati et al. 2006; Andersen et al., 2008; Breidenbach et al., 2008). It was anticipated that the change in incidence angle across swath from NR to MR to FR would be accompanied by an increase in canopy height errors; however, this was not the case. Instead, the results (Table 46), the best vertical accuracy results (Table 46) were located in the MR, whereas the worst results were observed in both the FR, with the NR results falling between the two.

\subsection{Proposed Canopy Height Methodology Benefits and Limitations}

This section provides a discussion of the benefits (Section 6.4.1) and limitations (Section 6.4.2) of the proposed canopy height methodology presented in this research.

\subsubsection{Benefits}

Conventional forest inventory techniques for measuring canopy height are timeconsuming, costly, and are largely inadequate to implement over large geographic extents (Andersen et al., 2006). Airborne and satellite SAR remotely sensed data provide economical and efficient means to estimate vegetation type and canopy height over large areas at accuracies approaching that of ground based measurements (Naesset, 1997; Drake et al., 2000; Balzter et al., 2007a; Andersen et al., 2006; Sexton et al., 2009). The canopy height methodology presented in this research has demonstrated that a 
combination of airborne remotely sensed multiple-data takes X-HH InSAR data or airborne L-Quad PolInSAR data, with land cover data, and some refinement steps can be used to accurately estimate canopy height from InSAR phase scattering centre height.

For continuous vegetation canopies, and at short SAR wavelengths (e.g. X-HH InSAR), $h_{s p c}$ will provide better estimates of canopy height, while for sparse vegetation cover (e.g. gaps within the forest canopy and or at forest/non-forest boundaries) and longer wavelengths (e.g. L-band InSAR), $\mathrm{h}_{\mathrm{spc}}$ will be not perform as well (Woodhouse et al., 2006; Balzter et al., 2007a; Andersen et al., 2008). Corrections to account for these conditions were successfully implemented in this research and should be considered in future canopy height methods from InSAR and PolInSAR techniques. Increasing availability of X-band InSAR and PolInSAR datasets makes this proposed approach attractive not only in regions dominated by cloud, but also in remote regions where geospatial data are limited. Furthermore, these findings support the creation of canopy height data over extensive areas of diverse landscape conditions (e.g. varied terrain and multiple-ecosystems).

\subsubsection{Limitations}

There are several important considerations to take into account when deriving interferometric canopy height. Four of these are discussed below.

First, accuracy of height estimates is dependent on the availability of a high quality digital terrain model (DTM) that accurately represents bare ground elevations beneath canopies, as the DTM is subtracted from the InSAR/PolInSAR digital surface model (DSM) to provide an estimate of $h_{\text {spc }}$. In this research, the edited X-band InSAR DTM and L-band PolInSAR DTM data met the Intermap vertical accuracy and data 
quality requirements and were therefore, used in development of the canopy height estimates. However, the NEXTMap DTM data are derived from the InSAR X-HH InSAR DSM data and required a semi-automated 3D production editing workflow process to extract bare ground elevations. Rapid changes in terrain (e.g. at road or drainage embankments) may not be preserved due to an inadequate sampling density. Commercially available Astrium TanDEM-X mission DSM data will consist of a seamless global DSM with accuracy equaling or surpassing the HRTI-3 specification (12 $\mathrm{m}$ GSD, $10 \mathrm{~m} \mathrm{LE} 90 \%$, and $3 \mathrm{~m} \mathrm{CE90 \% )} \mathrm{for} \mathrm{use} \mathrm{in} \mathrm{a} \mathrm{host} \mathrm{of} \mathrm{applications} \mathrm{(Krieger} \mathrm{et} \mathrm{al.,}$ 2007; Moreira et al., 2004). These data should be investigated as a DSM and DTM source for use with the proposed canopy height methodology. Of course they would need to undergo editing similar to that presented in section 3.3 to make the DSM useful and to derive a DTM. The L-band PolInSAR data are used to derive both a DTM and a DSM, however, the DTM, using the RVoG method presented here, required additional editing for it to be useful in deriving the canopy height. Further investigation into RVoG inversion methods for L-band PolInSAR could lead to a promising DSM and DTM source for the derivation of canopy height.

Second, the InSAR and PolInSAR techniques presented in this research represent single-pass InSAR, in comparison to the commercially available repeat-pass spaceborne InSAR systems. Repeat-pass InSAR configurations experience a time delay between image collections, thereby introducing temporal changes that can decrease the InSAR coherence causing a decorrelation in phase (e.g. no data) and a subsequent decrease in derived scattering phase centre height. Balmer et al. (2008) reported that X-band repeatpass SAR interferometry could not be applied practically over regions of forest due to 
temporal change in scatterers between data takes. Single pass InSAR data collections do not experience such temporal differences, thus, there is little or no decorrelation in phase. Consequently, temporal decorrelation in phase will need to be addressed when using repeat-pass interferometric data from spacebome systems like Tandem-X (Eineder et al. 2008) and COSMO - SkyMed (Agenzia Spaziale Italiana, 2007) to derive canopy height. These sensors are promising because they deliver very precise pointing accuracy data (Bresnahan et al., 2009) suitable for remote regions where no reference data (i.e., ground control points) are available.

Third, X-, C-, and L-band InSAR and PollnSAR techniques provide scattering phase centre heights that underestimate real canopy heights (Kobayashi et al., 2000; Izzawati et al., 2006; Balzter et al., 2007a; 2007b) requiring the application of a correction model to provide accurate estimates of canopy height. The corrections developed for this research were dependent on accurate land cover maps which may not be available. Corrections at gaps and edges were also discrete, being applied in two buffers. A more continuous estimate of $h_{\text {spc }}$ variation at such edges could further improve canopy height estimation.

Fourth, to improve the canopy height estimation methodology presented in this research, other variables should be taken into consideration when the topography has terrain slopes $>20^{\circ}$. For example, terrain slope corrections would be the most influential factor to improve interferometric canopy height estimation from single-data take and multi-take InSAR DSM - DTM data methods where terrain slopes are greater than $>20^{\circ}$. Moreover, terrain slopes of $>20^{\circ}$ cannot be mapped at steep incidence angles such as those by spaceborne systems (e.g. as low as $29^{\circ}$, RADARSAT) because the side looking 
nature generates too many shadows, which means data from other sources will need to be obtained in those regions (Balmer and Hartl, 1998).

\subsection{Proposed Canopy Height Methodology Compared to Other Canopy Height Methods that Use InSAR and PolInSAR Data}

Several theoretical studies of the use of InSAR to derive canopy height estimates use some different techniques than presented in this research and may warrant further investigation to improve upon what has been presented here. Investigations to derive true canopy heights from InSAR data by equating the downward bias with penetration depth have had some success be several authors; however, these studies have been limited to small study areas consisting of uniform vegetation cover (Treuhaft et al., 1996; Rignot et al., 2001; Williams and Greely, 2001; and Varekamp and Hoekman, 2002). Testing of these methods over several vegetation classes of varied densities may prove to be fruitful.

Askne et al. (1997) introduced an area fill factor into a water cloud model to take into account the presence of tree gaps within Boreal forest test sites, whereas Varekamp and Hoekman (2002) have embedded a forest structure function into the water cloud model to define the 3D location of trees within tropical rain forest. The canopy height methodology presented in this research differs because it uses a systematic approach to define gaps in canopy and canopy-barren land boundaries by using a land cover layer. Additional corrections are then applied using the land cover boundaries and correction factors to improve the accuracy of the canopy height near vegetation canopy caps and at edges (transition from bare ground to forest canopy). Results presented in this research indicate that significant improvements in canopy height estimate accuracy was achieved using this method. 
PRIS (polarimetric radar interferometry simulator), a SAR model that describes a forest as a 3D volume comprised of volume elements (voxels), each representing some fraction of crown volume, gap, or ground surface have been investigated by several authors. Woodhouse et al. (2006) used PRIS to model a forest as a random volume but with a 3-D crown shape parameterized from ground data and allometric relationships. This model was used to characterize the vegetation-barren landcover edge-effect trends and provided a more accurate determination of the relative amounts of energy being scattered and transmitted along the signal path length, leading to improvement in the estimation of the location of the $h_{\text {spe }}$. However, these results were performed on singletake data. Further investigation into this method using multiple takes InSAR like NEXTMap and SRTM are warranted.

Brown and Sarabandi (2003) used a single layer random-oriented vegetation scattering model (with no interaction from the ground) to obtain tree heights for red and Australian pine of $2.2 \mathrm{~m}$ RMSE. As expected, the predictive model was significantly closer to the true tree height than the SRTM scattering phase centre height values $(6.5 \mathrm{~m}$ RMSE). However, this model requires a significant number of field based inputs (diameter at breast height, canopy type, vegetation density, crown radius) to ensure success and it was only evaluated in uniform pine tree stands, thus, it needs further research in a wider variety of vegetation types and landscape conditions.

\subsection{Summary}

This chapter summarized a number of significant findings on the evaluation of the proposed vegetation canopy height estimation (CHE) methods. A detailed discussion on the multi-frequency InSAR/PolInSAR data for canopy height estimation is presented. 
Also outlined was a discussion of the canopy height estimation method refinements. The chapter closes with a discussion of the benefits and the limitations of CHE compared to other InSAR/PolInSAR canopy height methods dominating the literature, to set the stage for the conclusions chapter that follows. 


\section{CHAPTER SEVEN: CONCLUSIONS and RECOMMENDATIONS}

This research shows that airborne X-HH InSAR and L-Band Quad polarized PolInSAR data can be successfully applied to classify vegetation type and estimating canopy height over diverse vegetation types, varied terrain conditions, and different ecosystems, when an empirical methodology that accounts for signal penetration into vegetation canopy, at gaps, and near edges of vegetation-non-vegetation is applied.

These results were obtained from the subtraction of a high resolution digital terrain model (DTM) from an InSAR and PollnSAR derived digital surface model (DSM) to derive scattering phase centre height $\left(\mathrm{h}_{\mathrm{spc}}\right)$ as an initial estimate of canopy height. The X-HH InSAR and L-Quad PollnSAR DTMs required extensive editing to obtain bare ground elevations suitable for derivation of $h_{s p c}$. This empirical method also requires an accurate land cover map for the desired vegetation and non-vegetation classes in order to develop the vegetation dependent microwave attenuation bias correction factors to be applied to the derived $h_{\text {spc }}$. In this research, such a map was created using $h_{\text {spc }}$ and SAR image tone as input discriminators in object-based classification. Additional refinement of the canopy height method was conducted through application of correction factors applied in variable buffers at canopy edges and gaps of vegetation cover polygons, and within the interior of the vegetation canopy.

This empirical canopy height estimation (CHE) method, as well as the InSAR derived DTM accuracy assessment stratified by land cover type are new contributions. Additionally, few studies have been as broadly applied as this research, in which a canopy height estimates were developed and found to be accurate and robust for describing the height of shrub, deciduous, coniferous, mixed forest, and wetlands 
vegetation classes located in regions of various topographic settings and eco-regions. Moreover, the properties of InSAR and PolInSAR systems, which include cloud penetration, day/night time data collection, large area coverage, availability of data, and high resolution capabilities, all contribute to providing a technology with the ability to make fast highly accurate measurements of 3D forest structure, including vegetation type and canopy height estimates.

\subsection{X-HH InSAR Derived Canopy Height Estimates - Airborne}

The $\mathrm{h}_{\mathrm{spc}}$, given by X-HH InSAR (e.g. DSM - DTM) captured, on average, just under $50 \%$ of field measured canopy height for the five vegetation classes assessed in this research. Through the empirical CHE refinements summarized above, this improved to approximately $92 \%$ of canopy height overall.

The effect of SAR viewing geometry (variation in incidence angle across swath) on the vertical accuracy of the InSAR derived $h_{\text {spc }}$ was also assessed to determine whether the variations were insignificant enough to allow for accurate extraction of canopy height. It was found that such effects are significant but are mitigated for the most part when using multi-data takes or multi-pass InSAR data (e.g. NEXTMap). Thus, corrections for viewing geometry were not implemented.

The effect of terrain slope on the vertical accuracy of X-HH InSAR derived canopy height estimates was also assessed. It was evident in both the single- and multidata takes X-HH InSAR data, however, it was less pronounced in the multi-data take data (e.g. NEXTMap X-HH InSAR). When using single-data take InSAR data, terrain slope corrections could improve accuracies and should be further investigated. These results, from an InSAR frequency point, could support additional studies using spaceborne 
Tandem-X or COSMO-SkyMed X-InSAR data to derive land cover, especially, in regions where there is no coverage with airborne data.

The X-HH InSAR multi-take NEXTMap dataset used in this research is commercially available worldwide, for over 18 million $\mathrm{km}^{2}$ (USA, western Europe, parts of South and Central America, and South East Asia) providing the potential to improve nationwide 3D land cover mapping in terms of spatial resolution and attribute accuracy. Furthermore, the Tandem-X InSAR 12 m GSD DSM data with expected absolute and relative vertical accuracies of $10 \mathrm{~m}$ and $2 \mathrm{~m}$, respectively, for the entire Earth landmass will be available commercially by late-2014. This will provide DSM data that can be used at a global scale to extract canopy height estimates using the empirical method presented in this research.

\subsection{L-Quad PolInSAR Derived Canopy Height Estimates - Airborne}

L-Quad PolInSAR DSM data combined with a LiDAR DTM were also shown to be acceptable in estimating canopy height in two sites dominated by coniferous and mixed forests. RVoG techniques were used to extract the bare ground (DTM) and canopy height estimates from these data. The $h_{\mathrm{spc}}$, given by L-Quad PolInSAR (e.g. DSM DTM) captured, on average, just less than $65 \%$ of field measured canopy height. This improved to approximately $89 \%$ of canopy height after the corrections for vegetation type and gaps. The L-band DTM and DSM results were not as good as for X-HH InSAR, but following editing using the same methods as applied operationally to the X-HH data

- (NEXTMap), the results improved to be almost the same as X-HH. Additional testing of the RVoG DEM difference method is required to better separate volume scattering from ground scattering to achieve better DTM results beneath forest canopies and in barren 
land cover. The L-band PolInSAR is well suited to vegetation mapping because it is sufficiently sensitive to vegetation structure, including both canopy and sub-canopy elements. PollnSAR at L-band therefore, has the potential to produce a true ground DEM with minimal vegetation bias (Flynn et al., 2002; Tabb et al., 2004; Neumann et al., 2010) and provide reliable estimates of canopy height for deciduous, conifers, and mixed vegetation types.

\subsection{C-HH InSAR Derived Canopy Height Estimates - Spaceborne}

The SRTM C-HH InSAR derived $h_{\text {spc }}$ (e.g. C-HH InSAR DSM - X-HH InSAR DTM), provided mixed results. Results in the U.S. research sites were worse than those for the Canadian sites, possibly due to the differences in GSD of $30 \mathrm{~m}$ and $90 \mathrm{~m}$, respectively. In the U.S. sites, the C-HH InSAR $h_{\text {spc }}$ captured, on average, just less than $50 \%$ of field measured canopy height for the five vegetation classes assessed in this research, while it was on average $73 \%$ for the Canadian sites. Additional testing of the Cband InSAR data is required to determine if there is a horizontal offset from the X-and L-band and the reference data sets and if phase noise corrections should be applied.

\subsection{Broader Implications of the Research}

Natural and human forces are rapidly changing the structure and extent of global forest cover, altering the global carbon cycle, affecting our climate, altering biodiversity, and changing species diversity. High resolution local to global spatially explicit maps of 3D biophysical parameters like vegetation type and canopy height are required to understand changes and trends in terrestrial ecosystems, to characterize the impact of their changes on climate, habitat, and biodiversity, and to model processes such as photosynthesis, energy transfer, and evapo-transpiration. For example, the United 
Nations REDD+ initiative (Reducing Emissions from Deforestation and Degradation) seeks to reduce land use induced greenhouse gas emissions and requires independent monitoring of forest cover and biomass in a spatially explicit form. There are, however, considerable practical and logistical difficulties in mapping and measuring 3D vegetation structure, especially in remote and inaccessible places, as well as over large geographic extents. The methods and results of this research could make significant contributions to such programs of regional to global scales. Within the last 5 years, the operation of two commercial high resolution X-band SAR satellite systems from the TerraSAR$\mathrm{X} /$ Tandem-X and COSMO-SkyMed missions and the release of the SRTM X-band InSAR DSM data have led to a new era of X-band repeat-pass InSAR data collection systems and archived InSAR data. These spaceborne, SAR sensors are able to collect images with a GSD as small as $0.75 \mathrm{~m}$ (e.g. Tandem-X spotlight mode) with relative vertical accuracies of $2 \mathrm{~m}$ (LE90\%), at various look angles, and deliver SAR imagery with very precise pointing accuracy to allow for the data collection in remote regions where no reference data are available. The land cover and canopy height methods presented in this research can contribute to calibration and validation of such spaceborne monitoring efforts. Furthermore, the availability of high quality reference data from the ICESat spaceborne LiDAR sensor, coupled with X-band and L-band InSAR/PolInSAR techniques will provide highly accurate data for the extraction of vegetation type and canopy height data on a global scale.

\subsection{Improvements to the Proposed Empirical Method to Estimate Canopy Height}

Based on the outcomes of this research, various recommendations are made for

further research towards improving the InSAR and PolInSAR methods described in this 
research for vegetation type and canopy height estimation, but also for further research relevant to the use of $\mathrm{X}-, \mathrm{C}$ - and L-band InSAR and PolInSAR techniques for 3D biophysical parameter extraction.

The main constraint of the empirical method employed in this research is access to a high resolution DTM for the derivation of scattering phase centre height. The existence of a "bald Earth" DEM, i.e. a global DEM without vegetation bias, would be useful for canopy height retrieval using shortwave InSAR (e.g. X-, C-Band) in remote locations to achieve national to global coverage. However, many countries, especially developing countries, seldom have access to accurate DTM data. Alternatives for estimating bare ground surface elevations are the use of longer wavelength InSAR (e.g. P-band), or refined PolInSAR methods, or the use of a combination of ASTER $30 \mathrm{~m}$ and ICESat DSM data coupled with an editing process (e.g. method presented in this research) that can allow for the extraction of bare ground elevations.

The proposed correction factors for vegetation type and gaps/edges applied to derived $\mathrm{h}_{\mathrm{spc}}$ in this research may be considered 'brute force' and coarse in the sense that they are discrete corrections applied to whole objects (e.g. a classified vegetation object or a whole vegetation polygon buffer zone), when, in reality, $\mathrm{h}_{\mathrm{spc}}$ varies continuously over space. These correction factors were implemented in this way because of the very large data sets covering large areas in a diverse set of eco-regions. They provided a more accurate determination of the relative amounts of energy being scattered and transmitted along the signal path length, leading to improvement in the estimation of $h_{s p c}$. However, additional research into improving the method to derive more continuous correction gradients or functions is warranted. 
A slope correction applied to the InSAR/PolInSAR derived DTM could improve the vertical accuracy of the DTM data used in the derivation of canopy height. Future work should be conducted to characterize the spatial variability of vegetation type and canopy height across a broader geographic extent of sloped terrain and to further investigate the effects of rugged terrain and incidence angle on the canopy height.

The choice of an optimum RVoG inversion technique to derive a DTM is not trivial and warrants addition investigation. Little quantitative information has been put forth on how to improve bare ground measurements from PollnSAR techniques at any wavelength because PolInSAR research is focused on canopy height and biomass estimation rather than DTM generation. Using the RVoG method, according to Hajnsek et al. (2009), the location of the interferometric phase centre within the vegetation layer depends on the ground-scattering amplitude. Larger ground-to-volume amplitude ratio $\mathrm{m}$ values (Equation 8) correspond to stronger ground-scattering amplitudes and move the phase centre toward the ground and vice versa. The polarization dependence of $m$ (Equation 8) relates the variance of the interferometric phase centre as a function of polarization directly to the variance of the amplitude of the ground-scattering component.

Vegetation canopy density (or crown density) was not a parameter analysed in this research, however, the vegetation cover at the two Canadian sites was denser than at the U.S. sites, which may have led to the better retrieved $h_{\text {spe }}$ heights at the Canadian sites. The literature is sparse on the effect of canopy density on retrieved InSAR $h_{s p c}$ heights. Andersen et al. (2008) found little or no effect, whereas Izzawati et al. (2006) and Woodhouse et al. (2006) found that X-HH $\operatorname{lnSAR} h_{\text {spc }}$ errors were reduced in dense 
forest canopy. Further investigation on the relationship of canopy density and retrieved $h_{\text {spc }}$ heights is suggested.

The InSAR and PolInSAR data utilized in this research were single- or multitakes data with small temporal baselines. However, most past studies have used repeatpass spaceborne InSAR/PollnSAR data with a significant time delay (e.g., 46 days for ALOS PalSAR L-band repeat pass InSAR) between collections. Repeat-pass experience two significant problems: uncompensated residual sensor motion and temporal decorrelation. The former generates systematic errors in the DTM and DSM in the alongtrack direction; while the latter degrades the accuracy of both canopy height and bare ground elevations. Analyses of a number of sources of decorrelation have been conducted (e.g., Wegmuller and Werner, 1995; Lee et al., 1994; Zebker and Villasenor, 1992) and could be applied to repeat-pass InSAR techniques. Alternatively, the Tandem-X mission will derive multi-pass global InSAR derived DSM data with little temporal decorrelation in phase because of the short temporal baseline (less than one day), merging of multi-data takes, and varied interferometric baselines. Additional research is required to understand the types of accuracies possible from spaceborne data sets becoming available at global scales.

Previous research has demonstrated the ability of InSAR coherence data to improve land cover classification results (Engdahl et al., 2001; Blaes and Defourny, 2003; Bales et al., 2005). Additional research on the integration of interferometric coherence with InSAR phase, and multi-frequency SAR backscatter information may be useful in characterizing horizontal forest, wetlands, and shrub vegetation structure and the distribution of crown density and biomass. The Intermap supplied coherence data were 
not used in this research because they were not radiometrically balanced across swath. As a result, tonal variations from NR to FR created variations in the coherence tones that were not reflective of land cover, rather viewing geometry, and thus not usable in land cover classification.

The empirical method presented in this research requires land cover, in particular, vegetation type for the application of the vegetation bias correction factors. While the use of $h_{\text {spc }}$ in object-based classification provided a clear distinction between barren, shrub, and forest species, discrimination of vegetation classes is still somewhat challenging when using SAR imagery alone. Others have found that land cover types that are impossible to separate in SAR images might be distinguishable with optical images and vice versa because of the complementary information contained in the two datasets (Amarsaikhan and Douglas, 2004). SAR imagery captures the physical structure and dielectric properties of the Earth's surface materials, while multi-spectral optical imagery contains information on surface reflectance and emissivity characteristics. Many approaches integrating both SAR and optical imagery have been explored for land cover classification receiving significantly better results than those obtained from using an individual sensor, particularly for certain land cover types such as agriculture (Blaes et al., 2005), wetlands ( $\mathrm{Li}$ and Chen, 2005), and desert vegetation (Shupe and Marsh, 2004). Further investigation into the combined use of SAR and optical data is suggested.

The existence of, or the opportunity to collect field observations as reference data to validate ground surface elevations (DTMs), as was implemented in this research, is generally limited in operational applications. In the absence of in situ validation measurements, the spaceborne GLAS LiDAR instrument onboard ICESat could be useful 
if data are available (Lee et al., 2011). This was considered for this research, but the time to process the ICESat data to extract additional bare ground and canopy height reference data for the six research sites was too prohibitive. In general, though, LiDAR data, whether airborne or satellite based, can provide excellent ground and canopy height reference data to contribute to both canopy height estimation and validation.

\subsection{Comparison to Other InSAR/PolInSAR Canopy Height Estimate Methods}

Methods for estimating canopy height from SAR vary. The two methods presented in this research subtracted the InSAR DSM (method \#1) and PolinSAR RVoG DSM (method \#2) from a reliable DTM and then used discrete empirical correction factors for classified vegetation objects and at gaps/edges. This approach was chosen because of the availability of high resolution X-HH InSAR and L-Quad PolInSAR data, and the need to have improvements at vegetation-non-vegetation boundaries and within the interior canopies. Others have corrected $h_{\text {spc }}$ based on its regression against reference data (e.g. Kellndorfer et al., 2004; Sexton et al., 2009 for SRTM data), however, the results were worse. Future work could involve the assessment of similar regression methods, in lieu of applying the correction factors, using the datasets presented here. Another SAR canopy height estimation approach compares the difference in sensitivity of dual frequency SAR (e.g. X-band $\sim \mathrm{DSM}$ and P-band $\sim \mathrm{DTM}$ ) differences to estimate canopy height. Continued empirical studies using InSAR and PolInSAR techniques to extraction vegetation biophysical parameters are necessary to understand various methods' sensitivities and comparability for various forest types and their applicability at national to global mapping scales. 


\section{REFERENCES}

Abney, 2007. http://www.scribd.com/doc/42526655/Abney-Level. Accessed June 2007. Agenzia Spaziale Italiana, 2007. COSMO-SkyMed System Description \& User Guide, Doc.ASI-CSM-ENG-RS-093-A; Technical Report; ASU/Agenzia Spaziale Italiana, p. 46.

Amarsaikhan, D., and T. Douglas, 2004. Data fusion and multisource image classification, International Journal of Remote Sensing, 25(17):3529-3539.

Andersen, H-E, R. J. McGaughey, W. W. Carson. S. E. Reutebuch, B. Mercer, and J. Allen, 2004. A comparison of forest canopy models derived from LiDAR and InSAR data in a pacific northwest conifer forest, International Archives of Photogrammetry and Remote Sensing, 34(Commission III, WG, III/3):211-217.

Andersen, H.-E., R.J. McGaughey, and S. E. Reutebuch, 2005a. Estimating forest canopy fuel parameters using LiDAR data, Remote Sensing of Environment, 94:441-449.

Andersen, H.-E., S.E. Reutebuch, and R.J. McGaughey. 2005b. Accuracy of an IFSARderived digital terrain model under a conifer forest canopy, Canadian Journal of Remote Sensing, 31(4):283-288.

Andersen, H. E., S. E. Reutebuch, and R. J. McGaughey, 2006. A rigorous assessment of tree height measurements obtained using airborne LIDAR and conventional field methods, Canadian Journal of Remote Sensing, 32(5):355-366.

Andersen, H. E., S. E. Reutebuch, and R. J. McGaughe, 2007. A rigorous assessment of tree height measurements obtained using airborne LiDAR and conventional field methods, Canadian Journal of Remote Sensing, 32(5):355-366. 
Andersen, H. -E., R. J. McGaughey, and S. E. Reutebuch, 2008. Assessing the influence of flight parameters, interferometric processing, slope and canopy density on the accuracy of X-band IFSAR-derived forest canopy height models, International Journal of Remote Sensing, 29(5):1495-1510.

Askne, J., P. B. G. Dammert, and G. Smith, 1997. Interferometric SAR observations of forested areas, Proceeding 3rd ERS Symposium Space at the Service of Our Environment, Florence, Italy.

Balzter, H., 2001. Forest mapping and monitoring with interferometric synthetic aperture radar (InSAR) progress, Physical Geography, 25(2):159-177.

Balzter, H., P. Saich, A. J. Luckman, L. Skinner, and J. Grant, 2001. Forest stand structure from airborne polarimetric InSAR, Proceedings of the 3rd International Symposium on Retrieval of Bio- and Geophysical Parameters from SAR Data for Land Applications (LANDSAR 2001), Sheffield, ESA-SP 475:321-326.

Balzter, H., C.S. Rowland, and P. Saich, 2007a. Forest canopy height and carbon estimation at Monks Wood National Nature Reserve, UK, using dual-wavelength SAR interferometry, Remote Sensing of Environment, 108:224-239.

Balzter, H., A. Luckman, L. Skinner, C. Rowland, and T. Dawson, 2007b. Observations of forest stand top height and mean height from interferometric SAR and LiDAR over a conifer plantation at Thetford Forest, UK, International Journal of Remote Sensing, 28(6):1173-1197.

Bamler, R. 1999. The SRTM Mission: A world-wide $30 \mathrm{~m}$ resolution DEM from SAR interferometry in 11 days, Photogrammetric Week, pp. 145-154. 
Bamler, R. and P. Hartl, 1998. Synthetic aperture radar interferometry, Inverse Problems, 14:1-54.

Bamler, R., N. Adam, S. Hinz, and M. Eineder, 2008. SAR-Interferomterie fur geodatische Anwendungen. Allgemeine Vermessungs-Nachrichten, 7:243-252.

Barron, R.J. 2001. Precision of three tree height measuring devices in forest conditions, Research Note, No. 1, Northern Ireland Forest Service.

Becek, K., 2008. Investigation of elevation bias of the SRTM C- and X-Band digital elevation models, Proceedings of The International Archives of the Photogrammetry, Remote Sensing and Spatial Information Sciences, Vol. XXXVII, Part B1. Beijing, China, pp. 105-110.

Benz, U. C., P. Hofmann, G. Willhauck, I. Lingenfelder, and M. Heynen, 2004. Multiresolution, object-oriented fuzzy analysis of remote sensing data for GIS-ready information, ISPRS Journal of Photogrammetry and Remote Sensing, 58:239258.

Benz, U and E. Pottier, 2001. Object Based analysis of polarimetric SAR Data in alphaentrophy-anisotropy decomposition using fuzzy classification by eCognition, IEEE Transactions on Geoscience and Remote Sensing, 3:1427- 11429.

Bentz, J., A., Saxena and R. Schultz. 1994. Biophysical inventory of shoreland areas Burnstick Lake, Alberta, Prepared for Alberta Environmental Protection by Geowest Environmental Consultants Ltd.

Blaes, X., and P. Defourny, 2003. Retrieving crop parameters based on tandem ERS 1/2 interferometric coherence images, Remote Sensing of Environment, 88:374-385. 
Blaes, X., L. Vanhalle, and P. Defourny, 2005. Efficiency of crop identification based on optical and SAR image time series, Remote Sensing of Environment, 96:352-365.

Blaschke, T. and J. Strobl, 2001. What's wrong with pixels? some recent developments interfacing remote sensing and GIS, GIS, 6:12-17.

Boerner, W.M., 2008. Recent advances in polarimetric and interferometric radar remote sensing, $7^{\text {th }}$ European Conference on Synthetic Aperture Radar (EUSAR), pp. 1-4.

Bonan, G., B. 2008. Forests and climate change: forcing, feedbacks, and the climate benefits of forests, Science, 320(5882):1444-1449.

Brown, C. G. K. Sarabandi, and L. E. Pierce, 2005. Validation of the Shuttle Radar Topography Mission Height Data, IEEE Transactions on Geoscience and Remote Sensing, 43(8):1707- 1715 .

Boyer, S. E. and D. Elliott, 1982. Thrust systems, American Association of Petroleum Geologist Bulletin, 66:1196-1230.

Bresnahan, P. C., 2009. Absolute geo-location accuracy evaluation of TerraSAR-X-1 spotlight and strip-map imagery study results, Proceedings Civil Commercial Imagery Evaluation Workshop. Fairfax, VA, USA.

Breidenbach, J., B. Koch, G. Kandler, and A. Kleusberg, 2008. Qualifying the influence of slope, aspect, crown shape, and stem density on the estimation of tree height at plot level using LiDAR and InSAR, International Journal of Remote Sensing, 29(5):1511-1536.

- Brod, L. G., 2005. Geology of selected areas, Sawmill Canyon fault zone Northeast Santa Cruz Count, Arizona, Arizona Geological Survey Contributed Report Series, http://repository.azgs.az.gov/uri_gin/azgs/dlio/428, 48 pages. 
Brown, C. G., and K. Sarabandi, 2003. Estimation of red pine tree height using shuttle radar topography mission and ancillary data, IEEE: 2850-2852.

Capaldo, P., M. Crespi, F. Fratarcangeli, A. Nascetti, and F. Pieralice, 2011. Highresolution SAR radargrammetry: a first application with COSMO-SkyMed spotlight imagery, IEEE Geoscience and Remote Sensing Letters, 8(6):11001104.

Carabajal, CC. and D. J. Harding, 2005. ICESat validation of SRTM C-band digital elevation models, Geophysical Research Letters, 32(L22S01).

Carabajal, C.C. and D. J. Harding, 2006. SRTM C-band and ICESat laser altimetry elevation comparisons as a function of tree cover and relief, Photogrammetric Engineering and Remote Sensing, 72(3):287-298.

Chapman, E., S. Hensley, and D. Moller, 1999. Calibration of the GEOSAR dual frequency interferometric SAR, SAR Workshop: CEOS Committee on Earth Observation Satellites; Working Group on Calibration and Validation, Proceedings of a Conference held 26-29 October, Toulouse, France.

Chen, Q., 2010. Retrieving vegetation height of forests and woodlands over mountainous areas in the Pacific Coast region using satellite laser altimetry, Remote Sensing of Environment, 114:1610 - 1627.

Cloude, S., and D. Corr, 2003. Tree height retrieval using single baseline polarimetric interferometry, in PolInSAR ESA Workshop, Frascati, Italy.

Cloude, S. R. and K. P. Papathanassiou, 1997. Polarimetric optimization in radar interferometry, Electronic Letters, 33(13):1176-1178. 
Cloude, S. R., and K. P. Papathanassiou, 1998. Polarimetric SAR interferometry, IEEE Transactions on Geoscience and Remote Sensing, 36(5):1551-1565.

Cloude, S. R. and K. P. Papathanassiou, 2003. A 3-Stage inversion process for polarimetric SAR interferometry, Proceedings of European Conference on Synthetic Aperture Radar, EUSAR, pp. 279-282, and Proceedings Institute Electrical Engineering, Radar, Sonar Navigation, 150(3):125-134.

Cloude, S. and D. Corr, 2003. Tree height retrieval using single baseline polarimetric interferometry, in Polinsar ESA Workshop, Frascati, Italy.

Congalton, R. G., 1991. A review of assessing the accuracy of classifications of remotely sensed data, Remote Sensing of Environment, 37:35-46.

Corr, D.G., A. Walker, U. Benz, I. Lingenfelder, and A. Rodriguez, 2003. Classification of urban SAR imagery using object oriented techniques, IEEE International Conference on Geoscience and Remote Sensing Symposium IGRASS, 1:188 190.

Cruickshank, M. M., R W Tomlinson, and S Trew, 2000. Application of CORINE landcover mapping to estimate carbon stored in the vegetation of Ireland, Journal of Environmental Management, 58(4):269-287.

Curlander, J.C., and R.N. McDonough, 1991. Synthetic Aperture Radar System and Signal Processing, John Wiley and Sons Press, New York, pp. 671-672.

Dominy, N. J. and B. Duncan. 2001. GPS and GIS methods in an African rain forest: applications to tropical ecology and conservation. Conservation Ecology 5(2): 6. [online] URL: http://www.consecol.org/vol5/iss2/art6/. 
De Jong, S.M., T. Hornstra, and H. Maas, 2001. An integrated spatial and spectral approach to the classification of Mediterranean land cover types: the SSC method, International Journal of Applied Earth Observation and Geoinformation, 3(2):176-183.

Dobson, M. C., F. T. Ulaby, T. Le Toan, A. Beaudoin, E. S. Kasischke, and N. Christensen, 1992. Dependence of radar backscatter on coniferous forest biomass, IEEE Transactions on Geoscience and Remote Sensing, 30(2):412-415.

Dowman, I., P. Balan, K. Renner and P. Fischer, 2003. An evaluation of NEXTMap terrain data in the context of UK national datasets, University College London, Department of Geomatic Engineering, Report on the evaluation of NEXTMap Terrain Data in context of UK National Datasets, 19 p. http://www.intermap.com/uploads/1170362281.pdf.

Dowman I, and P. Fisher, 2003. Evaluation of IfSAR and LiDAR data for flood risk assessment, Proceedings of ISPRS Joint Workshop of ISPRS WG I/3 and II/2, Three dimensional Mapping from InSAR and LIDAR, Portland Oregon, USA $17^{\text {th }}$ - 19th June 2003. CDROM.

Drake, J., R. Dubayah, D. Clark, R. Knox, J. Blair, M. Hofton, R. Chazdon, J. Weishample, and S. Prince. 2002. Estimation of tropical forest structural characteristics using large-footprint LiDAR, Remote Sensing of Environment, 79:305-319.

'Drewry, D. T., P. Kimar, S. Long, C. Bernacchi, X. Z. Liang, and M. Sivapalan, 2010. Ecohydrological responses of dense canopies to environmental variability: 1 . 
interplay between vertical structure and photosynthetic pathway, Journal of Geophysical Research, 115(GO4022).

Dutra, L.V., J. R. dos Santos, C.C. Freitas, J. C. Mura, T. Neeff, M. A. T. Elmiro, and P. Moura, 2006. Digital Height Modeling (DHM) of Tropical Forests Using Multifrequency InSAR Methodology, IEEE International Conference on Geoscience and Remote Sensing Symposium IGRASS, pp. $2190-2192$.

Dwivedi, R.S., S. Kandrika, and K.V. Ramana, 2004. Comparison of classifiers of remote-sensing data for land-use/land-cover mapping, Current Science, $86(2): 328-335$.

Ecological Provinces, 1999. Ecological classification system, Minnesota Department of Natural Resources. Retrieved on 2009-09-03.

Eineder, M., B. Rabus, J. Holzner, S. Suchandt, and W. Knopfle, 2002. Filtering of interferometric SRTM X-SAR data, IEEE Geoscience and Remote Sensing Symposium, 1:164-166.

Elachi, C., 1988. Spaceborne Radar Remote Sensing: Applications and Techniques. New York: IEEE Press, 288p.

Engdahl, M.E. and J. M. Hyyppa, 2003. Land-cover classification using multi-temporal ERS-1/2 InSAR data, IEEE Transactions on Geoscience and Remote Sensing, 41(7):1620 - 1628.

Engdahl, M.E., M. Borgeaud, and M. Rast, 2001. The use of ERS-1/2 Tandem interferometric coherence in the estimation of agricultural crop heights, IEEE Transactions on Geoscience and Remote Sensing, 39(8):1799-1806. 
Enderle, D, and R.C. Weih, Jr., 2005. Integrating supervised and unsupervised classification methods to develop a more accurate land cover classification, Journal of the Arkansas Academy of Science, 59:65-73.

ENVI, 2007. ENVI object-based classification software manuals, (www.ittvis.com).

Evans, D. L., T. G. Farr, H. A. Zebker, J. J. van Zyl, and P. J. Mouganis-Mark. 1992. Radar interferometry studies of the Earth's topography, EOS Transactions, American Geophysical Union, 73(52):553p.

Farrell, J., T. Givargis, and M. Barth, 1999. Differential carrier phase GPS-aided INS for automotive applications. Proceedings of the American Control Conference, San Diego, CA, June 1999.

Feddema, J. J., K. W. Oleson, G. B. Bonan, L. O. Mearns, L. E. Bula, G. A. Meehl, and W. M. Washington, 2005. The importance of land-cover change in simulating future climates, Science, 310:1674 - 1678 .

Fensham, R.J., R. J. Fairfax, and J. E. Holman, 2002. Quantitative assessment of vegetation structural attributes from aerial photography, International Journal of Remote Sensing, 23(11):2293-2317.

Fisher, J.I., G. C. Hurtt, R. Q. Thomas, and J. Q. Chambers, 2008. Clustered disturbances lead to bias in large-scale estimates based on forest sample plots, Ecology Letters, 11:554-563.

Fleiss, J. L., and J. E. Cohen, 1969. Large sample standard errors of kappa and weighted kappa, Psychological Bulletin, 72(5):323-327.

Foody, G. M., 2002. Status of land cover classification accuracy assessment, Remote Sensing of Environment, 80:185-201. 
Foody, G. M., 2004. Thematic map comparison: evaluating the statistical significance of differences in classification accuracy, Photogrammetric Engineering and Remote Sensing, 70:627-633.

Fry, J. A., G. Xian, S. Jin, J. A. Dewitz, C. G. Homer, L. Yang, C. A. Barnes, N. D. Herold, and J. D. Wickham, 2011. Completion of the 2006 national land cover database for the conterminous United States, Photogrammetric Engineering and Remote Sensing, 77(9):858 - 864.

Franklin, S.E. 2001. Remote Sensing for Sustainable Forest Management. CRC Press, Florida, Edition 1, 421p.

Franklin, S.E., R. J. Hall, L. Smith, and G. R. Gerylo, 2003. Discrimination of conifer height, age, and crown closure classes using Landsat-5 TM imagery in the Canadian Northwest Territories, International Journal of Remote Sensing, 24(9):1823-1834.

Gamon, J. A, C. B. Field, M. L. Goulden, K. L. Griffin, A, E. Hartley, G. Joel, J. Penuelas, and R. Valentine, 1995. Relationships between NDVI, canopy structure, and photosynthesis in three California vegetation types, Ecological Applications, $5(1): 28-41$.

Garestier, F., P. Dubois-Fernandez, I. Champion, and T. Le Toan, 2011. Pine forest investigation using high resolution P-band Pol-InSAR data, Remote Sensing of Environment, 115(11):2897-2905.

Geńs, R., 2002. Introduction to SAR Interferometry. Presentation given at the University of Fairbanks, accessed on June 19, 2010 by $R$. Gens. http://www.asf.alaska.edu/ rgens/teaching/asf_seminar/intro_insar.pdf. 
Gesch, D., M. Oimoen, S. Greenlee, C. Nelson, M. Steuck, and D.Tyler, 2002. The national elevation dataset, Photogrammetric Engineering and Remote Sensing, $68: 5-11$.

Goetz, S.J., S.D. Prince, M.M. Thawley, A.J. Smith, R. Wright, and M. Weiner, 2000. Applications of multi-temporal land cover information in the mid-Atlantic region:

a RESAC initiative, Proceedings of the International Geoscience and Remote Sensing Symposium, Honolulu, Hawaii, 1:357-359.

Graham L.C., 1974. Synthetic interferometric radar for topographic mapping, Proceedings of the IEEE, 62(6):763-770.

Gray, A. L., and P. J. Farris-Manning, 1993. Repeat-pass interferometry with airborne synthetic aperture radar, IEEE Transactions Geoscience Remote Sensing, 31(1):180-191.

Haack, B.N., N.D. Herold, and M.A. Bechdol, 2000. Radar and optical data integration for land-use/land-cover mapping, Photogrammetric Engineering and Remote Sensing, 66(6):709-716.

Hagberg, J., M. Ulander, and J. Askne, 1995. Repeat-pass SAR interferometry over forest terrain, IEEE Transactions on Geoscience and Remote Sensing, 22(2):331-340.

Hajnsek, I., F. Kugler, J. P. Papathanassiou, R. Horn, R. Scheiber, A. Moreira, D. Hoekman, and M. Davidson, 2005. INDREX II - Indonesian airborne radar experiment campaign over tropical forest in L- and P-band: first results, IEEE International Conference on Geoscience and Remote Sensing Symposium IGRASS,, pp. 4335-4338. 
Hajnsek, I., F. Kugler, S-K Lee, and J. P. Papathanassiou, 2009. Tropical forest parameter estimation by means of PolInSAR: the INDREX-II campaign, IEEE Transactions on Geoscience and Remote Sensing, 47(2):481-493.

Hall, F.G., K.F. Huemmrich, D.E. Strebel, S.J. Goetz, J.E. Nickeson, and K.D. Woods, July 1992. Biophysical, morphological, canopy optical property, and productivity data from the Superior National Forest, NASA Technical Memorandum 104568, National Aeronautics and Space Administration, Washington, D.C.

Harding, D. J., and C. C. Carabajal, 2005. ICESat waveform measurements of within footprint topographic relief and vegetation vertical structure, Geophysical Research Letters, 32(L21S10):4p.

Henderson, F. M., A. J. Lewis, 1998. Principles and Applications of Imaging Radar, Manual of Remote Sensing, Third Edition, Volume 2, American Society of Photogrammetry and Remote Sensing, John Wiley and Sons, Incorporated, New York, $866 \mathrm{p}$.

Hensley, S., P. Rosen, and F. Gurrola, 2000. Topographic map generation for the shuttle radar topography mission C-band SCANSAR interferometry, Proceedings of SPIE, Microwave Remote Sensing of the Atmosphere and Environment II, 4152:179.189.

Hensley. S., R. Munjy, and P. A. Rosen, 2001. Interferometric synthetic aperture radar (IFSAR), digital elevation model technologies and applications: the DEM users' manual, ASPRS, Chapter 6:174-176. 
Hodgson, M., J. Jensen, L. Schmidt, S. Schill, and B. Davis, 2003. An evaluation of LIDAR- and IFSAR-derived digital elevation models in leaf on conditions with USGS Level 1 and Level 2 DEMs, Remote Sensing of Environment, 84:295-308. Homer, C., C. Huang, L. Yang, B. Wylie, and M. Coan, 2004. Development of a 2001 national land-cover, Photogrammetric Engineering and Remote Sensing, 70(7):829-840.

Homer, C., J. Dewitz, J. Fry, M. Coan, N. Hossain, C. Larson, N. Herold, A. McKerrow, J. N. VanDriel, and J. Wickham, 2007. Completion of the 2001 national land cover database for the conterminous United States, Photogrammetric Engineering and Remote Sensing, 73(4):337-341.

Huang, H., J. Legarsky, M. Othman, 2007. Land-cover classification using Radarsat and Landsat imagery for St. Louis, Missouri, Photogrammetric Engineering and Remote Sensing, 73(1):37-43.

Hyyppä, J., U. Pyysalo, H. Hyyppä, and A. Samberg, 2000. Elevation accuracy of laser scanning-derived digital terrain and target models in forest environment, Proceedings of the EARSeL-SIG Workshop on LIDAR, eProceedings, 1:39-147.

Hyde, P., R. Dubayah, W. Walker, J. B. Blair, M. Hofton, and C. Hunsaker, 2006. Mapping forest structure for wildlife habitat analysis using multi-sensor (LiDAR, SAR/InSAR, ETM plus, Quickbird) synergy, Remote Sensing of Environment, 102(1-2):63-73.

Intermap Product Handbook, 2011. http://info.intermap.com/product-handbook.html? site=-product-handbook 
Izzawati, E. D. Wallington, and I. H. Woodhouse, 2006. Forest height retrieval from commercial X-band SAR products, IEEE Transactions on Geoscience and Remote Sensing, 44:863-870.

Jensen, J: R., 2005. Introductory Digital Image Processing: A Remote Sensing Perspective, Pearson Prentice Hall, NJ, 526 p.

Joughin, I., L. Gray., R. Bindschadler, S. Price, D. Morse, C. Hulbe, K. Mattar, and C. Werner, 1999. Tributaries of west Antarctic ice streams revealed by RADARSAT interferometry, Science, New Series, 286(5438):283-286.

Kellndorfer, J.M., L. E. Pierce, M. C. Dobson, M.C., and F. T. Ulaby, 1998. Toward consistent regional-to-global-scale vegetation characterization using orbital SAR systems, IEEE Transactions on Geoscience and Remote Sensing, 36:1396-1411

Kellndorfer, J., W. Walker, L. Pierce, C. Dobson, J. A. Fites, C. Hunsaker, J. Vona, and M. C. Clutter, 2004. Vegetation height estimation from shuttle radar topography mission and national elevation datasets, Remote Sensing of the Environment, 93:339-358.

Kenyi, L. W., R. Dubayah, M. Hofton, and M. Schardt, 2009. Comparative analysis of SRTM-NED vegetation canopy height to LIDAR-derived vegetation canopy metrics, International Journal of Remote Sensing, 30(11):2797-2811.

Kleidon, A., 2012. How does the earth system generate and maintain thermodynamic disequilibrium and what does it imply for the future of the planet?, Philosophical Transactions of The Royal Society, 370:1012-1040. 
Kumar, S. 2009. Retrieval of forest parameters from Envisat ASAR data for biomass inventory in Dudhwa National park, U.P., India, 101 p. http://www.itc.nl/library/papers 2009/msc/gfm/kumar shashi.pdf.

Kobayashi, Y., K. Sarabandi, L. Pierce, and M. C. Dobson, 2000. An evaluation of the JPL TOPSAR for extracting tree heights, IEEE Transactions on Geoscience and Remote Sensing, 38:2446-2453.

Krieger, G., A. Moreira, H. Fiedler, I. Hanhsek, M. Werner, M. Younis, and M. Zink. 2007. TanDEM-X: a satellite formation for high-resolution SAR interferometry, IEEE Transactions on Geoscience and Remote Sensing, 45(1):3317- 3341.

LANDFIRE, 2010. http://www.landfire.gov/.

Lee, J.-S., K. W. Hoppel, S. A. Mango, and A. R. Allen, 1994. Intensity and phase statistics of multi-look polarimetric and interferometric SAR imagery, IEEE Transactions Geoscience and Remote Sensing, 32(5):1017-1027.

Lee, J-S, and R. Pottier, 2009. Polarimetric Radar Imaging from Basics to Applications, CRC Press, Taylor and Francis Group; New York, 298p.

Lee, S. W. Ni-Meister, W. Yang, and Q. Chen, 2011. Physically based vertical vegetation structure retrieval from ICESat data: validation using LVIS in White Mountain National Forest, New Hampshire, USA, Remote Sensing of Environment, 115:2776-2785.

Le Toan, T., S. Quegan, I. Woodward, L. Mark, D. Nicolas, and P. Ghislain, 2004. Relating radar remote sensing of biomass to modeling of forest carbon budgets, Climatic Change, 67:379-402. 
Le Toan, T., S. Quegan, M.W.J. Davidson, H. Balzter, P. Paillou, K. Papathanassiou, S. Plummer, F. Rocca, S. Saatchi, H. Shugart, and L. Ulander, 2011. The BIOMASS mission: mapping global forest biomass to better understand the terrestrial carbon cycle, Remote Sensing of Environment, 115:2850-2860.

Lefsky, M. A., W. B. Cohen, G. G. Parker, and D. J. Harding, 2002. LiDAR remote sensing for ecosystem studies, BioScience, 52:19-30.

Lefsky, M. A., M. Keller, Y. Pang, P. de Camargo, and M. O. Hunter, 2007. Revised method for forest canopy height estimation from the geoscience laser altimeter system waveforms, Journal of Applied Remote Sensing, 1(013537):18p.

Li, F., and R. Goldstein, 1990. Studies of multi-baseline spaceborne interferometric synthetic aperture radars, IEEE Transactions on Geoscience and Remote Sensing, 28(1):88- 97 .

Li, H., and W. Chen, 2005. A rule-based method for mapping Canada's wetlands using optical, radar and DEM data, International Journal of Remote Sensing, 26(22):5051-5069.

Lillesand, T. M. R.W. Kiefer, and J. Chipman, 2008. Remote, Sensing and Image Interpretation, 6th Edition, John Wiley and Sons, New York, 756 pp.

Lister, A., 2005. Converting GPS data to NAD83 from NAD27, http://www.fs.fed.us/database/gps/datum/index.htm.

Luckman, A., J. Baker, and U. Wegmuller, 2000. Repeat-pass interferometric coherence measurements of disturbed tropical forest from JERS and ERS Satellites, Remote Sensing of Environment, 73:350-360. 
Madsen, S.N., H. A. Zebker, and J. Martin, 1993. Topographic mapping using radar interferometry: processing techniques, IEEE Transactions on Geoscience and Remote Sensing, 31:246-256.

Martinez, J-M., N. Floury, T. Le Toan, A. Beaudoin, M. T. Hallikainen, and M. Mäkynen, 2000. Measurements and modeling of vertical backscatter distribution in forest canopy, IEEE Transactions on Geoscience and Remote Sensing, 38(2):710-719.

Matikainen, L., J. Hyyppa, and M.E. Engdahl, 2006. Mapping built-up areas from multitemporal interferometric SAR images - a segment-based approach, Photogrammetric Engineering and Remote Sensing, 72(6):701-714.

Maune, D.F., 2007. Digital Elevation model Technologies and Applications: The DEM Users Manual, 2nd Edition, ASPRS, 621 pages.

Maune, D. F., 2009. Personal communication.

McInerney, D. O., J. Suarez-Minguez, R. Valbuena, and M. Nieuwenhuis, 2010. Forest canopy height retrieval using LiDAR data, medium resolution satellite imagery and knn estimation in Aberfoyle, Scotland, Forestry, 85(3):437-444.

Means, J.E., S. A. Acker, B. J. Fitt, M. Renslow, L. Emerson, L., and C. J. Hendrix, 2000. Predicting forest stand characteristics with airborne scanning LiDAR, Photogrammetric Engineering and Remote Sensing, 66:1367-1371.

Mercer, B. 2001. Comparing LIDAR and InSAR: What can you expect? Fritsch/Spiller, eds. Proceedings of the Photogrammetric Week, Stuttgart, Germany, pp. 2-10. 
Mercer, B., 2004, DEMs created from airborne IFSAR - an update, International Archives of the Photogrammetry, Remote Sensing and Spatial Information Sciences, Istanbul, Turkey, Vol. XXXV, Part B, CD-ROM.

Mercer, B., Q. Zhang, and P. Lumsden, 2007a. L- and P-Band polarimetric InSAR for DEM extraction beneath the tropical canopy using INDREX-II data sets, Proceedings of ASAR, Vancouver Canada.

Mercer, B, 2007b. National and Regional Scales DEMS Created from Airborne InSAR, In: Stilla U et al (Eds) PIA07. International Archives of Photogrammetry, Remote Sensing and Spatial Information Sciences, 36(3/W49B):113 - 117.

Mercer, B., Q. Zhang, M. Denbina, M. Schwaebisch, and S. Cloude, 2009a. DTM extraction beneath forest canopy at L-band from experimental single-pass airborne PolInSAR system, PolInSAR 2009, ESA.

Mercer, B., Q. Zhang, . Schwaebisch, and M. Denbina, M. Schwaebisch, 2009b. 3D topography and forest recovery from an L-BAND single-pass airborne PolInSAR system. IEEE Geoscience and Remote Sensing Symposium (IGARSS), pp. III-33 - III-36.

Mikhail, E. M., J. S. Bethel, and J. C. McGlone, 2001. Introduction to Modern Photogrammetry, Volume 1, John and Wiley \& Sons, NY, 479 p.

Miller, D.R., C.P. Quine, and W. Hadley, 2000. An investigation of the potential of digital photogrammetry to provide measurements of forest characteristics and abiotic damage, Forest Ecology and Management, 13(5):279-288. 
Moreira, A., G. Krieger, I. Hajnsek, M. Werner, D. Hounam, S. Riegger, and E. Settelmeyer, 2004. TanDEM-X: A TerraSAR-X add-on satellite for single-pass SAR interferometry, IGARSS, pp. 1000-1003.

Morey, G.B., 1967, Stratigraphy and petrology of the type Fond du Lac Formation Duluth, Minnesota, Minnesota: Minnesota Geological Survey Report of Investigations 7:35 p.

Mulcare, D. M., 2004. North American Datum Conversion Utility, Geodetic Toolkit: NADCON, Profession Survey Magazine, 24(2), http://www.profsurv.com/magazine/article âspx?i=1193.

NAIP, 2011. National Agriculture Image Program (NAIP), accessed on January 01 of 2007, September 04 of 2009, and January 03 and April 10 of 2011, http://www.fsa.usda.gov/Internet/FSA_File/naip_2009_info_final.pdf.

Næsset, E., 2002. Predicting forest stand characteristics with airborne scanning laser using a practical two-stage procedure and field data. Remote Sensing of Environment, 80:88-99.

Neeff, T., L.V. Dutra, J.R. dos Santos, C.C. Freitas, and L.S. Araujo. 2005. Tropical forest measurement by interferometric height modeling and P-Band radar backscatter, Forest Science, 51(6):585-594.

Neil, B. H., 2005. Glasser Field Technique in Glaciology and Glacial Geomorphology, John and Sons, 400p.

NGS (National Geodetic Survey), 2003, GPS on bench marks for GEOID03, URL:http://www.ngs.noaa.gov/GEOID/GPSonBM03/index.html.

NED, 2011. Vertical Accuracy of the National Elevation Dataset. 
Neumann, M., L. Ferro-Famil, and A. Reigber, 2010. Estimation of Forest Structure, Ground, and Canopy Layer Characteristics From Multi-baseline Polarimetric Interferometric SAR Data, IEEE Transactions on Geoscience and Remote Sensing, 48(3):1086 - 1104.

NOAA, 2011. Global Land Cover, http://sos.noaa.gov/datasets/Land/land cover.html.

Olmsted, C. 1993. Alaska SAR facility scientific SAR's user guide, ASF-SD-003:53p. www.alaska.boenre.gov/icam/1994/z/94icam99-106.pdf.

Parcharidis, I., M. Foumelis, and E. Lekkas, 2005. Implication of secondary geodynamic phenomena on co-seismic interferometric coherence, advances in SAR interferometry from ENVISAT and ERS missions, ESA ESRIN, 28 November-2 December, Frascati, Italy.

Paine, D. P., and J. D. Kiser, 2003. Aerial Photography and Image Interpretation, John Wiley \& Sons, 672p.

Pang, Y., M. Lefsky, G. Suri, and J. Ranson, 2011. Impact of footprint diameter and offnadir pointing on the precision of canopy height estimates from spaceborne LiDAR, Remote Sensing of Environment, 115(11):2798-2809.

Papathanassiou, K. P., and S. R. Cloude, 2001. Single-baseline polarimetric SAR interferometry, IEEE Transactions on Geoscience and Remote Sensing, 39(11):2352-2363.

Papathanassiou, K. and S. R. Cloude. 2004. Forest height estimation using dualpolInSAR configurations, EUSAR2004, Ulm, Germany, Proceedings EUSAR, Vol. 1:93-96. 
Papathanassiou, K.P., S.R. Cloude, A. Liseno, T. Mette, and H. Pretzsch, 2005. Forest height estimation by means of polarimetric SAR interferometry: actual status and perspectives, Proceedings of 2nd ESA PolInSAR Workshop, Frascati, Italy, http://earth.esa.int/workshops/polinsar2005/.

Quegan, S, T. Le Toan, J. J. Lu, F. Ribbes, and N. Floury, 2000. Multi-temporal ERS SAR analysis applied to forest mapping, Transactions on Geoscience and Remote Sensing, 38(2):741-753.

Ranson, K. J., S. Saatchi, and G. Sun, 1995, Boreal forest ecosystem characterization with SIR-C/X-SAR, IEEE Transactions Geoscience Remote Sensing, 33(4):867876.

Rabus, B, M. Eineder, A. Roth, and R. Bamler, 2003. The shuttle radar Topography mission-a new class of digital elevation models acquired by spaceborne radar, ISPRS Journal Photogrammetry and Remote Sensing, 57(4):241-262.

Ricchetti, E. 2005. Comparison of satellite imagery DEMs produced using photogrammetry and radargrammetry techniques, IEEE International Geoscience and Remote Sensing Symposium IGRASS, 4:2903-2906.

Rieger, W., M. Kerschner, T. Reiter, and F. Rottensteiner, 1999. Roads and buildings from laser scanner data within a forest enterprise, International Archives of Photogrammetry and Remote Sensing, La Jolla, CA, XXXII/3-W14:185-191.

Rignot, E., K., Echelmeyer, and W. Krabill, 2001. Penetration depth of interferometric synthetic-aperture radar signals in snow and ice, Geophysical Research Letters, 28:3501-3504. 
Reutebuch, S.E., R. J. McGaughey, H. E. Andersen, and W. W. Carson, 2003. Accuracy of a high-resolution LiDAR terrain model under a conifer forest canopy, Canadian Journal of Remote Sensing, 29(5):527-535.

Richards, M. A., 2007. A beginners guide to interferometric SAR concepts and signal processing, IEEE Aerospace and Electronic Systems Magazine, 22(9):5-29.

Robinson, D. J., N. J., Redding, and D. J. Crisp, 2002. Implementation of a fast algorithm for segmenting SAR imagery, Scientific and Technical Report, 01, Australia: Defense Science and Technology Organization.

Rodriguez E. and J. M. Martin, 1992. Theory and design of interferometric synthetic aperture radars, IEE Proceedings, 139(2):147-159.

Rosen P.A., C. L. Werner, and A. Hiramatsu, 1994. Two-dimensional phase unwrapping of SAR interferograms by charge connection through neutral trees, IEEE International Geoscience and Remote Sensing Symposium IGRASS, JPL, Pasadena.

Rosen, P., M. Eineder, B. Rabus, E. Gurrola, S. Hensley, W. Knoepfle, H. Breit, and A. Roth, 2001a. SRTM mission cross comparison of X and C band data properties, IEEE International Geoscience and Remote Sensing Symposium IGRASS, 2:751753.

Rosen, P., S. Hensley, E. Gurrola, F. Rogez, S. Chan, J. Martin, and E. Rodriguez, 2001 b. SRTM C-band topographic data: quality assessments and calibration activities, IEEE International Geoscience and Remote Sensing Symposium IGRASS, 2:739741. 
Rowland, C. S. and H. Balzter, 2007. Data fusion for reconstruction of a DTM, under a woodland canopy, from airborne L-band InSAR, IEEE International Geoscience and Remote Sensing, 45(5):1154-1163.

Ryah, K. C., K. M., Lee, M. G. Rollins, Z. Zhu, J. Smith, and D. Johnson, 2006. LANDFIRE: landscape fire and resource management planning tools project, in Andrews, Patricia L.; Butler, Bret W., comps. 2006. Fuels Management-How to Measure Success: Conference Proceedings. 28-30, Portland, OR. Proceedings RMRS-P-41. Fort Collins, CO: U.S. Department of Agriculture, Forest Service, Rocky Mountain Research Station. p. 193-200.

Saatchi, S. and E. Rignot, 1997. Land cover classification of BOREAS modeling grid using AIRSAR images, Remote Sensing of Environment, 35:270-281.

Sala, O.E., F.S. Chapin III, J.J. Armesto, E. Berlow, J. Bloomfield, R. Dirzo, E. HuberSanwald, L.F. Huenneke, R.B. Jackson, A. Kinzig, R. Leemans, D.M. Lodge, H.A. Mooney, and D.H. Wall. 2000. Global biodiversity scenarios for year 2100, Science, 287:1770-1774.

Santoro, M., J. I. H. Askne, U. Wegmuller, and C. L. Werner, 2007. Observations, modeling, and applications of ERS-ENVISAT coherence over land surfaces, IEEE Transactions on Geoscience and Remote Sensing, 45(8):2600-2611.

Sarabandi, K. 1997. Delta k-radar equivalent of interferometric SAR's: a theoretical study for determination of vegetation height, IEEE Transactions on Geoscience and Remote Sensing, 35:1267-76. 
Sarabandi, K., and Y.C. Lin, 2000. Simulation of interferometric SAR response for characterization of scattering phase center statistics of forest canopies, IEEE Transactions on Geoscience and Remote Sensing, 38(1):115-125.

Schneider, R. Z., K. P. Papathanassiou, I. Hajnsek, and A. Moreira, 2006. Polarimetric and interferometric characterization of coherence scatters in urban areas, IEEE Transactions on Geoscience and Remote Sensing, 44(4):971-984.

Sexton, J. O., T. Bax, P. Siqueria. J. J. Swenson, and S. Hensley, 2009. A comparison of LiDAR, radar, and field measurements of canopy height in pine and hardwood forests of southeastern North America, Forest Ecology and Management, 257:1136-1147.

Shupe, S. M., and S. E. Marsh, 2004. Cover-and density-based vegetation classification of the Sonorant Desert using Landsat TM and ERS-1 SAR imagery, Remote Sensing of Environment, 93:131-149.

Simard M, K. Zhang, V. Rivera-Monroy, M. S. Ross, P. L. Ruiz, E. Castañeda-Moya, R. R. Twilley, and R. Rodriguez, 2006. Mapping height and biomass of mangrove forests in Everglades National Park with SRTM elevation data, Photogrammetric Engineering and Remote Sensing, 72(3):299-311.

Skolnik, M. L., 2001. Introduction to Radar Systems, $3^{\text {rd }}$ Edition, McGraw-Hill Companies, New York, NY, 772 pages.

Slater, J. A., G. Garvey, C. Johnston, J. Haase, B. Heady. G. Kroenung, and J. Little, 2006. The SRTM data "finishing" process and products, Photogrammetric Engineering and Remote Sensing, 72(3):237-247. 
Smith, B., and D. Sandwell, 2003. Accuracy and resolution of shuttle radar topography mission data, Geophysical Research Letters, 30:1467-1470.

Stilla, U., U. Soergel, and U. Thoennessen, 2003. Potential and limits for InSAR data for building reconstruction in built-up areas, ISPRS Journal of Photogrammetry and Remote Sensing, 58:113-123.

Story, M., and R. Congalton, 1986. Accuracy assessment: a user's perspective, Photogrammetric Engineering and Remote Sensing, 52:397-399.

Sun, G., K. J. Ranson, V. I. Khairuk, and K. Kovacs, 2003. Validation of surface height from shuttle radar topography mission using shuttle laser altimeter, Remote Sensing of Environment, 88(4):401-411.

Terrapoint, 2010. Now operating under the name Geodigital.. http://www.geodigital.com/.

Terzuoli, A. and Walker, R.G. 1997. Estuarine valley fills in the Lower Cretaceous Bluesky Formation, Edson area, Alberta, Bulletin of Canadian Petroleum Geology, 45:194-217.

Thenkabail, P.S., E. A. Enclona, M. S. Ashton, and V. Van Der Meer, 2004. Accuracy assessments of hyperspectral waveband performance for vegetation analysis applications, Remote Sensing of Environment, 91(2-3):354-376.

Tobler W., 1970. A computer movie simulating urban growth in the Detroit region, Economic Geography, 46(2):234-240.

Toutin, T., and L. Gray, 2000. State-of-the-art of elevation extraction from satellite SAR data, ISPRS Journal of Photogrammetry and Remote Sensing, 55(1):13-33. 
Toutin, T., C. Schmitt, and I. Zakharov, 2009. Calibration of radargrammetric DEMs from RADARSAT-2 high-resolution and fine-quad Modes, IEEE International Geoscience Remote Sensing Symposium, IGARSS, pp.41-43.

Treuhaft R. and P. Siqueira, 2000. Vertical structure of vegetated land surfaces from interferometric and polarimetric radar, Radio Science, 35(1):141-177.

Treuhaft, R. N., S. Madsen, M. Moghaddam, and J.J. van Zyl, 1996. Vegetation Characteristics and Underlying Topography from Interferometric Data, Radio Science, 31:1449-1495.

Turkar, V. and Y. S. Rao, 2008. Classification of polarimetric synthetic aperture radar images from SIR-C and ALOS PALSAR, IEEE Conference Publications, pp. $438-440$

U.S. Geological Survey, 2004. USGS National Land Cover Data, Sioux Falls: EROS.

Valtus, 2008. Valtus Imagery Services, http://www.valtus.com/products/spatial-datastore/, last accessed June of 2008.

Varekamp C., and D. H. Hoekman, 2002. High-resolution InSAR image simulation for forest canopies, IEEE Transactions on Geoscience and Remote Sensing., 40(7):1648-165.

Viergever, K. M., I. H. Woodhouse, A. Marino, M. Brolley and N. Stuart, 2008. SAR interferometry for estimating above-ground biomass of savanna woodlands in Belize, IEEE International Geoscience Remote Sensing Symposium, IGARSS, pp. V-290-293. 
Walker, W. S., J. M. Kellndorfer, and L. E. Pierce, 2007. Quality assessment of SRTM C- and X-band interferometric data: Implications for the retrieval of vegetation canopy height, Remote Sensing of Environment, 106:428-448.

Wallington, E.D., Izzawati and I. H. Woodhouse, 2004. Airborne SAR for Forest Height Retrieval, Proceedings of RSPSoc Annual Conference, 7th-10th September, Aberdeen, UK.

Wallington, E. D., I. H. Woodhouse, and Izzawati, 2005. Commercial airborne X-band synthetic aperture radar for forest height inventory, ForestSAT Symposium, Boras, Sweden, May 31-June 3.

Wallington E. D. and J. C. Suárez, 2006. Evaluation of commercial airborne LiDAR and SAR products to estimate top height and associated parameters in production forests in Britain, Sustainable Forestry, Chapter 19. pp 298-313.

Wang, Y., B. Mercer, V. C. Tao, J. Sharma, J. and S. Crawford, 2001. Automatic generation of bald earth Digital Elevation Models from Digital Surface Models created using airborne IFSAR, ASPRS Conference Proceedings.

Weilin, L., X. Buo, and L. Yu, 2008. Application of RS, GIS, and GPS to forest management, Journal of Forest Research, 11(1):69-71.

Wegmuller, U and C. L. Werner, 1995. SAR interferometric signatures of forest, IEEE Transactions on Geoscience Remote Sensing, 33:1153-1161.

Wegmuller, U. and C. L. Werner, 1997. Retrieval of vegetation parameters with SAR interferometry, IEEE Transactions on Geoscience Remote Sensing, 35:18-24.

West, P.W., 2009. Tree and Forest Measurement, Second Edition, Springer-Verlag, New York, $192 \mathrm{p}$. 
Weydahl, D. J., 2001. Analysis of ERS SAR coherence images acquired over vegetative areas and urban features, International Journal of Remote Sensing, 22(14):28112830.

Williams, M. L., M. Siman, S. Saatchi, S. Hensley, M. Sanford, A. Yohannan, B. Kofman, J. Reis, and B. Kampes, 2010. Analysis of GeoSAR dual-band InSAR data for Peruvian forest, IEEE Transactions on Geoscience Remote Sensing, IGRASS, pp. 1398-1401.

Williams, K. K. and R. Greeley, 2001. Radar attenuation by sand: Laboratory measurements of radar transmission IEEE Transactions on Geoscience Remote Sensing, 39(11):2521-2526.

Wing, M. D., D. Solmie, and L. Kellogg, 2004. Comparing digital range finders for forestry application, Journal of Forestry, 102(4):16-20.

Wofsy, S. C., Moorcroft, P. R., Palace, M., and Saleska, S., 2008. Global measurements of vegetation structure: a climate and carbon cycle science perspective, presentation at the NASA Veg3D and Biomass Workshop, Charlottesville VA, March 3-5.

Woodhouse, I. H., S. Cloude, K. Papathanassiou, and C. Hutchinson, 2003. Evaluating PolInSAR tree height and topography retrievals in Glen Affric, ESA-ESRIN PolInSAR Workshop, Frascati.

Woodhouse, I. H., Izzawati, E. D. Wallington, and D. Turner, 2006. Edge effects on tree height retrieval using X-Band interferometry, IEEE Geoscience and Remote Sensing Letters, July, 3(3):344-348. 
Yu, J. H. and G.E. Linlin, 2010. Digital elevation generation using ascending and descending multi-baseline ALOS/PALSAR radar images, FIG Congress, Facing the Challenges - Building the Capacity, 15p.

Zebker H., R. and R. M. Goldstein, 1986. Topographic mapping from SAR observation, Journal of Geophysical Research, 91(BS):4993 - 4999.

Zebker, H. A. and J. Villasenor, 1992. Decorrelation in interferometric radar echoes, IEEE Transactions on Geoscience Remote Sensing, 30(5):950-959.

Zhang, Q, B. Mercer, and S. Cloude, 2008. Forest height estimation from INDREX-Il Lband polarimetric InSAR data, Proceedings of the ISPRS XXIth Congress, July 311, 2008, Beijing, China 6p.

Zhu, P., Z. Lu, X. Chen, K. Honda, and A. Eiumnoh, 2004. Extraction of city roads through shadow path reconstruction using laser data, Photogrammetric Engineering and Remote Sensing, 70(12):1433-1440. 